\title{
WUERIEA BRASILILNSIS
}

6).

\section{PARA RUBBER,}

135 ROTAWY CULWWAWON CWEMSIRY AND DISERSES.

HEDACRT WRIGIT,

\section{SECOND ARHTON.}

CoLGNiva:

AH, 


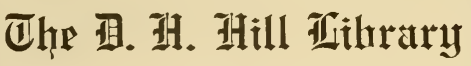
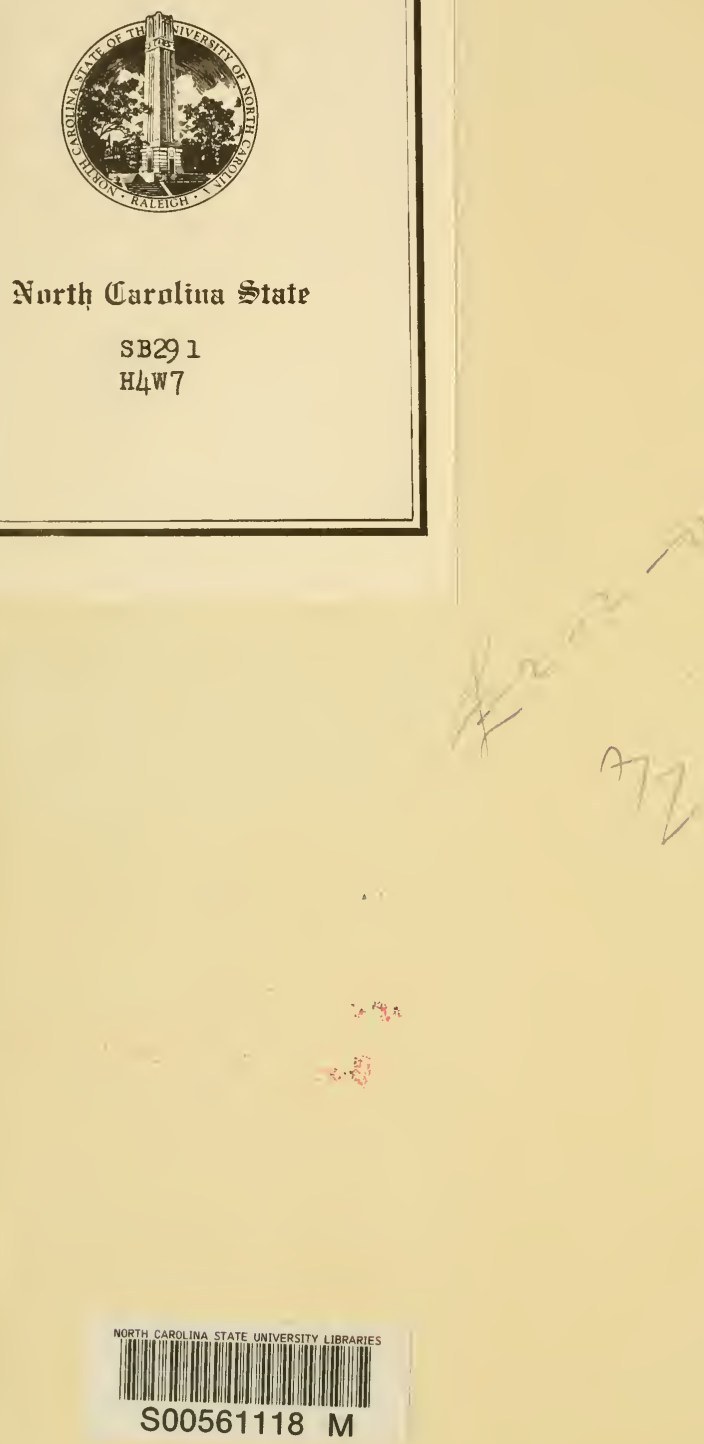
This book is due on the date indicated below and is subject to a fine of FIVE CENTS a day thereafter.

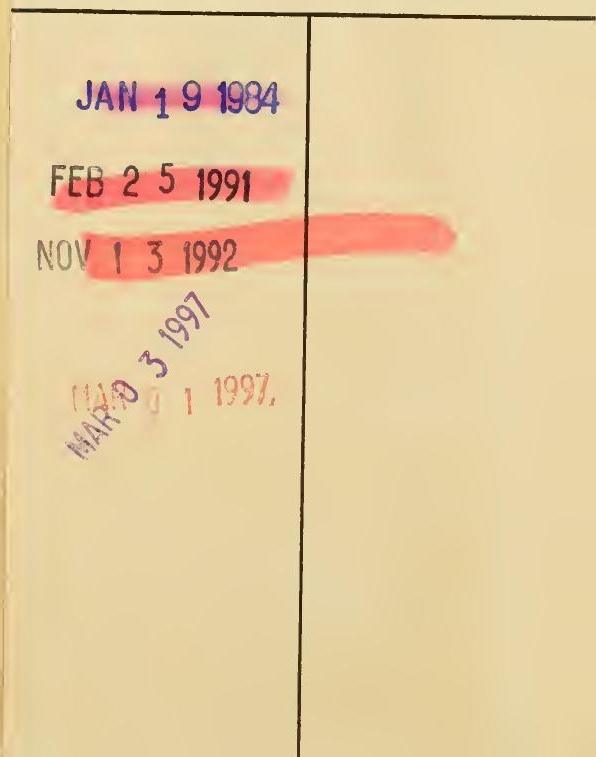





\section{HEVEA BRASILIENSIS}

OR

\section{PARA RUBBER}

ITS BOTANY, CULTIVATION, CHEMISTRY AND DISEASES

BY

HERBERT WRIGHT, A.R.C.S., F.L.S.,

Controller, Government Experiment Station,

Peradeniya, Ceylon.

SECOND EDITION.

WITH PLATES AND DIAGRAMS.

COLOMBO :

Mrasts. A. M. \& J. Ferguson.

1906.

[Copyright in Great Britain.] 



\section{PREFACE TO THE SECOND EDITION.}

$\mathrm{I}^{\mathrm{N}}$ response to requests made by persons engaged in tropical economic botany and agriculture a second edition of "Hevea Brasiliensis" has been written.

Advantage has been taken of the short interval between the two editions to collect all the data available regarding the botany, cultivation, chemistry, and diseases of Hevea brasiliensis. The results, which have been obtained during 1905 and 1906 in the Botanic Gardens at Henaratgoda and Peradeniya, on public properties in the Straits, India, and Ceylon, and the observations recorded in the various economic publications in the Tropics and Europe, have been as far as possible included in this issue.

In arranging the material for this edition frequent reference has been made to Weber's Chemistry of India Rubber, Journal D'Agriculture Tropicale, Jumelle's Caoutchouc et la Gutta, Revue des Cultures Coloniales, Der Tropenpflanzer, Seeligmann's Le Caoutchouc et la Gutta Percha, Obach's Cantor Lectures, the Annals of Botany, London, Johnson's Para Rubber, the India Rubber Journal, India Rubber World, the Tropical Agriculturist and Magazine of the Ceylon Agricultural Society, the Circulars and Annual Reports of the Royal Botanic Gardens, Ceylon, and the Bulletins and Official Journals of the Royal Gardens, Kew, the Imperial Institute, London, the Federated Malay States, and West Indian Departments of Botany and Agriculture.

The book takes a much wider view of the whole subject, with the object of giving a better understanding to persons not resident, but interested, in the Tropics, and to those directly concerned with the cultivation of the trees, the preparation of rubber, and the manufacture of articles therefrom. It should be clearly understood that the whole industry, especially as far as the producers are concerned, is in its infancy, and though our knowledge regarding the function of the latex, the effect of removing cortical tissues and latex from the plant, the methods of extracting latex, yields obtainable, and the production of rubber from latex, is considerable, one must be prepared to give up present-day ideas and commence work on new lines, whenever the latter have been shown to be worthy of adoption.

I cannot omit to acknowledge the valuable assistance which Planters and Officials have given me in Ceylon, India, the Straits, and the West Indies, in connection with this edition.

H. W. 



\title{
LIST OF ILLUSTRATIONS.
}

\author{
Cultivation and preparation of Para Rubber.
}

\begin{tabular}{|c|c|c|c|c|}
\hline Plate. & & Series $A$. & & $\begin{array}{l}\text { Facing } \\
\text { Page }\end{array}$ \\
\hline 1 & .. & A Plantation in the Henarat godia Botanic Gardens & & 1 \\
\hline 2 & .. & $\begin{array}{l}\text { Leaves, flower's, fruits, and sceds of Hever brasili } \\
\text { sis }\end{array}$ & ient- & 5 \\
\hline 3 & .. & $\begin{array}{l}\text { Diagram of latex tubes of Hovea bribsiliensis a } \\
\text { Carrica Papaya .. }\end{array}$ & & \\
\hline 4 & .. & Young rubber and Crotalabiab striabtia & $\ldots$ & 46 \\
\hline 5 & .. & Manuring young Para Rubber trees. . & .. & 45 \\
\hline ij & .. & Effect of bad tapping & .. & 49 \\
\hline 7 & $\therefore$ & Golledge's knife ... & . & 51 \\
\hline 8 & .. & Para chisel and knife & $\ldots$ & $5: 2$ \\
\hline 9 & .. & Bowman's and Northway's knives. .. & . & 55 \\
\hline 10) & .. & Dixon's tapping knife & $\cdots$ & 56 \\
\hline 10.1 & .. & Macadam's comb prieker & .. & 57 \\
\hline $10 \mathrm{~B}$ & .. & Macadam-Miller knif & .. & 58 \\
\hline 11 & .. & Vtapping & .. & 60 \\
\hline 12 & .. & Herring-bone systent & . & (i) \\
\hline 13 & .. & Full spiral system. .. & $\ldots$ & 94 \\
\hline 14 & .. & Centralising the latex from many trees & & (i3 \\
\hline 15 & .. & Drip-tins : their construction and application & $\cdots$ & (i.) \\
\hline 15.1. & .. & Double snd multiple (lrip-tins & & (6.j) \\
\hline 16 & .. & High tapping at Henaratgoda : base to 5 il feret & & 74 \\
\hline 17 & .. & A forked tree at Henaratgoda & & 79 \\
\hline 18 & .. & \multicolumn{3}{|l|}{$\begin{array}{l}\text { A tree tapped on the half-spiral system; photographi } \\
\text { taken after } 14 \mathrm{lb} \text {. of rubber have been oxtracted }\end{array}$} \\
\hline 19 & .. & \multicolumn{3}{|l|}{ Tappling the renewed bark after $16 \mathrm{lb}$. of rubber liave } \\
\hline 20 & . & Latex in setting pans & & 109 \\
\hline 21 & .. & Michie-Golledge coagulator & & 116 \\
\hline 22 & .. & Michie-Golledge seum rubber & $\ldots$ & 117 \\
\hline 23 & .. & Rolling Marhinery.. & & 119 \\
\hline 24 & .. & Dryine liseuit rubbor & & 122 \\
\hline 25 & .. & \multicolumn{2}{|l|}{ Dickson's coagulating and chying machine } & 121 \\
\hline 26 & & A rubber washing nlachine & & 132 \\
\hline 27 & .. & Kinds of plantation rubber & & 141 \\
\hline 28 & .. & Manufacture of lace rubber & & 144 \\
\hline 29 & & \multicolumn{3}{|c|}{ Illustrations showing hardy characteristics of Heveab } \\
\hline & & brasiliensis & & 146 \\
\hline
\end{tabular}


Para Rubber in the Tropics.

Series $B$.

Plate.

1 .. Tapping mature rubber, Malacea Rubber Plantations, Limited, Malacea . . 11

2 . Para Rubber and Coffee, at 3,500 feet, Stanmore Estate, South India _. . 14

3 .. Tapping Para Rubber, Para Rubber Estate, Sikong, Borneo $\quad$. $\quad \ldots .16$

4 .. Young Para Rubber, Experiment Garden, Buitenzorg, Java ..

Para Rubber and other Products.

Series $C$.

1 .. Para Rubber and Cacao, Kepitigalla Estate, Matale. . 30

2 .. Para Rubber and Tea ; both in bearing, Nikakotua Estate, Matale . . .. $\quad$. 32

3 .. Mature Rubber and Tea, Undugoda Estate, Kegalla. .

\section{Para Rubber in Ceylon Districts.}

\section{Series D.}

1 .. Para Rubber in drained swampy land, Kalutara .. 20

2 .. T'ara Rubber on rocky hillsides, Kalutara _. 22

3 .. Tapping operations at Gikiyanakanda, Kalutara .. 8

4 .. The famous Para trees, which have given $25 \mathrm{lb}$. of rubber in one year, Culloden Estate, Kalutara . 92

J .. Young Para Rubber; seventeen months old, Madam-

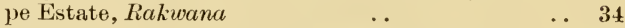

$6 \quad$.. Tapping mature trees, Madampe Estate, Rakwana .. $\quad 36$

7 .. Para Rubber trees, two years old, Ambalangoda .. 76

S .. Tapping eleven-year-old trees, Elpitiya, Ambalangoda 72

9 .. Tapping mature trees in 1905, Arampola Estate,

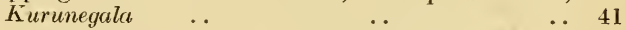

10 .. Old Para Rubber and Tea, Nikakotua Estate, Matale 40

11 .. Rubber and Cacao in bearing, Dangan Estate, Rubber Plantations, Ltd., Matale _. $\quad$.. 19

1.2 . . Para Rubber at 2,800 feet, Passara Group Estate,

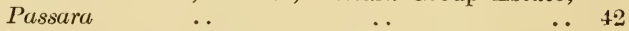

13 .. A Para Rubber clearing end nursery, South Ceylon .. 24

14 .. Para Rubber trees; thirty-two months old, Hunugalla Est .te, Kegalla .. $\quad$. $\quad \ldots 38$

15 .. Tapping mature trees, Yataderiya Eistate, Kegalla $\ldots .88$

16 .. Mature Rubber and Tea; tapping fifteen-year-old trees, Holton Estate, IVattegama .. $\quad$.. 86

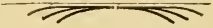




\section{CONTENTS.}

Chapter I.

PAGE:

History of Para RuBber in THE EAst. ...........

Work of Chapman, Wickham, and Cross-Illustration showing old trees-Propagation from cuttings from two to threeyear-old trees-Flowering for the first time in Ceylon and the Straits-First seed in Ceylon and the Straits-Distribution of seeds and plants from Ceylon-Cultivation-Yields-Preparation-Value-Export and Acreage of Para rubber in Ceylon from 1884 to 1906 - Distribution of Ceylon rubberAcreage in Malay Peninsula, Sumatra, Java, and IndiaAcreage in parts of Ceylon during 1906-Eastern rubber areas owned by public companies-Characters of the Para rubber tree-Illustration of leaves, flowers, fruits, and seeds of Hevea brasiliensis-The Laticiferons system-Origin-Distribution and characters-Functions of the latex-Anatomical details illustrated.

\section{Chapter II.}

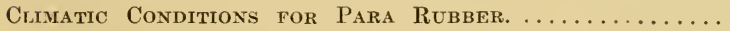

Descriptions of Para by Drs. Trimen and Ule-Para trees in Brazil-Illustration slowing Para rubber in Ceylon-Climate in Ceylon, Straits, Perak, Selangor, Seremban, Singapore, Penang, Malacea, and Java-Illustration showing young rubber at the Experiment Station. Buitenzorg, Java-IndiaAfrica, West Indies, \&c.-Illustration showing Para rubber in Malacca-Illustration showing Para rubber at an elevation of 3,500 feet in India-Illustration showing Para rubber on Sikong Estate, Borneo.

Chapter III.

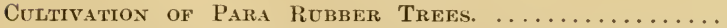

Rate of growth-Size of trees at Henaratgoda, Peradeniya, Edangoda, and parts of Ceylon-Illustrations showing Para rubber on rocky hillsides and in drained swampy landGrowth in the Kegalla, Knuckles, Nilambe, Katugastota, Sabaragamuwa, Wattegama, Kalutara, Matale, and Baddegama Districts-Spread of foliagecach year from second to thirtieth year-Rate of growth in the Gold Coast-Height and circumference - Rate of growth in the Straits, Perak, Selangor- 
Carruthers on rate of growth in Federated Malay States-Rate of growth in India-Mergui, Shevaroy. Nilgiris-High average incremental growth in the Straits-Leaf-fall-Root SystemPropagation of plants - Shade and wind in the Federated Malay States and Ceylon-Planting operations-Illustration showing a rubber clearing and nursery in Ceylon-NurseriesFencing-Draining-Distance, Holing, and Planting-Close planting and available tapping area-Number of trees per acre-Distance for rubber alone and catch crops-Pruning Para rubber-Principles and effect-Measurements of straightste mmed and forked trees in Ceylon-Inter and catch cropsCacao, Coffee, Tea, Groundnuts, Lemongrass, CassavaFuture of intercrops-Illustrations showing Para rubber and cacao at Kepitigalla-Para rubber and Tea on Nikakotua estate-Para rubber and tea on Undugoda estate, KegallaPara rubber and eacao on Dangan estate, Matale.

\section{Chapter IV.}

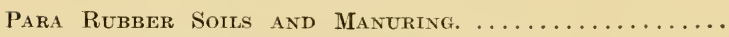

The mechanical and chemical composition of rubber soilsPeradeniya-Henaratgoda-Udugama-The soils and rubberplanting in various parts of Ceylon-Carruthers and Bamber on rubber land and soils in the Federated Malay StatesCabooky, alluvial, and swampy soils in Ceylon-Treatment of swampy soils-Illustrations showing Para rubber on Passara Group estate, Passara; Young and old rubber on Madampe estate, Rakwana, Arampola estate, Kurunegala ; Para rubber and tea on Nikakotua estate, Matale ; Para rubber on Hunugalla estate, Kegalla-The Kelani, Kegalla, Kalutara, Calle, Matale, Pussellawa, Ratnapura. Ambagamuwa, Kurunegala, and Passara Districts-Principles of rubber-manuring-Manuring to increase the latex-Para rubber trees-Artificial manures for rubber soils-How to apply readily soluble and stable manures-Forking, trenching, and root growth-Illustration showing trench-manuring for young rubber-Constituents in woody stem, twigs, fresh, and dried leaves-Composition of artificial manures obtainable locally-Green manuring for Para rubber trees-Limit 6 to 8 years-Suitable herbaceous plants and their composition-Illustration showing young Para rubber and Crotalaria striata-Tree forms, Dadaps and AlbizziasOrganic matter obtainable. $=\approx-\ldots$

\section{Chapter $V$.}

Tapping Operations and IMPlements. ............

Importance of tapping operations-The thickness of the bark tissues and shedding of dried latex tubes-Effect of bad tapping illustrated-Tapping knives-Requisites of a good tapping knife-Clean cuts and scraping-Protection of the cambiumParing from right to left and left to right-Minimum excision of cortex and bark-Paring and pricking-Patent tapping knives-Native implement-Carpenter's chisel-Surgical 
scrapers and planes-Beta knife-Golledge's knife: construction and illustration-Holloway's knives-Mackenzie's knifeCollet's knife-Brown \& Co.'s knives, construction and illustrations-Eastern Produce and Estates Co.'s knive-Bowman's and Northway's three knives: construction, method of use, and illustrations-Dixon's knife: construction, improvements, and illustration-Macadam's comb pricker-Macadam-Miller paring knife.

\section{Chapter VI.}

How to Tap Para RubBer Trees. ..............

Methods of tapping Para rubber trees-Methods of native collectors in Brazil and the Gold Coast-Observations of Jumelle and Bonnechaux-Modern methods-Single oblique euts, illustrated- $\mathrm{V}$ incisions, illustration showing a tree after ten weeks' tapping-Limited area-Herring-bone system-The photographs of trees in Ceylun tapped on the hering-bone system-The ziz-zag method and its use-Spiral curves-F. Crosbie Roles on the spiral method, yields and estimatesResults of the spiral system in parts of Ceylon-Collecting and storing of latex-Bury's protector-Centralizing the latex from many trees, illustrated-Drip-tins: their construction and action illustrated-Keeping the latex liquid and settling tanks-Method of marking the trees for tappingCollecting tins.

\section{Chapter VII.}

Where to TAP.

Occurrence of latex in parts of the plant-Rubber from young parts of trees-Tapping virgin and wound areas-Wound response and increased yields at Peradeniya, Java, and the Straits-Interval between successive tappings and wound respons:-Arder's results-Clotting of rubber in convex wound areas-Method of formation of Para milk tubes-Best yielding areas-Results of experiments from the base upwards in the Straits and Ceylon-lllustration showing tapping from 6 to 16 feet and base to 50 feet at Henaratgoda-Yields obtained from various levels at Henaratgoda.

\section{Chapter Vilit.}

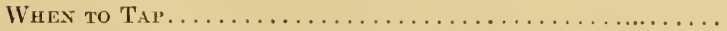

Age or size as criterion-Resin in young trees of Castilloa rubber-Analyses of rubber from $2,4,6,8,10-12$, and 30-yearold Para rubber trees-Two-year-old trec illustrated-Age of tapping trees in the Strait--Age of tapping trees in MalaceaAge of tapping trees in Ceylon-Age and size considered-I manufacturer's opinion of rubber from 8-year-old treesMinimum size for tapping- How to increase the tappling are: illustrated-Measurements of forked and straight-stemmed trees at Henaratgoda-The best season for tapping-Atmos- 
pheric conditions and the flow of latex-Results in Ceylon, Java, F.M.S., \&e.-Latex flow during the leafless phaseUse of ammonia and formalin--What part of the day to tapYields in morning and evening-Compass tapping-Frequency of tapping and results at Henaratgoda.

\section{Chapter IX}

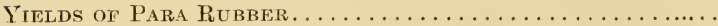

Natural variations-Yields in Ceylon and Brazil-Henaratgoda trees and Amazon yields - Yields on estates in Ceylon : Matale, Uva, Kalutara, and Ambalangoda Districts-Illustra tion showing the rubber trees on Passara Group Estate- ${ }_{4}^{3}$ to $52 \mathrm{lb}$. averages over large acreages-Yields obtained in the Kalutara District for 1905 by the Kalutara Rubber Co, Rayigam Tea Co., Neboda Tea Co., Vogan Tea Co., Southern Ceylon Tea and Rubber Co., Puiupaula Tea Estate Co., Yatiyantota Ceylon Tea, Co., Eastern Produce and Estates Co., Sunnygama Ceylon Estates Co., Yataderiya Tea Co., Kepitigalla and Passara Group Estates, Ceylon Tea and Coconut Estate Co., and Gikiyanakanda for 1905-Yields on Imboolpittiya estate, Nawalapitiya-Illustration showing rubber trees at Peradeniya tapped on the full spiral systemExceptional yields at Culloden, Elpitiya, and PeradeniyaComparison of yields at Peradeniya and HenaratgodaExperiments at Henaratgoda-Comparative yields from different systems of tapping-Spiral and herring-bone tapping compared-Results of high tapping at Henaratgoda from base to 50 feet-16 tappings yield $3 \mathrm{lb}$. rubber-Average yielding capacity per square foot of the bark tissues-Comparison of yields obtained at Henaratgoda-Illustration showing th ? Elpitiya tree after $14 \mathrm{lb}$. rubber extracted-Yields at Peradeniya by the $\mathrm{V}$ and spiral methods-Rubber from shavingsRubber yields in the Straits-Yield from the Sandycroft Rubber Co., 1905-Variation in Tields in Java-Yields in South India at high elevations-Hawthorn Estate and Mergiu Rubber Plantations-Para yields in the Gold Coast-Yields of Para and African rubber compared-Difficulty in forming average estimates-Effect of repetitional bark strippingIllustration showing the tapping ! of renewed bark-Excision and incision-Bark peeling.

\section{Chapter $\mathrm{X}$}

Physical and Chemrcal Properties of Latex...........

Colour-Consistency-Alkalinity-Sap exudations and acidity-Caoutchouc Globules-Object of producer-Mechanical impurities-Analyses of the latex of Para rubber by Seeligmann, Faraday, Scott, and Bamber-Variation in, composition-Properties of caoutchouc-Occurrences of resins and oily substances-Sugars-Proteids or Albuminoids-Removal of proteids with formaldehyde and centrifugal separator-Mineral matter-Effect of temperature, ammonia, formalin, and acids on coagulation. 


\section{( $\mathrm{xi}$ )}

Chapter Xi.

P.AGE

The Pronuction of Rubber from Latex.............

Production of rubber by natural coagulation-Production on a small scale illustrated-Suggestions for curing roomsEffect of Heat and Chemicals on coagulation-Smoking and coagulation-The chemistry of the Amazon method-Coagulation by chemical reagents-Acetic acid-Formic Acid-Hydrofluoric Acid-Tannic Acid-Corrosive sublimate-Amount of acid to be used-Determination of completeness of coagulation -A method of determining the amount of acetic acid required -Advantages and disadvantages of adding chemicals to the latex-Valuc of acids and preservatives discussed-Components of coagulated rubber-Amount of proteic in mothe. liquor and rubber-Putrefaction of rubber-Analyses of sound and tacky rubber-Keeping the proteid inactive-Antiseptics, drying, dilution, and washing-The removal of the proteid from the latex-Formalin and sodium sulphate-Rapid coagulation and removal of proteids by mechanical means-Biffen's centrifugal machine-Experiments in Ceylon with the Aktiebolaget Separator-Principles of mechanical separation-Rapid coagulation by mechanical and other means-The Michie-Golledge machine : construction, action, and illustration-Mathieu's apparatus.

Chapter Xil.

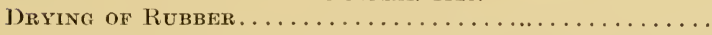

General methods-Illustration showing a method of drying biscuit rubber-Presence of water, putrefaction and surface deposits-Chemicals and artificial heat for drying-Suggestions by Parkin. Burgess, and Weber-Drying in vacuum chambers-Construction of vacuum chambers-High temperatures undesireable-Dickson's drying and coagulaticn machines-Use $0^{\circ}$ calcium chloride-Advantages-Simple rubber-drying sheds for use with calcium chloride-Disadvantages-Experiments in Ceylon, and softening of rubber.

\section{Chapter XIII}

Physical and Chemical Properties of Rubber. . . . . . . .

Analyses of Para rubber from Ceylon,Bukit Rajal Co., F.M. S., Penang, Straits, and Gold Coast-Market value of the samples-Para and African rubber analyses compared-Resins in Para and Castilloa rubber-Resins in rubber from parts of the same tree-Resins in rubber from Para trees of different age:Para compared with other rubbers-Chemical composition and value of Ceara, Castilloa, Ficus, Landolphia, Urceola, and Rhynocorlia rubber-Extraction of resins from Rubber by manufacturers and growers-Albuminoids and cause of putrefaction-Removal by mechanical and chemical processesAsh impurities and ingredients present in Para, Ceara, and African rubbers-The insoluble constituent in rubberProperties of indiarubber, reaction with alkalies, halogens, and acids-Absorption of water-Sulphur reaction-Action of heat on indiarubber. 
Purification of Rubber.....................

Analysis of washed and dried Para-Purification by the manufacturers-Loss in brands of Para rubber-Plantation versus Wild Para-Lawrence's apparatus-Loss on washing rubber-Oily and resinous substances and ash in various rubbers-Determination of loss on washing-High loss undesirable-Purification by the growers-Rubber washing machines-Burgess's account of a washing machine: construction and action-Illustration of a washing machineAdvantages of washing rubber-Scrap and dirty rubber.

\section{Chapter XV.}

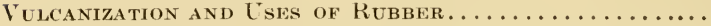

Vulcanization of rubber-Heat, sulphur, and indiarubberThe heat cure and cold cure-Quantity of indiarubber in common articles-Rubber in roller coverings, steam packing, tyres, tobacco pouch, and garden hose-High proportion of mixtures-Automobiles, instruments, clothing, and cablesDisuse of rubber and use of substitutes.

\section{Chapter Xit.}

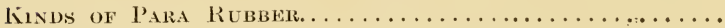

Plantation and fine hard Para-Uses of Plantation and cultivated rubber-Burgess on Plantation rubber and its inferiority - The effect of moisture and smoking on Plantation rubber-Chemical and physical tests-Commercial reports on Plantation rubber from Ceylon and the Straits-Biscuit and sheet rubber-Crèpe rubber, characters, preparation, and value-Worm rubber, characters, preparation, and valueIllustration showing forms of Plantation rubber-Lace rubber, preparation by mechanical means - Illustration of machinery used in the manufacture of lace rubber-Flake rubber-Scrap rubber-Chemical analysis of biscuit, crèpe, lace, and worm rubber.

CHAPTER XVII.

Diseases of Para Rubber Trees................

Diseases of plants grown on small areas-Epidemics over large acreages - Checking clisease by tree belts--Para rubber pests in Brazil and Java-Leaf diseases of Para rubber-Fungi, Helminthosporium, Periconia, Cladosporium, Macrosporium, Pestalozzia, Cercospora - Preventive measures - Insects, plant-sucking bugs, weevils, and mites-Preventive measures -Fruit diseases of Para Rubber-Fungi, Nectria and Phytophthora-Preventive measures-Stem diseases of Para rubberFungi on old stems and green twigs-Preventive measuresA bark fungus in the Straits - Insects, wood-borers, ants, and slugs-Preventive measures-Root diseases of Para rubberFungi in Straits and Ceylon-Fomes in the StraitsHelicobasidim and Hymenoehate-Insects, termites, cockchafers, grubs-Preventive mensures-A disease on preparcd 


\section{( xiii )}

PAGE

rubber-Probable causes and preventive measures-Analyses of black and yellow tacky rubber-Chemical analyses of tacky and sound rubber.

\section{Chapter XVIII.}

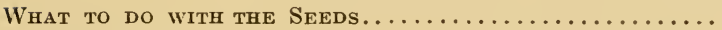

Number of seeds per tree-Seed characteristies-ValueSeed oil and fat-Meal and cake-Analysis of meal-Cake of Para rubber seed compared with linseed and cotton cakePacking Para seeds for transport-Experiments at Trinidad and Singapore-Charcoal, sawdust, and Wardian cases.

\section{Chapter XIX.}

Estimates of Rubber Planters in Ceylon: Costs of

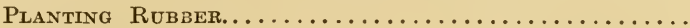

Estimate I. by E. Gordon Reeves, Rs. $322 \cdot 40$ per acre at end of 5th year for Matale-Estimate II., by F. J. Holloway, Rs. 283.50 per acre at end of 6 th year-Estimate III., Peradeniya District for first two years-Estimate IV., Kalutara District for first six years-Estimate V., Ambalangoda District f $n$ r first two years-Estimate VI., Ambalangoda District for first two years in swampy land-Esimate VII., Ambalangoda District for first two years.

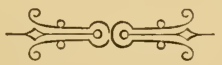






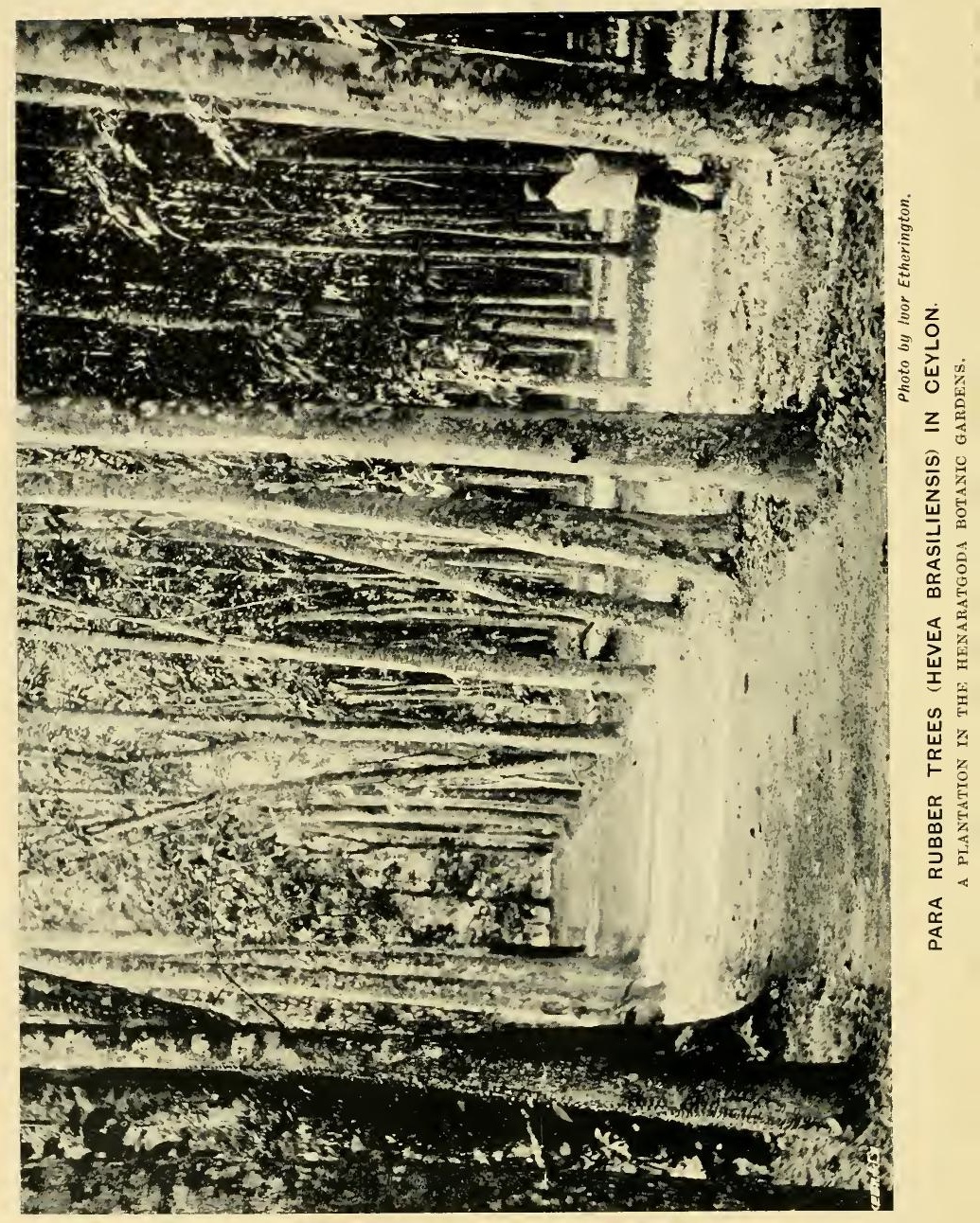




\section{CHAPTER I.}

\section{HISTORY OF PARA RUBBER IN THE EAST.}

Work of Chapman, Wickham and Cross - Illustration showing old trees-Propagation from euttings from two to three-year-old treesFlowering for the first time in Ceylon and the Straits-First seed in Ceylon and the Straits-Distribution of seeds and plants from CeylonCultivation-Yields-Preparation-Value-Export, and Acreage of Para rubber in Ceylon from 1884 to 1906-Distribution of Ceylon rubber-Acreage in Malay Peninsula, Sumatra, Java, and IndiaAcreage in parts of Ceylon during 1906-Eastern rubber areas ownerl by public eompanies-Characters of the Para rubber treeIllustration of leaves, flowers, fruits, and seeds of Hevea brasiliensis -The Laticiferous system-Origin-Distribution and character's -Functions of the latex-Anatomical details illustrated.

\section{History of Introduction to Ceylon and the East.}

HOUGH rubber had been known for many years it was not until 1875 that the now famous Para rubber was seriously talked about in Ceylon. In the following year nearly two thousand seedlings of Hevea brasiliensis were despatched to Peradeniya, Ceylon, from Kew. These were contained in Wardian cases and arrived by the ss. "Duke of Devonshire" in excellent condition, under the care of Mr. W. Chapman. They were raised from seeds collected by Mr. Wickham who succeeded in securing 70,000 in the Ciringals of the Rio Tapajos.

Mr. Cross was also sent to South America to bring home plants in case the transmission of living seed should prove impossible. $\mathrm{He}$ arrived at Kew in November, 1876, and brought with him about 1,080 seedlings without soil, of which, with the greatest care, scarcely three per cent. were saved; from these, about 100 plants were propagated at Kew and subsequently sent to Ceylon. A photograph of a Para rubber plantation at Henaratgoda with trees 15 to 20 years of age is shown on Plate 1, Series A. The cost of procuring the seeds and plants, including freight and other expenses, appears to have been no less than $£ 1,5054 \mathrm{~s}$. $2 d$, or an equivalent of about Rs. 11 for every plant delivered in Ceylon. The whole expenditure was borne by the Indian Government.

\section{Propagation from Cuttings and the First Seeds IN THE EAST.}

The plants were first propagated from cuttings, the twigs from two to three-year-old trees being used for this purpose, and a consignment of 500 rooted plants was sent to British Burma and Madras in 1878 . 
The plants at Henaratgoda flowered for the first time in 1881, when they were five years old. The plants at Peradeniya did not flower until a few years later-1884 - but curiously enough, at Perak the small trees only 35 feet high and $2 \frac{1}{2}$ years old flowered in 1880 .

The trees at Peradeniya did not flower in 1882 , and only 36 seeds were secured in that year at Henaratgoda. Mr. Low sent, from the Experimental Garden at Perak, eighteen seeds to Peradeniya, but on their arrival they were found to be dead.

In 1883 no less than nine trees flowered at Henaratgoda in March, and the fruit ripened in August. From this crop 260 seedlings were raised, many of which were sent to planters in Ceylon. In 1884 a good crop of seed was produced at Henaratgoda, and over 1,000 seedlings were raised and distributed to officials in suitable parts of the Colony. In the same year a few seeds were also produced for the first time at Peradeniya.

\section{Distribution of Seeds and Plants from Ceylon.}

After the trees had begun to produce seed the propagation of plants from cuttings was given up. The seed supply from less than 500 trees has risen from 260 in 1883 to about 200,000 at the present time, and every year large quantities of seeds are sent to many tropical countries.

India and the Straits have received a considerable number of Ceylon rubber seeds and plants, the first consignments dating back to 1877 when the cuttings from one-year-old trees were sent from Peradeniya. Mr. H. N. Ridley informs me that the Straits do not appear to have obtained seeds from Ceylon till 1886, when they were then distributing their own seeds, and is unable to account for the fate of the material sent from Ceylon at an earlier date. Seeds were also sent to Queensland in 1886 and 1889, to Jamaica and Buitenzorg in 1887, to Fiji in 1888, to Borneo and German East Africa in 1891, to Sumatra in 1901, and to the Gold Coast, Seychelles, and Australia during the last few years.

\section{Cultivation, Yields, Preparation, and Value, \&c.}

When Hevea brasiliensis was first introduced to Ceylon it was considered to be most suitable for places little above sea-level, but the good growth obtained at Peradeniya, though less satisfactory than that at Henaratgoda, was sufficient to interest several planters, and consequently seeds were supplied to residents in many parts of the island. At the present time it eannot be doubted that Hevea brasiliensis will grow in the Central Province of Ceylon up to 2,000 feet above sea-level and in the Province of Uva at a still higher elevation. This is evidenced by the acreages now under this product in the Peradeniya, Matale, Gampola, Nawalapitiya, Ambegamuwa, Uva, and other districts.

Ten or eleven years ago it was thought advisable not to tap trees until they were at least ten years old, and an estimate of $1 \frac{1}{2} l b$. of dry rubber, per tree, per year, from the 12th to the 20th year was considered satisfactory. Since that time it has been proved that 
some trees when four or five years old may yield rubber of marketable value, and in exceptional cases individual trees about eleven years old have given no less than $12 \mathrm{lb}$. of dry rubber in eight months, and others as much as $25 \mathrm{lb}$. per tree in twelve months. In the same way steady progress is to be seen in the substitution of paring and spur knives for the carpenter's chisel for tapping operations; in washing machinery for cleansing crude rubber, revolving cylinders for rapidly coagulating rubber and the use of chemicals and hot air apparatus for hastening coagulation and curing the product as rapidly and effectively as possible. Simultaneously with general improvements in yield and methods of manufacture there has been a steady rise in price to over $6 s$. per $\mathrm{lb}$. for some samples of plantation rubber and a large increase in the acreage under cultivation.

The progress in Ceylon is illustrative of what has taken place in other tropical countries, and the following tables show the range in value of Para rubber, the export, the price per lb., and the approximate acreage in Ceylon from 1884 to 1906 :-

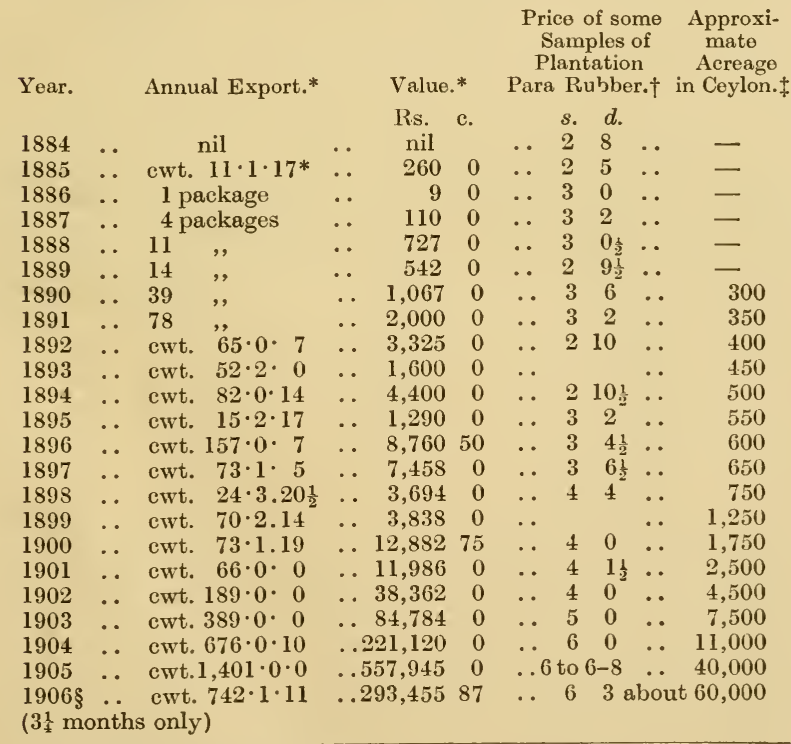

* From the Principal Collector of Customs, Colombo, Ceylon.

+ Bulletin of Miscellaneous information, Kew, No. 142, 1898.

+ From the "Ceylon Directory."

$\S$ Official figures up to April 7 th, 1906. 


\section{Distribution of Ceylon Rubber.}

The rubber from Ceylon in 1905 was distributed as indicated below :-

Countries to which exported.

$$
\text { Rubber, Quantity. }
$$

$\begin{array}{lc}\text { United Kingdom } & \ldots \\ \text { Victoria } & \ldots \\ \text { Belgium } & \ldots \\ \text { France } & \ldots \\ \text { Germany } & \ldots \\ \text { Holland } & \ldots \\ \text { United States of America }\end{array}$

\begin{tabular}{lrr} 
& \multicolumn{2}{r}{ Rubber, Quantity. } \\
& & Cwt. \\
$\ldots$ & $\ldots$ & 1,077 \\
$\ldots$ & $\ldots$ & 8 \\
$\ldots$ & $\ldots$ & 85 \\
$\ldots$ & $\ldots$ & 22 \\
$\ldots$ & $\ldots$ & 129 \\
$\ldots$ & $\ldots$ & 1 \\
$\ldots$ & $\ldots$ & 79 \\
& Total. . & 1,401
\end{tabular}

Acreage of Para Rubber in 1904.

The total acreage planted in 1904 with rubber in the Malay* Peninsula has been estimated at . To these might be added, Sumatra (say) .

\begin{tabular}{|c|c|c|}
\hline Sumatra (say) & .. & 5,000 \\
\hline Java & . & 5,000 \\
\hline Ceylon & . & 25,000 \\
\hline India and Burma & . & 5,000 \\
\hline
\end{tabular}

Acreage of Para Rubber in Ceylon during 1906.

It is difficult to obtain anything approaching a reliable record regarding the acreage planted in Para rubber at the present time, but the following table shows the areas occupied by this product, or about to be planted with it, in a few of the districts in Ceylon :1905.

$\begin{array}{lcrcccc}\text { Kalutara } & \ldots & 13,394 & \ldots & 16,000 \text { acres. } & \begin{array}{c}\text { (Applied } \\ \text { for.) }\end{array} \\ \text { Kegalla } & \ldots & 6,521 & . & - & & \\ \text { Pussellawa } & \ldots & 2,692 & . & - & & \\ \text { Galle } & . & 2,500 & . & 2,500 & , & \\ \text { Kelani } & . . & 14,000 & . & - & & \\ \text { Sabaragamuwa } & \ldots & 6,200 & \ldots & 6,000 & , & \\ \text { Matale } & \ldots & 1,898 & \ldots & - & & \\ \text { Ambegamuwa } & \ldots & 800 & . & \overline{-} & & \\ \text { Kurunegala } & . & - & \ldots & \ldots 4,500 & ,\end{array}$

In addition to the above there are in the Ratnapura, Passara, Badulla, Kandy, Gampola, Polgahawela, and Dumbara Districts, thousands of acres being planted with Para rubber, and there is every reason to believe that similar expansion is taking place in the Straits, India, Java, West Indies, Africa, Sumatra, Borneo, tropical America, and other countries. The Ceylon, India, and Straits public companies alone show no less than 70,000 acres planted, and double that area available and probably suitable for rubber; in addition to these there are large estates in private hands which are rapidly increasing their rubber acreages.

* Annual Report of the United Planters' Association, 1904.-F. M. S. 

SERIES A. PL. 2.

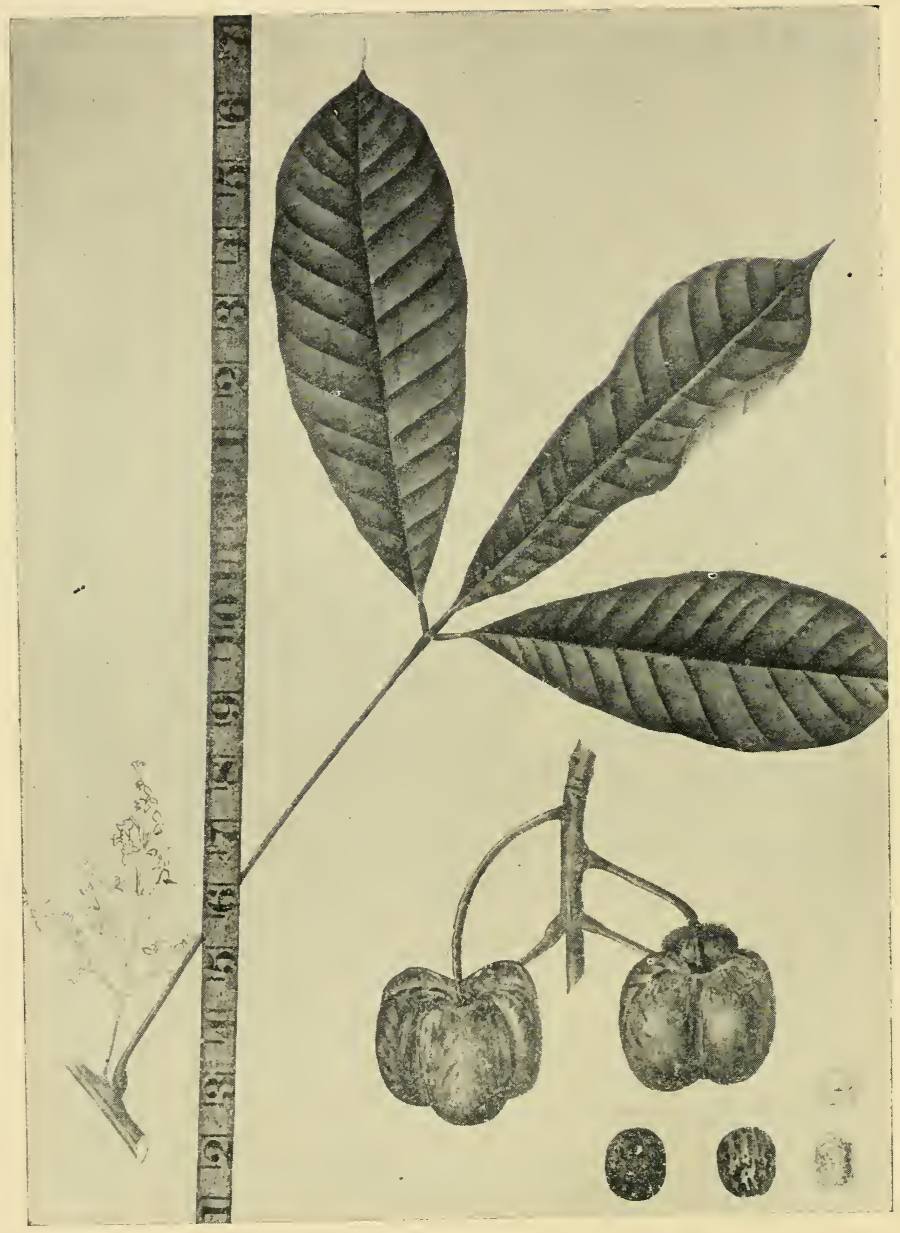

Photo by H. F. Macmillan.

THE LEAVES FLOWERS, FRUITS \& SEEDS OF HEVEA BRASILIENSIS. 


\section{Eastern Rubber Areas.}

The following table, compiled from the Colombo Brokers' Assoeiation Monthly List, April, 1906, shows the approximate acreage of land planted or available for rubber which is owned by wellknowr public companies in Ceylon, the Straits, and India. A part of the available land in these companies will probably be planted with rubber at some future date.

Eastern Rubber: Areas owned by public Companies.

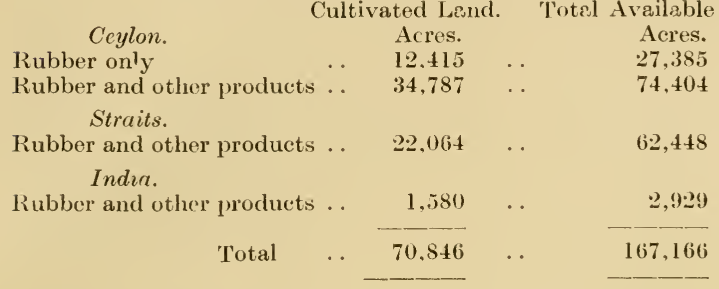

Botanical Characters of the Para Rubber Tree.

M. H. Jumelle * devotes considerable attention to the supposed varieties of Hevea brasiliensis, and like many other botanists concludes that the differences in colour, size, and shape of the leaves described by Ule and others are not constant and may be disregarded. The leaves are trifid, long, and lanceolate.

The flowers are monœeious, and are grouped in panicles of small cymes; each inflorescence has two kinds of flowers, male and female. The calyx is usually five-lobed; the stamens of the male flowers are united in the centre to form a column; the female flowers usually possess five staminodes, a small 3-celled ovary, and 3 sessile or shortly-styled stigmas; the fruit is a three-lobed capsule, in which the three oval oleagineous seeds are contained. The seeds are shiny and speckled brown on the surface.

There are about a dozen species of Hevea recognized by Miiller, Hemsley, and Huber. Hevea brasiliensis is considered to be claracterized by (1) having its anthers in a single whorl; (2) acuminate male flower bud, and (3) sessile stigmas.

The illustrations on Plate 2, Series A, show the characters of the leaves, flowers, fruits, and seeds of Hevea brasiliensis.

\section{The Laticiferous System.}

The latex is contained in definite ducts which occur throughout the stem, root, leaves, flowers, and fruits. The laticiferous ducts in Hevea brasiliensis consist of a series of sacs, the walls of which break down and thus give rise to the formation of a number of tubes, dis-

* Les Plantes à C'aoutchoue et à Gutta, by Henri Jumelle, Paris, 1903. 
posed more or less longitudinally. In some cases the walls of the cells are only incompletely disintegrated, and the flow of the latex is, therefore, not as free as when the partition walls are completely broken down. The disconnected series of cells in all stages of perforation is accountable for many of the variations in yield of latex and rubber described elsewhere.

\section{Functions of the Latex.}

It is well-known that a system of milk tubes may or may not occur in different species of plants, and that the presence of a laticiferous system is of importance in determining the identity of species. Several natural orders, such as those which include species of Euphorbia, Castilloa, Hevea, Funtumia, Landolphia, \&c., are characterized by large numbers of plants which possess milk tubes, whereas other natural orders are not known to possess any laticiferous species. It is also recognized that the number of species of plants, possessing milk tubes, is greater in the tropics than in colder or more temperate zones, and that many of the latex-bearing plants thrive on rocky soils and in dry districts in the tropics.

If one reflects on the thriving condition of widely different species of latex-bearing plants in the temperate, sub-temperate, and tropical regions, and the behaviour of such plants under various conditions the difficulty of ascribing a single function or series of functions to the latex will be manifest. Each species must be considered separately, and in the case of Hevea brasiliensis many observations have been made and various theories propounded.

Groom*, when dealing with this subject, pointed out that there was no reason to believe that the functions of the latex in all plants are the same, or that one function should exclude the other.

\section{Function of Storing Water.}

The latex of Para rubber consists mainly of water and caoutchouc globules together with small quantities of sugars, proteids, gums, resins, mineral matter, \&c. Most of the constituents cannot be regarded as forming reserve food, and even in the case of sugars and proteids their presence in such small quantities would prevent their being of vital importance to the plant in times of emergency. Furthermore, the fact that the tubes arise, de novo, by a process of perforation and decomposition, and during their ramifications in the cortex are never in direct communication but contact only with the vital elements of the bast, supports the contention that the small quantities of food they contain are probably of very minor importance to the plant.

The water is, according to most observers, of more importance than the other constituents. It is well-known that the flow of latex is largely determined by the humidity of the air and the quantity of water present in the soil. The increased flow which follows the rain after a drought is often very remarkable.

* Function of laticiferous tubes, Annals of Botany, 1889. 

SERIES A. PL. 3
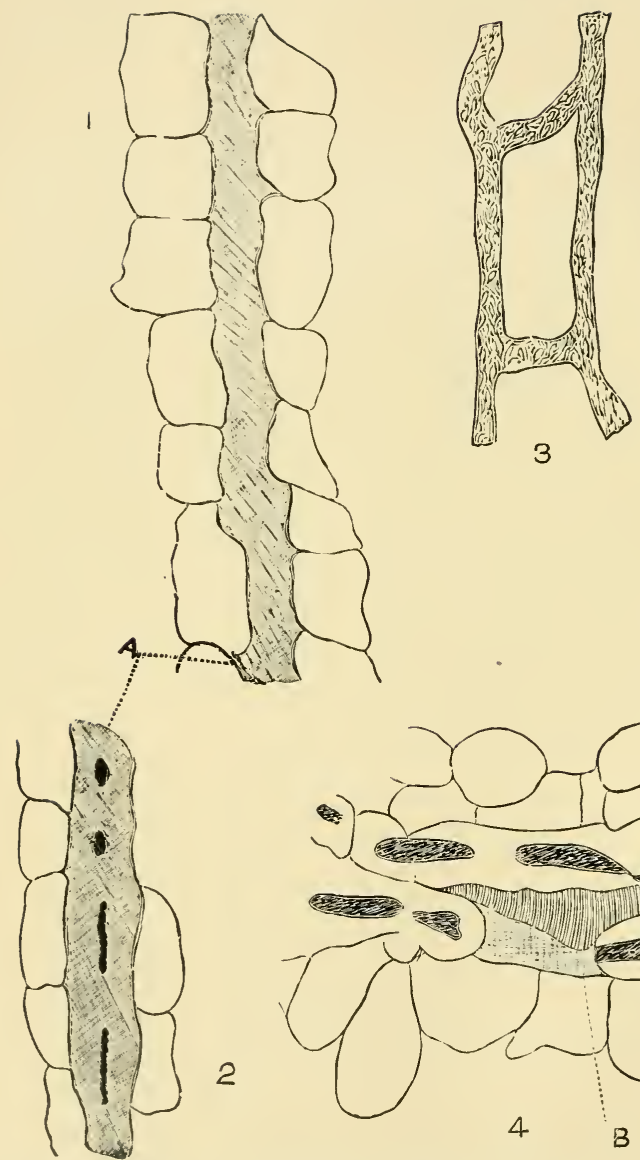

3

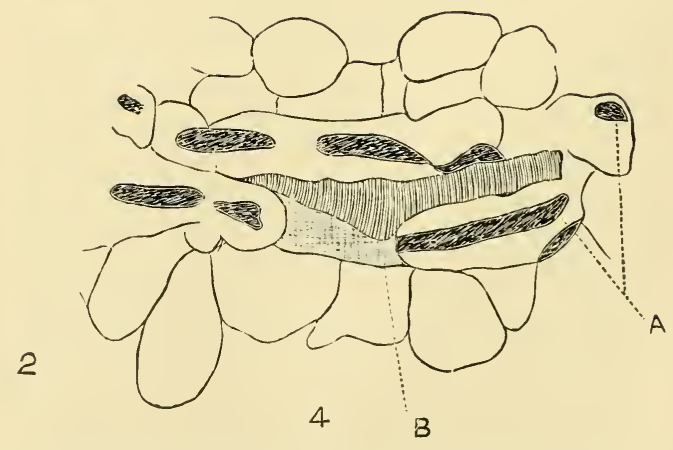

LATEX TUBES OF HEVEA BRASILIENSIS, (1, 2); AND CARICA PAPAYA (3.) (A) LATEX TLBES; (B) VESSEL. 
Warming, after studying the vegetation of tropical America, concluded that the latex probably served many functions, one of them being a source of water supply during the dry hot part of the day or year.

Parkin* considered that the latex did not play an important part in nutrition and inclined to the belief that the laticiferous system served as channels for holding water in reserve to be called upon during times of drought. The exudation and clotting of the milk prevent the entrance of many insects, but this is not of much importance.

The complete stripping of the cortex from the base up to 5 feet, and with it the greater part of the laticiferous system, has not, in the case of Hevea brasiliensis, resulted in any very bad effects on the tree.

The present appearance of trees, from which large quantities of latex have been extracted, is such as to confirm the belief that the latexi s of minor importance to plants freely supplied with water, and that the main source of danger lies in the removal of the cortieal and bark tissues often effected in collecting the latex.

It should be recorded that Hevea brasiliensis grows exceedingly well on land which is frequently inundated, and in some parts of Ceylon I have seen trees with their tap roots and a large proportion of the feeding rootlets permanently under water and yet yielding over 10 pounds of rubber, per tree, per year. An abundant supply of water, in well-drained land, is not harmful to Para rubber trees.

\section{General Considerations.}

In the accompanying Plate, No. 3, Series A, figures 1 and 2 represent the latex tubes running in a vertical direction through the stem of Hevea brasiliensis. In each case they are surrounded by cells which naturally store up reserve food materials, and in figure 2 , curious rod-like bodies are seen in the laticiferous vessels. In some instances the milk tubes are pitted, so that a transference of solutions may be effected from one series of cells to the other. Furthermore, the milk tubes often run very close to those elements of the wood, the function of which is to eonvey watery solutions from the roots upwards. Figure 3, drawn from a section of the fruit wall of Carica Papaya, shows the proximity of the water-conducting elements of the wood to the latex tubes, the latter possessing irregular patches of coagulated indiarubber. In figure 4 the general outline of a series of tubes is shown. On account of these relationships one may be inclined to attach some importance to the theory that the milk tubes are partially connected with conducting functions.

But the fact that the laticiferous tubes may be concerned in conducting solutions, that they contain in their earlier stages a certain quantity of protoplasm, and that nuclei and starch grains may be occasionally found, does not exclude the view that they are mainly excretory or act as water reservoirs. 
Generally speaking the milk tubes contain an emulsion of many substances, such as caoutchouc, resin, gum, sugar, proteids, alkaloids, and fats, and it is therefore very difficult to identify each component in sections under the microscope. Schulerus observed that in the embryo the latex is rich in suspended matters, and that as the plant grows the latex becomes more watery. He suggested that the emulsion of substances might be of use during the early stages. He also noticed that after germination the laticiferous system becomes prominent owing to an increase in the substances in suspension.

Sachs found that if the leaves of some caoutchouc plants were subjected to continuous darkness the quality of the latex was affected, the milk becoming less opaque; a marked change was also noticed if the plants were deprived of carbonic acid gas.

Haberlandt and others found that in some plants the starch grains disappeared from the milk tubes if kept in darkness for two or three weeks, thus suggesting that under certain circumstances the occasional starch grains may be converted into sugar to be used by the plant.

The presence of nuclei in certain laticiferous tubes, determined, I believe, by Treub, the close association of milk tubes with conducting elements in the leaf and the occurrence of minute quantities of carbohydrates, proteids, fats, and peptinizing ferments certainly support the idea that under certain conditions the latex contents may be useful to the plant. These substances are present in very variable proportions and the percentage of valuable ingredients in the latex often diminishes as the result of tapping operations. The physiological effect of extracting large quantities of latex from trees of known age is being studied at Henaratgoda, where tapping is done more by incision of the laticiferous tubes rather than by excision of dry cortical tissues, but up to the present no remarkable phenomena have been observed. But as previously pointed out the occurrence of such material in very small quantities prevents one from attributing undue importance to the "reserve food " conception.

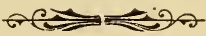




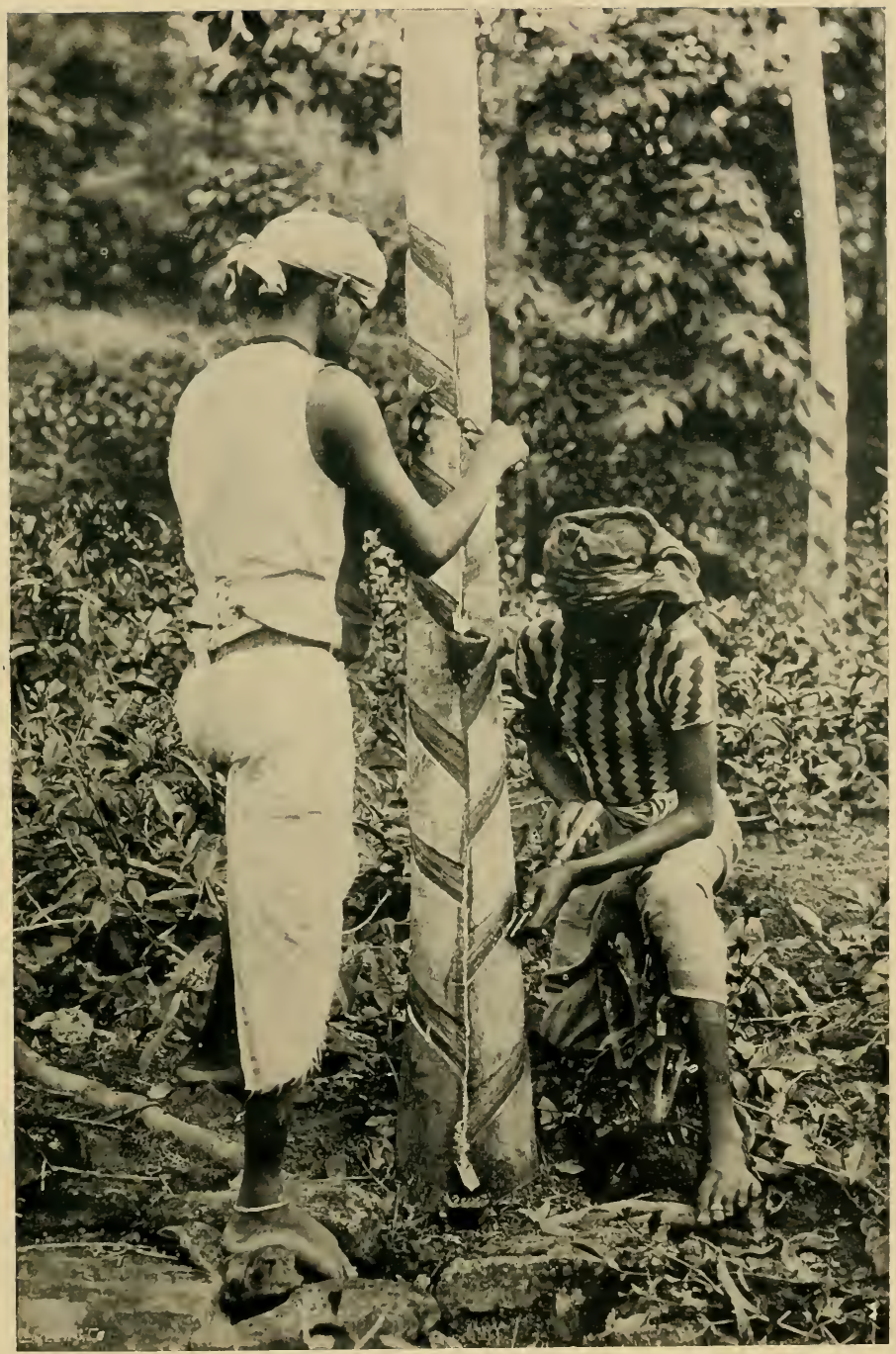





\section{CHAPTER II.}

\section{CLIMATIC CONDITIONS FOR PARA RUBBER.}

Descriptions of Para by Drs. Trimen \& Ule-Para trees in BrazilIllustration showing Para rubber in Ceylon-Climate in Ceylon, Straits, Perak, Selangor, Seremban, Singapore, Penang, and Nalacca-Java-Illustration showing young rubber at the Experiment Station, Buitenzorg, Java-India-Africa, West Indies, \&c.Illustration slowing Para rubber in Malacea-Illustration showing Para rubber at an elovation of $: 3,500$ feet in India-Illustration showing Para rubber on Sikong Estate, Borneo.

\section{Conditions in Para.}

6. PARA* occupies a position near the mouth of one of the vast embouchures of the Amazon in about south latitude 1, but the district of the same name extends over a vast forest region to the south and west, throughout which and the enormous forests of Central and Northern Brazil, Hevea brasiliensis and allied species are abundantly found. The climate is remarkable for its uniformity of temperature, usually not exceeding $87^{\circ} \mathrm{F}$. at midday or falling below $74^{\circ}$ at night. The greatest heat recorded is $95^{\circ}$, and the mean for the year is $81^{\circ}$. The rainfall occurs principally during the months from January to June, the maximum being in April, when it reaches 15 inches; for the remaining six months of the year very little rain falls, but there are fine days in the wet season and oceasional showers in the dry. During the wet season much of the low-lying country near the Amazon's mouths is flooded."

According to E. Ule, $\uparrow$ in his book dealing with rubber in the Amazon district, "the Para tree loses its leaves annually as in Ceylon, and in the flooded regions this occurs when the water is at its highest, i.e., between March and July. It flowers in July and August, and ripens its fruit in January and February. Like most forests in the tropics those of the Amazon are composed of many kinds of trees intermixed, and rubber occurs scattered among the

* Notes on Rubber-yielding plants. by Dr. Trimen.

$\dagger$ Review by Dr. Willis, “T.A. \& M.C.A.S.," March, 1905. 
rest. The lower-lying forests (Vargem or Igapo) are exposed to yearly floods and have a distinct character, differing from those on the higher lands.

There are two chief seasons, a dry and a wet. The driest months are July, August, and September, when the river-level is also lowest. The rains begin in October and last till March, and then decrease ; the rain is not however continuous: there are showers with clear intervals. The rivers rise till in January they overflow into the forest ; their highest level is reached in March or April and then they fall, leaving the woods dry again. In the lower course of the Amazon itself the water reaches its highest level in June, and this level is often 45 to 60 feet above the lowest. The annual rainfall is usually between 80 and 120 inches, and the mean temperature between $76^{\circ}$ and $81^{\circ} \mathrm{F}$. There are a great many kinds of trees in the forests, and in a distance of 100 yards one may only find one or two rubber trees."

\section{Para Rubber Trees in Brazil.}

It has been pointed out by Wickham that the true forests of the Para rubber trees lie back on the highlands, and those commonly seen by travellers along the river side are scattered, poor in growth, and do not give one a fair idea of the conditions under which a good growth of the Hevea tree is obtained. The Hevea trees found in these forests attain a circumference of 10 to 12 feet in the bole, a considerable difference to the 6 - to- 7 foot trees recorded by Cross.

The foregoing accounts of the climatic conditions in the native home of Hevea brasiliensis should be closely studied by persons who intend to cultivate this product. The rainfall of 80 to 120 inches and temperature of $75^{\circ}$ to $81^{\circ} \mathrm{F}$., though characteristic of the forests where this species grows luxuriantly, should not, however, be accepted as strictly defining the limits under which Para rubber can be cultivated. But even if the adaptability of the tree were insignificant, it is obvious that in the tropics there are many areas which might reasonably be expected to give good results with this species of rubber. Already the cultivation has aroused considerable interest in Africa, Fiji, Java, Queensland, Seychelles, Borneo, Samoa, Sumatra, and in many of these areas where the climatic factors are approximately similar to those of the Amazon, the industry promises to become as important as in the Straits, Ceylon, and India.

\section{Climate in Ceylon.}

The combination of rainfall, temperature, and elevation required for the profitable cultivation of Para rubber eliminates many parts of the tropics for this species. In Ceylon, India, and the Straits the large tracts of land in the hilly districts cannot be included in the Para zone on account of low temperatures or unfavourable moisture conditions. In Ceylon an elevation of 2,000 feet in the Central Province, and 3,000 feet in the Uva Province, is 

SERIES B. PL. 1 .

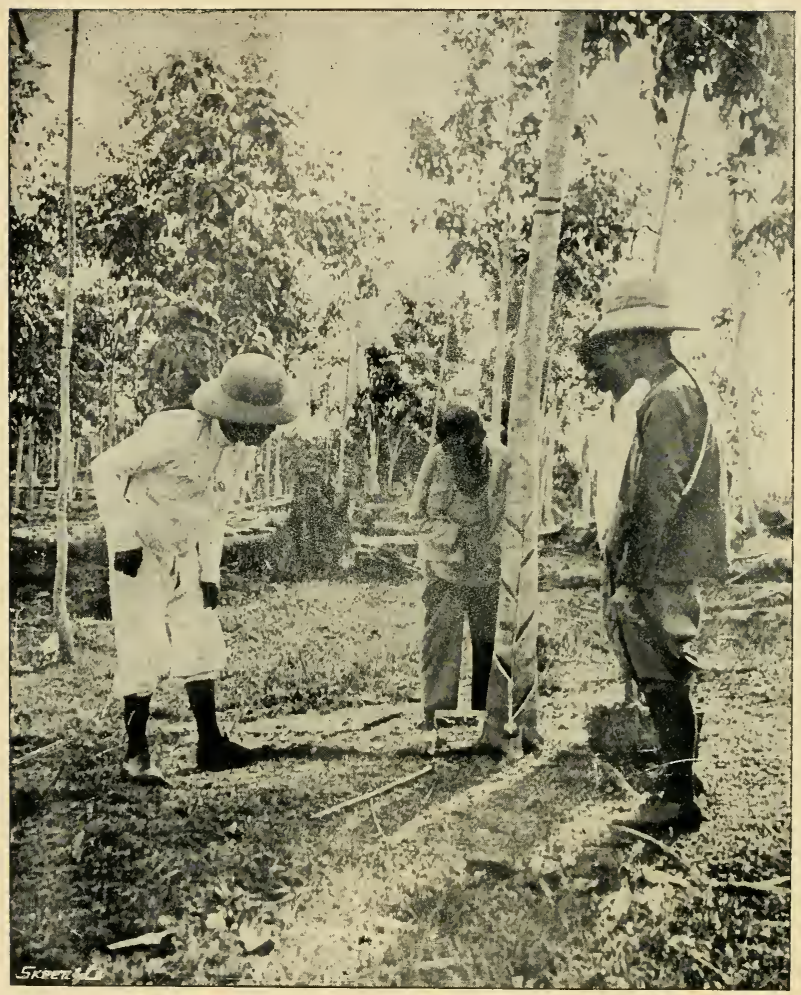

Photo lent by Dodwell \& Co.

PARA RUBBER IN MALACCA.

Tapping Mature Rubber. Malacca Rubber Plantations, Ltb. 
considered to be near the maximum and a rainfall of 70 inches near the minimum for the cultivation of this species. There are trees, planted in 1899 , measuring 18 to 26 inches in girth and 22 to 33 feet in height, growing on Weweltalawa, Halgolle estate, on the borders of the Kelani Valley and Yakdessa districts, at an elevation of 3,300 feet. It is being tried in districts having 200 inches of rain per year and also in dry irrigable areas, but reliable results cannot be obtained for many years.

The following are the meteorological details of places in particular districts in Ceylon where Para rubber trees are being successfully grown (Surveyor-General's Report, 1902 and by letter):-

\begin{tabular}{|c|c|c|c|c|c|c|}
\hline District & & $\begin{array}{l}\text { Annual } \\
\text { Rainfall } \\
\text { Inclies. }\end{array}$ & \multicolumn{3}{|c|}{$\begin{array}{c}\text { Average } \\
\text { Annual } \\
\text { Temperature. }\end{array}$} & \multirow{2}{*}{$\begin{array}{c}\text { Elevation. } \\
\text { Feet. } \\
200\end{array}$} \\
\hline \multicolumn{3}{|c|}{ Kalutara(Gikiyanakanda) $150 \cdot 74$} & .. & - & .. & \\
\hline Colombo & . & $87 \cdot 52$ & .. & $80 \cdot 7 \mathrm{~F}$. & . & 40 \\
\hline Henaratgoda & . & $106 \cdot 12$ & . & 一 & .. & 33 \\
\hline Kelani i & . & $161 \cdot 06$ & . & 一 & . & 250 \\
\hline Kurunegala & . & $84 \cdot 71$ & $\cdots$ & 一 & . & 409 \\
\hline Kéegalla & . & $12 \cdot 2 \cdot 33$ & . & 一 & . & 729 \\
\hline Kiandy & . & $81 \cdot 52$ & . & $75 \cdot 5$ & . & 1,654 \\
\hline Badulla & . & $75 \cdot 28$ & . & $73 \cdot 4$ & . & 2,225 \\
\hline Passara & . & $88 \cdot 91$ & .. & - & . & 2,800 \\
\hline Matale & . & $84 \cdot 38$ & . & - & . & 1,208 \\
\hline Ratnapura & .. & $151 \cdot 39$ & . & $79 \cdot 1$ & . & 84 \\
\hline Galle & . & $91 \cdot 16$ & . & $79 \cdot 9$ & .. & 48 \\
\hline Ragama & . & $100 \cdot 03$ & . & $79 \cdot 5$ & . & - \\
\hline
\end{tabular}

In the Colombo, Galle, Ratnapura, Kelani, and Kalutara Districts the rains in the N.-E. and S.-W. monsoons are very heavy; in the Kurunegala, Matale, Badulla, and Passara Distriets they are less violent, but in all the districts mentioned above, rain falls every month in the year, the monthly variation being from about five to twenty-four inches.

\section{The Clmate in the Federated Malay States.}

In the Federated Malay States there is no evidence of the highest elevation at which Para rubber will thrive, though some young trees are growing at Gunong Angsi at an elevation of 2,500 feet. According to Carruthers the growth of Para rubber from sea-level up to 300 feet in the Feclerated Malay States is better than that at most places. 
Aceording to the Manual of Statistics published by the Federated Malay States Government " the climate of the Federated Malay States is very uniform and can be described in general terms as hot and moist. The annual rainfall, except in places close to the mountain ranges, is about 90 inches. In towns, such as Taiping, Tapalı, Selama, \&c., close to high mountains, upwards of 50 per cent. more is registered, the average of ten years' records at the first-named being 164 inches. There is no weil-marked dry season. Generally speaking July is the driest month, but has seldom a less rainfall than $3 \frac{1}{2}$ inches. The wettest season is from October to December, and there is another wet season of slightly less degree during March and April. Rain rarely falls before 11 A.M., so that 6 hours of outdoor work can generally be depended upon all the year round.

The average maximum temperature, occurring between noon and 3 P.M., is in the low-country just under $90^{\circ}$, and the average minimum occurring before sunrise is just over $70^{\circ}$. The general mean temperature is about $80^{\circ}$. There is very little change in the mean monthly temperature during the year, the average of ten years' readings in Taiping exhibiting a difference of only $3^{\circ} \cdot 2$ between the mean temperature of May, the hottest, and of December, the coldest, month of the year.

The variation of temperature with altitude may be taken roughly as a decrease of 3 for every 1,000 feet increase of altitude."

\section{Average Rainfall at Perak, Selangor, Seremban.}

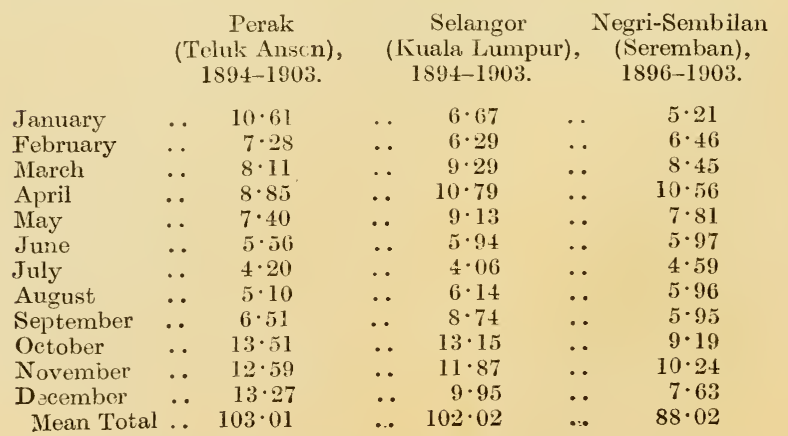

The above details of rainfall will be of value to all interested in the cultivation of Para rubber in Perak, Selangor, and Seremban. An illustration showing mature rubber on the property of the Ialacca rubber plantations is here given (See Plate 1, Scries B). 



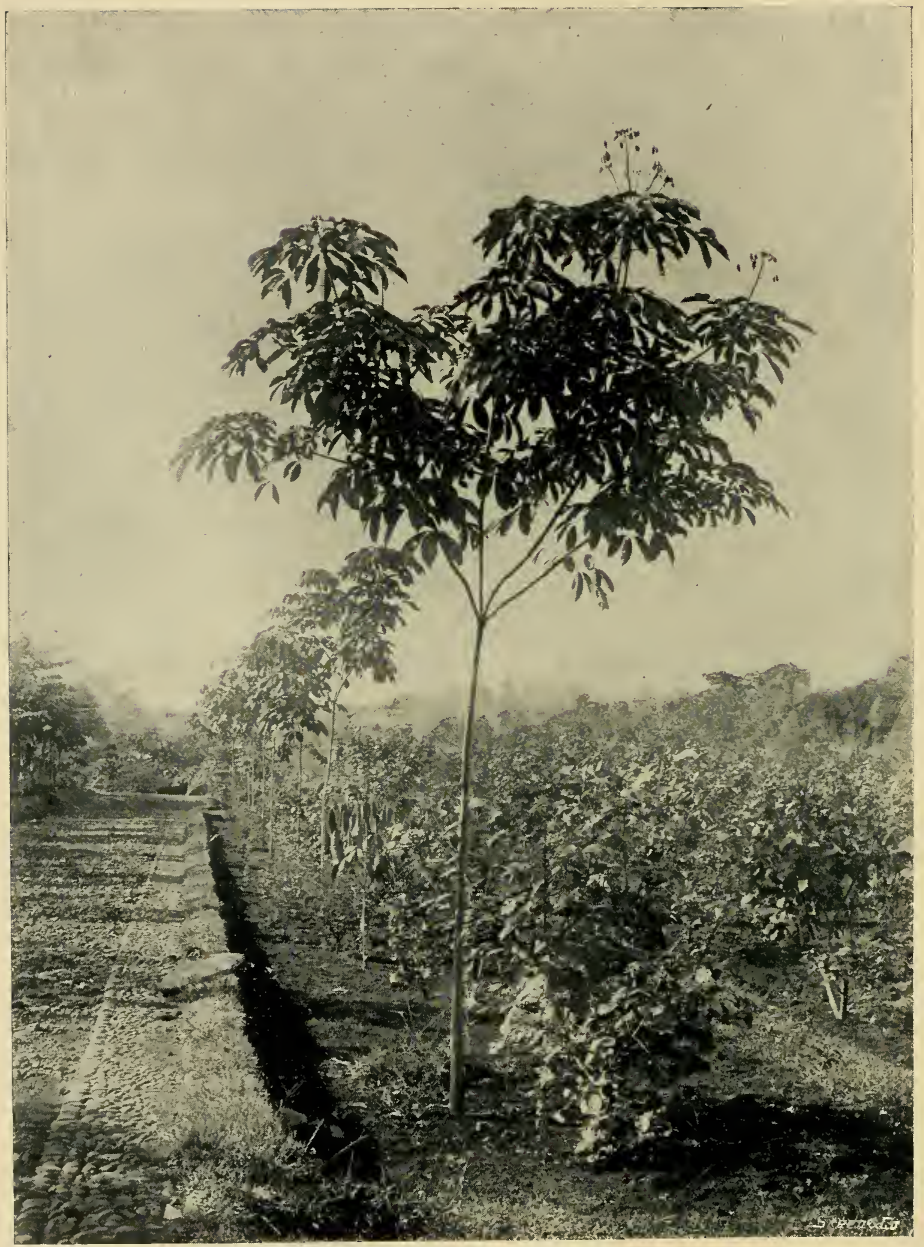

Lent by Dr. Tromp de Haas.

YOUNG PARA RUBBER IN JAVA.

Experiment Station, Buitenzorg.

Stumps Planted in January, 1904, Photograph taken in December, 1905. 


\section{Singapore, Penang, and Malacca.}

I am indebted to the Principal Civil Medical Officer of Singapore for the following statement showing the average monthly Rainfall, Temperature, and Humidity at Singapore, Penang, and Malacca:-

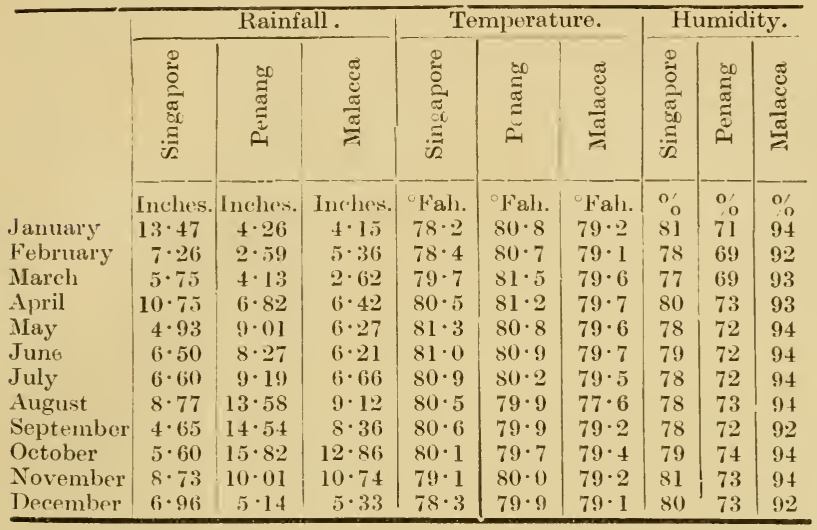

JAYA.

The climate in Java varies like that in Ceylon according to the locality, but we have definite information regarding the climatic factors at Buitenzorg and East Java.

The climate at Buitenzorg differs from that at Peradeniya, Ceylon, in many ways. At Buitenzorg the rain during 1901 to 1904 , inclusive, fell on an arerage of 263 days in each year. The humidity of the air in 1904 ranged from 75 in August to 85 in December, and the average for the years 1901 to 1904 , inclusive, was 79 . The average monthly temperature ranged in 1901 from $23 \cdot 6$ to $25 \cdot 3^{\circ} \mathrm{C}$. The climate in Buitenzorg is more equal than that at Peradeniya, but a definite periodicity does exist, the rainfall and humidity throughout the year approximating to those at Badulla in the Uva Province of Ceylon.

In East Java the climate is more exacting and a comparison of the two places is given below.

I am indebted to Dr. Treub for the information in the following synopsis of the monthly rainfall, humidity, and temperature at Pasocroan in Last Java and Buitenzorg. 
Climate during 1904 IN Java.

\begin{tabular}{|c|c|c|c|c|c|c|c|}
\hline & & \multicolumn{2}{|c|}{ Rainfall in $\mathrm{mm}$. } & \multicolumn{2}{|c|}{$\begin{array}{l}\text { Monthly Average } \\
\text { Mean Humidity. }\end{array}$} & \multicolumn{2}{|c|}{$\begin{array}{c}\text { Monthly Average } \\
\text { Mean Shade } \\
\text { Temperature in }{ }^{\circ} \mathrm{C}\end{array}$} \\
\hline & & $\begin{array}{l}\text { Buiten- } \\
\text { zorg. }\end{array}$ & $\begin{array}{l}\text { East. } \\
\text { Java. }\end{array}$ & $\begin{array}{c}\text { Buiten- } \\
\text { zorg. }\end{array}$ & $\begin{array}{l}\text { East. } \\
\text { Java. }\end{array}$ & $\begin{array}{c}\text { Buiten- } \\
\text { zorg. }\end{array}$ & $\begin{array}{l}\text { East } \\
\text { Java. }\end{array}$ \\
\hline January & . & 417 & 221 & 83 & 77 & $24 \cdot 0$ & $27 \cdot 2$ \\
\hline February & . & 455 & 192 & 85 & so & $23 \cdot 6$ & $26 \cdot 9$ \\
\hline March & . & 169 & 287 & 80 & 80 & $24 \cdot 5$ & $26 \cdot 6$ \\
\hline April & . & 204 & 33 & 79 & 76 & $25 \cdot 0$ & $27 \cdot 4$ \\
\hline May & . & 541 & 155 & 80 & 76 & $25 \cdot 3$ & $27 \cdot 3$ \\
\hline June & . & 389 & 27 & 78 & 73 & $25 \cdot 1$ & $27 \cdot 1$ \\
\hline July & . & 312 & 48 & 79 & 71 & $24 \cdot 8$ & $26 \cdot 7$ \\
\hline August & . & 344 & 18 & 75 & 67 & $25 \cdot 1$ & $27 \cdot 1$ \\
\hline September &. & 388 & 一 & 76 & 64 & $25 \cdot 3$ & $27 \cdot 7$ \\
\hline October &. & 799 & 11 & 81 & 64 & $24 \cdot 9$ & $28 \cdot 7$ \\
\hline November &. & 312 & 24 & 80 & 67 & $25 \cdot 2$ & $28 \cdot 7$ \\
\hline $\begin{array}{l}\text { December } \\
\text { Average }\end{array}$ & & 498 & 110 & 85 & 74 & $24 \cdot 21$ & $27 \cdot 9$ \\
\hline $\begin{array}{c}\text { mean, yearl } \\
1901-190\end{array}$ & & 4.416 & 1,200 & 79 & $71 \cdot 9$ & $25 \cdot 0$ & $27 \cdot 6$ \\
\hline
\end{tabular}

Large areas are likely to be planted by companies in suitable parts of Java, and it is of importance to notice that the Forest Department of that island have already approximately (112 H. A.), about 270 acres in Para rubber at the present time. Seeds of Para rubber were sent to Java in 1887, but Para rubber in that island at the present time is mainly young. Illustrations have been seen showing young rubber on the property of Passir Oetjing estate in the Western part of Java, and satisfactory growth was obtained with the trees planted nine feet apart. I am indebted to Dr. Tromp de Haas, for the illustration showing Para rubber at tho Experiment Station, Buitenzorg, planted as stumps in January, 1904; the photograph was taken in December, 1905 , so that the trees were then nearly two years old.

\section{Climate in India.}

In some parts of Iudia the climatic conditions are such as to allow of the cultivation of Para rubber up to 3,500 feet above sealevel, and what appear to be satisfactory rates of growth are reported from many parts. Extensive tracts of country are being opened up, especially in the Travancore district, and good results are anticipated on account of the abundance of rich alluvial soil which is reported to exist there.

The accompanying illustration Series B, Plate 2, will indicate the growth obtainable in the Anamallai Hills, in S. India, at an elevation of 3,500 feet above sea-level. In this particular instance 


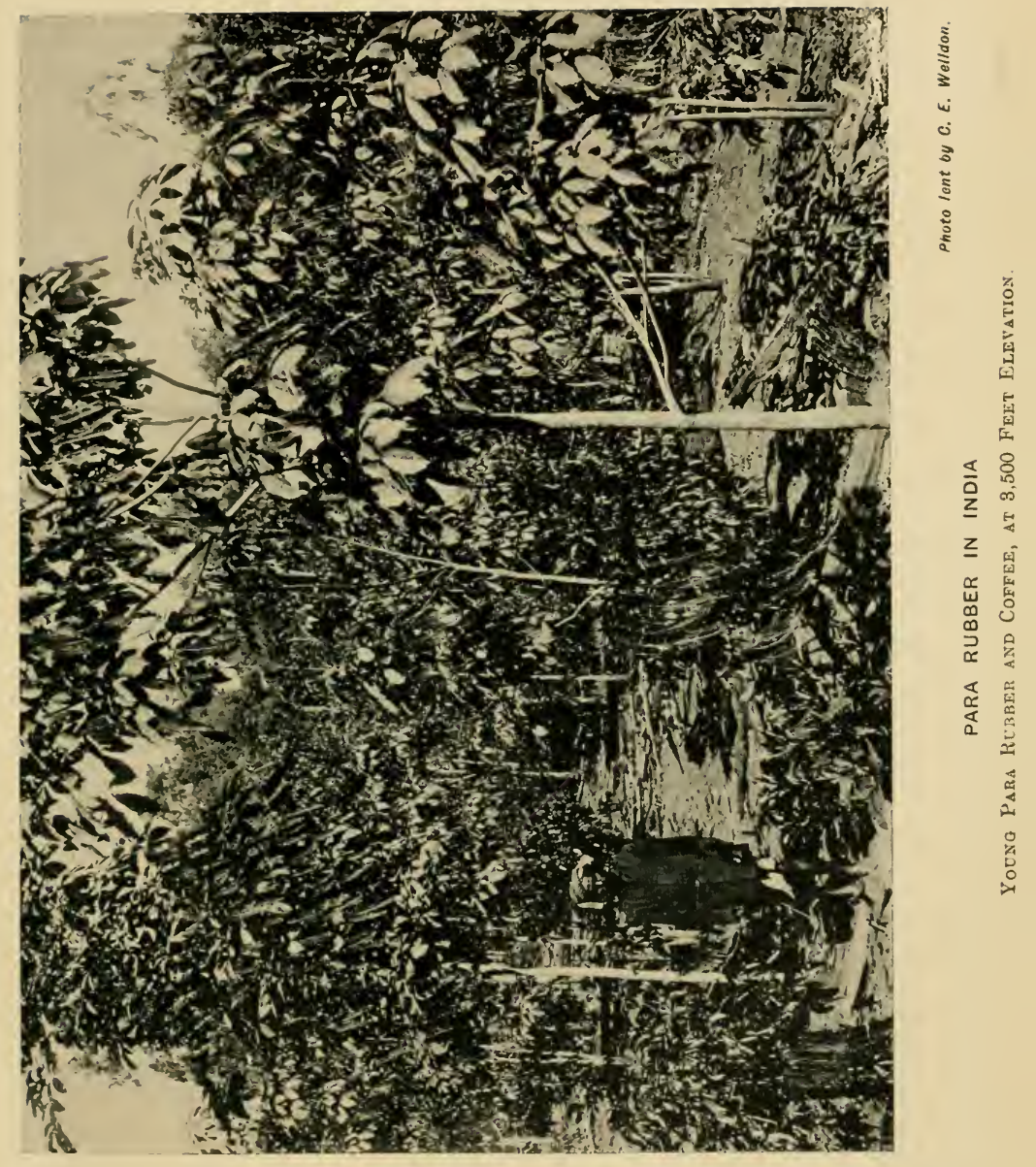



coffee is interplanted with Para rubber. In South India various species of rubber-yielding plants are loeing tried at high elevations, in conjunction with tea and coffee. The illustration, Series B, Plate 2, shows Para rubber and coffee both doing well at a high elevation, and the results of tapping on an estate in the Shevaroy Hills are given in the chapter dealing with yields. It is as well to bear in mind that the elevation up to 3,500 feet in so far that it is affected with changes of atmospheric pressure has very little influence on the growth of the rubber: far more important are the questions of ranges of temperature and rainfall.

\section{Africa, West Indies, Borneo, \&c.}

The illustrations given elsewhere will show under what conditions Para rubber is being grown in Ceylon and other parts of the tropical world, for in addition to alluvial flats and gentle slopes, rocky hillsides and well-drained swampy land have been proved to be suitable for this product.

In the Gold Coast, West Africa, it is according to Johnson, being grown at an elevation of 1,500 feet above sea-level, where the average mean temperature is about $8 \mathrm{I} .5 \mathrm{~F}$. and the annual average rainfall only 47 inches, and there promises to do better than other rubber-producing plants, indigenous or exotic.

The following table shows the rainfall and number of days on which rain fell during 1900-1904, at Aburi-Gold Coast :-

\begin{tabular}{|c|c|c|c|c|c|c|c|c|c|}
\hline \multicolumn{2}{|c|}{1900.} & \multicolumn{2}{|c|}{1901.} & \multicolumn{2}{|c|}{1902.} & \multicolumn{2}{|c|}{1903.} & \multicolumn{2}{|c|}{1904.} \\
\hline $\begin{array}{l}\text { Rain- } \\
\text { fall. }\end{array}$ & $\begin{array}{l}\text { No. of } \\
\text { Wet } \\
\text { Days. }\end{array}$ & $\begin{array}{l}\text { Rain- } \\
\text { fall. }\end{array}$ & $\begin{array}{l}\text { No. of } \\
\text { Wet } \\
\text { Days. }\end{array}$ & $\begin{array}{l}\text { Rain- } \\
\text { fall. }\end{array}$ & $\begin{array}{l}\text { No. of } \\
\text { Wet } \\
\text { Days. }\end{array}$ & $\begin{array}{l}\text { Rain- } \\
\text { fall. }\end{array}$ & $\left|\begin{array}{c}\text { No. of } \\
\text { Wet } \\
\text { Days. }\end{array}\right|$ & $\begin{array}{l}\text { Rain- } \\
\text { fall. }\end{array}$ & $\begin{array}{l}\text { No. of } \\
\text { Wet } \\
\text { Days. }\end{array}$ \\
\hline $1 \cdot 51$ & 3 & $2 \cdot 11$ & 5 & $\cdot 30$ & 1 & $\cdot 73$ & 1 & 1 . & 1 \\
\hline $2 \cdot 30$ & 13 & $5 \cdot 32$ & 5 & $5 \cdot 03$ & 5 & $1 \cdot 09$ & 3 & $\cdot 55$ & 2 \\
\hline $2 \cdot 72$ & 4 & $4 \cdot 53$ & 8 & $3 \cdot 82$ & 9 & $5 \cdot 89$ & 6 & $4 \cdot 16$ & 8 \\
\hline $4 \cdot 88$ & 8 & $4 \cdot 07$ & 6 & $7 \cdot 01$ & 10 & $2 \cdot 63$ & 9 & $1 \cdot 84$ & 5 \\
\hline $3 \cdot 14$ & 6 & $5 \cdot 48$ & 9 & $3 \cdot 27$ & 10 & $4 \cdot 56$ & 8 & $6 \cdot 24$ & 9 \\
\hline $5 \cdot 72$ & 15 & $6 \cdot 87$ & 10 & $7 \cdot 09$ & 11 & $7 \cdot 44$ & 11 & $6 \cdot 47$ & 13 \\
\hline $2 \cdot 48$ & 18 & $6 \cdot 89$ & 14 & $2 \cdot 07$ & 6 & $3 \cdot 72$ & 13 & $2 \cdot 19$ & 7 \\
\hline $1 \cdot 49$ & 15 & $2 \cdot 57$ & 14 & $2 \cdot 93$ & 7 & $1 \cdot 58$ & 10 & $\cdot 65$ & 3 \\
\hline $2 \cdot 29$ & 14 & $6 \cdot 97$ & 24 & $\cdot 73$ & 2 & $1 \cdot 93$ & 11 & $2 \cdot 97$ & 6 \\
\hline $5 \cdot 90$ & 15 & $4 \cdot 95$ & 15 & $7 \cdot 16$ & 11 & $4 \cdot 78$ & 13 & $2 \cdot 20$ & 8 \\
\hline $2 \cdot 53$ & 4 & $5 \cdot 43$ & 10 & $2 \cdot 16$ & 2 & $6 \cdot 60$ & 14 & $\cdot 52$ & 4 \\
\hline $2 \cdot 69$ & 5 & $1 \cdot 23$ & 6 & $\cdot 74$ & 3 & $2 \cdot 13$ & 5 & $3 \cdot 30$ & 5 \\
\hline $37 \cdot 65$ & 120 & 56.42 & 126 & $42 \cdot 31$ & 77 & $43 \cdot 08$ & 104 & $32 \cdot 09$ & 71 \\
\hline
\end{tabular}

(Annual Report for 1904 by Director, Botanic Department, Gold Coast.) 
It is likewise farourably reported upon in Jamaica, Dominica, St. Vincent, Grenada, Trinidad, Zanzibar, Uganda Protectorate, Mozambique, and many other places in the tropics supplied with seeds from Ceylon and the Straits.

Para rubber plants were sent to Borneo from Peradeniya as far back as 1891, and the illustration on Plate 3. Series B, shows how well this species of rubber grows in that country. The photograph was obtained from the North Borneo Trading Co, Ltd., and shows well-developed trees on the Para rubber estate at Sikong, being as far as one can judge from the illustration, lightly and carefully tapped on a system other than the herringbone or spiral.

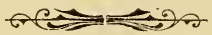




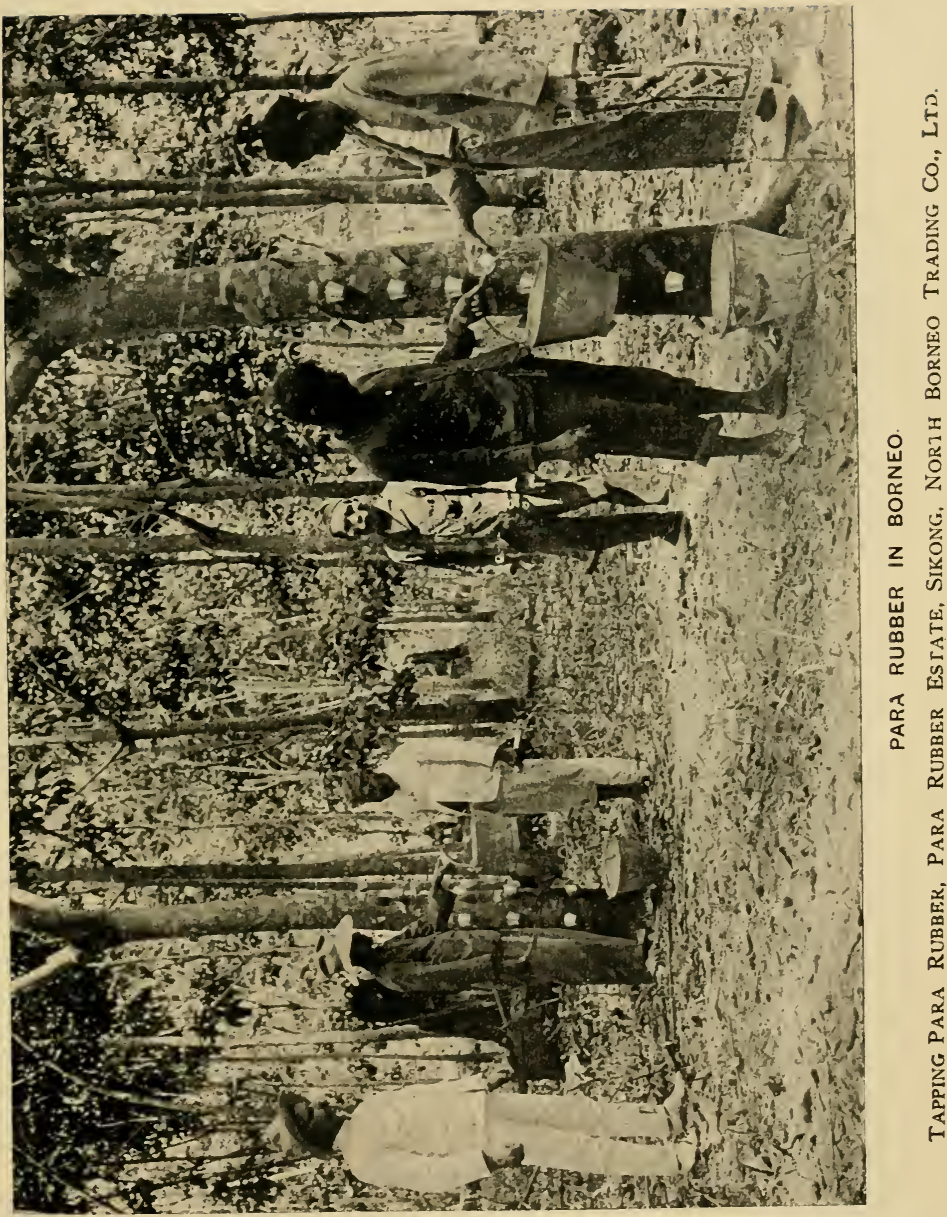



CH.IPTER III.

CULTIVATION OF PARA RLBBER TREES.

Rate of growth-Size of trees at Henaratgoda, Peradeniya, Edangoda, and parts of Ceylon-Illustrations showing Para rubber on rocky hillsides and in drained swampy land-Kingalle, Kinuckles, Nilembe, Ketugastote, Sabsregemuwe, Wattegems, Kelutara, Matale, 13addegama-Spread of foliage each yoar from 2nd to 30th yoar - Rate of growth in the Gold Coast-Height and circumforeneeRete of growth in the Straits, Perak, Selangor-Carruthers on rate of growth in F. M. S.-Rate of Growth in India-Mergui, Shevaroy, Nilgiris-High average incr-mental growth in the Straits-Leaf-fall-Root System-Propagation of plants - Shade and wind in the F.M. S. and Ceylon-Planting operationsIllustration showing a rubber clearing and nursery in Ceylon -Nurseries-Fencing-Drwining-Distance, Holing, and Planting -Close planting and available tapping area-Number of trees per acre-Distance for rubber alone and eatch crops-Pruning Para rubber-Principles and effect-Measurements of straightstemmed and forked trees in Ceylon-Inter and eatch cropsCacao, Coffee, Tea, Groundnuts, Lemon-grass. Cassava-Future of inter erops-Illustrations showing Prra rubber and cacao at Kepitigalla-Para rubber and Tea on Nikakotua estate-Para rubber and tea on Undugoda estate, IVegalle-Para rubber and cacao on Dangan Estate, Matale.

\section{Rate of Growth and Size of Mature Trees in Ceylon.}

r $\mathrm{HE}$ rate of growth depends upon the nature of the soil and 1. climate and the care which has been exercised in selecting seed parents and in planting operations. In rlistricts having a rainfall of about 100 inches per year, an average mean annual temperature of $80^{\circ} \mathrm{F}$., and soil of medium quality, the trees will grow about six to ten feet in height every year for the first three or four years and attain a height of 80 to 90 feet within thirty years. The growth in circumference is by no means slow; trees one year old from planting may have a circumference of three to four inches, and they usually increase at the rate of four to five inches each year for the first few years when planted as a single product. During the first few years the growth is mainly in length, and the rapid increase in girth is 
most noticeable after the trees are a few years old. The following table shows the dimensions of trees of known ages at Henaratgoda; the stumps were about one year old when planted.

\section{Henaratgoda Trees planted in 1876.}

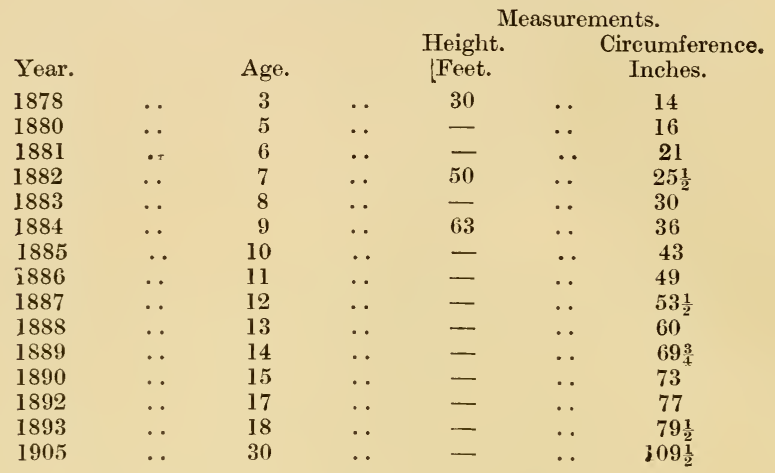

\section{Peradeniya Trees planted in 1876.}

Para rubber trees were planted at Peradeniya in the South Garden near the river banks, above flood level. They were planted 10 feet apart, probably in 1876 when the stumps were about one year old, and the following were the dimensions of the trees in June, 1905 :-

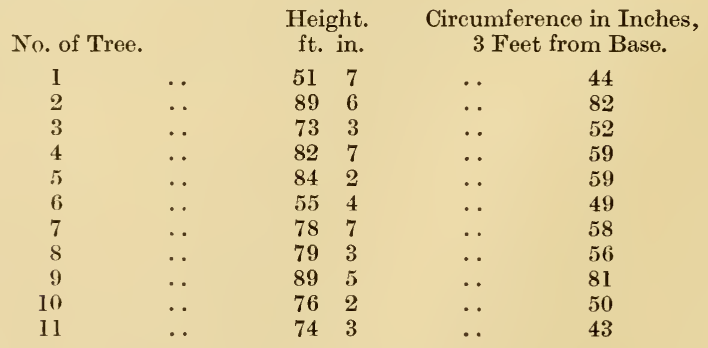

The following list gives the dimensions of the trees planted in 1881 along the river bank, where they are liable to be flooded when the water is high. They are remarkable on account of the growth obtained when planted so close, the average distance between the trees at the present time being 9 to 10 feet. 


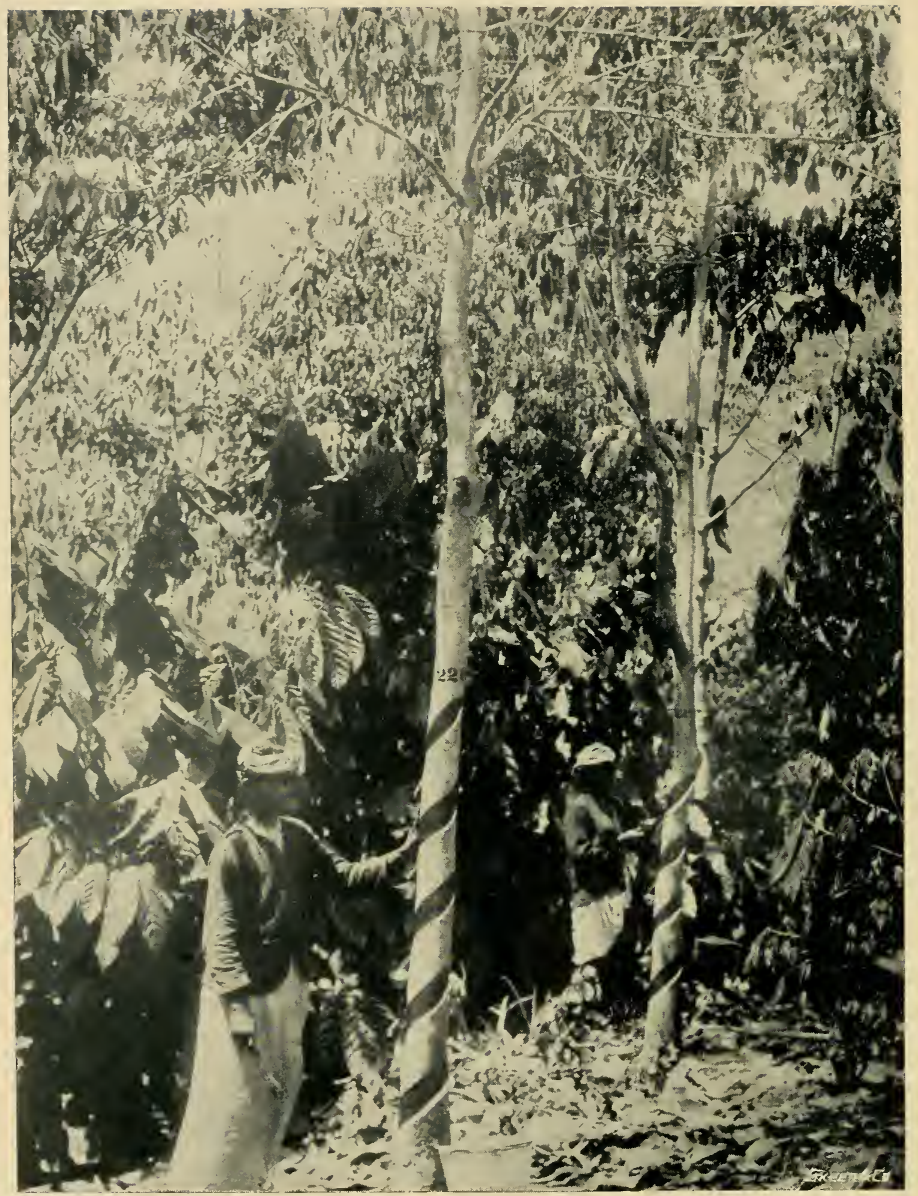

Pnoto by Colombo Apothecaries Co.

PARA RUBBER IN CEYLON.

Rubber and Cocoa in Bearing, Matale.

Dangan Estate, Rubber Piantations, Lto. 


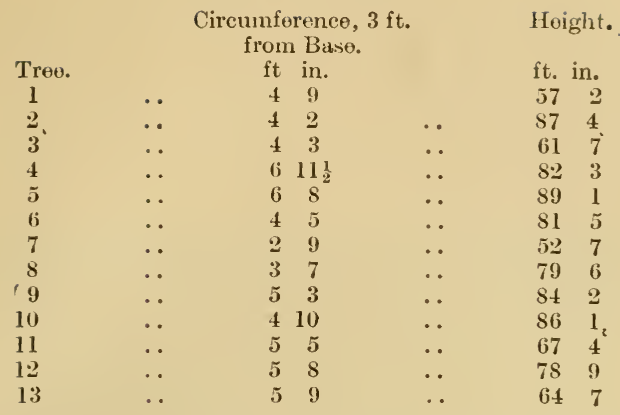

Other measurements have previously been taken of the trees on the Forest Department Plantations and are here quoted:-

Edangoda Trees.

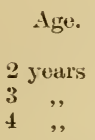

Years. 3
Mean Circunforenco, $3 \mathrm{ft}$. from Base.

.. $\quad 4.96$ inches.

. 8.75, ,

.. $12 \cdot 96$,

YatTipawa Trees.

Rate of Growth in Other Parts of Ceylon.

The following figures show the dimensions of Para rubber trees, interplanted with tea and cacao, in Ceylon:-

Circumference of the Ste $m$ in Inches, 3 Feet from the Base.

\begin{tabular}{|c|c|c|c|c|c|c|c|}
\hline $\begin{array}{c}\text { Trees in } \\
\text { years. } \\
2\end{array}$ & Kiegalla. & $\begin{array}{c}\text { Knuckles. } \\
5\end{array}$ & $\begin{array}{l}\text { Sabara- I } \\
\text { gamuwa. }\end{array}$ & $\begin{array}{c}\text { Katugas- } \\
\text { tota. }\end{array}$ & $\begin{array}{l}\text { Pera- } \\
\text { deniya. } \\
2 \text { to } 6\end{array}$ & Nilambe. & $\begin{array}{l}\text { Kalu- } \\
\text { tara. } \\
5\end{array}$ \\
\hline 3 & - & - & 14 & - & 10 & 一 & 9 \\
\hline 4 & - & $14-16$ & 15 & - & - & - & 17 to 20 \\
\hline 5 & 21 to $30 \frac{1}{2}$ & - & 21 & - & - & - & $\ldots$ \\
\hline 6 & - & - & $27 \frac{1}{2}$ & 19 & - & - & - \\
\hline 7 & - & - & 31 & - & - & - & - \\
\hline 8 & 一 & - & $31 !$ & 24 & - & - & - \\
\hline 9 & - & - & 65 & 38 & - & 15 to 46 & 一 \\
\hline 10 & - & - & - & - & - & - & 一 \\
\hline 11 & - & - & - & - & - & - & 一 \\
\hline
\end{tabular}

In distriets over 2,000 feet above sea-level or where the rubber has been planted in inferior or unsuitable soils the growth is much poorer. On one estate near Peradeniya, 2,200 feet above sea-level, 9-year-old trees only measure 24 to 46 feet in height and 15 to 46 inches in circumference a yard from the ground, and the following dimensions of the trees referred to will be of interest to those plan- 
ters who are trying Para rubber at high elevations in Ceylon and elsewhere:-

\begin{tabular}{ccccccc}
$\begin{array}{c}\text { No. of } \\
\text { Tree. }\end{array}$ & \multicolumn{4}{c}{$\begin{array}{c}\text { Length of } \\
\text { Trunk. } \\
\text { Tt. }\end{array}$} & \multicolumn{3}{c}{$\begin{array}{c}\text { Spread in } \\
\text { Widest Part. } \\
\text { ft. }\end{array}$} \\
1 & $\ldots$ & 42 & 0 & $\ldots$ & 29 & 8 \\
2 &. & 36 & 0 & $\ldots$ & 21 & 0 \\
3 &. & 34 & 6 & $\ldots$ & 13 & 0 \\
4 &. & 46 & 10 &. & 22 & 6 \\
5 &. & 42 & 6 &. & 22 & 8 \\
8 &. & 32 & 5 &. & 18 & 0 \\
7 &. & 36 & 6 &. & 17 & 0 \\
8 &. & 46 & 8 &. & 25 & 6 \\
9 &. & 24 & 4 & $\ldots$ & 13 & 4 \\
10 &. & 42 & 8 & $\ldots$ & 29 & 0
\end{tabular}

$\begin{array}{cc} & \text { Circumference, } \\ & \text { 3 Feet from the Base. } \\ \text { in. } & \\ . & 46 \\ . & 22 \frac{1}{2} \\ . & 15 \frac{1}{2} \\ . & 24 \\ . & 22 \\ . & 22 \frac{1}{2} \\ . & 25 \frac{1}{2} \\ . & 33 \\ . & 17 \\ \text {. } & 35\end{array}$

In other districts where the rubber has been planted in very poor tea and eacao land the growth is often very slow.

The Neboda Tea Co., in their annual report for 1905, state that the 1904 clearings range from 17 to $27 \frac{1}{2}$ feet in height and from 6 to 10 inches in circumference, while last year's basket plants, put out in April-May, from August, 1904, seed, show the best growth : $8 \frac{3}{4}$ to $12 \frac{1}{2}$ feet in height and $3 \frac{1}{4}$ to $4 \frac{1}{4}$ inches in girth.

Under suitable conditions of soil and climate in Ceylon, one must allow for the full development of the plant and a spread of branch diameter of at least 30 feet for trees 10 years old, and 40 feet for 20 . year-old trees might form the basis of calculations where pruning is not adopted, and where the cultivation is intended to be permanent.

The diameters of the branch and foliar system of trees of known ages measured on rubber property in Ceylon are here given, but it must be understood that the growth has been obtained where Para rubber is interplanted with cacao or tea. The growth is very variable. The Para stumps were from one to two years old when planted.

Diameter of Branches with Foliage.

\begin{tabular}{|c|c|c|c|c|c|c|c|c|c|}
\hline $\begin{array}{l}\text { Age of } \\
\text { Trees. }\end{array}$ & $\begin{array}{r}\text { Ba } \\
\text { Matale. ga }\end{array}$ & $\begin{array}{l}\text { 3adde- } \\
\text { gama. }\end{array}$ & $\begin{array}{l}\text { Katu- } \\
\text { gastota. }\end{array}$ & $\begin{array}{l}\text { Nilam- } \\
\text { be. }\end{array}$ & $\begin{array}{l}\text { Knuek } \\
\text { cles. }\end{array}$ & $\begin{array}{l}\text { Pera- Se } \\
\text { deniya. ge }\end{array}$ & Sabara & $\begin{array}{l}\text { a- Watte } \\
\text { wa. game }\end{array}$ & $\begin{array}{l}\text { - Kalu } \\
\text { tara. }\end{array}$ \\
\hline Years. & ft. & ft. & ft. & ft. & $\mathrm{ft}$. & ft. & $\mathrm{ft}$. & ft. & ft. \\
\hline 3 & 4 to $4 \frac{1}{2}$ & - & - & 二 & - & - & 10 & - & 12 \\
\hline 4 & $13 \frac{1}{2}$ & 12 & - & - & 12 to & $13-$ & 19 & - & 16 \\
\hline 6 & - & 13 & - & - & - & - & 28 & - & 17 \\
\hline 7 & 15 to 24 & +18 & - & - & - & - & - & - & 20 \\
\hline 8 & - & - & 29 & - & - & - & 37 & - & 25 \\
\hline 9 & - & - & -1 & 17 to 30 & o- & - & - & 23 & .25 \\
\hline 10 & 32 to 34 & $4-$ & - & - & - & - & $\ldots$ & 28 & 33 \\
\hline 11 & - & - & - & - & - & - & - & - & 35 \\
\hline 13 & - & - & - & - & - & - & - & - & 46 \\
\hline 15 & 27 to $4 f$ & $f-$ & - & - & - & - & - & 一 & - \\
\hline 25 & - & - & - & - & - & 15 to 43 & $3-$ & - & - \\
\hline \multirow{2}{*}{\multicolumn{10}{|c|}{ Elevation in }} \\
\hline & & & & & & & & & 100 \\
\hline \multicolumn{10}{|c|}{ Rainfall in } \\
\hline & & $11 !$ & 85 & 30 & 75 & 90 & 170 & to & 130 \\
\hline
\end{tabular}




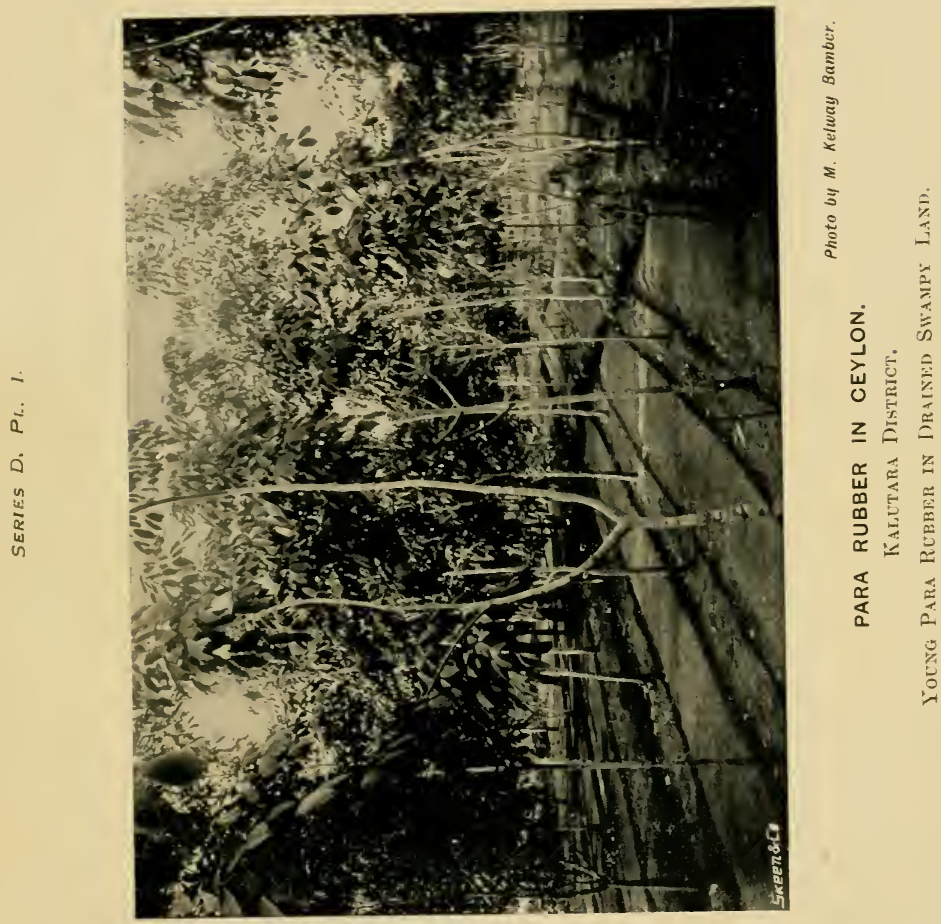



Where the trees are planted closer than $10 \times 15$ feet apart they will probably show a greater height and smaller cireumference. One tree, ten years old, grown more or less in the open, has a spread of 36 feet, whereas one of the same age surrounded with other trees has a spread of only 20 feet. The largest tree in Ceylon, now thirty years old from seed, measures about 90 feet in height and $109 \frac{1}{2}$ inches in eireumference, and there are many others of the same age which have a eireumference of 8 to 9 feet and a height in proportion to the above examples. Several of the Henaratgodia trees, owing to their being too elosely planted, have only a branch spread of 15 to 20 feet in diameter. (See Plate 1, Series A.)

\section{Rate of Growth in the Gold Coast.}

Plants have been established in the Botanic Gardens,* Aburi, at different dates, and most of them have made very rapid growth. Some of the trees only 18 months old are 10 feet high, and have stems 3 inches in diameter. The following table shows the growth of eertain trees at different ages in the Gold Coast :-

Age of Tree in Years.

Height in Feet.

$\begin{array}{rlccc}10 & \ldots & 30 \cdot 25 & \ldots & 27 \\ 4 & \ldots & 23 & \ldots & 10 \\ 3 & \ldots & 17.5 & \ldots & 65 \\ 1 & \text { RiATE OF GroWTH IN THE STRATTS. }\end{array}$

The growth in most parts of the Straits is considered to be very eneouraging and superior to that obtained in many other Para rubber-growing countries. In Perak $\dagger 11$-year-old speeimens may be $70-75$ feet high and have a mean girth of $4 \frac{1}{2}$ feet, at 3 feet from the base.

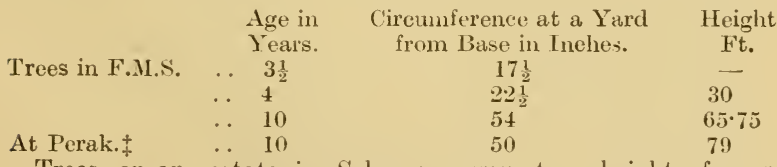

Trees on an estate in Selangor grew to a height of over 30 feet and attained a girth of 19 inches in four years. At Perak, an 18-year-old tree growing at Kuala, Kingsar, has a girth of $\mathrm{st}$. 6 inches at a yard from the ground. Phenomenal growth in some parts of the Straits is often met with, trees 18 months old being sometimes nearly 30 fect high, and trees 8 years old having a circumference of 45 or more inches a vard from the ground. Aceording to Carruthers the rate of growth in the Federated Malay States eannot be definitely given but 3 to 9 inches girth in 2 years, 10 to 30 inches in 4 to 6 years, and 30 to 60 inches in 7 to 10 years are quoted as averages by that gentleman.

* Jolnnson, Report on Rubber in the Gold Coast, 1905.

t Annual Report, F. MI. S., for 1902, by Stanley Arden. $\div$ Agr. Bul, of the Straits and F. M. S., June, 1902 . 


\section{Rate of Growth in India.}

The following figures showing the dimensions of nine-year-old trees in Mergui have been given by Colonel W. J. Seaton:-

\begin{tabular}{ccccc} 
No. & & Height in Feet. & \multicolumn{2}{c}{$\begin{array}{c}\text { Circumference } 2 \mathrm{ft} . \\
\text { from th }\end{array}$} \\
1 & $\ldots$ & 39 & $\ldots$ & $29 \frac{1}{2}$ \\
2 & $\ldots$ & $34 \frac{1}{2}$ & $\ldots$ & 37 \\
3 & $\ldots$ & 40 & $\ldots$ & 38 \\
4 & $\ldots$ & $43 \frac{1}{2}$ & $\ldots$ & $40 \frac{1}{2}$ \\
5 & $\ldots$ & $36 \frac{1}{2}$ & $\ldots$ & $39 \frac{1}{2}$ \\
6 & $\ldots$ & $38 \frac{1}{2}$ & $\ldots$ & $27 \frac{1}{2}$ \\
7 & $\ldots$ & $36 \frac{3}{4}$ & $\ldots$ & 31 \\
8 & $\ldots$ & 30 & $\ldots$ & 18 \\
9 & $\ldots$ & 31 & $\ldots$ & 27 \\
10 & $\ldots$ & $21 \frac{1}{2}$ & $\ldots$ & $18 \frac{1}{2}$
\end{tabular}

In many parts of Southern India, Para rubber is being more or less successfully grown up to 3,500 fęet above sea-level. Trees at an elevation of 2,500 feet have attained a height of 18 feet in three years, a circumference of 42 inches in 17 years, and nearly 60 inches in 22 years.

On the Shevaroy Hills, at an elevation of 3,400 feet, Para rubber trees are reported to be about 10 inches in circumference when three years old ; others are reported at 3,600 feet in the Nilgiris and the Anamallais to be from 9 to 13 inches in circumference and 19 to 29 feet in height, when three and a half years old. On many of these properties the rubber is used as shade for coffee, and from all accounts the latter is thriving under the shade of Para and Castilloa rubber.

The Para rubber trees in many parts of South India do not appear to increase much more than 3 to 4 inches in circumference per year, and a girth of 20 inches in 5 years would be considered good.

Speaking in quite a general way it is fairly correct to say that the average growth obtained in the good soils of the Straits, when the rubber is grown as a single product, is better than that in Ceylon, India, or in the Gold Coast, but that local areas in each country, and especially in the drained black soils of Ceylon and along the Malabar coast of India, show excellent growth of Para rubber.

\section{LEAF-FALL.}

The Para rubber tree is not evergreen. During the first two or three years the young tree may retain its leaves and show a nett increase in foliage at regular intervals. After the second or third year, however, the tree annually drops its leaves, but quickly puts on a fresh supply of young foliage. When growing under healthy conditions the trees in Ceylon and the Straits usually drop their leaves in February and March ; in badly-drained places the foliar change is very irregular. The tapping operations are believed, by many persons, to change to a varying degrce the periodicity of leaf-fall and production. 


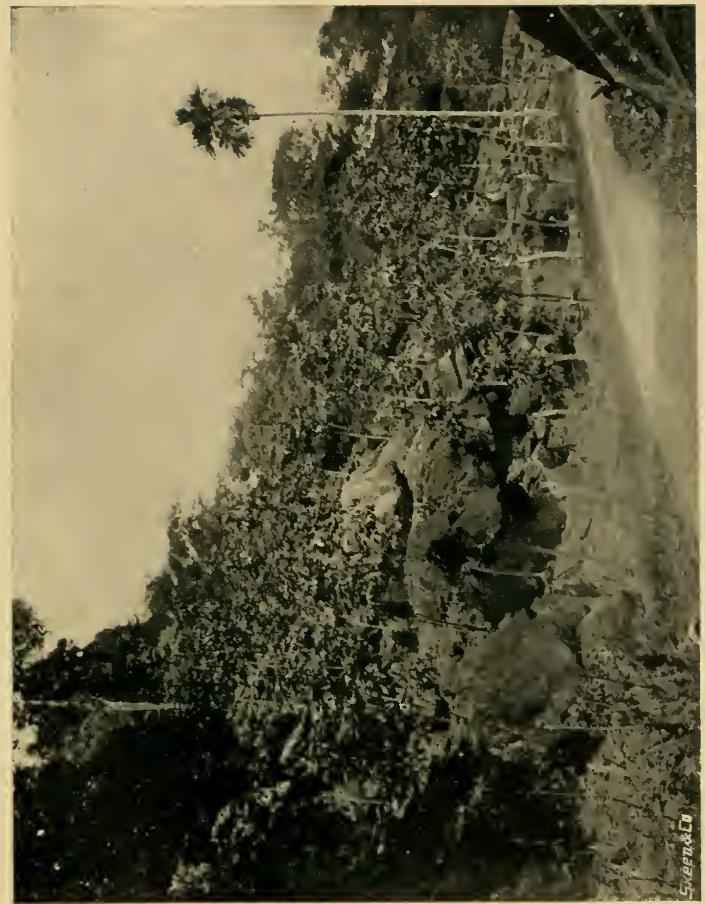

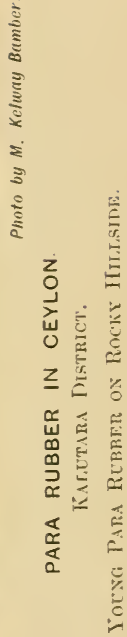



In its native home the tree becomes leafless between March and July.

The annual leaf-fall should be taken into consideration if the Para rubber trees are interplanted with other products, as the leafless pliase usually occurs when the dryness and temperature of the air are at the maximum, and the inter crops will therefore be exposed to the dry hot winds at a time when rain is not expected.

\section{Root System.}

The tree has a very well-developed root system which may ultimately crowd out many inter crops if planted too close. The tap root may grow to a considerable length and the lateral rootlets form a very compact mass. It is on account of the rapidly-growing, compact, and superficial root system that plants such as the coconut and other palms, tea and coffee, cannot be grown successfully for very many years in conjunction with Para rubber. The lateral roots grow at varying rates according to the conditions prevailing, but if grown alone on moderately good and flat land, an incremental yearly increase in radius of about 10 to 12 inches can be allowed for. In six to seven years the lateral roots of plants distanced $12 \times 12^{\prime}$ may be expected to meet; when planted $10 \times 15^{\prime}$ the larger distance will be covered in 7 to 8 years. The rate of development of the lateral root system is of considerable importance as will be shown when dealing with weeding, inter crops, and manuring.

\section{Propagation of Plants.}

Hevea brasiliensis usually seeds freely after its fifth year. Mature trees can be expected to give about 500 seeds per year, though individual trees or special groups have been known to yield fewer seeds and others twice this quantity. It is interesting to learn that on the above basis-each tree producing 500 seeds each year after its fifth year-that a single five-year-old tree and its offspring will yield in 20 years no less than $4,000,000,000,000$ seeds.

The yield may, however, suffer reduction owing to excessive tapping, bad treatment, and disease, and it is therefore satisfactory to know that this plant can be propagated from cuttings. The first plants sent from Ceylon to India and the Straits were rooted cuttings, and the most remarkable feature of the consignment was that the cuttings were taken from plants only one year old. It is possible that many of the plants now in the Straits and India are the offspring of the original cuttings despatched in 1877 , and the fact that they produce plants capable of yielding latex in desired quantity and quality should be reassuring to planters in the event of seed supplies ever becoming unsatisfactory.

\section{Shade ANd Wind.}

In the F I. S., according to Carruthers, the shading of rubber plants is generally of very little importance owing to the absence of severe droughts in that part of the tropics; it is only 
recommended in districts where "seed at stake" is the method of planting and where dry weather may occur within ten weeks after planting.

It would be unfortunate if the Para rubber tree required a permanent shade as there are but few shade trees which could be relied upon to always outreach the tops of tall rubber trees, especially when the latter have never been pruned and when planted very close. Only trees such as Albizzia moluccana and perhaps Erythrina lithosperma would combine the quick growth and spreading of branches which would be necessary. Trees of Peltophorum and Pterospermum species, \&c., though attaining huge dimensions, grow at too slow a rate especially when cultivated in conjunction with other tree forms.

Para rubber trees develop better if shaded after being planted, and a light shade for the first and second years such as is given by cuttings or plants of Erythrina species is beneficial. After their second year, they grow satisfactorily without shade.

Windbelts are generally only necessary during the early stages: owing to the protection from wind which the mature trees give to one another and their general strength special windbelts can be disregarded except in very windy places, where the retention of forest belts to break the wind is a feasible way out of the difficulty.

\section{Planting Operations}

Nurseries.-If clearing and holing have been completed the seeds should be planted as soon as they have germinated. The seeds germinate in a few days if regularly watered. If it is intended to plant stumps in the following year a well-prepared nursery should be used. The larger the plant-in an interval of 9 to 12 months-the better. Good growth has been obtained by adding cattle manure and leaf-mould to the nursery soil before sowing the seeds. An application of a well-balanced artificial manure to the nursery plants when about four months old will also help them on and give better stumps for planting in due course. The use of seedbaskets is to be recommended as there is minimum interruption in the root development during planting operations ; the success with which stumps can be used has led to the disuse of baskets in many districts. Considering that so few trees are planted per acre, and that baskets are so cheap the disuse of the latter at the expense of the interruption in development of the rubber plant is to be regretted. The Neboda Tea Co., Ceylon, in their annual report for 1905 , attribute the success of recent clearings to the use of basket plants.

Fencing.-This work is necessary if the vacancies are to be kept at a minimum. Animals attack the Para rubber plants at all stages, particularly during the first and second years, and the amount of damage done to young clearings by rats, hares, procupines, pigs, deer, and cattle cannot be too seriously considered. If it is intended to cultivate catch crops which are equally attractive to animals, 


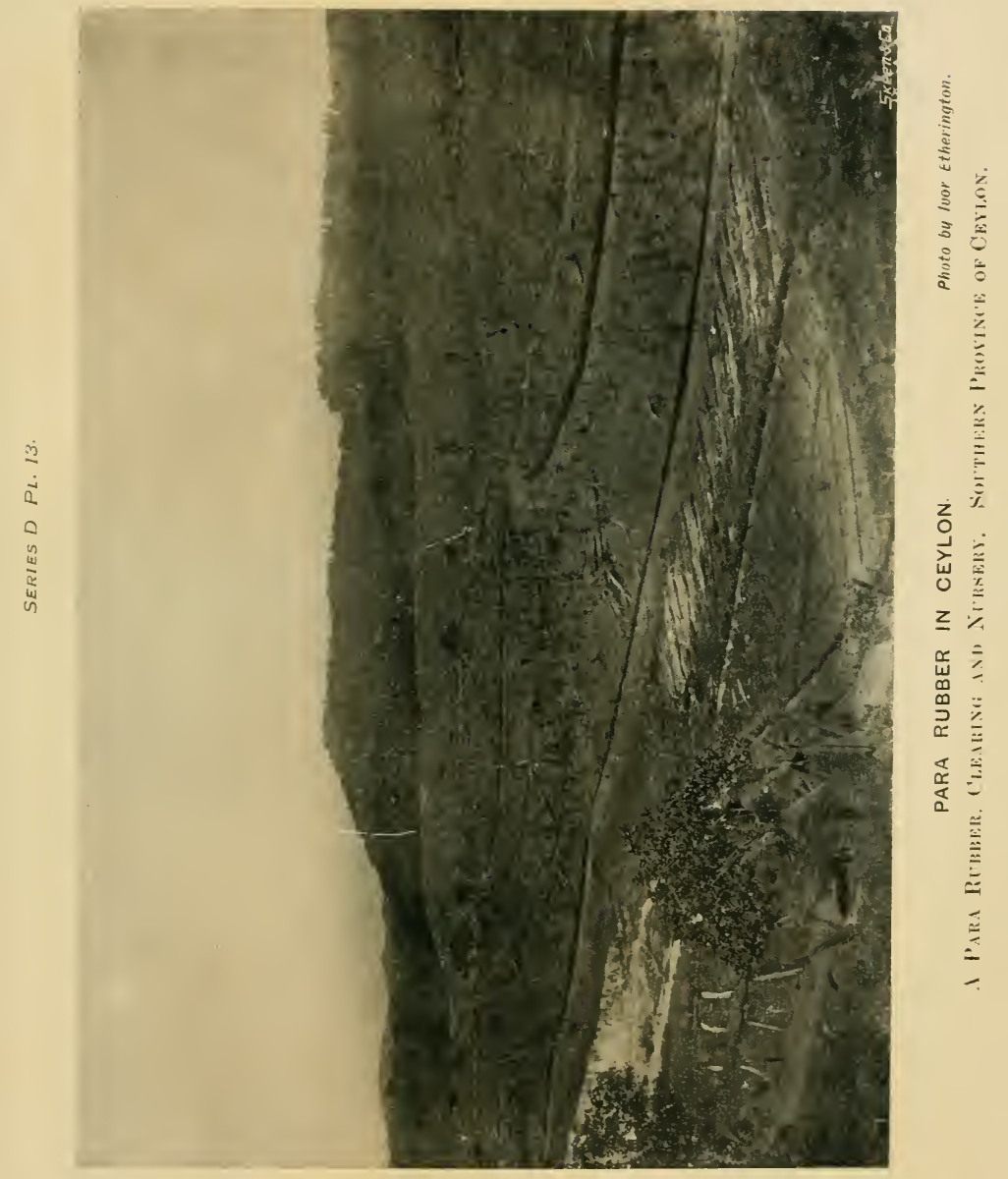


fencing is imperative. The boundaries of newly-planted clearings are often enclosed in rabbit wire netting, but where the rubber is planted in established products, such as tea, cacao, coffee, \&c., it is usually sufficient to fence around each plant, either with netting or sticks. When rabbit netting is used the plants are protected by a circle of netting about six to nine inches from the plant to a height of 3 or more feet.

Draining.-It is erroneous to suppose that because Para rubber is a forest cultivation draining is unneeessary. Draining is as necessary for rubber trees as it is for any other product in order to encourage the free circulation of air, water, and food solutions throughout the soil, and to eheck wash on steep hillsides.

The distance of the drains from one another and their size must depend upon the soil conditions. In swampy and boggy land, little above the water-level, the drains should be as wide and deep as possible, either between each row of trees or in exceptional cases around individual trees. Several areas in the low-country of Ceylon, consisting of bogs rich in organic matter, have been converted into good rubber land by making drains two to three feet wide and three to four feet deep, and heaping the earth in the middle to form a dry soil on which the rubber plant ean live for a couple of years. An illustration is given elsewhere to show swampy land which by means of good drainage has been converted into good rubber soil.

On hillsides the drains need be only about one to one and a half feet deep. They should be made at right angles to the slope in order to check the formation of gorges. The distance of the drains from one another will vary according to the slope and climatic conditions; on flat land a distance of 60 to 70 feet seems sufficient, whereas on steep hillsides 20 to 30 feet is not too close. The illustration reproduced elsewhere, Plate 1, Series D, shows a young rubber plantation established on very rocky land.

Distance, Holing, and Planting.-It is a principle recognized in forestry that close planting will give tall trees, and wide or open planting thick trees. The object in planting Para rubber is to produce trees which will, as early as possible after the fourth or sixth year, give a straight stem of at least ten to fifteen feet in height and a circumference of 20 inches or more. Such trees can be tapped. If the trees are very tall, but have a circumference of less than 20 inches, tapping operations are generally impossible owing to the smallness of the available tapping area from 6 feet downwards. And such trees 8 years old are known, the undesirable result being the outcome of too close planting and not thinning-out or pruning the trees at the proper time. In parts of Ceylon Para trees have been planted $10^{\prime} \times 10,^{\prime} 12^{\prime} \times 12,^{\prime} 14^{\prime} \times 14,^{\prime} 15^{\prime} \times 15$, $^{\prime}$ and $20^{\prime} \times 20$ ' $^{\prime}$ It should be mentioned that trees in the Straits, planted $36^{\prime} \times 36^{\prime}$, showed contact of branches in nine years, and in Ceylon the branches of trees planted forty feet apart have been known to meet in ten years: 
In order to allow the plants to develop freely in circumference the maximum distance should be allowed, as the desired length of trunk is usually obtained even when the Para rubber tree is grown in the open. From considerations of the condition of trees from 2 to 20 years old, the following table is compiled in order to show the probable number of Para rubber trees of known age an estate can bear without interfering with the natural growth of the plants:-

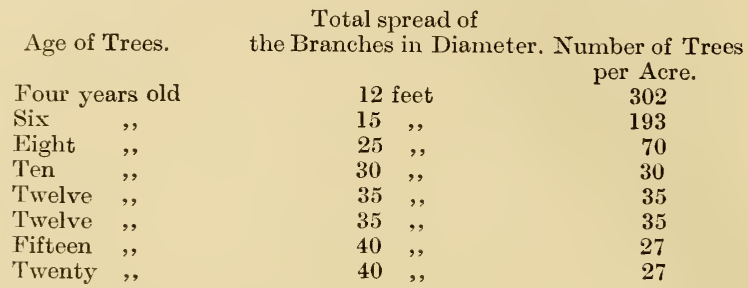

This shows the approximate number of trees to the acre at different ages without any interference of the branches of adjacent trees with one another. There is, however, no objection to the branches of trees partially overlapping, and it is more than likely that any excessive branch development will be kept back by pruning or pollarding rather than by reducing the number of trees below 200 to the acre.

Holing.-The question of holing should be well considered, as the Para rubber plant is a greedy feeder and responds to generous treatment. The holes should be $1 \frac{1}{2}$ foot deep and as wide in area as possible, and if made $1 \frac{1}{2} \times 2 \times 2$ feet they would not be any too large. The larger the holes, the better for the plant. Good holing will give the plants an excellent start; the dribbling in of seeds in small alavangoe holes is not to be recommended. It is hardly necessary to point out that the planting operations should be carried out when rain is plentiful ; the plants should, if possible, be stumped and every care taken to avoid unnecessary destruction of the young roots. The stumps will stand one or two weeks' drought, but if dry weather continues for a long period the soil around the plants should be shaded. In some instances, where it has been necessary to plant in moderately dry weather, the nurseries have been flooded for two or three days prior to the plants being removed, and the results have been considered good

\section{Distance in Planting.}

Johnson recommends planting $15^{\prime} \times 15^{\prime}$ to $20^{\prime} \times 20^{\prime}$, and afterwards thinning out. If the estate is planted for rubber alone, and all ideas of catch crops are disregarded, then a distance of 10 feet by 10 feet can be allowed in planting; but when the trees are six years old the branches will certainly have met. On such an estate individual trees could be tapped on the full spiral system until they died, 


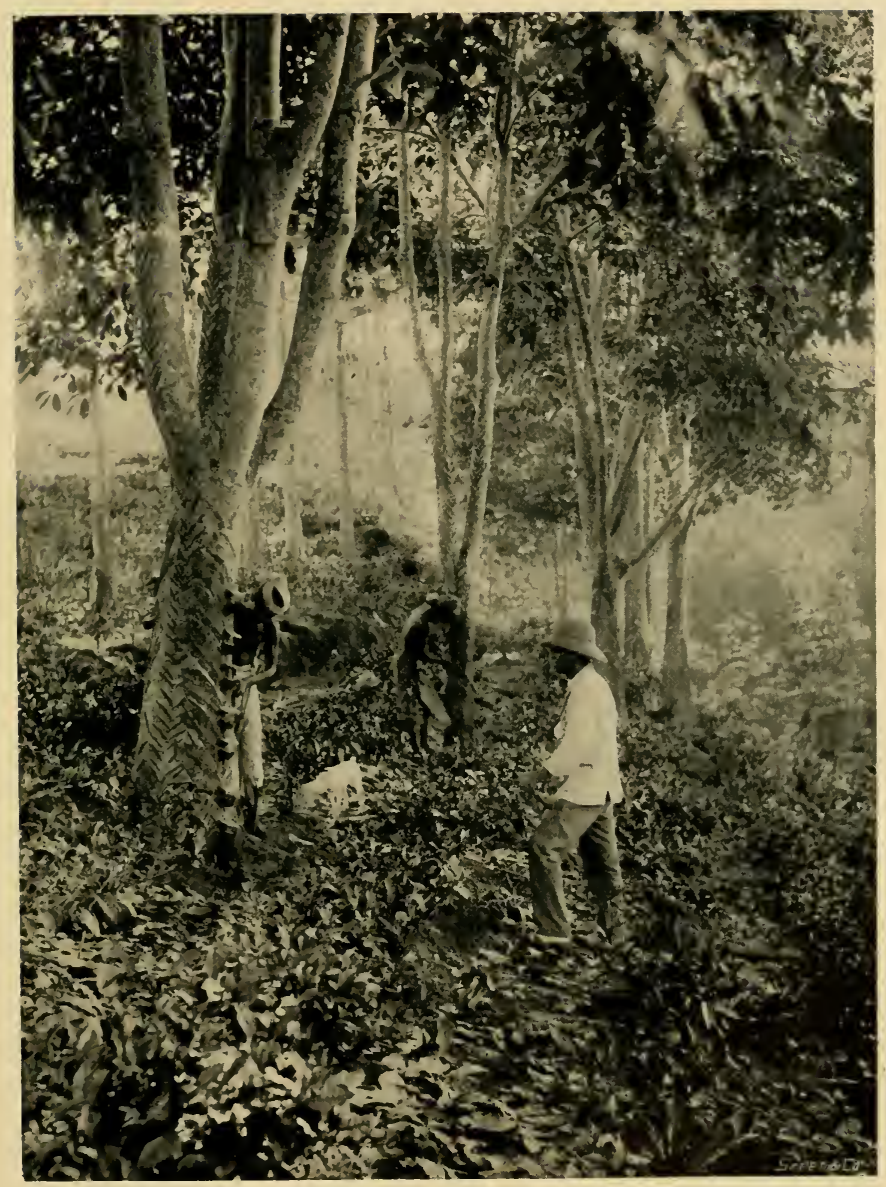

Photo lent by the Kegalle Planters' Association.

PARA RUBBER AND TEA IN BEARING.

Uxidgona Estate, Kegalle. 

and thus makeroom for the further development of the remaining plants. It should be mentioned that there are trees which have been grown in moderately rich soil for over twenty years, and though they are still only from eight to ten feet apart they have a circumference of from forty to over eighty inches, and a branch and foliar system measuring less than thirty feet in diameter. I have frequently seen Para trees which, though planted the same distance and over 10 years old, did not appear to be too crowded.

\section{Close Planting and Available Tapping Area.}

The main justification for elosely planting Para rubber trees is the increased tapping area which is available from the fourth year onwards; the disadvantages are in connection with the spreading of diseases, and possibly checking the growth by not thinning-out at the proper time.

The object of most persons who are only just planting this product is to place their rubber on the market as early as possible, in order to benefit by the high prices and to obtain quick returns. The results obtained by close planting can be made clear by ealculating the available tapping area from the data previously given. The table given below shows the tapping area per acre when the plants are distanced from 10 to 20 feet apart :-

Available tapping Arca per Acre at the End of

Distance of Trees in Feet.

\author{
Number of 'Trees \\ to the Acre.
}

the 4 th or 5th Year in Square Inches ;

Base to 5 Feet.

$\begin{array}{lllll}10 \text { by } 10 & \ldots & 435 & \ldots & 522,000 \\ 10 \text { by } 15 & \ldots & 290 & \ldots & 348,000 \\ 20 \text { by } 20 & \ldots & 109 & \ldots & 130,800\end{array}$

From this table it is obvious that by planting 20 by 20 feet the available tapping area at the end of the 4th or 5th year is reduced to about one-quarter of what it would be if planted 10 by 10 feet. On an estate planted 10 by 10 about 5 per cent. of the trees could be killed out at the end of the 4 th year, and a larger proportion dealt with likewise in succeeding years, until by the end of the 8th year an average of about 250 trees per acre would remain.

The distance of 10 feet by 10 feet suggested on the above calculations is still open to the objection that the soil will be considerably exposed during the first few years, but this can be overcome by the interplanting of cuttings or plants of Erythrina lithosperma (Dadap), a species which can be made to afford shade for the first few years and at the same time provide a rich mulch for the benefit of the young Para rubber plants.

On several estates the rubber trees have been planted 8 by $\&$ feet and even closer, on the assumption that half of them would die from one cause or another or could be cut out when the growth became too dense. 
The use of the Dadap or Albizzia stumps between Para rubber plants would, I believe, be accompanied by good results. The presence of a young Dadap between every two rubber plants would not interfere with the growth of the latter for several years, as is obvious from the previous considerations regarding the rate of growth of the lateral root system.

\section{Pruning Young Trees.}

The Para rubber tree naturally grows to a tall slender tree, and it remains to be seen how by pruning or pollarding the young plants an increase in circumference may be obtained at the expense of the growth in height. Considering what has been accomplished with tea, where plants ordinarily growing into fairly stout trees over twenty feet high have been converted into small bushes two to four feet in height, it would be idle to predict the possibilities with Para rubber. The prevention of the unnecessary growth in height may well form the subject of many experiments.

The plants can be prevented from growing into slender woody structures by removing the terminal bud with a knife or thumb-nail pruning, or, as is more commonly the case, by pruning the terminal young leaves and the enclosed bud. If the central bud is effectively and repeatedly removed, without doing considerable clamage, the stem cannot grow in height except by means of lateral shoots; these will subsequently require bud-pruning once they have attained the required size. Buds which appear in undesirable places can be removed in the same manner, the ultimate result being that a tree considerably forked and supplied with abundance of foliage is obtained. The production of woody tissue in the upper part of the tree is appreciably checked, and the girth of the basal stem increases more rapidly than when the tree is allowed to grow upwards uninterrupted.

At Henaratgoda the trees which have forked at 7,9, and 11 feet from the ground show an increase of about 30 inches in thirty years or an average of one inch, per year, throughout a long and fairly reliable period. Young trees which have been bud-pruned in the manner suggested above show an increased rate of circumferential growth, and this means the attainment to a tappable size at an earlier period.

\section{When Prunisg Should be Tried.}

This operation is impossible or useless on old trees which have produced high woody stems. To eut off the whole of the stem and branclies above fitteen feet would check the growth of the remaining stem, and such a measure is not recommended. Old trees treated in this manner produce foliage, but this mainly testifies to their hardy characteristies.

The stems of plants, when less than 20 feet in height, are more suitable for such an operation; when 12 to 15 feet high the terminal bud alone can be easily removed by thumb-nail pruning, and 
lateral shoots will soon appear in the axils of the leaves on the "green wood" of the stem. The object is simply to produce a forked tree, the advantages of which can be observed on any young rubber plantation. If the plants have been allowed to grew too high it is too late to perform the operation.

This treatment has reference only to young clearings of Para rubber, but, considering how many thousands of acres are being yearly planted with this product and the possibility of appreciably reducing the long years of waiting, it is important that it should be carefully considered and tried wherever possible.

The large acreages of rubber trees planted during the last two years will in all probability be regularly tapped as soon as they have attained the proper circuniference, and it is therefore necessary to do all in one's power to help the trees on to the desired condition. Not only is it necessary to get a return as quickly as possible, but it is advisable to place the rubber on the market while the price is high, without unduly taxing the powers of the tree. The lower six feet of each tree will provide work for about 3 years' systematic and economic tapping, and the question of high tapping, as at present being carried out at Henaratgoda and elsewhere, can perhaps be dismissed.

If the young plants are made to branch too much there may be a disadvantage, as the foliage of adjacent trees may interfere. In such case, however, were it desirable, the excessive branch development could be kept down by repetitional pruning. It should be remembered that the lateral shoots, induced by pruning the terminal bud, ultimately form stout branches which tend to grow upwards and not horizontally.

Effect of Pruning Para Rubber Trees.

Dumensions of straight-stemmed and forked Trees in Ceylon.

\begin{tabular}{|c|c|c|c|c|c|c|}
\hline \multirow{3}{*}{ District. } & \multirow{3}{*}{$\begin{array}{l}\text { Age of } \\
\text { Pub- } \\
\text { ber } \\
\text { Trees. }\end{array}$} & \multicolumn{5}{|c|}{$\begin{array}{l}\text { Average Circumference of Trees a yard from the } \\
\text { grounc. }\end{array}$} \\
\hline & & \multicolumn{2}{|c|}{$\begin{array}{l}\text { Straight-stemmed } \\
\text { Trees. }\end{array}$} & \multicolumn{2}{|c|}{ Forked Trees. } & \multirow{2}{*}{$\begin{array}{l}\text { Arerage } \\
\text { Difference. }\end{array}$} \\
\hline & & Number. & $\begin{array}{l}\text { Arerage } \\
\text { Girth. }\end{array}$ & Number. & $\begin{array}{l}\text { Average } \\
\text { Girth. }\end{array}$ & \\
\hline Galaha & $\begin{array}{r}\text { years. } \\
7\end{array}$ & 15 & $\begin{array}{l}\text { Inches. } \\
21 \cdot 33\end{array}$ & 7 & $\begin{array}{l}\text { Inches. } \\
25 \cdot 14\end{array}$ & $\begin{array}{l}\text { Inch. } \\
3 \cdot 81\end{array}$ \\
\hline Galaha & 10 & 14 & $28 \cdot 78$ & 4 & $38 \cdot 37$ & $9 \cdot 51$ \\
\hline Kalutara & 2 & 94 & $7 \cdot 5$ & 76 & $8 \cdot 3$ & 0.8 \\
\hline Matale & 3 & 329 & $13 \cdot 9$ & 78 & $15 \cdot 5$ & $1 \cdot 6$ \\
\hline Kalutara & $1 \frac{1}{2}$ & 14 & 4 to 7 & 32 & $4 \frac{1}{2}$ to $7 \frac{1}{2}$ & 0.4 \\
\hline Moneragala & $2 \frac{1}{4}$ & 250 & $6 \frac{7}{8}$ & 250 & $8 \frac{1}{8}$ & $1 \frac{1}{2}$ \\
\hline Kalutara & old ${ }^{*}$ & 1 & $31^{\circ}$ & 1 & $35^{8}$ & $4^{2}$ \\
\hline Do. & old & 1 & $23 \frac{1}{2}$ & 1 & 29 & $5 \frac{1}{2}$ \\
\hline Do. & old & 1 & 23 & 1 & 32 & $9^{2}$ \\
\hline Henaratgoda & 30 & 10 & 75 & 10 & 10.5 & 30 \\
\hline
\end{tabular}


An interesting series of figures obtained in the Kandy District showed that trees of the same age, which had branched at a point 12 to 14 feet above ground, had an average circumference of 19 inches, and those which had branched at 5 and 8 feet from the ground had an average of 26 inches.

In the Kalutara District trees of the same age, but divided at the base into two, three, and four stems respectively, measured, in stem circumferences per tree, $14 \cdot 4,18 \cdot 1$, and 22 inches respectively. In all parts of the Island the increased circumference due to forking of the trees can be seen, and the fact has even been noted in the annual report of a prominent Company largely interested in rubber.

The Neboda Tea Co. of Ceylon, Ltd., in their annual report for 1905 , state that the two tallest trees show the smallest girth, and the shortest and well-branched trees the best.

\section{Inter and CATCh Crops.}

Where the rubber plants are closer than 10 to 15 feet the cultivation of inter or catch crops is limited to about four to eight years. Cassava, bananas, cacao, coffee, chillies, groundnuts, lemon grass, pepper, gingelly, and perhaps tobacco and cotton, are anongst the most notable products for use under such conditions. If the intercrops are such that they can under ordinary circumstances be grown permanently-as cacao and coffee-it is better to grow them only in widely-planted rubber and to arrange them among the rubber plants, so that a fair root space is available for all the plants. Cacao and coffee are among the best products to be grown as intercrops in rubber, and are being cultivated extensively in India, Samoa, Java, Straits, and Ceylon as permanent intercrops. Coffee is known to grow well under shade, and in parts of India it is being cultivated as an inter or catch crop in rubber clearings, where the rubber plants are planted twenty-four feet apart and the coffee six feet apart.

If real catch crops are grown to occupy the land from 6 to 12 months at a time, care should be taken not to plant them too near the rubber plants. A radial distance of one foot should be allowed for the growth of the roots of the rubber trees each year, and catch crops should not be planted within the rubber root area.

The catch crops can be planted one, two, three, and four feet from one, two, three, and four-year-old rubber trees respectively, and in all cases the foliage or ashes obtained as by-products of the catch crops can be forked in around the trees or broadcasted over the areas which are partly occupied by the rubber roots.

\section{Groundnuts, Lemon Grass, and Cassava.}

Three profitable catch crops for export or use are lemon grass, cassava, and groundnuts. Lemon grass gives a return six months after planting, and may be expected to yield about $14,000 \mathrm{lb}$. of fresh grass containing about $20 \mathrm{lb}$. of pure oil, per acre, per year, when grown in open free soil. The oil is valued at $8 d$. to $8 \frac{1}{2} d$. per 


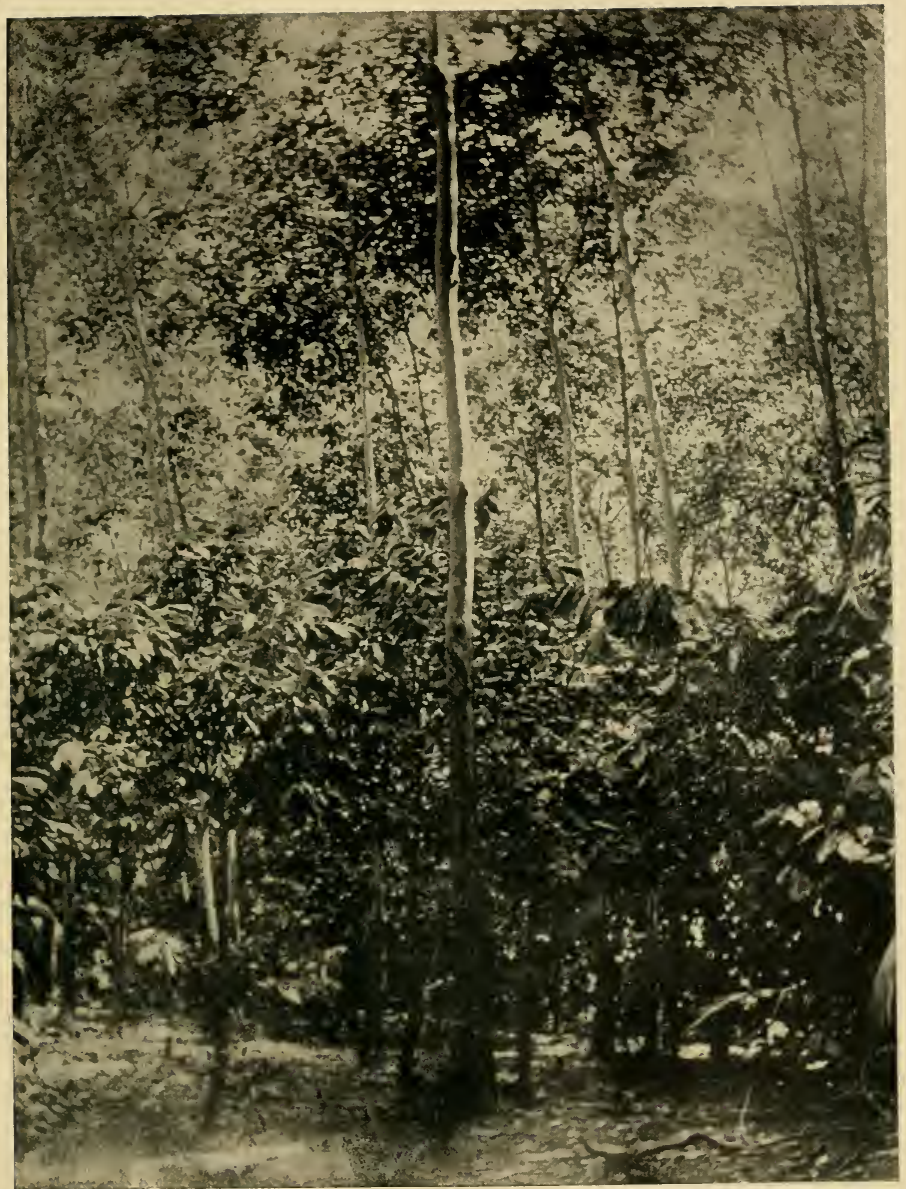

Photo by F. J. Holloway.

PARA RUBBER AND COCOA.

Kepitigalla, Matale, Ceylon. 

ounce, and is obtained by steaming the freshly-cut grass. A distilling apparatus is required and ean be kept in constant use by the grass from 300 acres. The fresh lemon grass contains $0 \cdot 65$ per cent. of potash, 0.09 per cent. of phosphoric acid, and 0.12 per cent. of nitrogen, but if the dried distilled grass is used as fuel and the ashes for manuring the rubber plants, the exhaustion is considerably reduced. The plant is propagated from cuttings. It is being cultivated in parts of Ceylon and the Straits.

Groundnuts yield as a single product a crop of 1,500 to 3,000 lb. of nuts per acre in various countries, the best-yielding varieties in Ceylon being the "Mauritius" and "Barbadoes." The nuts are valued at from $£ 8$ to $£ 14$, according to size, number of seeds per nut, and cleanliness. The seeds yield a valuable oil, equal to Olive oil in quality, and the residue after extracting the oil is sold as a manure-groundnut cake-containing $7 \frac{1}{2}$ per cent. of nitrogen. The foliage can be used as a green manure or cattle food, and is known as pea-nut hay in America. The leaves and roots contain nearly 1 per cent.of nitrogen, and when mixed with lime form a good plant food for the young rubber trees. The plants are propagated from seeds. The crop ripens in 4 to 6 months, very little machinery is required, and there is a good demand for the oil and cake.

There are several famous Para rubber plantations in the Straits which have practically paid for all working expenses by cultivating varieties of cassava as catch crops for the first three or four years. On one plantation the rubber was planted 15 by 15 feet and the cassava 6 feet apart at the same time as the rubber. The crop was ready for harvesting in 18 months from planting. A second crop was taken off the land before the end of the fourth year, after which the cassava cultivation ceased to be profitable. I have been informed that a crop of tapioca or cassava flour of $1 \frac{1}{2}$ to 2 tons per acre, per crop, is thus obtainable. The proceeds from these crops have on several estates more than paid for the upkeep of the rubber. On one estate in the Straits cassava or tapioca is largely cultivated, and on one field, from which very good crops of this product have been taken, the six-year-old Para rubber trees have an average circumference of 20.21 inches, the largest measuring 33 inches and the smallest 13 inches in girth at a yard from the ground.

The profitable cultivation of eatch crops is limited to about the first four years, as the products grown cannot be planted close to the Para rubber trees, and at the end of the fifth year would be almost limited to the middle of the lines. Furthermore, they are all very exhausting.

\section{Future of Inter Crops.}

The successful and continued cultivation of inter crops with Para rubber mainly depends on the distance the plants are from one another. The rapidly-growing surface roots of Para rubber will ultimately take possession of the soil, and the inter crops of tea, cacao, or coffee cannot be expected to thrive except the rubber plants 
are widely planted. I have seen several examples of 14-year-old tea planted with 6-year-old Para rubber, the latter 15 by 10 feet apart ; the tea presented a very weak, spindly appearance and could not be profitably plucked. The cultivation of tea under closelyplanted rubber is more or less of a catch crop, but several estates are known where the rubber is widely planted amongst tea and both are bearing and doing well. The two products are very frequently grown together in Ceylon-especially in the low-country and in parts of Matale, Kegalla and the Uva Province up to 2,600 feet, and in South India up to 3,500 feet. The illustrations on Plate 2, \& 3, Series C, and Plate 12, Series D, show properties in Ceylon where tea and rubber are growing together.

Cacao and coffee planted in the middle of the lines will last for several years under rubber. The roots of these plants do not as closely ramify the soil as those of the crowded tea plants, though they will ultimately have to face the struggle for existence with the roots of Para rubber and will probably be choked out. Cacao may be planted 10 to 20 feet apart, and the amount of soil on good cacao estates which is free from roots is often very large and permits of the growth of other trees on the same acreage. Cacao under rubber will last much longer than tea, and the protection of the Para rubber trees against excessive exposure is no doubt greatly in favour of the two products being grown together. In the Mata!e, Dumbara, Kurunegala, Polgahawela, and Kandy Districts of Ceylon, cacao and Para rubber as a mixed cultivation is extending. Good results have been obtained on Kepitigalla, Dangan, Wariapolla and many other estates in Matale and on numerous private and public properties in the above-mentioned districts. The planting of both products on the same soil is done in such a way as to allow free root areas for both species during the first five years, many planting the cacao and rubber both twenty fee apart so that there will be approximately 100 rubber and 100 cacao trees per acre. Though the rubber ultimately becomes the stronger component, it is surprising how long both products can be successfully grown together. In the cultivation of inter crops under Para rubber it is essential that both products be planted at the same time, as the Para rubber tree is about as strong as the cocoanut palm in its root system and quickly takes possession of the soil. The illustrations which have been given elsewhere, showing Para rubber in association with cacao and tea in Ceylon and with coffee in South India, could be considerably increased, but they are sufficient for the purpose and are worthy of careful study by all rubber planters. Apart from the question of having more than one product to rely on, it is often better, for plant sanitation reasons alone, to have mixed plantations; plants of different genera grown together are often helpful to one another.

The cultivation of pepper among rubber neccesitates permanent stumps, preferably of the Dadap plant. 


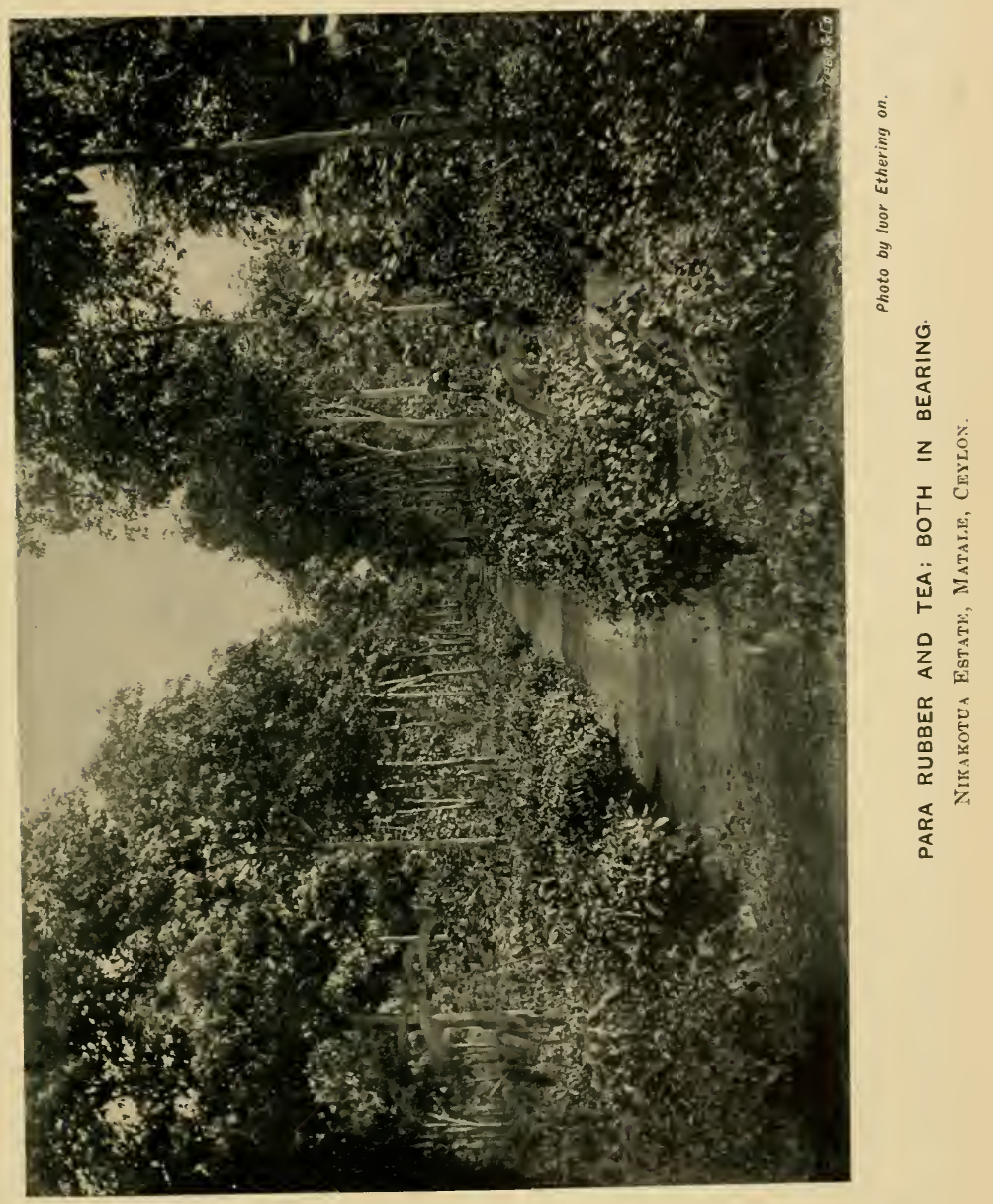


CHAPTER IV.

\section{PARA RUBBER SOILS AND MANURING.}

The mechanical and chemical composition of rubber soils-PeradeniyaHenaratgoda-U'dugama-The soils and rubber-planting in various parts of Ceylon-Carruthers and Bamber on rubber land and soils in the Federated Malay States-Cabooky, alluvial, and swampy soils in Ceylon-Treatment of swampy soils-Illustrations showing Para rubber on Passara Group estate, Passara ; young and old rubber on Madampe estate. Rakwana, Arampola estate, Kurunegala; Para rubber and tea on Nikakotua estate, Matale; Para rubber on Hunugalla estate, Kegalla-The Kelani, Kegalla, Kalutara, Galle, Matale, Pussellawa, Ratnapura, Ambagamuwa, Kurunegala, and Passara Districts-Principles of rubber-manuring-Manuring to increase the latex-Para rubber trees-Artificial manures for rubber soils-How to apply readily soluble and stable manures-Forking, trenching, and root growth-Illustration showing trench-manuring for young rubber-Constituents in woody stem, twigs, fresh, and dried leaves-Composition of artificial manures obtainable locally-Green manuring for Para rubber trees-Limit 6 to 8 years-Suitable herbaceous plants and their composition-Illustration showing young Para rubber and crotaleria striata - Tree forms, Dadaps and Albizzias-Organic inatter obtainable.

\section{Para Rubber Solls ayd Manuring.}

It has been conclusively shown that Para rubber ean be grown in soils which are relatively poor in physical and chemical properties, and the following analyses of soils in different parts of Ceylon* will illustrate the composition of those which have given good results with Para rubber:-

Peradeniya

$\checkmark$, Soils.

Nechanical Udagama

Composition. Swumps.

Rubber Soils at

Henaratgoda.

$$
1
$$$$
2
$$

Soil under Soil from

Old Pasture

Rubber. Land.

Per cent. Per cent. Per cent. Per cent.

$\begin{array}{llrrrr}\text { Fine soil passing } 90 \text { mesh } \ldots & 27 \cdot 00 & 59 \cdot 00 & 20 \cdot 00 & 26 \cdot 00 \\ \text { Fine soil passing } 60 \text { mesh } & \ldots & 20 \cdot 00 & 36 \cdot 00 & 28 \cdot 00 & 28 \cdot 00 \\ \text { Medium soil passing } 30 \text { mesh } & 9 \cdot 00 & 1 \cdot 00 & 14 \cdot 00 & 21 \cdot 00\end{array}$

* Circular of the R. B. G., Peradeniya, by Herbert Wright and A. Bruce, Vol. III., No. 6, July, 190 J. 


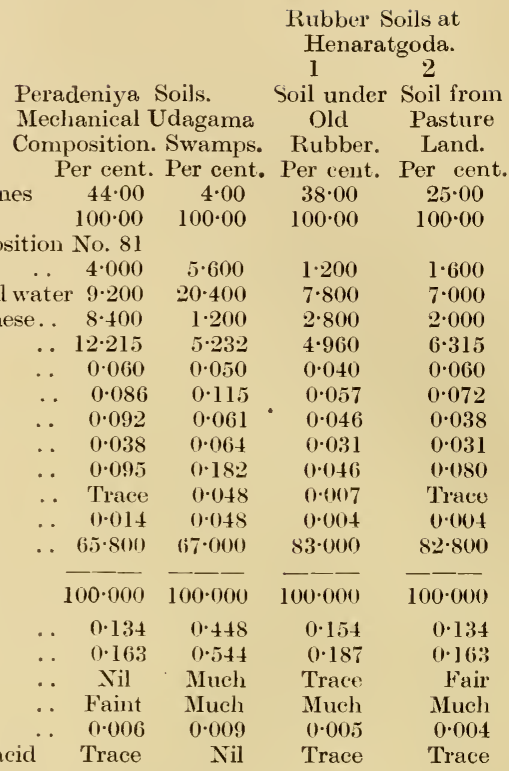

\section{Para Rubuer Solls in Ceylon}

The extension of Para rubber cultivation in various parts of Ceylon is, in a general way, an indication of the suitability of the soil and climate for this product, and it is therefore of importance to dwell upon the soil characteristics in some of the more promising districts, though these points should be considered in conjunction with the climatic factors for the same areas.

The large tracts of land in the up-country districts which are richest from a chemical standpoint cannot be included in the Para zone of the island on account of unfavourable climatic conditions. The following notes and analyses of Ceylon soils are largely taken from a circular* dealing with this subject.

The soils in which rubber is cultivated in Ceylon are relatively poor from a chemical standpoint. The organic matter and combined water vary from about 2 to 20 per cent., the potash from 0.03 to 0.04 per cent., phosphoric acid from 0.01 to 0.1 per cent., and the nitrogen from $0 \cdot 1$ to 0.5 per cent. But it has been proved beyond doubt that the physical and elimatic characteristics often outweigh any advantages of richness in chemical properties.

* K. B. G. Circular on Para Rubber in Ceylon, No. 6, 1905. 


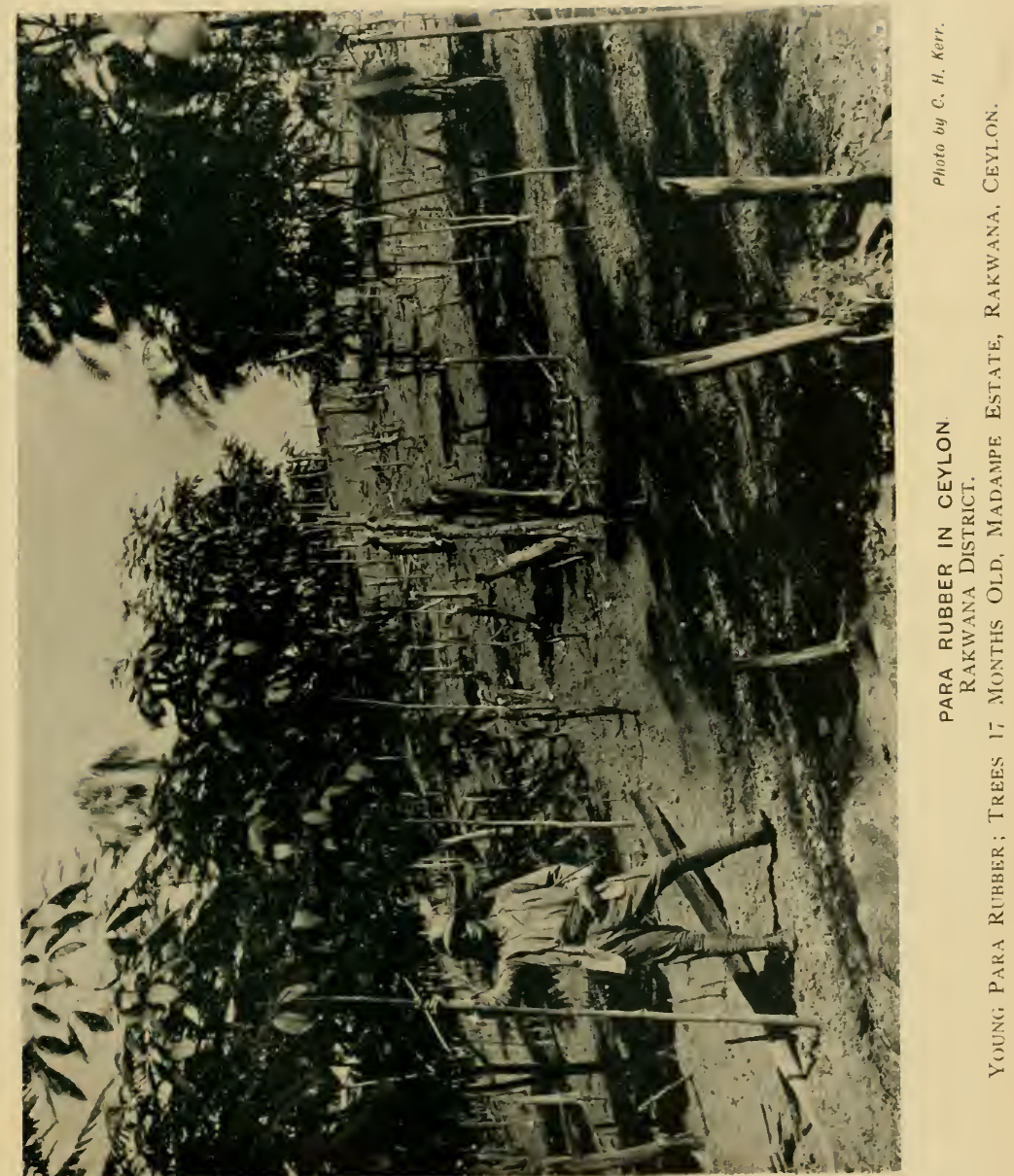



Para Rubber Land \& Solls in the Federated Malay States.

I am indebted to Mr. J. B. Carruthers for much information regarding the land and soil in various parts of the Federated Malay States. The rocks from which most of the non-alluvial soils are formed are limestones, sandstones, laterites, and granites, the disintegration products of red laterite being considered good. The low-lying land at the foot of the mountain range is composed of a deep alluvial deposit; the subsoil in such areas is said to be far below the water level, and for purposes of cultivation may therefore be neglected. The majority of the alluvial land, planted in Para rubber, is, if anything, too well supplicd with water, the latter being within 3 to + feet from the surface all the year round; the water level all over the plains on the west of the mountain range is, according to Carruthers, very near the surface, often as near as 16 to 18 inches.

Mr. M. Kelway Bamber, who recently toured through the Federated Malay States and visited several of the leading Para rubber properties, is convinced of the richness of many of the soils and the suitability of large areas for the cultivation of Hevea brasiliensis. The physical composition of the soils is often remarkably good, and on Mr. Bamber's authority it can be stated that some of the samples pass, almost entirely, through a sieve of 8,100 meshes to the inch. The organic matter frequently exceeds 30 per cent. and the nitrogen is sometimes as high as 0.9 per cent. These high percentages are not, however, obtainable over all estates in the Federated Malay States. Many of the Ceylon soils are quite as good as, and occasionally superior from a chemical standpoint to, those in the Federated Malay States, but in only a few low-country soils in Ceylon does the organic matter reach 20 per cent. In relation to Ceylon soils the mineral contents of the Federated Malay States soils are very often inferior, the chief deficiency being potash, rather than phosphoric acid.

\section{Cabooky, Alluvial, and Swaypy Solls in Ceylon.}

"Cabook.-The cabook soils are met with as local areas in many districts. They are usually inferior from a chemical and physical standpoint, though in many cases the growth of the rubber trees appears to be satisfactory. Such soils usually show a small percentage of organic matter, potash, phosphoric acid, and lime.

"One analysis shows only 8 per cent. of organic matter and combined water, 0.085 per cent. of potash, 0.010 per cent. of phosphoric acid, $0 \cdot 060$ per cent of lime, and $0 \cdot 1.8$ per cent. of nitrogen."

"Alluvial soil.-In physical properties these soils are usually good, and the amount of sediment periodically deposited during floods adds considerably to the chemical richness of the soil. 
"They are largely composed of the lighter materials carried down in suspension by moving water. The particles are very fine, most of ihem passing a 60 mesh.

"The particles are arrested and precipitated all along the bank of the river during flood time. During heavy floods very large quantities of matter are often deposited along the banks, but they are often of a coarser nature due to the higher speed.

"The particles which go to make up an alluvial soil may have been brought from considerable distances ; they constitute the fine parts of soils liable to wash within the drainage area of the river."

One analysis shows about 11 per cent. of organic matter and combined water, $0 \cdot 130$ per cent. of lime, $0 \cdot 162$ per cent. of potash, 0.076 per cent. of phosphoric acid, and 0.230 per cent. of nitrogen. The soils are usually good, and we know that Para rubber grows exceedingly well in such soils and continues to thrive therein for over twenty years in the Peradeniya District.

"Swamps.-The cultivation of rubber in such areas has, during the last year or so, shown a considerable increase. Providing the draining and liming of the soils are efficiently carried out, there seems no reason why continued satisfactory growth should not be obtained on such land.

" The drainage should be very thorough, so as to allow of a good percolation of air and water through the otherwise sour soils.

" In some cases each rubber tree should have a separate drainage system, the drains being two or more feet wide and 3 to 4 feet deep, the material from them being heaped up near the rubber tree. In other cases each line of rubber trees may be separately drained. When the drains are sufficiently large and the soil from them is heaped around the rubber, a dry soil is ultimately obtained in areas which have hitherto been too swampy for any cultivation except paddy."

One analysis shows the soil to contain 20.4 per cent. of organic matter and combined water, 0.05 per cent. of lime, 0.061 per cent. of potash, 0.064 per cent. of phosphoric acid, and 0.448 per cent. of nitrogen.

Such an analysis shows a chemical richness in organic matter and nitrogen which rarely obtains in low-country districts, and strongly reminds one of the soils at high elevations in Ceylon. It is to be regretted that the area of such rich land in the low-country is small, and the above analysis is certainly encouraging to planters who have such swampy soils capable of being effectively drained and made sweet by the application of lime or by burning.

\section{Treatment of Swampy Solls.}

In the Straits and in parts of Czylon drained swamps have been proved to grow Para rubber, and in the former place large sums of money have been spent in providing good canals for the free circulation of water through rubber estates near the coast. 

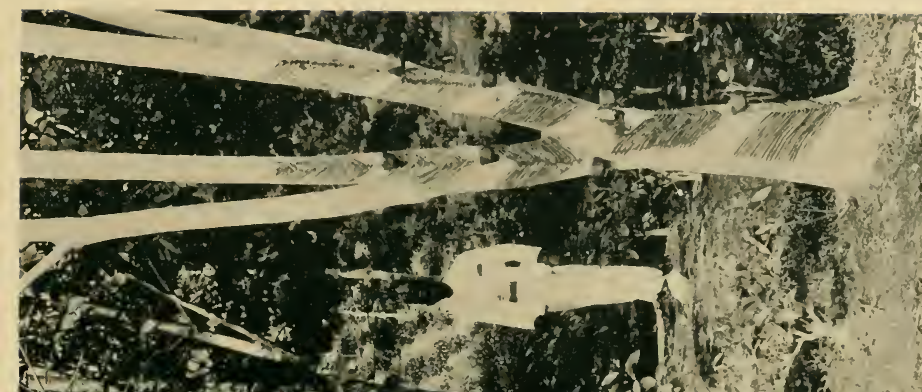

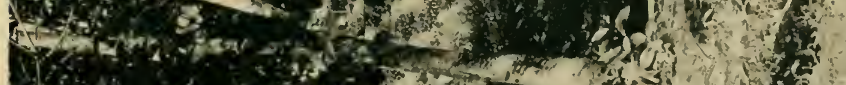

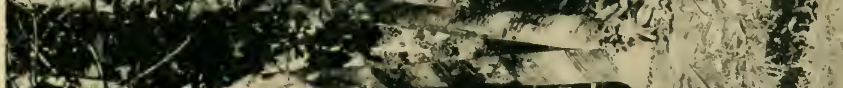

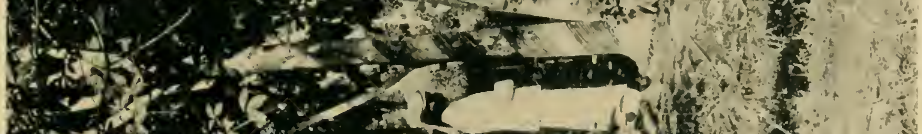
B.

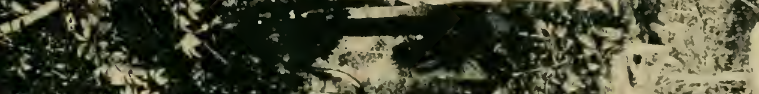

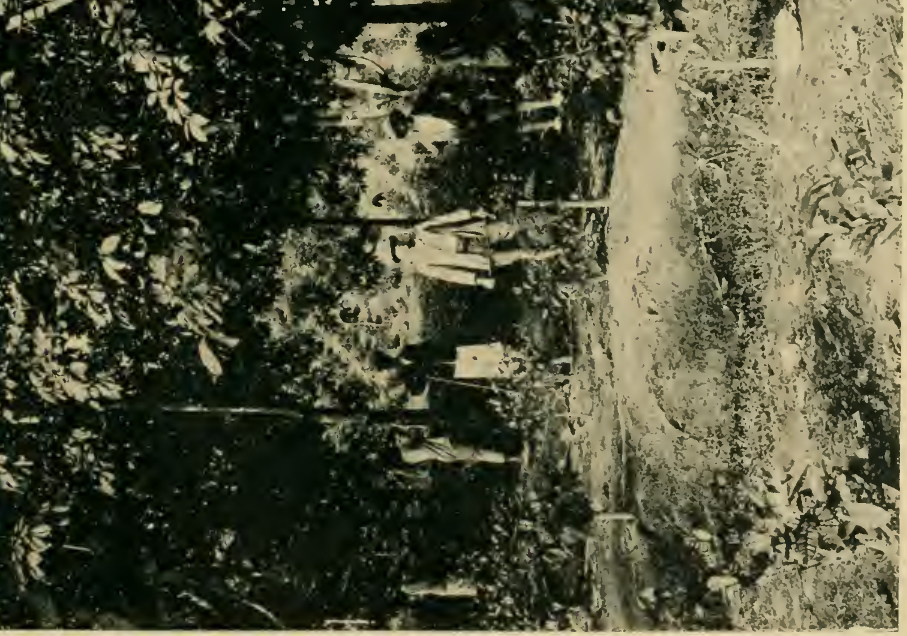



"Swampy soils are usually in a very fine state of division, a condition which may prevent the soil being aërated, and to some extent may hinder the free oxidation of the humus. Owing to the extremely fine state of division the soil can retain large quantities of water, due to the particles being in such close contact with one another that they form a very large number of capillary tubes which become full of water. Again, such a soil may suffer during periods of drought, as it is difficult to get the air out of the capillaries. A water-logged soil is usually cold and therefore generally unsuitable for cultivation, unless it can be modified both physically and chemically. One of the chief aims in reclaiming such land is to have the soil well-drained, in order that the superfluous water may be carried off and the air drawn through the soil.

"Burning has been tried on peaty soils at high elevations, and the results are satisfactory. Paring the surface and collecting into heaps and then burning has also proved successful. The heat should not be allowed to become too great and should just be sufficient to char the vegetable organic matter; the heaps should then be distributed over the surface. There is a loss of nitrogen and organic matter, but the physical condition of the soil is improved, and the potash salts are converted into carbonates which are useful for the neutralization of the free acids present. After burning, the potash, \&c., is in a much more available condition.

" Opening up of swampy soil by the addition of sand or gravel has been tried, but this is expensive. Liming is very beneficial for such soils, as it not only opens them up but also neutralizes the free acids present, and thus gives a freer action to nitrifying organisms. The addition of lime frees the potash from the double salts by double decomposition, and makes the mineral plant food generally more available. Swampy soils are usually deficient in mineral plant food, and should have occasional dressings of potash and phosphatic manures, basic slag, and sulphate of potash or kainit being considered suitable."

\section{Para Rubber Solls in various Districts in Ceylon.}

In order to give some idea of the composition of the soils of typical rubber districts in Ceylon, it is necessary to draw inferences from many analyses. The districts known as Kelani, Kalutara, Kegalla. Matale, Peradeniya, Kurunegala, Ratnapura, and Passara are of considerable importance, and the information given in the Circular previously referred to is here quoted.

\section{Kelani Valley District.}

According to the latest report of the District Planters' Association, for the year 1905 , it is estimated that there are at present 14,000 acres planted in rubber alone in addition to a large acreage interplanted with tea. The abundant rainfall and high tempera- 
ture together with the moderately good soils in the Kelani district seem very suitable for Hevea brasiliensis.

"Mechanical characters.-The mechanical composition of the soil is moderately good; generally 14 to 35 per cent. passes through a 90 mesh, 20 to 40 per cent. through a 60 mesh, and 3 to 8 per cent. through a 30 mesh; sand and small stones constitute 30 to 60 per cent. on an average. The plants are mainly dependent upon the finely-divided soil particles for their food supplies, and therefore the amount which passes through the 90 mesh is of the greatest importance. Some soils which are very finely divided are not so well suited for cultivation as coarser types, the latter frequently allowing of a quicker and more complete circulation of air and water in the soil. The retentive power of moisture of the soils depends upon the physical properties and the amount of organic matter present. This variation for the Kelani soils is from 2 to 6 per cent.: i.e., every $100 \mathrm{lb}$. of air-dried or sun-dried soil can retain from 2 to $6 \mathrm{lb}$. of water."

"Chemical properties.-The percentage of chemical ingredients is, relatively speaking, rather low when compared with soils at higher elevations. In some cases the percentages of organic matter and nitrogen are satisfactory. The organic matter varies from 8 to 13 per cent. ; the nitrogen from 0.05 to 0.2 per cent. ; the lime from $\checkmark 05$ to 0.15 per cent. ; the magnesia from 0.05 to 0.35 per cent. ; potash from 0.05 to 0.2 per cent.; and the phosphoric acid from traces to 0.07 per cent. In some cases the high percentages of organic matter and potash are exceptional, and do not represent the general characters in the Kelani District. The figures here quoted indicate the general variation in the proportions of the ingredients which may be expected in the district; they do not represent the maximum and minimum compositions."

\section{Kegalla District.}

The Kegalla District might also be considered in connection with the Kelani, as the soil and climate appear equally suitable for Para rubber. According to the 1905 report of the District Association the Kegalla planters possess over 6,500 acres of rubber, either alone or interplanted with tea. Good growth has been obtained in clearings only 10 and 18 months old on the Makopitiya, Dickellia, Waharaka, Parambe and other estates in this district and the tapping of trees from 12 years upwards on Yataderiya and Undugoda estates has been accompanied by profitable yields. On many of the estates in the Kegalle district, the Para rubber is interplanted among tea; the illustration on Plate 3 , Series $\mathrm{C}$, shows both products doing well on Undugoda Estate, Kegalle. Elsewhere illustrations are given showing trees only 32 months old (Series D, Plate 14) on Hunugalla estate and tapping of mature trees on the property of the Yataderiya Tea Co., (Series D, Plate 15.), all in the Kegalla district. 


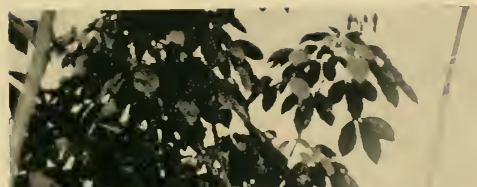

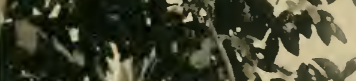

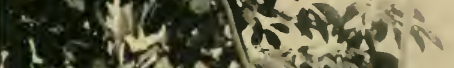

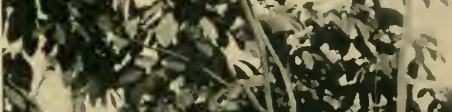

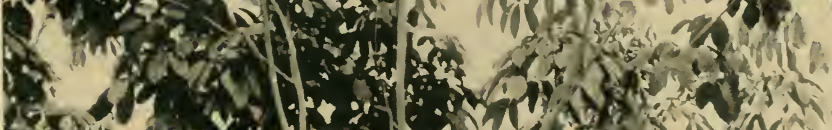

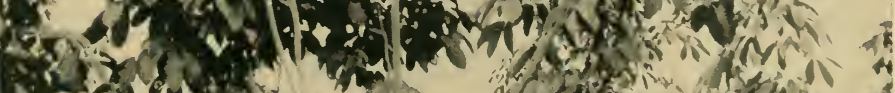

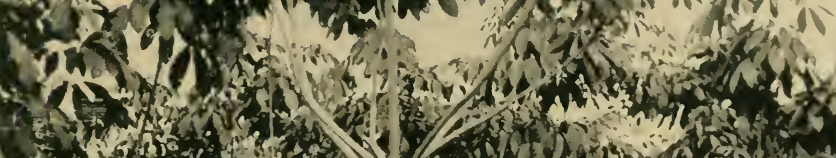

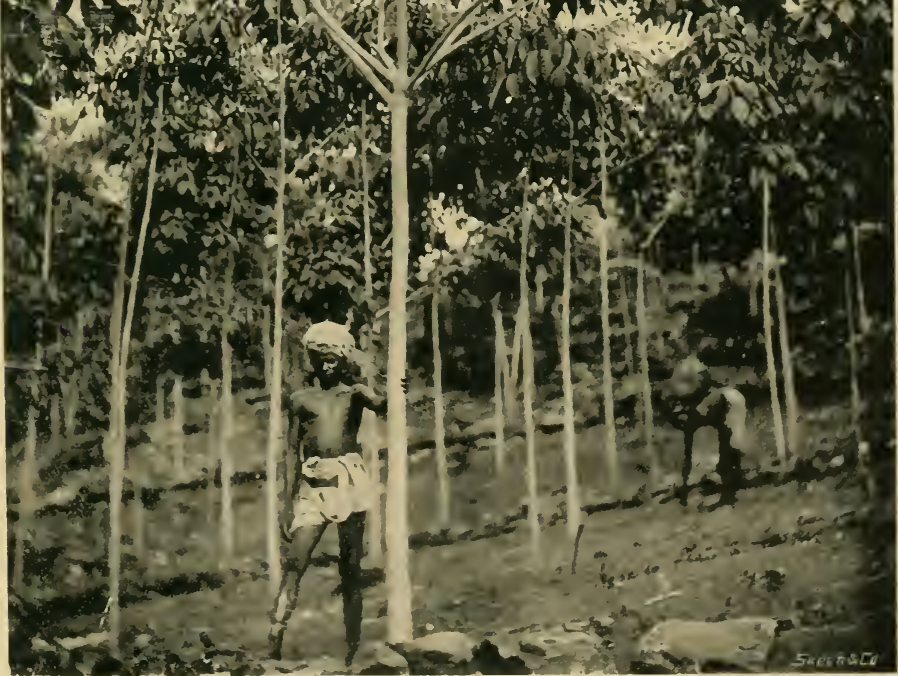

Photo lent by the Kegalle Planters' Association.

PARA RUBBER TREES, 32 MONTHS OLD.

Huxggalla Estate, Kegalle. 



\section{Kalutara District.}

During the year 1905 the acreage under Para rubber in the Kalutara District has largely increased. The report of the District Association for 1905 slows 6,038 acres in rubber alone and 7,256 in rubber planted through tea, making a total of 13,394 against the figures (for 1904) of 3.128 acres in rubber alone and 6,759 planted through tea. It is probable that during 1906 a considerably larger acreage of new land will be planted, but it is not thought that very nuch more tea will be planted up with rubber. In addition to the above, large acreages are being planted by European and native proprietary plante $\mathrm{s}$ in the district.

Several illustrations are given showing the growth of Para rubber trees in various parts of the Kalutara District, some of them in the young stages and many mature and now being tapped.

South of Kalutara, in the Galle District, soils of similar character are met with and swamps frequently occur. According to the report for 1905 , no less than 2,500 acres were then in Para rubber and other 2,500 acres were cstimated for 1906 .

Mechanical Composition.- "The soil analyses show a slightly coarser texture than those examined from the Kclani; usually from 11 to 28 per cent. passes through the 90 mesh, 16 to 40 per cent. through the 60 mesh, 4 to 10 per cent. through the 30 mesh, and sand and small stones form from 30 to 70 per cent. of the soil. The retentive power of moisture is very similar to the Kelani, varying from 2 to 6 per cent."

Chemical Composition.-." The organic matter shows a variation similar to that in the Kelani Valley soils ; the general range is from 7 to 15 per cent., and the same can be said about the nitrogen, which varies from 0.1 to 0.15 per cent. This is of course excluding swampy areas, which we have seen to be very rich in organic matter and nitrogen, and alluvial soil such as that quoted below. The potash varies from 0.04 to $0^{\circ} 2$ per cent. and usually shows a relation to the amount of magnesia, both being derived from the decomposition of double silicates. The phosphoric acid varies from a trace to 0.06 per cent., and this low percentage is common in most Ceylon soils. The lime varies from $0^{\circ} 03$ to $0^{-15}$ per cent. and the magnesia from 0.04 to 0.2 per cent."

\section{Matale District.}

It is almost impossible to give the acreages under rubber in the Matale District, but as far as can be gathered there were about 1,359 acres of cacao interplanted with rubber and 539 acres in rubber alone in 1905. Plate 11, Series 1), shows Para rubber growing on Dangan estate, the property of the Rubber Plantations, Ltd., where the rubber and cacao trees are about $5 \frac{1}{2}$ years old and a e both in bearing. Plate 2, Series C, shows Para rubber in association with tea, both in bearing and doing well, on Nikakotua estate in the same distriet. 
It is well-known that the Matale District contains some very old Para rubber trees, now being tapped, and that large areas have been planted in association with cacao and tea as well as a single product. Trees at an elevation of 2,300 feet are now being tapped in this district.

"The soils characterizing the Matale District are frequently similar to those near Peradeniya.

Mechanical Composition.-. "The soils from the Matale District are on an average in a better state of division than those in the districts previously dealt with, usually from 15 to 30 per c int. passing through a 90 mesh, 14 to 25 per cent. through a 60 mesh, and 3 to 7 through a 30 mesh. Sand and small stones may form from 40 to 60 per cent. of the soil. The retentive power for moisture of air-dried soil does not show a very great variation, and is from 3 to 6 per cent.

Chemicai Composition.-_"The organic matter usually varies from 8 to 14 per cent. and the nitrogen from $0^{\cdot} 1$ to $0^{\cdot 2}$ per cent.; the lime from 0.08 to 0.2 per cent.; the magnesia from 0.05 to 0.25 per cent.; the potash from 0.03 to 0.25 per cent., and the phosphoric acid from 0.01 to 0.1 per cent."

\section{Pussellawa District.}

In the Pussellawa District the soil and climate appear to resemble those in sections of the Peradeniya and Matale Districts, and although part of the district is considered to be too high for Para rubber, there are nearly 2,700 acres of this product planted alone or with tea.

Ratnapura, Sabaragamuwa, and Ambagamuwa.

The Ratnapura District, differing so widely from the foregoing in having such a heavy rainfall and being one likely to be extensively cultivated in rubber, is here synoptically dealt with.

Regarding the mechanical composition, "out of about a dozen soils 17 to 20 per cent. of the soil passes a 90 mesh, 16 to 25 per cent. a 60 mesh, and 4 to 5 per cent. a 30 mesh, and sand and small stones account for from 50 to 60 per cent. The retentive power of moisture varie.s from 3 to 5 . The chemical composition shows from 10 to 12 per cent. of organic matter, 0.1 to 0.2 per cent. of nitrogen, 0.06 to 0.2 per cent. of lime, 0.07 to 0.15 per cent. of magnesia, 0.04 to 0.1 of potash, and from 0.03 to 0.8 per cent. of phosphoric acid." Para rubber is being extensively planted in this and the surrounding districts.

According to information supplied by the Secretary of the Sabaragamuwa Planters' Association, the acreage of tea interplanted with iubber is 4,477--in rubber alone 1,743 acresand during the present year quite 6,000 acres will be opened in rubber, thus bringing the acreage in this district up to over 12,000 acres for 1906. The photographs, showing the growth of Para rubber at Madampe, Rakwana, are all the more interesting as indicating the possibilities in this district. 


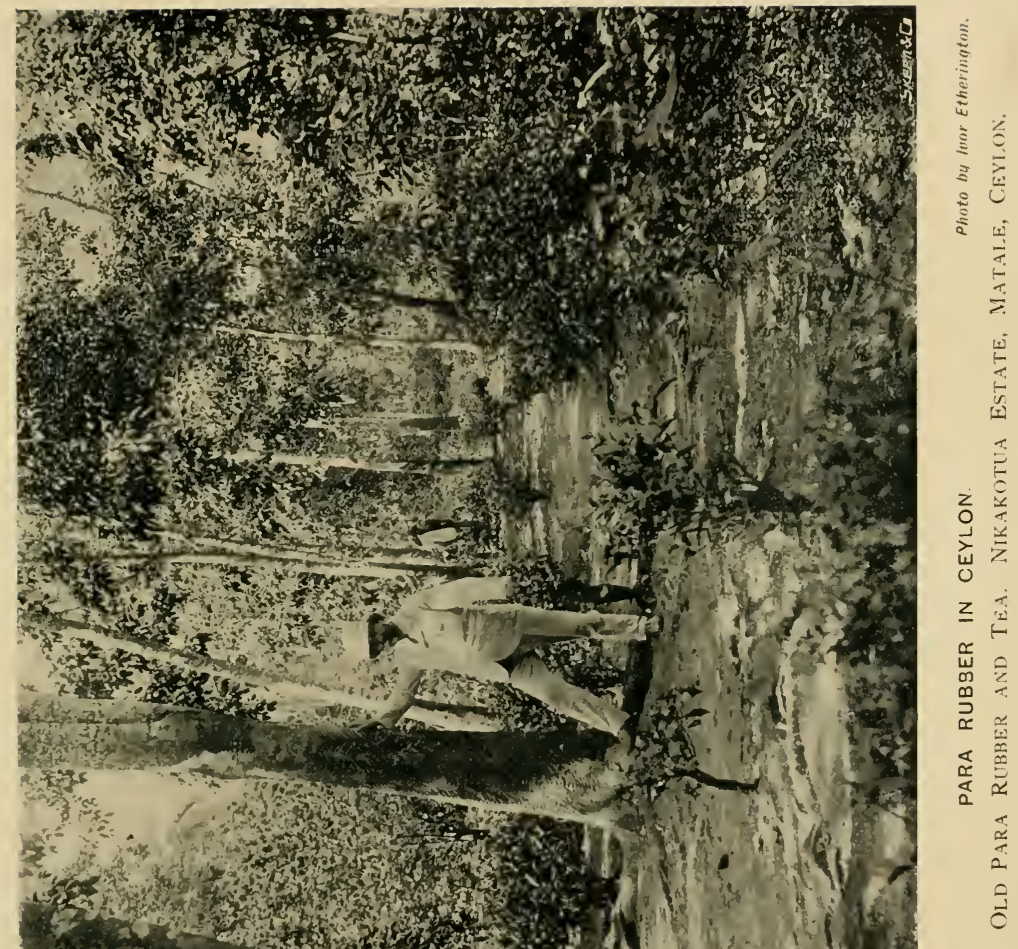




SERIES D. PL. 9 .

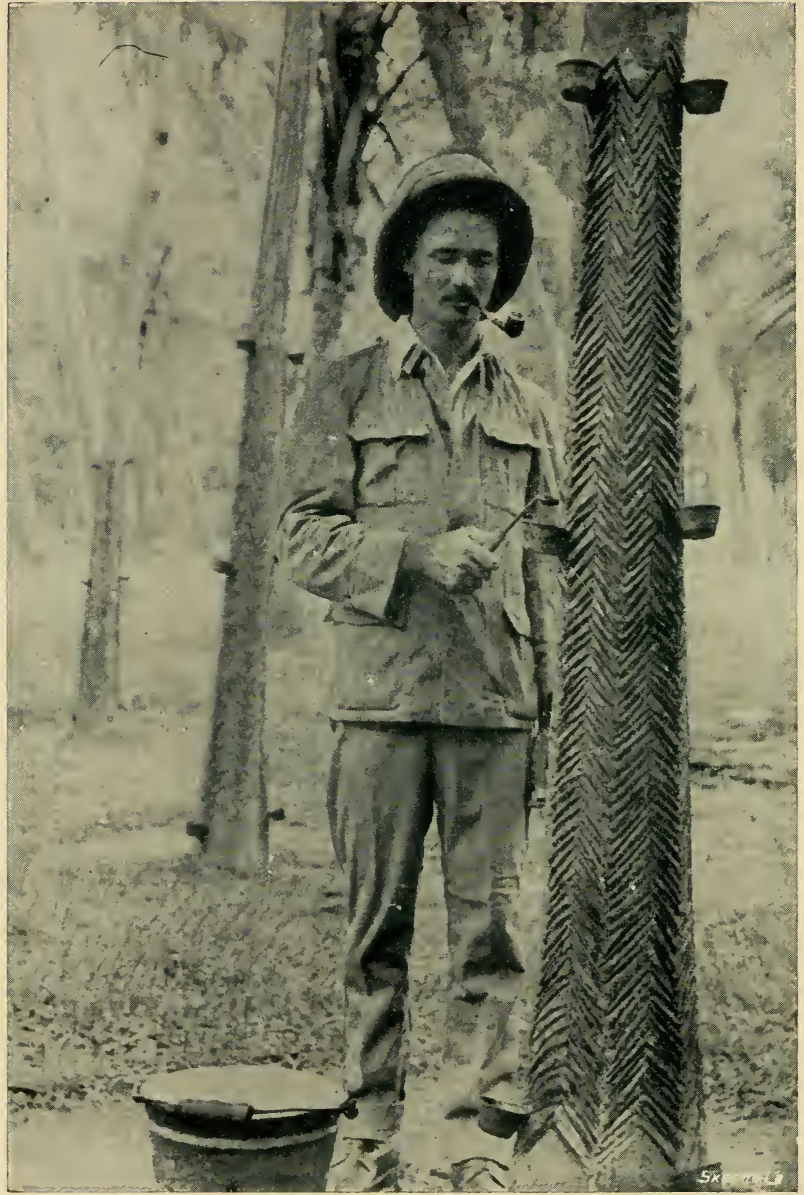

Whuto lent liy A. W. W. Gray.

PAPA RUBBER IN CEYLON.

KuRUNEgala DistFict.

Tapping Mature Trees in 1965. Arampola Estate, Kurunegala. Ceylon 
The illustrations, Series D, Nos. 5 and 6, show the growth obtainable in the Rakwana District, where the elevation above sea-level varies from 700 to 900 feet, and the rainfall from 95 to 110 inches. Figure 5 shows a rubber clearing planted from stumps in June, 1904, the plants being 17 months old at the time the photograph was taken, and varying in height between 12 to 20 feet. Figure 6 shows trees which have been obtained by planting two-rear-old stumps in 1899 , the trees being about six years old at the time the photograph was taken.

In the Upper Ambagamuwa District, where the rainfall is very heavy, Para rubber trees are being tapped and planting operations continued, though the elevation in such a wet district is thought by many to be near the maximum. About 800 acres have already been planted and some of the plants are showing satisfactory growth.

\section{Kurunegala District.}

The rainfall of 75 to 100 inches is evidently suitable, and a general glance at the average composition of the soils would not be out of place here. The soils vary greatly, as can be seen from tho following figures:-

\section{Mechanical Composition.}

$\begin{array}{llll}\text { Fine soll passing } 90 \text { mesh } & \ldots & & \text { Per cent. } \\ \text { Fine soil passing } 60 \text { mesh } & \ldots & \ldots & 17 \text { to } 35 \\ \text { Medium soil passing } 30 \text { mesh } & & \ldots & 20 \text { to } 35 \\ & & \ldots & 5 \text { to } 9\end{array}$

Chemical Composition.

\begin{tabular}{|c|c|c|}
\hline \multirow{2}{*}{\multicolumn{2}{|c|}{ Coarse sand and small stones }} & Per cent. \\
\hline & & 20 to 60 \\
\hline Moisture & & 3 to 7 \\
\hline Organic matter a & d water & 4 to 8 \\
\hline Lime & . & $\ldots 0.1$ to 0.35 \\
\hline Magnesia & . . & .. 0.1 to 0.45 \\
\hline Potash & . & .. 0.08 to 0.18 \\
\hline Phosphoric acid & . & $\ldots 0.02$ to 0.0 .1 \\
\hline Nitrogen & .. & $\ldots 0.08$ to 0.11 \\
\hline
\end{tabular}

During 1905 Para rubber has been largely planted, and a to:al estimate of about 4,000 acres for the year 1906 is considered to bo below the probable area for this district.

\section{Passara District。}

According to the Passara District Association, in their report for 1905, large areas in Moneragalla and the lower elevations of Madulsima and Passara were planted in rubber during the year, and it is estimated that over 11,000 additional acres will be opened within the next ten years. The results from the older trees being tapped at all elevations up to nearly 3,000 feet are satisfactory. In the Uva Province the climatic conditions are said to be such as to 
allow of the cultivation of Para rubber up to an elevation of 2,900 feet. The illustrations on Plate 12, Series D, show Para rubber at an elevation of 2,600 feet on Passara Group Estate, Passara, where trees varying in age from 7 to 13 years have given $2 \mathrm{lb}$. of rubber each during 1905.

"Very few soils have been analysed from the Province of Uva, but from those obtained from Passara the following information has been compiled. Usually from 17 to 30 per cent. passes the 90 mesh, 20 to 30 per cent. the 60 mesh, 7 to 8 per cent. the 30 mesh, and sand and small stones form from 40 to 43 per cent. The retentive power of moisture is about $2 \frac{1}{2}$. The chemical analyses show the presence of from 7 to 11 per cent. of organic matter, 0.1 to 0.15 per cent. of nitrogen, 0.06 to 0.1 per cent. of lime, 0.07 to 0.13 per cent. of magnesia, 0.05 to 0.08 per cent. of potash, and from 0.03 to 0.04 per cent. of phosphoric acid."

ManURING For 1NCREASING the Yield of Latex.

If latex is mainly an excretory or useless product it may appear doubtful as to whether manuring will have a beneficial effect on the rubber-producing capacity of the tree. This is an interesting point, and is well worth considering.

The latex is obtained from cortical tissues. These areas contain, besides the milk tubes, series of cells which store up food, and others which are directly associated with conducting the materials elaborated in the leaves from above downwards to various parts of the plant. These tissues are removed in the course of tapping operations, and their renewal entirely depends upon the activity of the cambium. The cambium produces new wood internally and cortical tissues externally ; generally the cambium produces these two series of tissue in a definite order, and a large production of woody material is accompanied by a proportionate amount of cortical tissues. As the wood is marked off into annual zones it is therefore possible to compare the rate of growth of trees in different countries by examina. tion of transverse sections of the trees, and indirectly to form some idea of the development of the narrow band of cortical tissues in which the milk tubes are contained.

The latex tubes form part of the cortical tissues, and an increased leaf activity appreciably affects the elements in this region. The more abundant the foliage, the more rapidly will the food material be built up and the more vigorous will the cambium become. From these and other considerations it may be concluded that if manuring is carried out, so that the growth of the leaves and woody material is appreciably increased, the cortical tissue will be proportionately increased in quantity, and there will be a larger number of cells available for transformation into laticiferous tubes. Any manure which affects the growth of the leaves or the wood must have a correspond. ing effect on the cortical tissues. The main object in manuring Para rubber should be to increase the number of cortical cells as rapidly as possible; this increase is dependent upon the activity of the cambium, though the subsequent condition of the newly-formed 


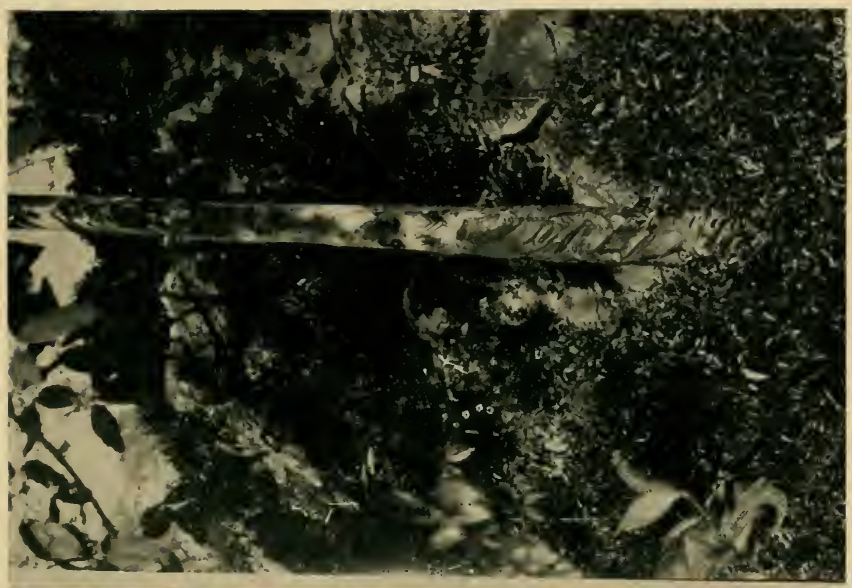

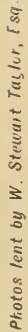

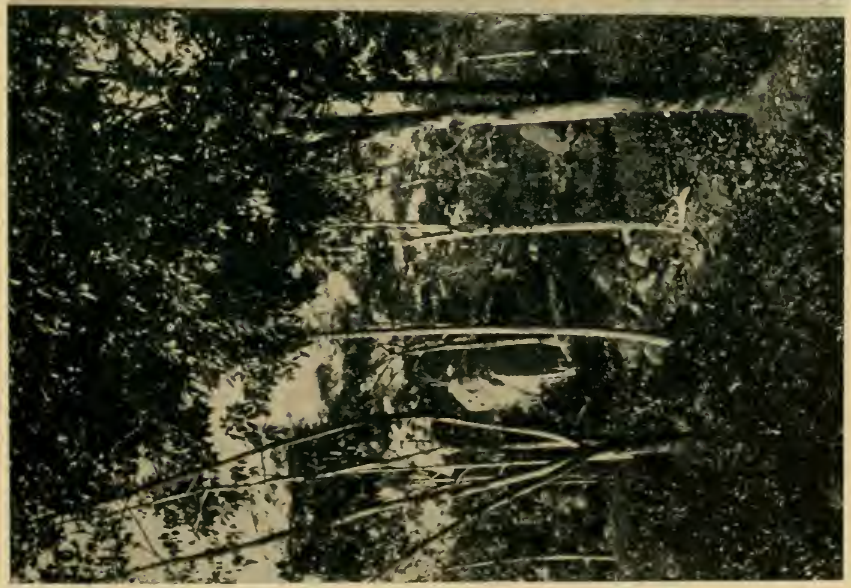



elements is closely associated with the abundance and activity of the leaves. It may appear absurd to advocate manuring with a view to increasing what is eommonly regardecl as mainly a waste product, but it cannot be gainsaid that abundance of cortical tissue provides more cells for perforation and disintegration, processes involved in the formation of the latex tubes of Para rubber.

The analyses of various parts of the Para rubber plant, given elsewhere, should be carefully considered when mixtures of artificial rubber manures are being compounded.

\section{Forest Vegetation and Soli. Improvements.}

It must be remembered that Para rubber trees form a forest vegetation, and that they will grow well in relatively inferior soils, providing there is a fair balanee of plant food and the elimatic conditions are favourable. The soil uncler forest vegetation improves in mechanical and chemical composition with age, owing to the protection which the trees afford to the soil, to the action of the roots, and the accumulation of leaf-mould. The annual fall of leaf from Para rubher trees ultimately effects an improvement in the soil in which the trees are being grown. This is borne out by the analyses of the soils at Henaratgoda, the results proving that the organic matter, potash, and nitrogen are greater in the soil which has been under rubber for 29 years than that which has been under pasture; the lime and magnesia have decreased under the old rubber, while the phosphoric acid is the same under both conditions.

\section{Food in Para Rubber Leaves.}

The manurial value of the leaves from Para rubber trees cannot be doubted when it is remembered that the material, dried at $100^{\circ} \mathrm{C}$., contains 1.72 per cent. of potash, 3.44 per cent. of nitrogen, 0.6 per cent. of phosphoric acid, and 0.51 per cent. of lime. If this material is regularly forked in either alone or with lime or artificial manures, excellent results will be obtained. The artificial manure required will largely depend upon the physical and chemical properties of the soil, but the figures showing the composition of various parts of the Para rubber plant will indicate, in a general way, the ingredients required. Potash and nitrogen are very abundant in the fresh and fallen leaves and lime is abundant in the woody structures.

\section{Manuring Old and Young Trees.}

The method to be adopted in manuring this product is determined by the age of the trees and the kind of manure used.

Where very soluble manures such as sodium and potassium nitrate, ammonium sulphate, potassium chloride or sulphate, and similar compounds are used, they should be mixed with dry earth and broadcasted over the area where the young rootlets are actively growing. If such manures are applied to areas which do not possess rootlets, the greater part will probably be carried away during the first few rainy days. After the manures have been applied the land should be forked to a depth of four to six inches. 
Where cattle manure, green manure, leaf-mould, or bulky artificial manure is used on rubber estates a slightly different method can be adopted. The object in such manuring is not only to supply at a very short notice ingredients required for the rapid growth of parts of the plant, but to lead to the development of a quicker-growing, larger, and stronger root system. This result can be obtained if the organic manure is mixed with the soil around the trees at a definite distance according to the age of the tree. The rootlets of the Para rubber tree grow approximately at the rate of 10 to 12 inches per year, radially, in good free soil, and the manure can be applied at a distance just within reach of the last-formed rootlets. Around each tree a shallow trench can be dug, about 12 inches wide and gradually increasing in depth from the tree outwards to a maximum depth of six to ten inches. The manure can then be mixed with part of the soil, returned to the trench, and subsequently covered with the balance of soil available. The distance of the trench from the tree should be approximately 2 feet for two-year-old trees, 3 feet for three-yearold trees, an allowance of about ten inches to one foot per year being made in each subsequent year until the trees are 6 to 8 years old, when the lateral roots will probably have met. The accompanying illustration on Plate 5, Series A, shows the system applied to young plants. In this instance the leaves of crotalaria, dadaps, and groundnuts were buried in the trenches after mixing with lime and soil. The Para rubber plants were only six months old and the trenches 6 to 9 inches from the stems. By such a system of manuring the rubber plants will be able to obtain a supply of food at a very early stage, and the development of the rootlets from within outwards be considerably accelerated. Once the rootlets of adjacent trees have met, the manure should be either buried in shallow trenches between the trees or broadcasted and the ground forked to a depth of 4 to 6 inches.

\section{Constituents in Woody Stems and Twigs.}

In order to furnish some idea of the constituents of various parts of the rubber tree the following synopsis is given of the constituents of the fresh material, as determined by Mr. A. Bruce:-**

Analysis of Parts of a Para Rubber Tree dried at $100^{\circ} \mathrm{C}$.

\begin{tabular}{|c|c|c|c|c|c|c|}
\hline & & $\begin{array}{c}\text { Fresh } \\
\text { Leaves } \\
\text { Per cent. }\end{array}$ & $\begin{array}{l}\text { Decayed } \\
\text { fallen } \\
\text { Leaves } \\
\text { Per cent. }\end{array}$ & $\begin{array}{c}\text { Fallen } \\
\text { Stalks } \\
\text { Per cent. }\end{array}$ & $\begin{array}{l}\text { Wood } \\
\text { Per cent. }\end{array}$ & $\begin{array}{l}\text { Twigs. } \\
\text { Per cent }\end{array}$ \\
\hline Water & .. & 70 & $\begin{array}{lll}. . & 60 & \text {. }\end{array}$ & 60. & 60. & 50 \\
\hline Ash & & $4 \cdot 69$ & . 4.08 & $3 \cdot 18$. & $3 \cdot 12$. & $2 \cdot 62$ \\
\hline Lime & .. & 0.51 & .. $1 \cdot 40$ & 0.80. & .. 0.80 . & 0.83 \\
\hline Magnesia & .. & $0 \cdot 56$ & $\begin{array}{ll}\ldots & 0.89\end{array}$ & . 0.30 . & .. 0.15 . & $0 \cdot 17$ \\
\hline Potash & & $1 \cdot 72$ & .. 0.54 & . 0.64 . & .. 0.30 . & 0.28 \\
\hline Phosphoric & acid & $0 \cdot 66$ & .. 0.30 & .. 0.15 . & .. 0.18 . & $0 \cdot 09$ \\
\hline Nitrogen & .. & 3.44 & $\begin{array}{ll}\ldots & 1 \cdot 92\end{array}$ & . 0.84 . & $\begin{array}{lll}\ldots & 0.59\end{array}$ & .. 0.62 \\
\hline
\end{tabular}





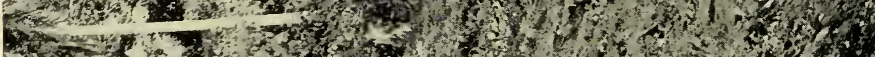

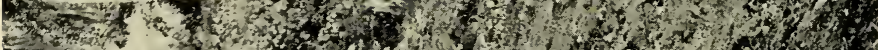

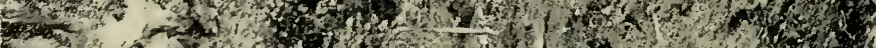
-

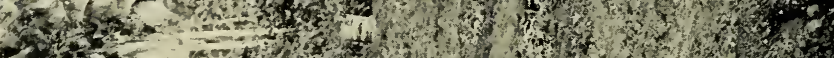

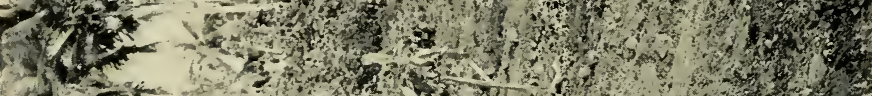

FIf

i

s.t.

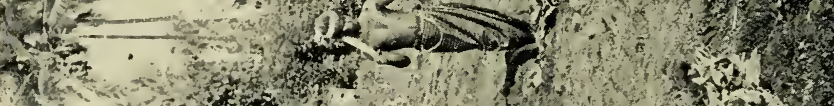

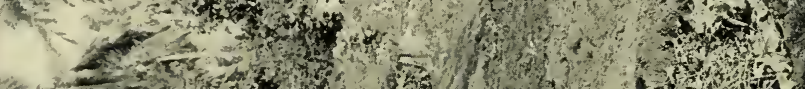

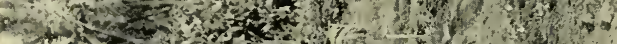

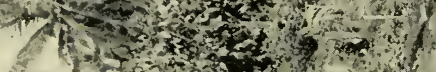

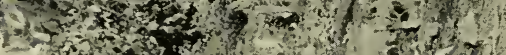

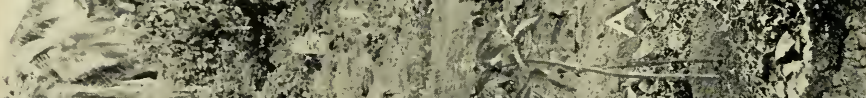

10. 0.15

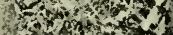

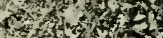

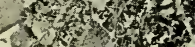
-

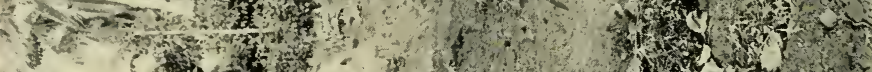

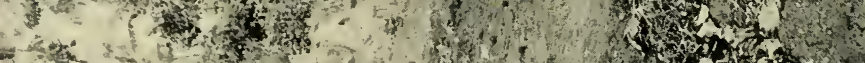

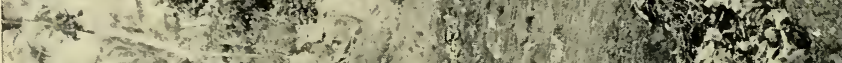

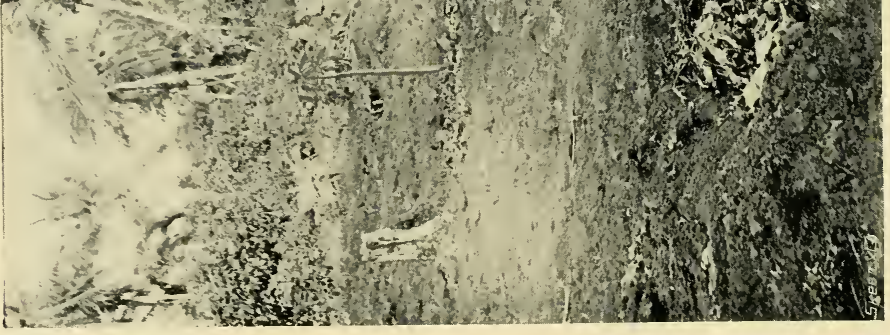




\section{Conposition of Artificial Manurese}

The following table shows the constitucuts of common artificial manures obtainable from local firms, and the compositions here quoted are those guaranteed by various firms in Colombo:-

\begin{tabular}{|c|c|c|c|c|c|}
\hline Manure. & $\begin{array}{l}\text { Potashl. } \\
\text { Per cent. }\end{array}$ & & $\begin{array}{c}\text { Phosphoric } \\
\text { Per cent }\end{array}$ & Acid. & $\begin{array}{l}\text { Nitrogen. } \\
\text { P'er cent. }\end{array}$ \\
\hline Blood meal & - & .. & - & .. & 10 tol4 \\
\hline Groundnut cako & 1 to 2 & .. & 1 to 2 & .. & \\
\hline Cinstor cake & 1 to 2 & .. & 1 to 2 & .. & 6 to 7 \\
\hline Riape cake & 1 to 2 & .. & 2 to 3 & . & $5 \operatorname{ton} 6$ \\
\hline Nitrato of sodu & - & .. & - & . & 15 to 16 \\
\hline Sulphate of ammonia & - & .. & $\ldots$ & .. & $20 \frac{1}{2}$ to $21 \frac{1}{2}$ \\
\hline potash . & 57 to 59 & .. & - & .. & - \\
\hline potesh & $\therefore \quad 49$ to 52 & .. & - & .. & - \\
\hline I'recipitated phosphat & & & & & \\
\hline of $\mathrm{li}$ & - & .. & 35 to 40 & .. & - \\
\hline Concentrated & & & & & \\
\hline asic slag & 二 & $\ddot{.}$ & $\begin{array}{r}44 \text { to } 46 \\
193 \text { to } 21\end{array}$ & . & - \\
\hline $\begin{array}{l}\text { ish } \\
\text { ish } h(x)\end{array}$ & - & 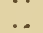 & 4 to 6 & .. & $5 \frac{1}{2}$ to $6 \frac{1}{2}$ \\
\hline or & - & 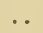 & 23 to 24 & . & $3 \frac{1}{2}$ to 4 \\
\hline it & . 37 to 40 & .. & - & .. & 11 to 13 \\
\hline Kainit & .. 13 to 15 & .. & - & .. & - \\
\hline
\end{tabular}

\section{Green Manuring for Para Rubber Trees.}

It is a fortunate coincidence that the climatic conditions favourable to the cultivation of Para rubber in the young stage are identical with those required for the plants of value as green manure. When estates are planted with rubber alone one must either elect to allow the soil to be exposed to the sun and rain and to be thereby imporerished, or decide to protect it by a green crop and increase the organic matter and mineral constituents for the future benefit of the growing rubber.

It is hardly necessary to point out the advantages of green manuring, seeing that the system is adopted in European as well as tropical countries. One great advantage attending the use of the plants mentioned below lies in the fact that they are able, in virtue of the bacteria associated with the nodules on the root, to absorb nitrogen direct from the air, a capacity not possessed by most of the plants under cultivation.

The points to be considered are during what stage in the life of a rubber plantation green manures can be cultivated, and which plants are best suited for the purpose. It is unnecessary to explain that after a good rubber estate is six to eight years old green manuring must practically ceasc. But during the first few years it is possible to keep a green cover over thuse prarts of the land not affected by the rubber plants. 


\section{Herbaceous Plants.}

Herbaceous plants ean be best grown from the first to the fourth year on account of the abundance of light which they are able to obtain and the relative freedom of the soil particles from the roots of other plants. The plants which can be used are Crotalaria striata, D.C., C. laburnifolia, L., C. incana, L., Cajanus indicus, Spreng, and species of Indigofera and Cassia. These plants are shrubby in habit, grow to a height of one to five feet, and will stand pruning at intervals of four to six months. Trailing or creeping plants such as the groundnut and species of Vigna can be successfully grown and also the sensitive plant. All these plants give a good cover to the soil and help to keep the weeds in check and produce large quantities of organic matter rich in plant food. Space forbids a full account of this subject, but the following facts are of interest as showing the weight of green material obtainable and the composition of several species :-

\begin{tabular}{|c|c|c|}
\hline f Plant. & $\begin{array}{l}\text { Weight of Organi } \\
\text { Matter per Acre }\end{array}$ & $\begin{array}{c}\text { Time between sowing } \\
\text { and Uprooting. }\end{array}$ \\
\hline striata & $20,2+4 \mathrm{lb}$. & Ten months. \\
\hline Vigna. & 12,092 & Four months. \\
\hline Pondicherry groundnut & 4,692 , & Five months. \\
\hline
\end{tabular}

Composition of Various Grehn Plants, in the Fresh State.

Nitrogen. Potash. Phosphoric Acid Lime.

Name of Plant. Per Cent. Per Cent. Per Cent. Per Cent.

Crotalaria striata $\quad \ldots 0.7$ to $1.0 .00 .47 \quad \ldots \quad 0.154 \quad \ldots \quad 0.210$

$\begin{array}{llllllllll}\text { Vigna } & \ldots & 0.6 & \ldots & 0.738 & \ldots & 0.177 & \ldots & 0.727\end{array}$

$\begin{array}{llllllll}\text { Pondicherry groundnut } & 0.914 & \ldots & 0.493 & \ldots & 0.155 & \ldots & 0.242\end{array}$

It is interesting to work out what the equivalent of $15,000 \mathrm{lb}$. of green manure of Crotalaria striata is from a purely theortiical standpoint.

Aceording to the above analyses it is approximately equal to a manure of the following composition :-

$\begin{array}{llll} & & & \text { lb } \\ \text { Castor cake. } & \ldots & \ldots & 500 \\ \text { Blood meal } & \ldots & \ldots & 500 \\ \text { Nitrate of soda } & \ldots & \ldots & 140 \\ \text { Basic slag .. } & \ldots & \ldots & 115 \\ \text { Potassium sulphate } & \ldots & \ldots & 140\end{array}$

If the whole of the material is to be used, it should be buried with lime or basic slag around the trees or forked in, as previously explained. During its decomposition it leads to the liberation of large quantities of plant food, which would otherwise remain in a latent stage for many years. 


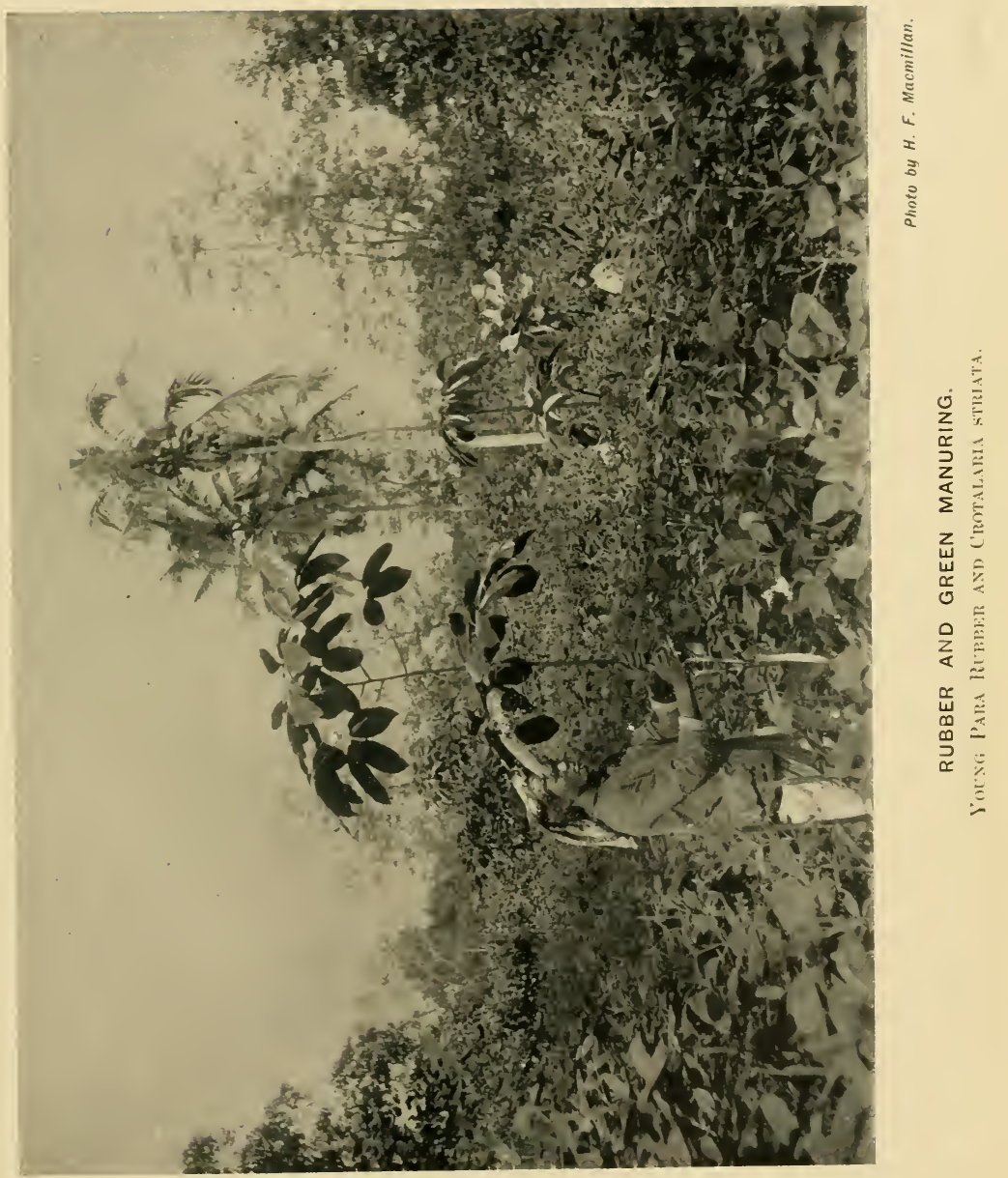



For the successful eultivation of the herbaceous green manures about 10 to $20 \mathrm{lb}$. of seed, per aere, should be broadcasted on clean land in wet weather and the land lightly forked. In Fiji as mueh as $50 \mathrm{lb}$. of Vigna seed is used, per acre, in connection with other products.

An illustration is here given to show the characters of C. striata, when only six months old, on Plate 4, Series A. The young rubber, a year old, is just showing above the Crotalaria; the latter covers nearly the whole of the ground and tends to kcep the weeds in check.

\section{Tree Forms.}

The best tree forms to use for green manure are Dadaps (Erythrina species) and Albizzia moluceana. Dadaps ean be propagated from cuttings; in some distriets they will give a very large amount of organic matter within a few months from planting the cuttings; plants can also be used, though the organic matter obtainable from them within a couple of years is less than that from cuttings in a few months. If cuttings are used, they can be planted between every two rubber plants. The best results are obtained if the cuttings are about two inches in diameter and four feet long with one foot below ground; they should be planted in very wet weather. Dadaps can be used on hillsides where the cultivation of herbaceous green manures is practically impossible. They should be lopped or hand-pruned as frequently as possible and the material buried in the same manner as for other species. The following table shows the weight of fresh leaves obtainable from one acre of Dadap cuttings planted 4 by 8 feet apart in July, 1904 .

\begin{tabular}{|c|c|c|c|c|}
\hline November, & 1904 & . & .. & 791 \\
\hline December & ,, & . & . & $967 \frac{1}{2}$ \\
\hline March & $190 . \overline{5}$ & . & .. & $1,93.5^{2}$ \\
\hline April & , & .. & .. & - $1,444 \frac{1}{4}$ \\
\hline May & , & . & . & $2,25.5$ \\
\hline June & , & .. & $\ldots$ & 2,2411 \\
\hline July & , & . & . & 2.180 \\
\hline August & , & . & . & 3,058 \\
\hline Septernbur & , , & $\ldots$ & . & $1,569_{4}^{3}$ \\
\hline November & , & .. & . & $2,104 \frac{1}{1}$ \\
\hline December & , , & .. & . & $1,6533_{2}^{i}$ \\
\hline & & Total & . & 20,198 \\
\hline
\end{tabular}

\section{DADAP LEAVES.}

These experiments show that Dadap cuttings may produce over $11,000 \mathrm{lb}$. of fresh green leaves within one year from planting, and the leaves may be hand-pruned nearly every month in the year. The fresh leaves contain 0.3 to 0.8 of nitrogen, $0 \cdot 148$ of potash, 0.08 of phosphoric acid and 0.197 of lime. 
Albizzia moluccana is one of the quickest-growing trees known, but it is not easily propagated from euttings. The woody tissues pre. ponderate, and the weight of leaf obtainable within one or two years is less than with Dadaps. The leaves are a valuable plant food, and if the trees are regularly lopped will give a fair amount of material fit to be buried. A one-acre plot, planted in July, 1904, 20 feet apart, gave up to January, 1906, 3,246 lb. of green material and woody twigs, so that if planted as close as the Dadaps ( 8 by 4 ) they should yield about $13,000 \mathrm{lb}$. per acre per year. On some rubber estates the young Albizzia plants have been so pruned as to be easily overtopped by two-year-old Para rubber trees, the branches and foliage of the Albizzia trees covering the greater part of the soil. The fresh leaves contain $0 \cdot 395$ per cent. of nitrogen, 0.406 per cent. of potash, 0.178 per cent. of phosphoric acid, and 0.441 per cent. of lime.

If it is found necessary to plant belts of trees enclosing various sections of a Para rubber estate for the purpose of checking the sp cead of disease, the possibility of using mixed lines of Dadap and Albizzia trees should be worth considering; the former can be easily pruned and made to produce a close low-lying bushy fence, and the latter allowed to grow and form a belt of foliage and branches above the tops of the Dadap plants.

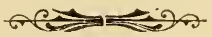


EFFECT OF BAD TAPPING ON THE WOOD.

SHOWING DECAY OF INTERNAL WOOD WHERE INJURED BY TAPPING.

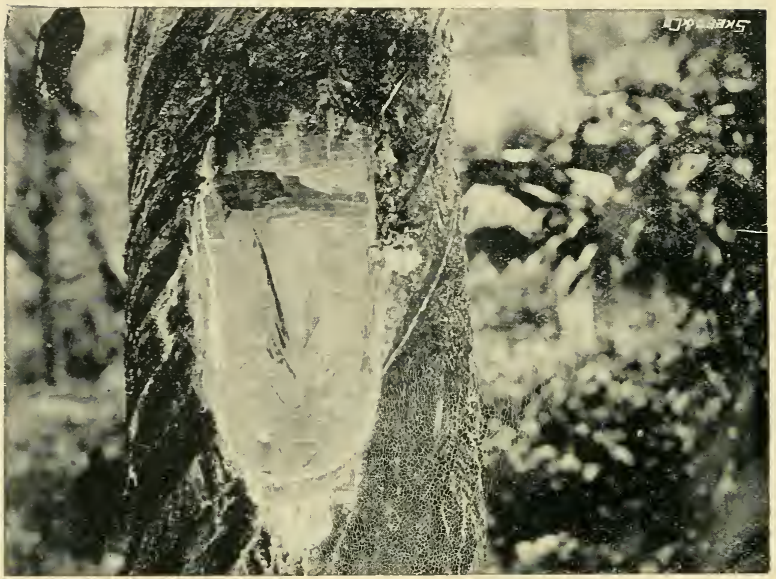

$\boldsymbol{f}$

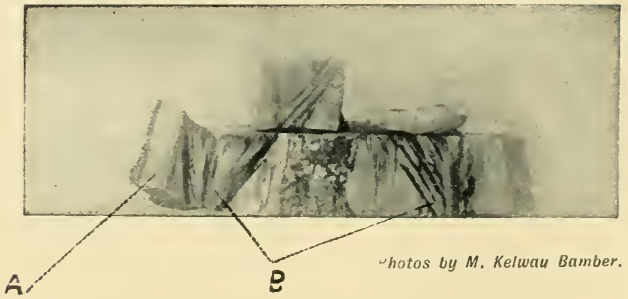

(A) OUTER WOOD REMOVED; (B) DART V TirVES INDICATING THE DECOMPOSITION OF THE WOOD. 


\section{CHAPTER V. \\ TAPPING OPERATIONS AND IMPLEMENTS.}

Importance of tapping operations-Tho thickness of the bark tissue; and shedding of dried latex tubes-Effect of bacl tapping illustratedTapping knives-Requisites of a good tapping knife-Clean cuts and scraping-Protection of the cambium-Paring from right to left and left to right-Minimum excision of cortex and bark-Paring and pricking-Patent tapping knires-Native implement-Carpenter's chisel-Surgical scraper's and planes-Beta knife-Golledge's knife, construction and illustration-Holloway's knives-Mackenzie's knife-Collet's knife-Brown \& Co.'s knives, construction and illustrations-Eastern Produce and Estates Co.'s knife-Bowman's and Northway's three knives, construction, method of use, and illustrations-Dixon's knife, construction, improvements, and illustration -Macadam's Comb pricker-Macadam-Miller paring knife.

r THE question of how to tap Para rubber trees is one which 1 deserves special consideration and is not outweighed in importance by even the process of euring or methods of planting this product. On the methods of tapping depend not only the quality and quantity of the latex and rubber, but the life and future condition of the trees.

We are concerned with the laticiferous tubes in the outer part of the stems when the trees are ready for tapping.

The thickness of this tissue may rary from $!$ to about $\underset{2}{1}$ inch or more, according to the age of the tree.

The average thickness of the undisturbed bark of twenty-year-old trees in ('evlon is about ${ }_{3}^{3}$ inch $(9.5 \mathrm{~mm}$.), though trees at Singapore, only il years old, possess bark of this thickness. The outer part to a depth of 1 inch $(3 \mathrm{~mm}$.) does not contain many tubes, but the inner part has a large number, and from the inner $\gamma_{\frac{1}{6}}^{1}$ to $3_{2}^{3}$ inch the milk mainly flows. The tubes in the outer part dry "1p and are regularly shed with the outer bark tissues.

When the original cortex has been removed new tissue is produced, mainly from above downwards and within outwards, and in this the latex tubes arise de novo as in the original material. It is important to remember that the extension of these tubes in the cortex of Hevea is a gradual one, and that in many instances the parts of the laticiferous system are not extensive, and in tapping operations only a fraction of the whole milk-containing tubes may be drawn upon. 
Recent experiments have shown how improvement can be made on the old method of tapping every alternate year and obtaining $1 \frac{1}{2}$ lb. of rubber per tree, per year, from eleven-year-old trees. It ha been stated that the yields which are possible in the near future may, if present prices are maintained, be such as to allow one to consider the contingency of re-planting every twelfth year. The yield which has been obtained in some parts of Ceylon shows that by somewhat drastic methods it is possible to obtain from particular trees in one year's tapping as much as the most sanguine only a few years ago anticipated in ten years' tapping, though it must be borne in mind that the effect on the trees cannot, with our present knowledge, be accurately forecasted and may or may not prove to be detrimental.

\section{Effect of Bad Tapeing.}

It is more than likely that the tapping implements and methods of the future will be such as to ensure that the minimum, if any, damage is done to the cambium. With all due respect to the inventors who have placed their knives before the public, it may be stated that the faultless or ideal paring implement has not yet been produced, though there seems every likelihood that it will soon be on the market. There are still several implements sold and used which should be classed as dangerous. In order to impress all planters with the ultimate effect of bad tapping, a couple of photographs are here reproduced.

In the accompanying illustration--Plate 6 - the upper figure shows a part of a large tree with the bark and part of the wood removed. The large approximately V-shaped hollow in the exposed section is due to the decay of the wood, which occurred internally to a depth of several inches, and was caused originally by making a large $V$ wound that scraped below the cambium into the timber all along the incision. The lower figure on th s same Plate shows a section of the wood with part of the bark and outer tissues removed. The wood was, with the original tapping. considerably damaged, and several years after the injury was made the parts above it were found to be very hard and to give very little latex : the wood was permanently damaged. In this particular case the outward appearance was not striking in any way, and only the poor yield of latex led to the inquiry which revealed the extent of the permanent injury that had been made. The black $V$-shaped lines in the exposed wood show the direction and extent of the old $V$ cuts, which penetrated to the cambium. In all such cases the decomposition of a vital part of the tree has been set up. and the vigour and longevity of the tree appreciably affected. I have seen several other malformations produced by damaging the wood while tapping; often the areas become very "warty" and present a series of very large balls of hard woody tissue which cannot be tapped, and which seem to rest in sockets of the timber; in other cases large scars exist where the chisel has cut below the cambium. The injury in all cases is permanent and can. 

SERIES A. PL. 7

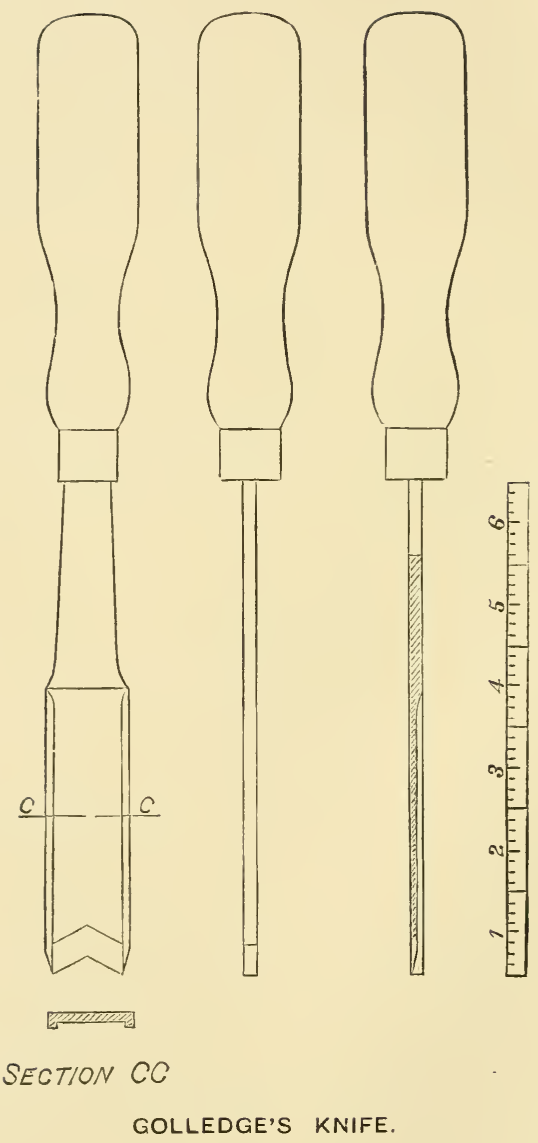


be detected many years after it has been made. Such knobs and scars are not clue to "canker," and the establishment of a smooth surface on such trees without eutting into the wood is practically an impossibility.

The tapping of irregular surfaces requires special consideration; but it may be stated that in no case should the woody protuberances be excised ; the incisions should, if possible, be made above or below all woody warts, and the latter allowed to work themselves out in their own way and time. In such cases the zigzag method of tapping (sec next chapter) can of ten be adopted with advantage.

\section{Tapping Knives.}

The various methods of tapping now in vogue are often associated with the use of a particular knife or series of knives, and it is therefore necessary to first consider the knives which are commonly used and the general requirements of such implements.

\section{Requisites of a Good Tapping Knife.}

There are several points which should be borne in mind by those who desire to effect improvements in tapping knives or to invent new ones.

The first requisite is that the cutting surfaces shall be such as to enable the operator to either make an even clean cut or to excise the cortical tissues without dragging the cells or clogging the knife. Several friends have shown me instruments which are best described as surgical scrapers, planes, and closed knives; in each case the idea was to scrape away a thin film of the cortical tissue, but in every instance the operation dragged the cortical cells considerably, clogged up the latex tubes, and left an uneven surface along which watery latex would not flow. A clean cut is essential, and for this reason it is doubtful whether the principle of scraping will ever be generally adopted.

A second point of very great importance is that the knife should, if possible, be provided with some structure which will prevent the cooly from cutting too deep when making the initial excision, and also protect the cambium during subsequent paring operations. In several cases separate knives are used for making the original incision and subsequent paring operations ; those used in the latter processes are frequently made so that they can be adjusted beforehand, or they are protected by a fixed or detachable blade. A glance at illustrations on Plates 8, 9, and 10, Series A, will show the appliances referred to. The effect of bad tapping is shown elsewhere. It is a great advantage if the cutting parts can be adjusted with ease and replaced without great expense.

A third consideration, which should not be lost sight of, is that the knife should be one which can be used in cutting from left to right and right to left from above downwards. Illustrations 7 and 10 show knives which can be so used, and also from below upwards if desired. This is a necessary qualification in all tapping methods except the right-hand half-herring-bone and spiral systems 
A fourth point, which has obvionsly received attention in the knives recently put on the market, is that the instrument used for re-opening or paring the lower surface of the wound should be so construeted that only the minimum quantity of material is cut away at each operation. The longevity of the tapping area depends upon this operation, and at the present time there are knives which will demolish 12 inches of hark in three months, and others which will not use up the same quantity of tissue in two or three years. The very narrow cutting margin of knife No. 2, shown on Plate 9, Series A, is specialy devised for paring away very thin shavings of the bark.

The introduction of pricking instruments for cutting the laticiferous tubes in the wound area, though duplicating the tools, is very useful; generally the duplication of the tools required to make the first and subsequent incisions is undesirable, and in several instruments the power of adjustment is such as to allow all the operations to be carried out by means of one knife only.

\section{Paring and Pricking.}

The amount of cortical or bark tissue which is cut away by one paring operation is sometimes surprisingly large. The average cooly will excise the lower surface until a large number of white globules of latex have appeared, when by the use of other implements the latex tubes might have been tapped without excising any cortical cells at all. It has been asserted that since the most careful method may only allow one to tap the whole of the surface from the base up to six feet in two to three years, the care advocated is not necessary when large acreages have to be tapped. But the necessity of tapping every tree on a large plantation is no excuse for excising the cortical tissues in a wasteful manner. The best results will follow from those methods which involve the removal of the minimum amount of cortical substance during tapping operations.

It has been urged that even if one removes large quantities of tissue when tapping, the rubber can still be extracted from the material thus removed. This is correct especially when large quantities of bark are cut away, but the greater part of the rubber can, by proper paring and pricking, be removed without great waste of tissues.

Furthermore, it should be distinctly borne in mind that the removal of the cortical cells means the destruction of the living tissues wherein the latex tubes arise. The actual quantity of rubber in the cortex at any particular time is very small compared with that which can be obtained by pricking the latex tubes, allowing them to become refilled, and encouraging their development.

\section{Patent Tapping Knives.}

The native collectors of rubber in the uncultivated forests of Brazil use an axe-like implement, with which a heavy blow can be inflicted and all the tissues from the bark to the cambium be cut in one stroke. At the present time Ceylon is taking a very active interest in invent- 


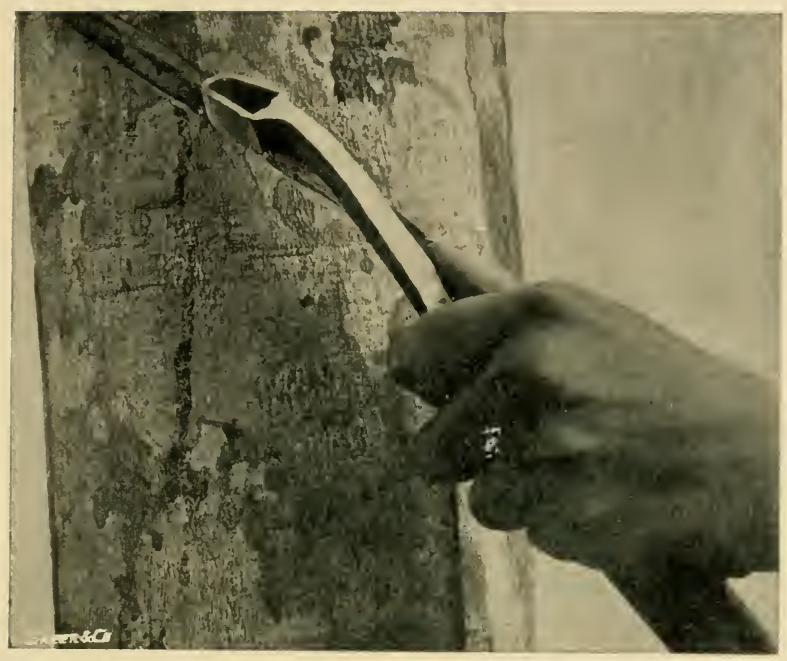

THE "SAFETY" TAPPING KNIFE.

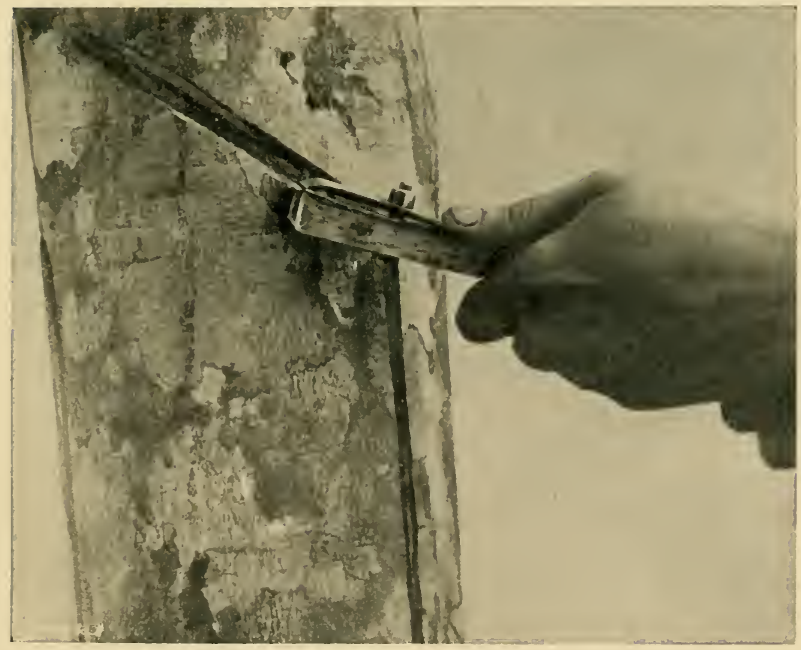

THE PARA CHISEL 

ing and improving tapping knives for use in obtaining latex from Para rubber trees, and the following accounts of some of those implements which are fairly well-known will be of value.

\section{The Carpenter's Chisei.}

This was used in the early tapping days, but has been superseded by more useful tools. Parkin carried out experiments to see "whether incisions made with a stone or cold chisel gave more latex than corresponding ones made with an ordinary chisel, but did not find any appreciable difference in the amount of latex collected from the two kinds of incision on the single oblique pattern." He finally recommended a wedge-shaped ehisel with a thickness of ${ }_{16}^{3}$ to 1 inch, at a distance of $\frac{1}{2}$ inch from the cutting edge; the breadth of the chisel varied from 1 to $1 \frac{1}{2}$ inch.

With the idea of re-opening the wound area without cutting away a large quantity of tissue, several surgical scrapers and planes have been brought forward, but in every case have proved unsatisfactory. They tend to clog the freshly-opened latex tubes.

\section{The "Beta Knife."}

The Beta knife, placed on the market by Messrs. T. Christy \& Co., is, according to Johnson, a useful instrument; the length of the blade is regulated by means of a screw to suit the varying thicknesses of the bark of different trees and so prevent its damaging the wood of the tree.

\section{Golledge's Kinife.}

In the accompanying illustration-Plate 7 , Series $\mathrm{A}$-it will be seen that this knife consists of a flat piece of steel provided'at the end with a short sharp bevelled $\mathrm{V}$ and a cutting groove along the sides. The knife can be used for making cuts from above downwards, below upwards, and from left to right or right to left. It can be used to make the original incision and during subsequent paring operations. The illustration on Plate 3, Series D, showing the herring-bone system of tapping, indicates the good work which has been done by means of this knife.

\section{Holloway's KNives.}

The Holloway tapping knife is an improved $\mathrm{V}$ knife provided with movable blades; the $\mathrm{V}$ head is fastened to the handle by two small screws and nuts, and the blade when worn down is easily replaced.

Holloway has brought out another knife which is essentially provided with a two-flanged and a basal cutting surface. The blade is made of metal and is curved like a hook at the top ; the cutting area is provided with a flange at either side at right angles to the base and all parts can be easily sharpened. The basal cutting surface or either of the angles ean be used in making the original incision, and the two angles may be used for paring either from right to left or left to right. The parts are changeable and all operations can be done with one implement. 


\section{Mackenzie's Kinife.}

This consists of a tempered steel head of box section having cutting edges on three sides. The cutting surfaces are in one piece and movable; by an ingenious screw arrangement the depth of the cutting edges can be adjusted according to requirements by two side guards. The knife can be used for tapping from left to right or right to left. When the incision is so broad that the guard on the upper side of the knife does not rest against the bark on the top side of the cut, the upper guard can be lowered so as to come in contact with the excised area, along which it rubs during paring operations.

\section{Collet's Knife.}

M. Collet recently exhibited a new tapping knife which I am informed has been patented in Belgium. It is made entirely of metal: running down the handle, and coming out at the base, is a bluntlypointed piece which is inserted in the bark of the tree to be tapped, and by this means the depth of the bark is measured.

The blade of the knife, which is like a sharp, curved gouge, has on it a brass support, which is set at an angle with the blade andbefore cutting -is adjusted at a definite angle, so that when the knife is in use and the brass support resting against the bark, the cut can only go as deep as it is set for, which is the depth of the bark measured at first; by this means the laticiferous cells are reached, but the cambium is not cut.

\section{The "Para" Rubber Tapping Knife and Chisel.}

The two instruments indicated are obtainable from Messrs. Brown \& Co., Colombo. The "tapping knife" is designed for making the first incisions in rubber trees, when the paring process is intended to be carried out in the subsequent tapping rounds. It is constructed to make incisions on the left and right of the perpendicular, and after these cuttings to leave flat surfaces on the lower sides of the incisions ; it provides ample head room for the "Para Chisel" to work in during the early rounds of paring. The "Para Chisel" is a tool for reopening the original incision in such a manner as to renew the flow of latex with the minimum loss of bark tissue. It is first adjusted to cut to the required depth, then placed in the incision and pressed gently forward in a direction parallel to that of the incision. The cutting blade can be easily renewed. The llustration on Plate 8 , Series A, shows the construction of the important parts.

\section{An Implement for Tapping Rubber Trees.}

The Eastern Produce and Estates Company are responsible for a knife, which has been used on many estates in Ceylon. The patentee claims that it is a simple knife and one which can be economically used over large acreages of rubber. It consists of a wooden handle of suitable size and shape, furnished at one end with a stabbing or piercing point for the purpose of clearing the old cuts 

SERIES A, PL. 9.

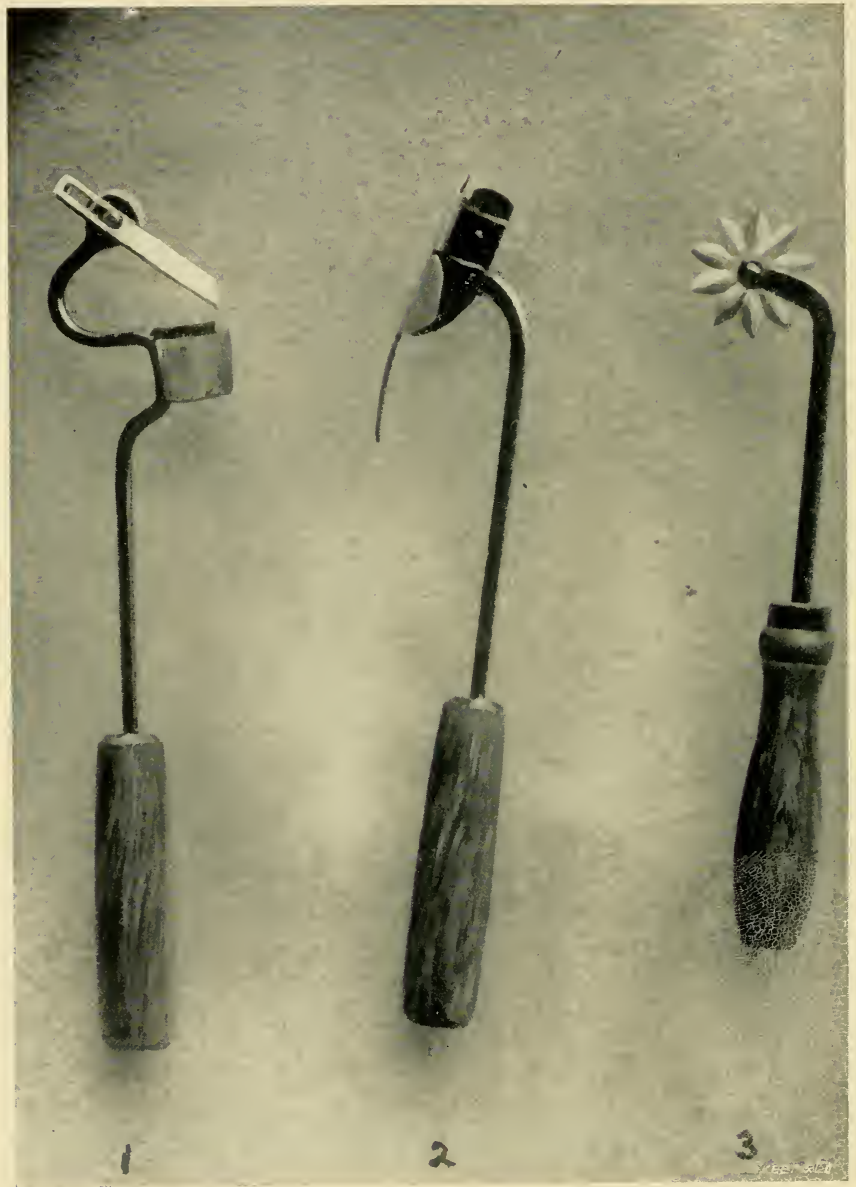

Photo by D. L. Goonewardane. BOWMAN'S AND NORTHWAY'S KNIVES. 
of scrap rubber; it is oceasionally used on estates for piercing the stem or newly-formed cortical tissue to see if the latcx is abundant. The cutting device is mounted at the other end of the handle and consists of a haft or stem with a hollow wedge or triangular-shaped cutting portion at the apex. This knife was one of the first to be placed on the market, and a detailed account of it is given in the India Rubber Journal of February, 1904.

\section{Bowman's and Northway's linives.}

These knives have been continually used in the experiments at Peradeniya and Henaratgoda, and in response to suggestions the originals have been slightly modified in order to be of use in any of the numerous systems of tapping, and to still further economize in the removal of the cortical tissues. There are three knives in all : No. 1 for making the original groove, No. 2 for re-opening the lower surface of the wound, and No. 3 for pricking the latex tubes in the area of the wound response without removal of any cortical tissue. These knives are shown in the aecompanying illustrations on Plate 9, Series A.

Knife No. 1 is provided with a two-edged guide, which on pressing against the bark cuts the tissue and clefines the area to be cut away by the knife edge behind it: by this means the original groove shows clean cut surfaces above and below. It is used much like a plane, the head being suitably adjusted to shave the bark gradually; as soon as the proper depth is reached the bark is of a white colour and becomes lighter and lighter the nearer one gets to the cambium, so that by practice it is possible to tell almost correctly when the right depth has been eut.

Young trees are more difficult to eut to the correct depth than old ones, as the latex-bearing tissues below the bark and next to the cambium are very thin indeed; it is therefore advisable to mark lightly with No. 1 and reach the correet depth gradually with a few tappings with No. 2 in the manner deseribed below for cutting deeper.

Knife No. 2 in its improved form is very ingenious. The cutting part eonsists of three surfaces, a narrow basal one along which a spring blade is inserted, and two side surfaces at right angles to the basal one. When the flexible spring blade is inserted there are two small eutting edges available, one to use when cutting from right to left and one for use from left to right. Several of the No. 2 knives are only provided with one angular cutting surface. By this means only a very thin layer of cortical or bark tissue is removed during each paring operation, the removed substance being so small that it takes quite 30 parings to remove one inch of tissue. This is a most important point, as the trees are made to last eonsiderably over one year instead of only 3 to 6 months. This knife is used only for paring off the lower edge of the grooves originally made, and when cutting should be held so as not to make 
the cuts deeper than the previous ones; this is effected by holding the knife at the proper angle. Leaning the knife over to the right makes the cut deeper, while leaning over to the left makes it less deep. The knife is constructed to prevent the cooly cutting deep enough to touch the cambium.

The basal cutting surface of this knife has now been made much narrower, the change effecting a greater economy as less material s likely to be removed during each operation.

No. 3 consists of a spur-like arrangement, which is provided with a number of sharp cutting teeth. It is used to cut the latex tubes near the cambium or to tap the milk vessels which have become unduly distended with latex.

The latest patterns are provided with one or two pieces of metal, the solid margins of which prevent the teeth from penetrating too deeply; these can be changed in order to allow the teeth to penetrate the cortex to the necessary depth-a wise provision when tapping trees of widely different ages. It can be used alternately with No.2 knife, though in the Peradeniya experiments the spur knife is used at least twice as often as knife No. 2 . It is by the use of these knives that the yield of $12 \mathrm{lb}$. of rubber was obtained in 6 months from an cleven-year-old tree in the south of Ceylon, and $4 \mathrm{lb}$. in two months from each of four trees at Peradeniya. The knives have elicited the admiration of many rubber planters who have adopted the pricking and paring method. The value of a pricking instrument does not appear to be fully appreciated by many, but when it is pointed out that by means of such an implement the excised area in three months' work, tapping twice per week, is less than one inch, its usefulness cannot be doubted.

\section{Dixon's KNife.}

This consists of a grooved open knife blade, which can be adjusted to cut the bark to any depth or at any angle. The cutting part can be easily removed from the handle of the knife and is therefore capable of being replaced when worn out. The base is provided with a pricker for determining bark thicknesses, removing scrap rubber from the cuts and making holes for attaching tins, \&c. It can be used for making the original groove or for paring the lower surfaces in any direction, the excision being made by drawing the knife towards the operator.

In a later pattern the cutting blade is provided with sharp margins, two blades, detachable and adjustable, to be used according to particular requirements. By favour of Mr. Dixon the accompanying illustration on Plate 10 , Series A, is here reproduced.

\section{Macad.uM's Come Pricker.}

A specimen of a pricking instrument has just been received from Mr. Macadam of Culloden estate, Kalutara, which is worthy of a detailed description as it is constructed on a sound principle and is 
SERIES A. PL. 10.

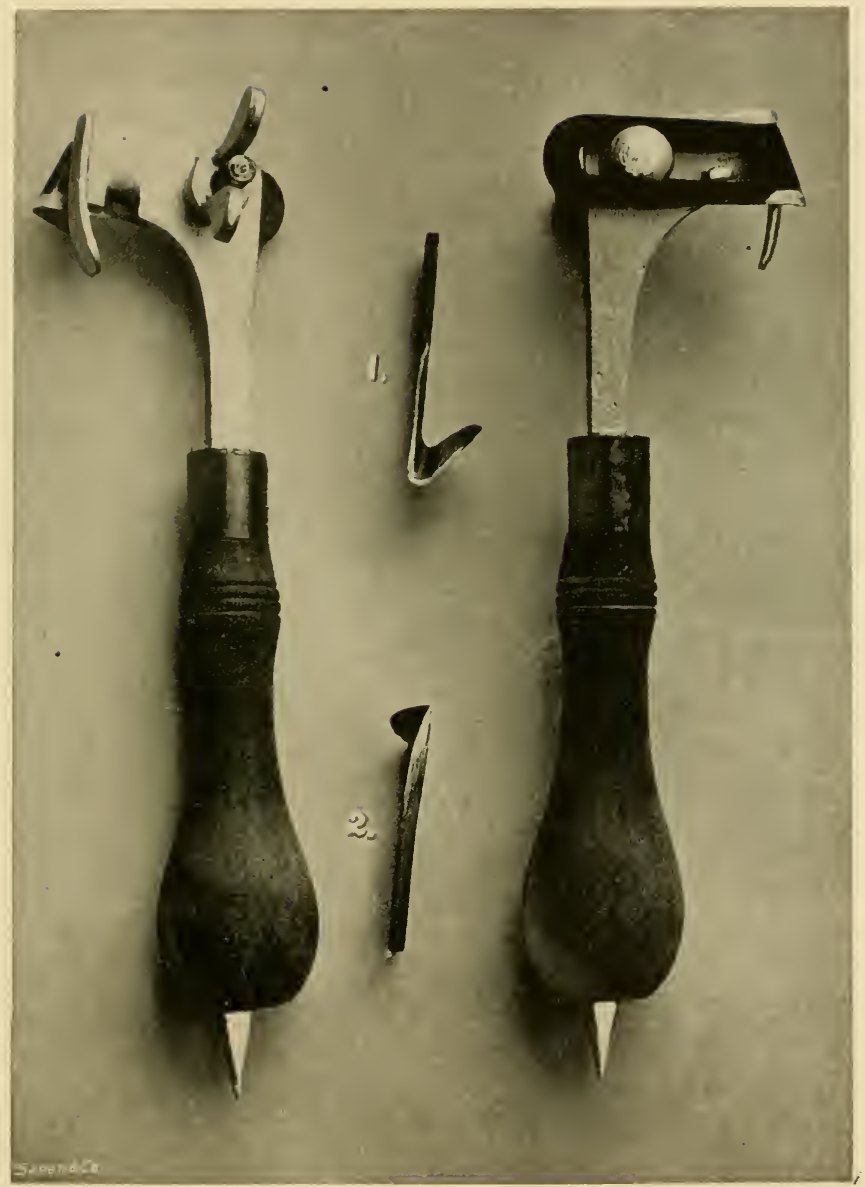

DIXON'S TAPPING KNIFE. 



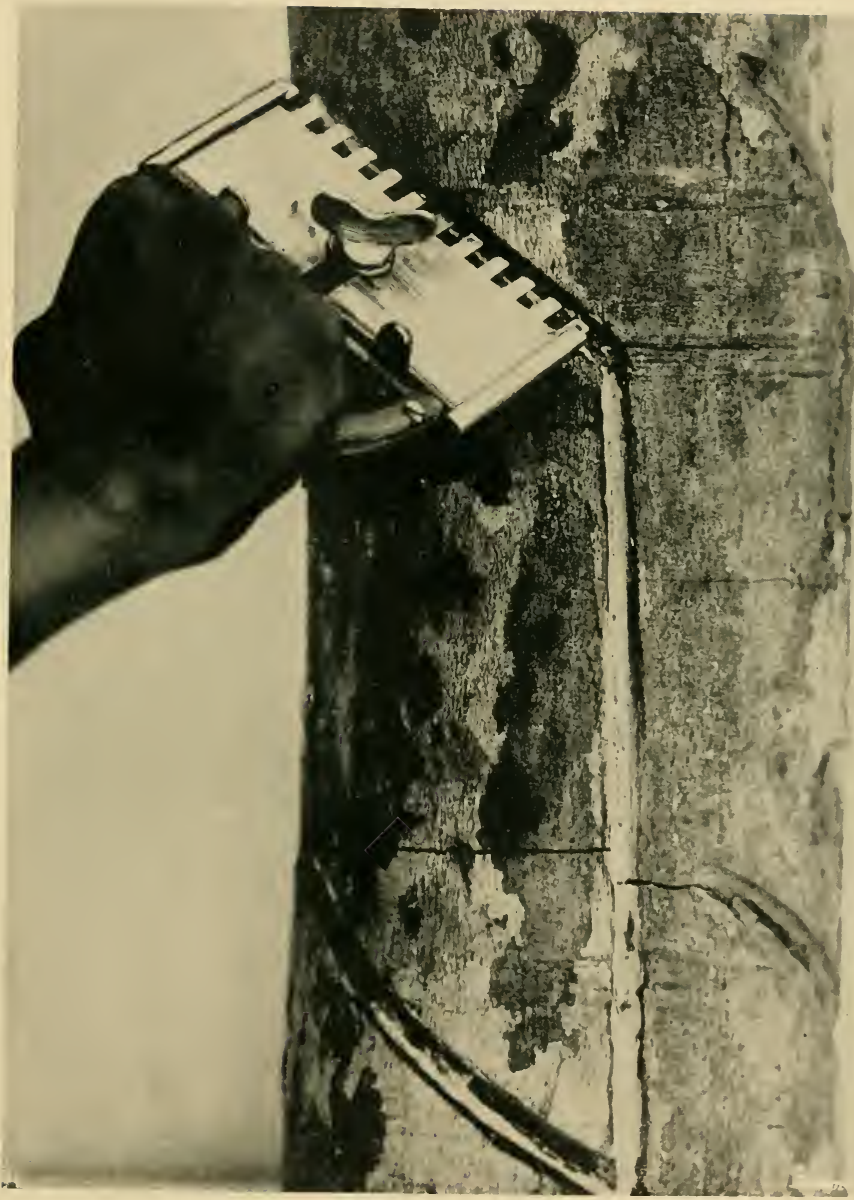




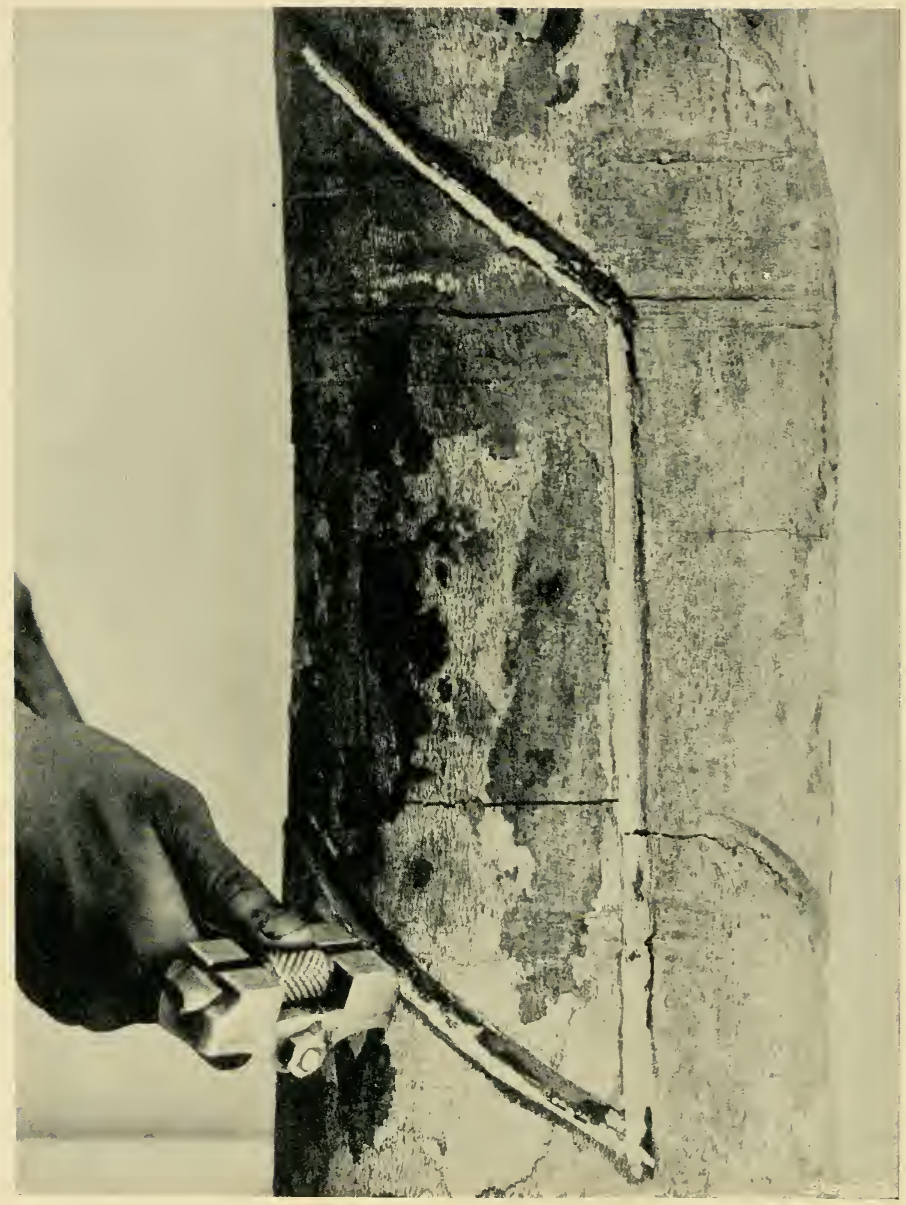


different from any other pricking instrument known. In order to disting?ish it from others I propose to name it a "Comb" pricker. It consists essentially of a flat steel blade or comb provided with a dozen sharp teeth on one side; the teeth are $5 \mathrm{~mm}$. wide and $9 \mathrm{~mm}$. long and the blade is $113 \mathrm{~cm}$. in length, so that a tapping line one foct in length $\left(30 \frac{1}{2} \mathrm{~cm}\right.$.) could be pricked in three operations. The blade slides along two side grooves and is provided with two projecting pieces of metal for handling during adjustment. The blade can be pushed outwards or drawn inwards, thus allowing only a definite length of each tooth for the pricking operation. The ease with which the length of all the teeth can be adjusted is a great advantage, as a cooly going from tree to tree can, though he only possesses one piece of metal, accurately change the length of the teeth according to the thickness of the bark on the trees being tapped.

A further advantage in the "Comb" pricker is that the latex tubes are incised by merely pressing the line of teeth against the cortex, and dragging of the bark cells is therefore almost imf,ossible. In other prickers the tapper naturally draws or pushes the instrument in a particular direction, and the unavoidable dragging may result in a clogging up of individual milk tubes. The teeth of the "Comb" are very easily sharpened and the simple and effective apparatus is mounted on an arched handle whereby a good grip is obtainable, and the required pressure can be applied during tapping operations.

\section{The Macadan-Miller Parivg Knjfe.}

This paring knife consists of two detachable paring surfaces connected by a screw roller; the cutting parts are on opposite sides and may be moved outwards or inwards by turning the screw, and can therefore be adjusted according to the depth of the bark to be excised. The essential parts are lodged in a substantial steel head which is attached below to a wood handle. The knife is constructed so that the operator may cut from right to left or left to right, from above downwards or below upwards. The essential parts are rather difficult to get at and may prove troublesome to a cooly who is not accustomed to adjusting the paring edges.

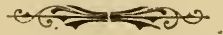




\section{CHAPTER YI}

\section{HOW TO TAP PARA RUBBER TREES.}

Methods of tapping Para rubber trees-Methods of native collectors in Brazil and the Gold Coast-observations of Jumelle and Bonnechaux-Modern methods-Single oblique cuts, ililustrated-V incisions, illustration showing a tree after ten weeks' tapping-Limited area-Herring-bone system-Photographs of trees in Ceylon tapped on the herring-bone system-The zig-zag method and its use -Spiral curves-F. Crosbie Roles on the spiral method, yields and estimates-Results of the spiral system in parts of CeylonCollecting and storing of latex-Bury's protector-Centralizing the latex from many trees, illustrated-Drip-tins, their construction and action, illustrated-Keeping the latex liquid and settling tanksMethod of marking the trees for tapping-Collecting tins

\section{Methods of Tapping.}

The best method of tapping is that which extracts the maximum amount of latex from the tree with removal of the minimum quantity of cortical tissue, and without damaging the thin layer of cambium cells. The cambium is responsible for the renewal of the cortical tissue in which the latex tubes arise by a process of perforation and decomposition at a later stage. If the cambium is damaged the repairing of the cortical tissue is long delayed, and in very many cases the areas so damaged can never be tapped to the same advantage as previously.

At Henaratgoda and on estates many examples of the effect of injuring the cambium may be seen at the present time, though the damage may have been done many years ago. The surface of a badly-tapped tree does not become even and smooth for many years, and tapping on the latest system on such trees is difficult and often impossible.

\section{Methods of Native Coljaectors in Brazil.}

The felling of the wild trees and the ringing of the bark and cortex in order to collect the milk are now rarely practised by native collectors. The latex is usually collected from the trees while standing, and in the Amazon Districts an upward incision is made in the bark by means of a small axe, and a cup is then placed beneath each cut. 
According to Jumelle, ${ }^{*}$ M. Bonnechaux has investigated many of the Brazilian forests, and the information regarding the rubber from Hevea species which that explorer has compiled is of interest to all cultivators of Para rubber. The collection of caoutchouc is mainly from species of Hevea, but certain species of Sapium are credited as yielding good latex which is frequently mixed with that from the Hevea trees.

According to Bonnechaux, the Hevea trees are to be found in groups of from 120 to 180 wild trees, mainly along the courses of the rivers. When they are numerous the average distance between two Hevea trees is about 30 steps; when less abundant, about 50 steps; and where more widely scattered the collection of caoutchouc is considered to be too difficult and laborious. The trees on one group were measured by Bonnechaux and varied from $0 \cdot 25$ to $0 \cdot 90$ metre in diameter. (1 metre =about $39 !$ inches).

Collecting operations are, according to the above authority, commenced in July when the rainy season is drawing to a close and when the rivers are low, and are continued until February. Tapping is commenced in the morning immediately after sunrise, the men making their incisions from below to a height of about six to seven feet with axes; receptacles are fixed in the bark and the latex allowed to run into them, while the tapping of other trees is continued. In other parts of Brazil the latex is collected by puncturing the bark and conducting the latex by means of the leaf stalks of Mauritia flexuosa, Mart., to the apex of a $V$, where a receptacle is placed. The receptacles have a capacity of 10 to 20 centilitres, three or four being used for trees having a diameter of $50 \mathrm{~cm}$., (19 $\frac{3}{4}$ inches). All the trees in one group are tapped on the same day, the men spending very little time in making the incisions and fixing the receptacles. The latex is finally poured and stored in a vessel made to hold from 4 to 8 litres. The men on the following day make new incisions below the old ones and continue the operation for as long as convenient.

\section{Method in the Gold Const.}

In the Gold ('oast a system rather similar to the full herringbone is often used, a series of small transverse channels opening into a perpendicular one at the base of which the latex is collected.

\section{Modelis Methods of Tapping.}

At the present time the various methods of tapping Para rubber trees may be roughly described as $(a)$ single oblique lines; $(b)$ V-shaped incisions; $(c)$ single cuts with a vertical channel joining them : when the cuts are on one side only of the vertical line, the system is often termed the half-herring-bone, and when on both sides the full herring-bone system; $(d)$ spiral curves. There are various modifications, but they are not of sufficient importance to warrant a detailed separate description.

* Les Plantes Caoutchore et Fituta, by Henri Jumelle, Paris, 1903. 


\section{Single Oblique Cuts.}

It should be explained at this point that the laticiferous tubes from which latex is obtainable in large quantities are mainly disposed internally - very near the cambium-and for the most part run through the cortex in a vertical direction.

It should also be remembered that the latex, even when most dilute, is apt to rapidly coagulate on the tree and to form scrap rubber. A cut made horizontally will not conduct the latex to a central point, and horizontal tapping is invariably accompanied by a large proportion of scrap owing to the latex trickling down the stem and drying there. A vertical channel is naturally the best for conducting the latex to a desired point, but it is as extravagant as it is unnecessary in most cases. Parkin proved that simple incisions made in an oblique direction gave about double the yield of latex as either the vertical or horizontal, the latter two showing very little difference in yield of rubber. Each oblique cut may be from one to six or more inches in length, but a distance of nearly one foot apart should be allowed. The oblique incision is practically the basis of most other methods now in use, and is spoken of as the half-spiral system when the incisions are of considerable length.

In this system collecting cups can be placed at the base of each incision, but an invention for conducting the latex from all the incisions to a central basal coil lias been brought forward, which, if adopted, will add greatly to the value of this system of tapping.

\section{INCISIONS.}

The $\mathrm{V}$ incision is nothing more or less than a duplicated or double oblique system. The sides of each $V$ may be from 2 to 12 inches in length with the apex of the $\mathrm{V}$ at the lowest point. The yield obtainable from such incisions is generally, but not always, about double that obtained from a single oblique cut, and having one centre for two incisions seems to be one of the greatest advantages of this system. The V's are usually made on the stem from the base up to a height of six feet, and are distanced about six inches apart. The open end of the $V$ is usually about six inches wide. There is, however, a great variation in the size of the cuts, the smallest incisions measuring about one inch in length.

It has been suggested that the reason why the quantity of latex obtainable is not double that from a single oblique line is because the lines are very close to one another and may draw on the same system of laticiferous tubes, a conclusion which is warranted by the results of many experiments in various parts of Ceylon. In addition to this drawback there is also another serious result which often accompanies this method of tapping, viz., the loosening of the bark on drying and tapping from the apex of the $V$ upwards. 


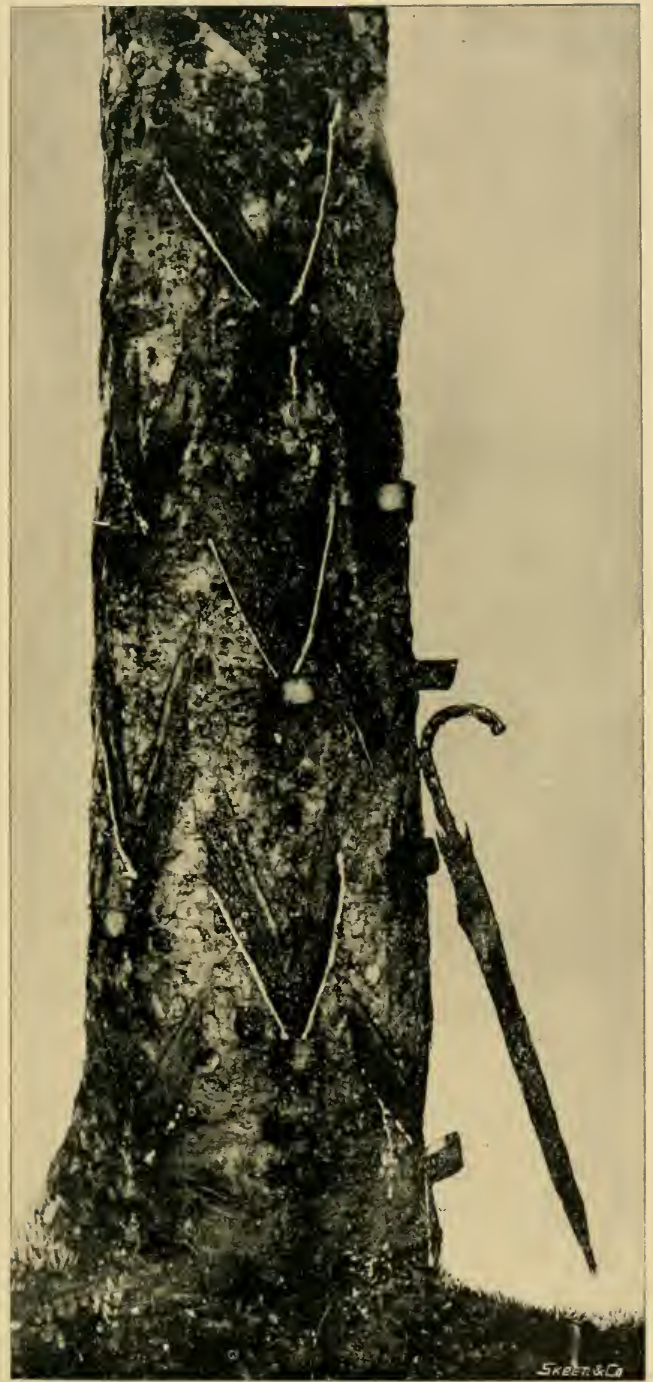

Photo by H. F. Macmillan.

V. TAPPING.

A TREE AFTER IT HAS GIVEN 2 LB, OF DRY RUBBER, 




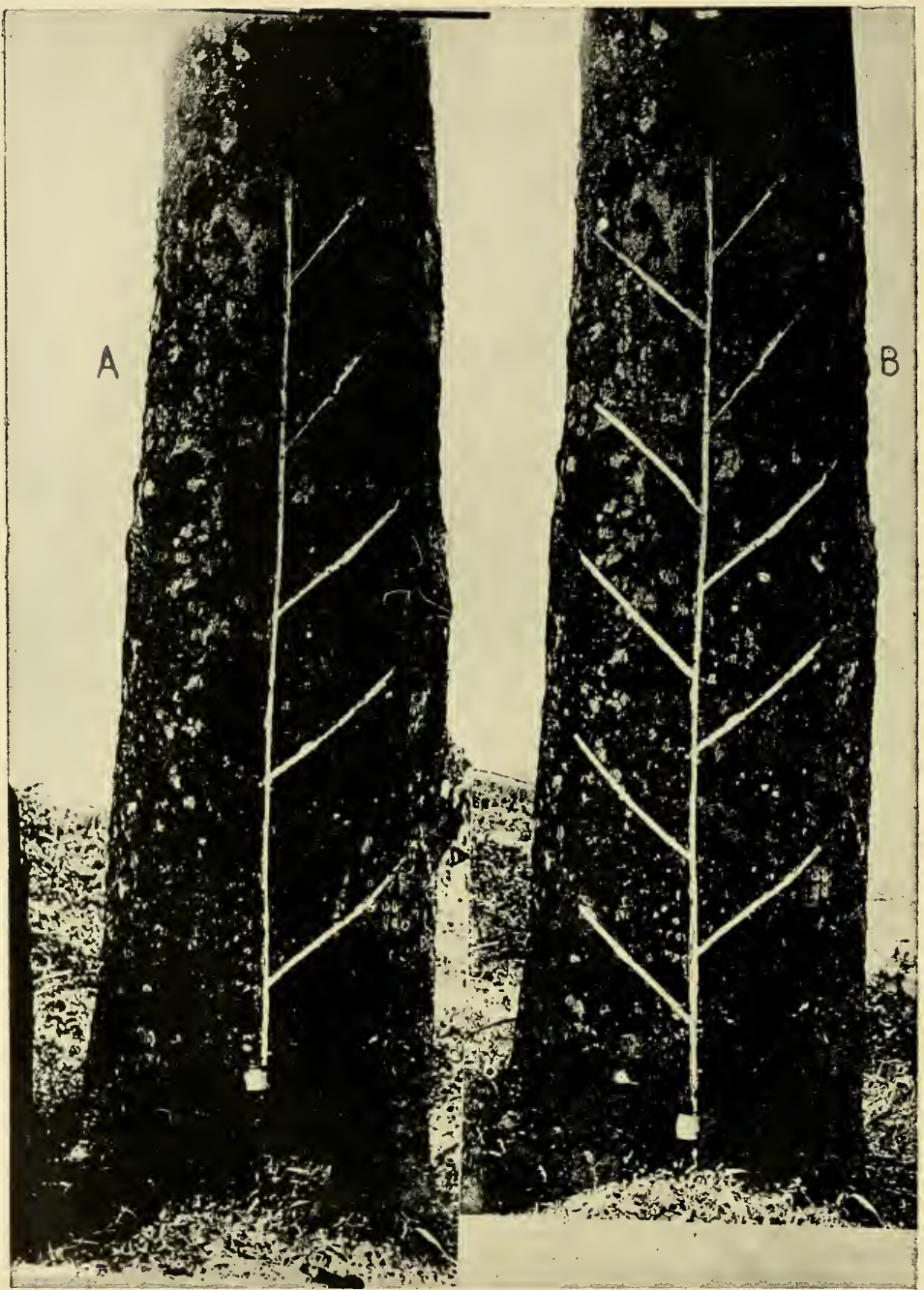

THE HERRING-BONE SYSTEM. 
It cannot be doubted that in a system of small oblique or $\mathrm{V}$ cuts a considerable amount of labour is involved in fixing and adjusting a very large number of collecting tins at the base of each incision, and though this system cannot be regarded as drastic and harmful to the tree, it is likely to be superseded by others when planters have to find labour sufficient to regularly tap large acreages of mature rubber. In the oblique or $\mathrm{V}$ incisions a chisel or paring knife is commonly used, though most of the implements previously described may be used in this system.

In the $\mathrm{V}$ method it has been noticed that when the sides of four adjacent $V$ cuts are drawing on an area of 60 to 80 square inehes, the flow of milk after two months' tapping becomes very poor. The photograph here reproduced on Plate 11, Series A, shows the V cuts after tapping for ten weeks every alternate day. There was, at the time the photograph was taken, still plenty of space between the adjacent incisions, but the flow of milk was too small to warrant further tapping. This method obviously cannot be carried out for the same length of time as the half or full spiral curves, because the oblique cuts sooner or later interfere with one another and draw on the same limited area. Four trees, tapped similar to that indicated on Plate 11 by the use of a paring knife and the spur, gave $10 \mathrm{lb} .14 \frac{3}{4}$ oz. of dry rubber from the 29th June to the 6th September, 1905.

In some countries the exudations from trees are obtained by mak. ing incisions in the form of inverted V's, but such a method has no advantage in connection with the tapping of Para rubber trees.

\section{Herring-Bone System.}

This consists of a series of short, parallel, oblique incisions connected with a vertical one ; the incisions may be on one or both sides of the vertical channel, and vary in length from about 4 to 12 inches. The illustrations on Plate 12, Series A, show both systems at the beginning. The vertical channel usually varies from 1 to 6 feet in length, and is usually sufficiently wide to conduet the latex from a dozen oblique cuts; the tin placed at the base is the only receptacle for the latex. The advantage of this system lies in the minimum labour required for collecting operations, but there are many reasonable objections against the waste of tissue which occurs when a vertical channel of considerable depth and width is made. Though it is considered to be more drastic than the foregoing method, this system is in use on several estates in Ceylon, and has at times been adopted with success by planters and officials in the Malay Peninsula, India, and Africa.

After the original oblique incisions have been made they are re-opened by paring away the lower surface, this operation being continued until the whole of the tissue between the lines is used up. Any of the knives described may be used for these operations.

When the herring-bone system is used there is no necessity to fix spouts at the base of each incision, as the latex flows down the groove in the bark. Experiments have been made with conducting channels 
composed of clay, the inner ridge being left open at the base of the incision and the outer one continuous from top to bottom in the half-herring-bone system, and both ridges open at the base of the incisions when the full herring-bone system is adopted; such a channel is easily made, it lasts for quite a long time, and in so far that it does away with the vertical cut in the bark is to be recommended.

The illustrations given here and elsewhere show trees which have been tapped on this system in parts of Ceylon and Malacca.

According to Ridley the tree has, for tapping purposes on the herring-bone system, four sides, and may be tapped along one side only during each year so that operations will be recommenced on the tapping area of $1900 \mathrm{in} 1905$. This is a very gentle method, and has much in its favour and can be used to advantage when tapping according to exposure to the sun is adopted.

The zig-zag system of tapping consists of a downward line joining two oblique cuts, on opposite sides but at different levels, and so arranged that the latex is collected at the base of the lowest incision. This system is about the only one that can be recommended for trees which, on account of previous bad tapping, have become gnarled and woody on the surface ; the downward and oblique lines can be made of any length and at any angle, and the knots thereby avoided.

It has been pointed out* that vertical incisions lay open very few latex tubes, and must in some degree have the effect of relieving the tension, and may therefore cause a reduction in the flow of latex.

\section{Northway's and Bowman's Spiral Curves.}

A third method which has, on account of the good yields obtained, gained considerable favour recently in Ceylon and elsewhere is the long spiral curve. The system consists of a series of parallel cuts rumning round the stem and each ending separately at the base of the tree; or of shorter cuts ending at convenient places. The numher of spiral cuts is determined by the circumference of the tree, there being usually one curve for every girth of 12 to 18 inches at the top of the tapping area. In this method of tapping a series of special kuives has been used which ensure the minimum waste of tissue when re-opening the lower side of the wound. As this system has given an average of $2 \mathrm{lb}$. per tree for each month's tapping at Peradeniya, and has been continued in some districts until a total of 16 lb. per tree in twelve months has been obtained, a detailed description is here given. The illustrations on Plates 13 and 19, Series A, show the stages from the beginning to the end of the first cortical stripping.

It cannot be doubted that the full spiral system is drastic, and though excellent yields have so far been obtained by its adoption it is as well to realize that the cortical stripping should not be effected

* Mr. Henri Lecomte, Journal d'Agriculture Tropicale, April, 1902. 



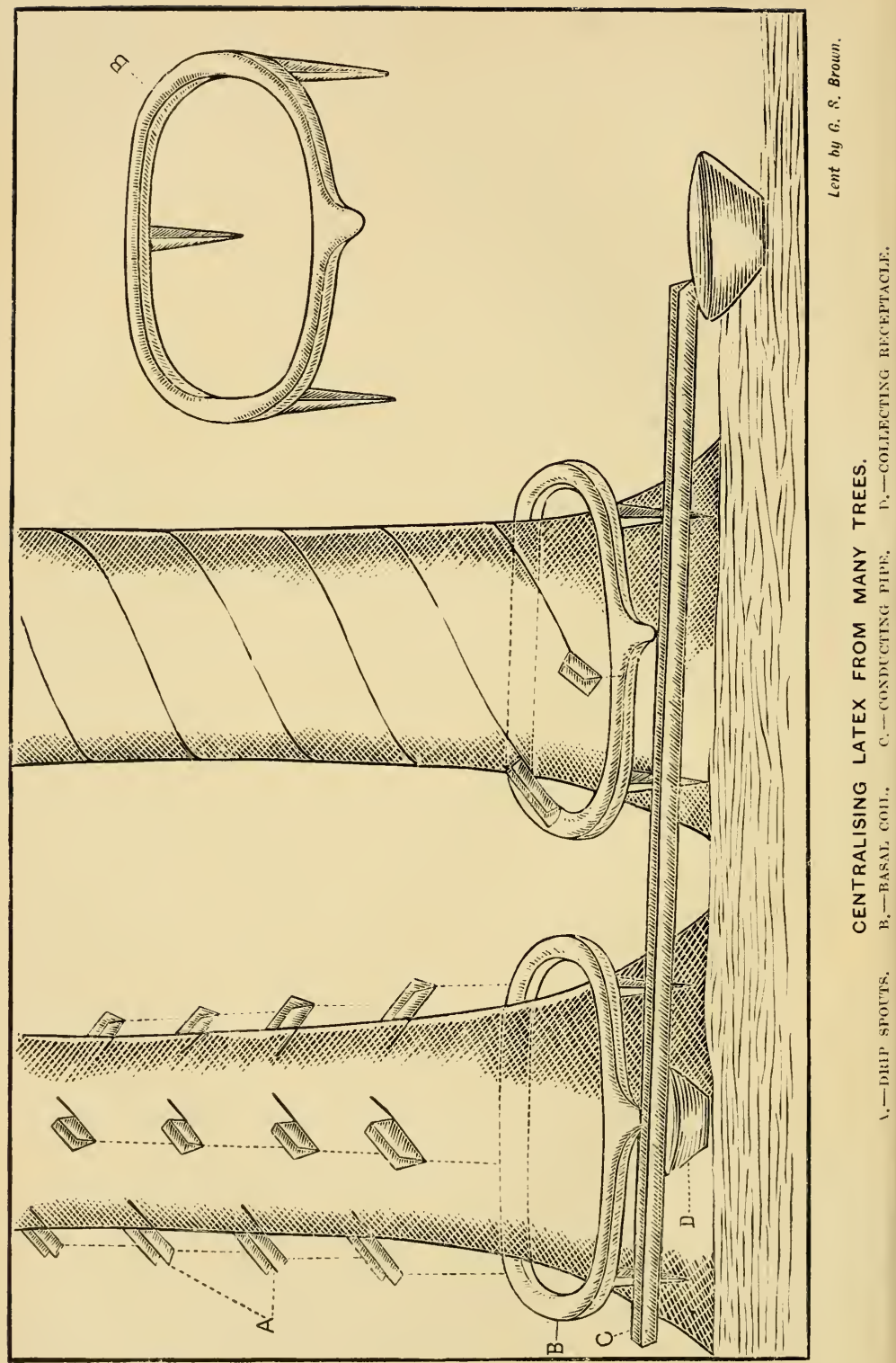


too rapidly even on old trees. It is the best system to adopt when it is intended to kill out intermediate trees on estates which are too densely planted, and can in such instances be carried out on young trees. The results obtained by this system on 10 - to 30 -yearold trees at Henaratgoda and Peradeniya are also such as to justify its adoption on old Para trees, if the operation is carried out carefully and slowly. The bark on the old trees at the places mentioned has been removed at the rate of only one inch in three months, and further improvements in the same direction are still possible.

\section{The Spiral System at Peradeniya and Henaratgoda.}

The spiral system has, in addition to all the foregoing methods, been tried at Peradeniya and Henaratgoda with fairly satisfactory results. It will be seen that the yields obtained at Peradeniya are not as large as those reported from other parts of the island, and the results at Henaratgoda are good considering the number of times the trees have been tapped. The results obtained by different systems at Henaratgoda are given elsewhere, and from them the reader may make his own deductions. The half or full spiral system allows one to systematically tap the tree from above downwards for one or more years, and to repeat the same operation when convenient. Any system of tapping, which allows the cooty to go over the whole of the bark tissues on a regular plan, is to be preferred to the old $\mathrm{V}$ or single short cuts.

I am indebted to Mr. F. Crosbie Roles, Editor of the Times of Ceylon, Colombo, for the following description of the method as carried out on a well-known rubber property in the south of the island :-

\section{The Method of Cutting.}

"The first cuts are made each a foot above the other, and in the case of a tree 18 inches in circumference the groove would go nearly round the stem. For trees 30 inches in circumference two lines of cups on opposite sides of the tree would be required, and a tree 54 inches in girth would take three lines of cups. The first cut is made with a knife used much like a plane; and the second knife is used thereafter day by day for paring off the edge of the groove originally made. One month's tapping with the original knives made the groove two inches wide, so that the whole bark area would be cut away in the course of the year's work, assuming that the tapping were carried on throughout the year in alternate months. The cutting face of No. 2 knife, however, has been reduced to the 16 th of an inch. This reduces the bark area cut away in a month from two inches to one inch. A third instrument has been invented for use in this process. It is in the form of a circular pricking instrument, which is used to penetrate to the cambium at the edge of the previous cut. This is done alternately with the cutting and is believed to free the inner bark from any accumulation of latex. 


\section{The Yield From Such a Method.}

"This method was systematically begun in October, 1904, and the group of trees has since averaged over $2 \mathrm{lb}$. of rubber per tree for each month's tapping, and those trees which have been tapped hardest have produced $16 \mathrm{lb}$. each in twelve months. Although these trees, like the rest, were tapped in alternate months at first with rest in November and January, they were continously tapped from February, right through the drought, up to early in June. Then it was found that the yield was falling off, and they were rested for some time. Tapping was recommenced in September. None of them show signs of drooping, and as further token that new and handsome figures in Ceylon yields are not confined to a few trees, records were produced which showed that the whole of the 255 trees on the estate of tappable age had yielded an average of $4 \mathrm{lb}$. per tree in the eight months, without the trees being harassed. A platform is to be erected round some of the trees for tapping higher up; and an average yield of $3 \mathrm{lb}$. per tree is expected at from 6 feet to 10 feet from the ground."

The illustrations on Plates 15 and 18 show at a glance the method adopted; and the results obtained, both by the inventor and at Peradeniya, will arrest considerable attention among all cultivators of Para rubber.

\section{The Collecting and Storing of the Latex.}

Having briefly indicated the general principles of tapping implements and operations, it now remains for us to consider the more special contrivances and methods adopted in the process of collecting the latex.

\section{A Protector.}

Mr. A. H. Bury, Ceylon, has devised an apparatus to protect the collecting cups during tapping operations from rain and mechanical impurities. "The protector is to consist of a zinc collar round the trunk of a rubber tree, sloping slightly downwards at an angle approaching 45 degrees. The protector will have a centre edging of felt, fitting on the tree so as to eatch any moisture running down it and allow it to drain off the roof over the latex cup. It will also fasten with a stud fastening, in the same way as an ordinary collar, only there will be several holes on the one end of the collar that fastens over the other, so as to allow of the same sized collar being attached at various times to trees of different girth."*

\section{Centralizing the Latex from many Trees.}

On most estates the latex is collected from separate incisions on a tree or from individual trees, an arrangement which will require a very large labour force when large acreages come into bearing. If the trees are regularly planted and the slope of the ground is favourable, 


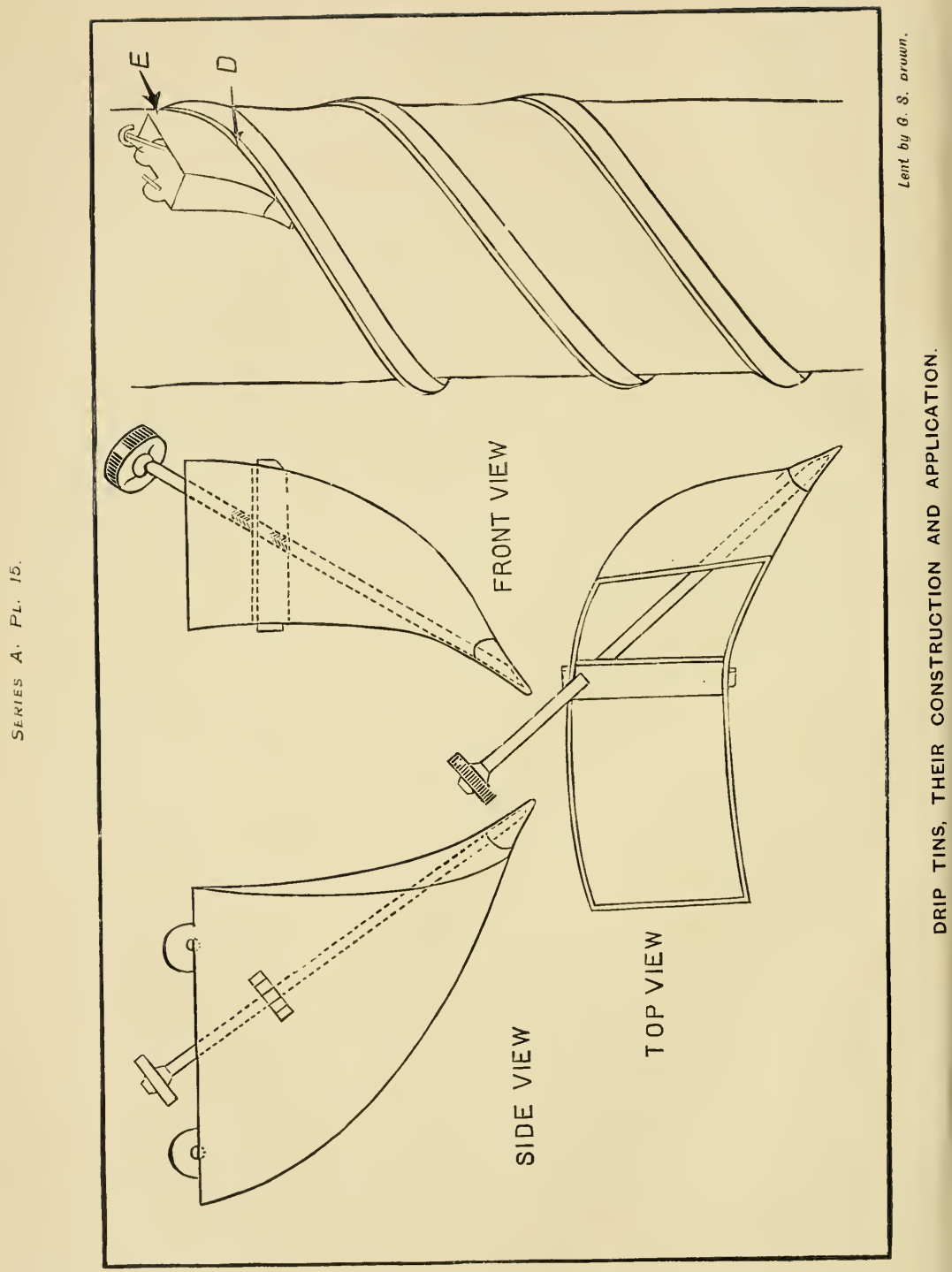



SERI ES A. PL. 15A.

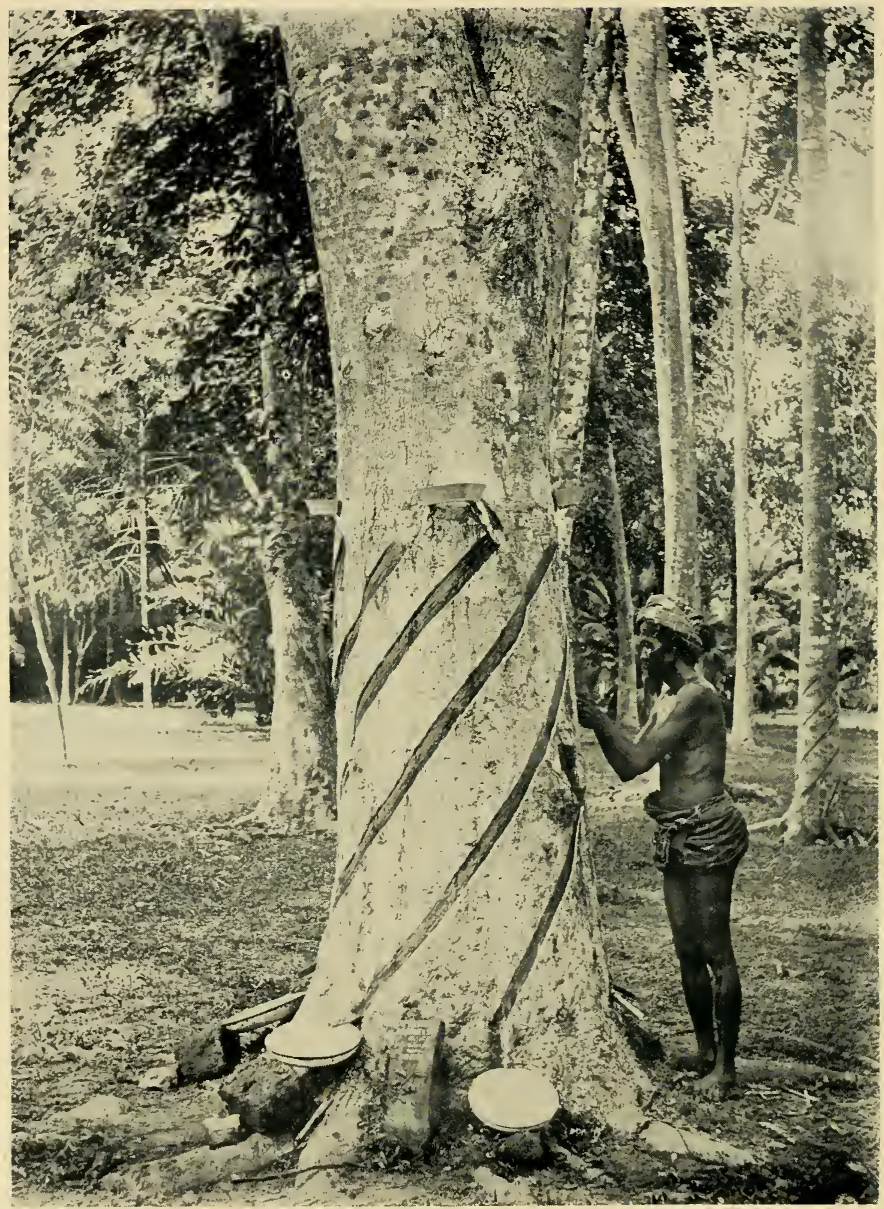

Photo by luor Etherington.

DOUBLE AND MULTIPLE DRIP-TINS.

ONE DRIP-TIN FOR TWO OR MORE TAPPING LINES. 
there seems to be no reason why a much simpler arrangement for collecting the latex from all or a large number of the treas should not be adopted.

A method has been brought forward which has for its object the collecting of the latex from an indefinite number of incisions in one or more trees and conveying it to a common centre, a method which affects the question of labour on large estates. Its complete success depends upon keeping the latex in a liquid condition for a period of time which varies according to the distance over which the latex has to be transmitted. The invention is applicable to the $\mathrm{V}$, single oblique, half and full spiral methods of tapping, and in part is applicable to other systems. By favour of Mr. Brown, the system is here briefly outlined.

Numerous drip spouts made of suitable material are fixed to the base of each incision; the spouts are grooved and of unequal length and are so positioned on the stem as to allow the latex to drip from the upper into the lower spout and finally into a basal coil at the bottom of the tree. The basil coil is grooved and goes completely round the stem at the bottom, and is provided with legs adjusted so as to tilt forward on one side and so allow the latex to escape at a lip or through a hole into a receptacle or ocnducting channel beneath. By these means it is claimed that the latex from a very large number of trees can be brought to one point, a great advantage in collecting latex from widely distant trees. The accompanying illustration, on Plate It, Series A, shows the arrangement of the vario us parts.

\section{Drip-tins : theIr CONSTRUCTION AND ACTION.}

It is well-known to most planters who are tapping Para rubber trees that the latex as it issues from a newly-made incision may vary much in consistency, sometimes being very watery and flow ing freely, at other times being too thick to trickle along the lines prepared for it. In high tapping the latex may have to traverse a distance of over twenty feet along the stem before it reaches the receptacle at the base and in many instances nevier succeeds in being collected except as scrap rubber. Furthermore, the latex during the periods of drought does not run as freely as when the. moisture conditions are more favourable.

In all such instances the latex tends to coagulate on the tree and is subsequently collected as scrap. An attempt has been made to overcome this difficulty on an invention patented by Brown, called the drip-tin. This consists of a receptacle made to hold a known quantity of water and ammonia or water and formalin. It has a concave surface to fit the convex outline of the tree and is fixed to the bark by means of pins. At the base it is drawn out to a fine point, which, when the drip-tin is adjusted, is in contact with the tapping area on the stem. The point is provided with an ingenious screw arrangement by means of which the drops of liquid allowed to issue can be regulated according to requirements. The apparatus is placed at the top of each incision, and as soon as the tree 
has been tapped the drip is allowed to commence. By these means the latex is to a great extent prevented from drying up on the stem and is carried rapidly towards the base; the latex tubes not being blocked by the coagulated substances continue to give forth the latex for a long period. It is claimed that this invention will greatly reduce the amount of scrap, and that the laticiferous tubes are more nearly emptied by its adoption.

It is certainly an advantage to be able to secure, when necessary, the latex in such a state that it will remain in a liquid condition until the formalin or ammonia is driven off. The accompanying sketches are, by favour of the patentee, here reproduced on Plate 15.

The above refers to the more complex type of drip-tin, but several others designed on an improved and simpler plan and more suitable for coolies have already been made by the same patentee.

\section{Keeping the Latex Liquid and Settling Tanks.}

On small estates where few and widely-scattered trees are being tapped the planter is often compelled to resort to the production of rubber on a small scale; this frequently involves a daily repetition of the same process and much petty hand labour. The latex can, however, be kept in a liquid condition for several days or even weeks, without doing any harm to the finished product, and the rubber can be manufactured on a big scale when a sufficient quantity of latex has been accumulated.

The latex can be kept in the liquid condition by the addition of ammonia, formalin, sodium carbonate, and any alkaline chemical which is readily soluble in cold water. It is better to use either ammonia or formalin and to avoid any of the mineral salts; the former can be readily removed and may even escape on exposure to the air in the ordinary processes of manufacture.

In one invention, patented by Brown, the latex is kept in covered settling tanks supplied with (1) a drip-tin apparatus filled with chemicals to retain the milk in an alkaline condition, and (2) with a paddle to keep the latex in motion. If a receptacle containing ammonia is exposed to the air, the reagent will evaporate and the latex coagulate within a few days. If, however, the receptacles are covered or sealed, the ammonia cannot easily escape and the latex can be accumulated in a liquid state indefinitely.

Formalin has a similar effect, as it stops putrefaction and therefore prevents the development of acidity. The ammonia probably neutralizes the acids as they are formed and thus maintains the latex in an akaline or neutral state, and thereby prevents the precipitation of the proteid matter. By the use of such reagents and apparatus a great saving of labour may be effected.

The Editor of the India Rubber Journal has recently reviewed a translation of a privately circulated French pamphlet, on the subject of exporting the latex in a liquid condition in order to allow the manufacturer to prepare his materials at the first coagulation. 
Northway's and Bowman's System of Marking the Trees.

The system consists first in marking out the grooves at the correct distance and angle they are to be cut during tapping. This is effected by means of a guide in the shape of a right-angled triangular piece of tin, the side subtending the right angle being $2 \mathrm{ft}$. in length, and the other sides $17^{\prime \prime}$ by $17^{\prime \prime}$. The hypotenuse is the line along which the trees are marked, one of the 17" sides being arranged vertically before marking is commenced.

The grooves to be cut along the sloping side or hypotenuse of the triangle will then be at an angle of 45 degrees to the base, each groove $2 \mathrm{ft}$. long and at intervals of one foot, starting one foot from the base of the tree, up to a height of $5 \mathrm{ft}$., and all leading into a vertical channel running down to within a few inches from the ground-level. A small tin spout is inserted at the lower end of the vertical channel to convey the latex into the tin vessels, which are placed on the ground near the tree. The tin spout is left in position permanently, thus obviating the necessity of constantly inserting cups into the bark and removing them, and at the same time avoiding injury to the tree. In the case of a tree $18^{\prime \prime}$ in circumference, the grooves would go nearly once round, and therefore for trees of this size there would be one vertical channel to convey the latex flowing from the several spiral cuts into the tin receptacle, and only one of the latter would be needed. A tree $36^{\prime \prime}$ in circumference would require 2 vertical channels on opposite sides of it, and correspondingly a tree 54" in circumference would take 3 vertical channels, each leading into a tin receptacle placed on the ground as previously stated. To suit trees of various sizes and yielding capacities, the grooves can be made longer or shorter as may be found necessary or convenient. One month's tapping with certain knives would carry the grooves down about one inch, so that tapping on and off, one month at a time, the whole space between the top and bottom grooves would be covered in the course of two years' work. The operation is carried on continuously, so that at the end of each period of two years only the original top cut would have to be re-tapped, the lower cuts being made into the sections below when the bark tissues have been completely renewed.

Mr. Francis Holloway has also given me particulars of his method of marking the trees. A long rod, marked off into feet, is placed against each tree. A sheet of zinc or tin cut at a certain angle (about $45^{\circ}$ ), fits at one end into the rod, and can be moved up and down as desired. The remaining part of the zinc or tin ribbon is then wound round the tree and the markings made. The rod, being marked into distances of one foot, can be used at any height on the trunk, the spaces between the oblique tapping markings heing in every case parallel and distanced one foot from each other. This plan can be adopted for marking out spiral curves or oblique incisions, and is therefore applicable to the herring-bone system. 
Collecting Tins.

Tin or iron receptacles for collecting the latex are not so good us enamelled ones or those made of aluminium, as they are apt to corrode on exposure and to lead to a discolouration of the rubber, when the latex contains large quantities of tannin. In all methods, except the herring-bone and spiral systems, it is necessary to fix the tins on the trees and therefore to have some sharp point to press against the bark for fixing. Where the herring-bone or spiral systems are in vogue, a permanent channel is fixed at the base of each line and the tins placed on the ground immediately under the channel ; the latter arrangement is found to be economical. 


\section{CHAPTER VII.}

WHERE TO TAP.

Occurrence of latex in parts of the plant-Rubber from young parts of trees-Tapping virgin and wound areas-Wound response and increased yields at Peradeniya, Java, and the Straits-Interval between successive tappings and wound response-Arden's resultsClotting of rubber in convex wound areas-Method of formation of Para inilk tubes-Best yielding areas-Results of experiments from the base upwards in the Straits and Ceylon-Illustration showing tapping from 6 to 16 feet and base to 50 feet at HenaratgodaYields obtained from various levels at Henaratgoda.

$T^{T}$ is well-known that in the Para rubber tree the latex occurs in 1 all parts of the stem and branches and in the leaves. But the quality and quantity of the latex in the leaves, young twigs, and branches are such as to render the collection from these areas unremunerative. The more or less successful production of guttapercha from leaves led many to anticipate that rubber might be obtainable from the foliage and young twigs of Hevea brasiliensis. "The latex in young stems* and leaves does not freely ooze out and mix with water, but clots 'where it exudes in little lumps, which cling to the broken pieces of stem." The rubber from these tissues is adhesive and has less elasticity and strength than the rubber from the trunks of mature trees. It may be safely asserted that the collection of latex from this species must be made from the stem, and in some cases perhaps the main branches, and that all other parts may be neglected as sources of paying quantities of marketable rubber. In practice it is easier to tap the stem from six feet downwards than any other part, though the erection of stands, scaffolding, and the use of ladders for tapping higher parts of the stem and thick branches has been tried with successful results. Estates are known where rubber in paying quantities has been obtained from six to twenty feet, but tapping above six feet is not generally adopted. The fact that a maximum of 10 to over $20 \mathrm{lb}$. of rubber per tree has been obtained from the lower part of the stem alone within twelve months from commencing tapping operations makes it very doubtful whether tapping of less accessible parts will come into general force. The strain on the plant to heal the wound area from six feet downwards is quite as much as it need stand. 
Furthermore, it must be remembered that the maximum quantity of latex and rubber may be obtained not so much by tapping virgin areas as by taking advantage of the wound response and pricking or cutting the laticiferous tubes when they contain the maximum amount of latex.

\section{The Wound Response.}

It has been stated that native collectors of Para rubber do not attempt to collect the latex from the first incisions, and that a quantity capable of being collected is only obtained after two or more tappings in approximately the same area. It is certainly not advisable to make the first incision so deep that a good flow of latex is obtained at once; only small quantities of latex should be expected from the original incisions. The first cuts can be deepened as necessity determines in subsequent tapping operations. The flow to the injured part increases gradually, and may reach the maximum after three to fourteen tappings, after which it is said to decline if the wound area is continuously tapped. The first reliable results were obtained by Willis and Parkin, and as the "wound response" is now recognized as one of the most important principles in determining the frequency of tapping, the following digest of Parkin's results is given :-

\begin{tabular}{|c|c|c|c|c|c|c|c|c|}
\hline \multicolumn{2}{|c|}{$\begin{array}{l}\text { Number of } \\
\text { Tappings. }\end{array}$} & \multicolumn{2}{|c|}{$\begin{array}{l}\text { Number of } \\
\text { Incisions. }\end{array}$} & & \multicolumn{2}{|c|}{$\begin{array}{l}\text { Date of } \\
\text { Tapping. }\end{array}$} & \multicolumn{2}{|c|}{$\begin{array}{c}\text { Yield of } \\
\text { Latex in c.c. }\end{array}$} \\
\hline lst & pping & .. & 40 & .. & March & 25 & .. & $61 \cdot 0$ \\
\hline 2nd & , & . & 40 & .. & & 30 & .. & $105 \cdot 5$ \\
\hline $3 r d$ & , & . & 40 & .. & April & 6 & . & $220 \cdot 0$ \\
\hline 4th & ," & . & 40 & . & , , & 12 & . & $208 \cdot 5$ \\
\hline 5 th & , , & . & 40 & .. & ,, & 15 & .. & $255 \cdot 5$ \\
\hline 6th & ," & .. & 40 & .. & ,: & 20 & $\ldots$ & $290 \cdot 0$ \\
\hline 7th & ,, & . & 40 & . & ,", & 25 & . & $276 \cdot 0$ \\
\hline 8 th & , , & $\cdots$ & 40 & .. & May & 1 & .. & $253 \cdot 0$ \\
\hline 9 th & , , & . & 40 & . & , & 6 & . & $264 \cdot 5$ \\
\hline 10th & , , & $\cdots$ & 40 & . & , & 13 & . & $275 \cdot 0$ \\
\hline 11th & ,, & $\cdots$ & 40 & . & ,, & 20 & . & $255 \cdot 0$ \\
\hline 12th & , , & . & 40 & $\ldots$ & , , & 26 & . & $262 \cdot 0$ \\
\hline 13th & , & $\cdots$ & 40 & .. & June & 1 & $\cdots$ & $328 \cdot 0$ \\
\hline 14th & , & . & 40 & .. & ," & 6 & $\cdots$ & $449 \cdot 0$ \\
\hline
\end{tabular}

The increase in yield from 61 to 449 c.c. of latex by repetitional tapping in approximately the same area is little less than wonderful, and it now remains to determine the interval which must be allowed between successive tappings. The wound response is not evident twelve hours after tapping, but within twenty-four to forty-eight hours is decidedly obvious. These results suggest the advisability of every planter carrying out his own experiments to determine whether it is better to tap every day for the half of each month, alternate days during each month, or only during certain months. Tapping every day, either for the whole of the months when rain is abundant or only during alternate months, has already given 
excellent results on a large scale on several estates in Ceylon. The nature of the origin of the latex tubes in Hevea brasiliensis accounts for the variation in yields from the same area; the tubes require a certain time to complete their formation, and for this reason areas which do not yield any latex on particular days may give abundant flows subsequently, when the processes of perforation and decomposition are sufficiently advanced.

In Java, Haas* has proved that wound response occurs in the Para trees in that island. He also points out that an increase in the number of incisions increases the yield of rubber, but not in the same proportion, and states that an increase of 25 grammes of rubber per square metre of tapped surface is only obtained after more than doubling the number of incisions.

\section{Wound Response in 24 Hours.}

Arden concluded from the following experiments that the length of time which should elapse before re-opening incisions need only be 24 hours, and that tapping every alternate day instead of daily was not always advisable. The following were his results :-

60 incisions made on six consecutive days gave $99 \frac{1}{2} \mathrm{oz}$. wet rubber.

60

60 ", ," , , one week ", 104 ", ,

In the Peradeniya experiments where the spiral system has been used, it has been noticed that the renewed cortical tissue becomes more or less convex in outline. In some instances clots of rubber were found beneath the bulging areas, and from microscopic examination it was concluded that the convex outline was due, to some extent, to the abnormal rapid distension of the cells of the newly-formed tissue; the coagulated rubber seemed to arise by the bursting of the inflated tubes. This was "wound response" to a remarkable degree, and on all such areas the use of Bowman's and Northway's pricking instrument gave abundant flows of latex.

There is a certain amount of reason in tapping any yielding area of the stem and branches, on account of the peculiar manner in which the latex tubes are produced and their connection with one another. The tubes in Para rubber are produced by the breaking down of the partition walls of adjacent cells or sacs, and the final tubes may be very short or long according to the age and the number of partition walls which have been dissolved. The tubes arise de novo, and in tapping operations one does not necessarily drain the latex from all parts of the tree, but very often only from one or two inches around the incision, where latex tubes have been formed.

* Results of experimental tappings of Hevea brasiliensis, Java, 19001904, by Dr. IV. R. Tromp de Haas. (Vide Bullet in of Straits \& F. M. S., August, 1905. 


\section{Best Yielding Areas.}

Experiments to prove which is the best area to tap have been carried out by many observers. The larger flow at the base of the trunk than from higher parts has been noticed by Parkin and others in Ceylon, by Seaton in India, by Haas in Java, by Arden in the Straits, as well as by native collectors in the Amazon valley. It is on account of this that the idea of increasing the lower tapping area, by pruning the young plants and retaining a few of the basal shoots to grow into leaders in after years, is often recom. mended, for instead of one stem there might be two or three available for tapping. If only one stem is retained, it will show a large increase in circumference.

\section{Results of Experiments Regarding Quality AND QUANTITY. \\ Experiments in the Straits.}

The following experimental tappings by Burgess* indicate the quality of the rubber from different parts of the plants :-

\begin{tabular}{|c|c|c|c|}
\hline $\begin{array}{l}\text { Position of the } \\
\text { Cut. }\end{array}$ & Nature of Cut. & $\begin{array}{l}\text { Percentage of } \\
\text { Crude Rubber in } \\
\text { Latex. }\end{array}$ & $\begin{array}{l}\text { Percentage of } \\
\text { Resin in the } \\
\text { Crude Rubber. }\end{array}$ \\
\hline $\begin{array}{l}\text { A large root ex- } \\
\text { posed by removal } \\
\text { of some soil. }\end{array}$ & $\begin{array}{l}\text { Simple three- } \\
\text { inch cut. }\end{array}$ & $43 \cdot 8$ & $2 \cdot 27$ \\
\hline $\begin{array}{l}\text { 2. The main trunk } \\
1-2 \text { feet above } \\
\text { the ground. }\end{array}$ & Herring-bone. & $44 \cdot 4$ & $2 \cdot 12$ \\
\hline $\begin{array}{l}\text { 3. The trunk after } \\
\text { forking } 20 \text { feet } \\
\text { above ground. }\end{array}$ & Herring-bone. & $39 \cdot 8$ & $1 \cdot 88$ \\
\hline
\end{tabular}

"It will be noted that the latex from the higher portions of the trunk are, in the above experiments, poorer in rubber than the latex from lower down-at the same time the proportional amount of resin in the latex appears to decrease."

The following experiments $\dagger$ indicate that the lower part up to $98 \mathrm{~cm}$. ( $1 \mathrm{~cm}$. equals to $0.39 \mathrm{inch}$ ) yields considerably more rubber than the higher parts :-

Number of Incisions.

120

100

120
Area tapped.

0 to $60 \mathrm{~cm}$.

60 to $120 \mathrm{~cm}$.

120 to $180 \mathrm{~cm}$.
Yield of Latex in grammes.

$2226 \cdot 44$

$1111 \cdot 09$

$587 \cdot 43$

* Burgess in Agricultural Bulletin of the Straits \& F.M. S., May, 1904.

$\dagger$ L. Hevea Asiatique, M. Collet. 


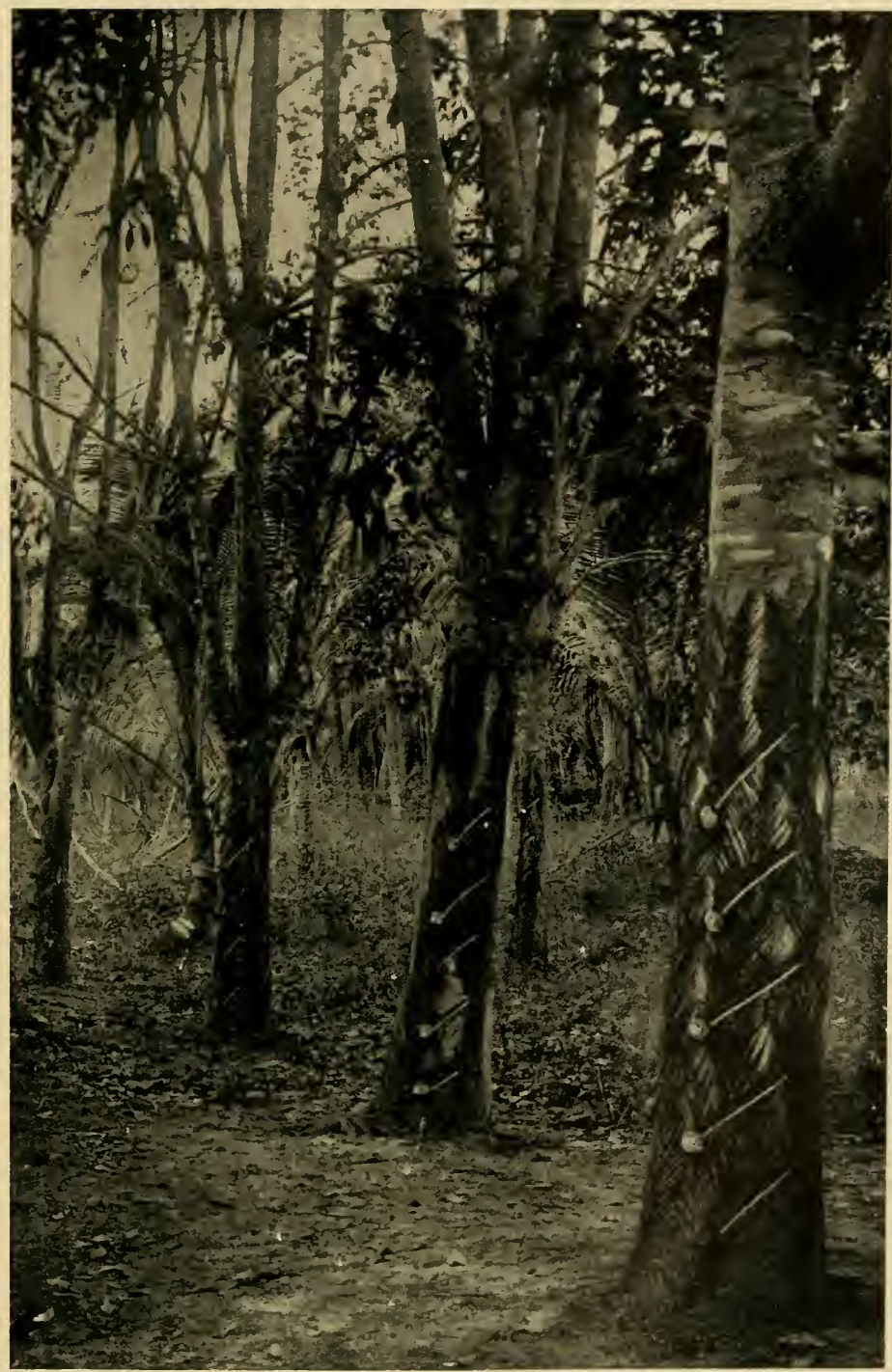

Photo by D. L. Goonewardane. 

These results show that the maximum yield, per given area, is to be obtained from the base up to a height of about five feet. Other experiments have proved that the yield from the base to three feet is considerably more than that from three to six feet.

\section{Experinents in Ceylox.}

Experiments carried out in Ceylon * strongly support the same conclusion, and the following are typical examples of the results obtained :-

Number of

Incisions.

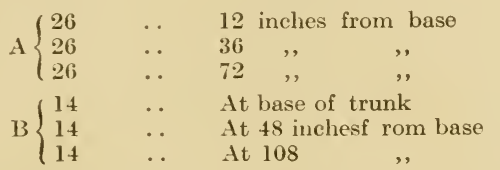

Area tapped.

Yield of

I.atex in c.c.

The conclusions which Parkin drew from his experiments were, "that there is a greater exudation of latex from wounds made at the base of the trunks of Hevea trees than at any higher region; that the exudations from one to five or six feet up the trunk differ little; and that above five or six feet the latex exuded falls off very considerably." Experiments in the Straits have shown that the first four feet from the base contain tho maximum amount of latex, but a height of six feet is allowed by many planters. It is well-known to planters in Ceylon that the quantity of latex obtained at five to six feet from the ground is little more than half that at the base of the trunk; nevertheless, a yield of over 1 to $3 \mathrm{lb}$. of rubber, per tree, is expected on eertain estates by tapping the area from six to ten feet above ground. The latex obtained from areas twenty feet from the base is often very sticky and may not yield good rubber, but this is by no means always the case. On some estates in the Ambalangoda, Kalutara, and Matale Districts the old rubber trees are said to give latex of good quality from six feet upwards.

According to Dr. Haas, the trees in Java gave the largest yield in their lower parts, and tapping up to a height of 1.5 metre gave the best results.

\section{Tappisg the Higher Parts of Trees.}

\section{Base to 50 feet.}

As previously indicated, it is possible to obtain rubber in paying quantities from parts of the stem above six feet. At Henaratgoda the trees have really never been cultivated, and many of them, though thirty years old, have never been tapped. The result is the stems are very high, and present smooth surfaces such as one would desire for ideal tapping operations. Such trees are oceasionally found

$$
\text { * Parkin, l.c., pp. } 128 \text { and } 131 .
$$


on a few rubber properties in Ceylon, the Straits, and elsewhere, but it is not likely that similar development will be allowed on rubber properties now being planted. Generally speaking, the planters who are now laying out their estates desire to obtain some return as early as possible, and their object will probably be to prevent the production of tall heavy timber trees and accentuate the growth of the lower part of the stem up to 15 to 20 feet, in order to secure the minimum girth required for commencing tapping operations.

It is for this reason that the following results should not be taken into too serious consideration, as they have been obtained from the old and previously untapped trees at Henaratgoda. In the Henaratgoda experiments the trees have been tapped at various heights: (1) from the base to a height of 5 and 6 feet; (2) from 6 to 16 feet only; (3) from 10 to 20 feet; (4) from 20 to 30 feet; (5) from the base to a height of 30 feet; and (6) from the base to 50 feet. The following are the details of the experiments and the results obtained up to date :-

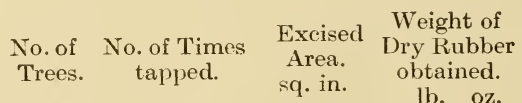

$\begin{array}{lrrrrrrrrr}\text { Base to } 5 \text { and } 6 \text { feet } & 25 & \ldots & 37 & \ldots & 12,414_{4}^{3} & \ldots & 50 & 0 \frac{7}{x} \\ 6 \text { to } 16 \text { feet } & \ldots & 2 & \ldots & 16 & \ldots & 796 \frac{1}{2} & \ldots & 4 & 10 \frac{5}{8} \\ 10 \text { to } 20 \text { feet } & \ldots & 2 & \ldots & 16 & \ldots & 1,472 \frac{1}{2} & \ldots & 6 & 9 \frac{1}{4} \\ 20 \text { to } 30 \text { feet } & \ldots & 2 & \ldots & 16 & \ldots & 1,424 \frac{3}{3} & \ldots & 4 & 11 \frac{1}{2} \\ \text { Base to } 30 \text { feet } & \ldots & 1 & \ldots & 23 & \ldots & 1,666 & \ldots & 4 & 6 \frac{3}{8} \\ \text { Base to } 50 \text { feet } & \ldots & 2 & \ldots & 8 & \ldots & 2,726 & \ldots & 3 & 4_{4}^{1}\end{array}$

The higher parts of such trees can be tapped alternately with the lower parts, but how long this can be continued it is impossible to say at the present time. The illustrations on Plate 16, Series A, show one specimen tapped from the base to a height of about 50 feet, and another being tapped from 6 to 16 feet from the base.

The amount of labour involved in tapping such large areas on a large number of trees is beyond comparison with that required for the ordinary basal and more accessible tapping. 
1.

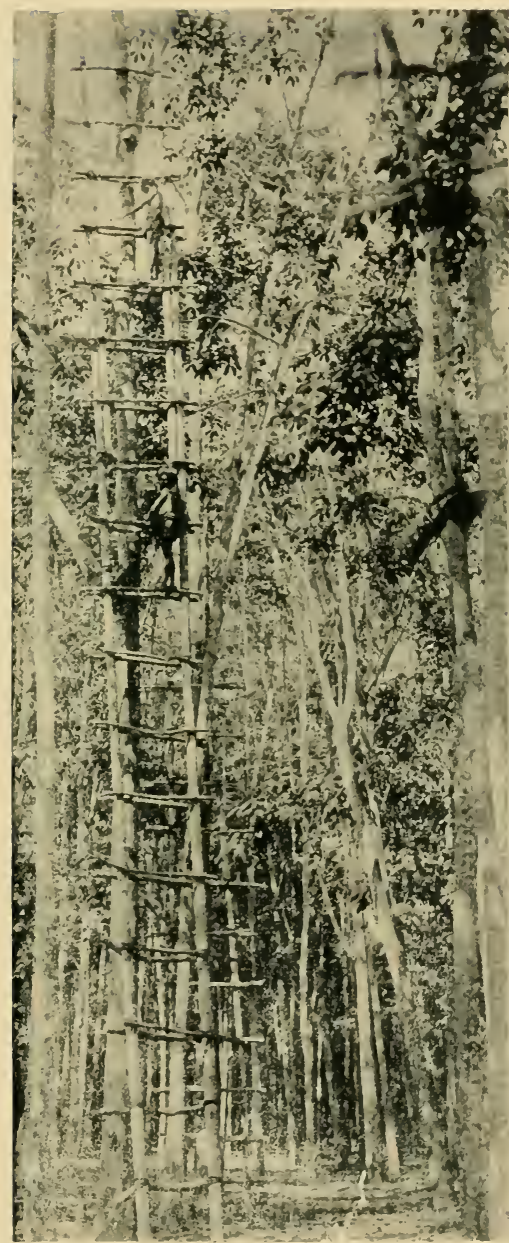

2.

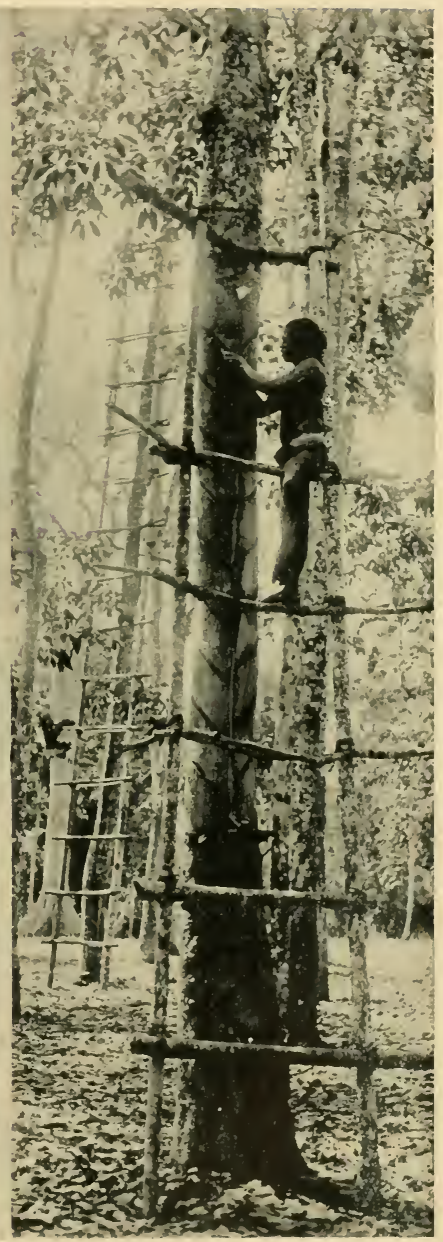

Photo by H. F. Macmilla\%. 

CHAPTER VIII.

WHEN TO TAP.

Age or size as rritcrion-Resin in young trees of Castilloa RubberAnalyses of rubber from 2,4,6,8,10-12, and 30-year-old Para rubber trees-Two-year-old tree illustrated-Age of tapping trees in the Straits-Age of tapping trees in Malacca-Age of tapping trees in Ceylon-Age and size considered-A manufacturer's opinion of rubber from 8-year-old trees-Minimum size for tapping-How to inerease the tapping area illustrated-Measurements of forked and straight-stemmed trees at Henaratgoda-The best season for tapping-Atmospheric conditions and the flow of latex-Results in Ceylon. Java, F.M.S.. \& .-Latex flow during the leafless phase - Use of ammonia and formalin-What part of the day to tapYields in morning and evening-Compass tapping-Frequency of tapping and results at Henaratgoda.

$\mathrm{T}$ discussing this part of the subject it is necessary to take into 1 consideration the age and size of the tree, so as to determine when it may be tapped for the first time.

Several hotanists have argued the question, and as it is one which concerns the quality and quantity of the latex and the dimensions and physical condition of the tapping arca, it needs to be considered carefully.

\section{Importance of Age.}

Ule and Seeligmann state that in the Amazon District the tree requires 15 years to come to tapping maturity in open plantations and 25 years in the forest, and one cannot help concluding from this statement that either the cultivated plants in the East thrive much better in their land of adoption than the wild ones in their native habitat, or that the colleetors are less eager to commence tapping operations in the Amazon District than in Ceylon and the Straits.

Cross stated that in Para the trees were tapped if they had a circumference above 18 or 24 inches, the operations being carried out until the trees were killed. On plantations in the Fast such dimensions may be attained in four to six years.

Trimen, in 1884, believed that the trees in Ceylon should be ten years old before commencing tapping operations.

Johnson is of the opinion that the size, and not the age, of the tree indicates when it can be safely tapped, and that tapping may be commenced when a tree has a girth of 20 to 24 inches a yard from the ground. 


\section{Analyses of young Castilloa Rubber.}

If one studies the many analyses of Castilloa rubber quoted by Weber and the publications of the West Indian Botanic and Agricultural Departments, he cannot help being struck with the fact that the quality of the rubber from Castilloa trees depends, in almost every case, on the age of the trees. In some cases the rubber from old trees is shown to contain 82.6 per cent. of caoutchouc and $7 \cdot 4$ per cent. of resin. The rubber from four-yearold Castilloa trees has been shown to contain $64 \cdot 1$ per cent. of resin as against $8 \cdot 2$ per cent. for twelve-year-old trees.

The importance of age is further exemplified by analyses showing a gradual decrease in percentage of resinous substances, which occurs with an increase in the age of the part of the Castilloa tree from which the rubber is obtained, the young twigs yielding $5 \cdot 8$ per cent., the large branches $3 \cdot 77$ per cent., and the main trunk only $2 \cdot 61$ per cent. of the resinous bodies. If the rubber contains a very high percentage of resins, it is usually considered inferior, and is in some cases almost useless. Increase in age is certainly to bc associated with an improvement in the physical properties and quality of the rubber, whether one considers plantations of different ages or parts of the same tree.

$$
\begin{aligned}
& \text { Analyses of Para Rubber frou different aged Trefs. }
\end{aligned}
$$

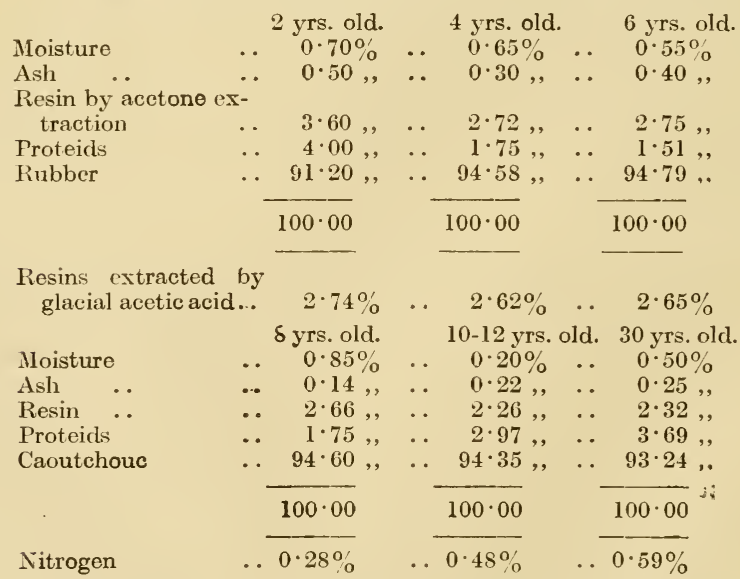

The above analyses* show the chemical composition of Ceylongrown Para rubber prepared from trees varying in age from 2 to 30 years. It will be noticed that the two-year-old rubber does not differ conspicuously from the older mature rubber. The analyses represent

* Committee of Agricultural Experiments, Peradeniya. M. Kelway Bamber. 


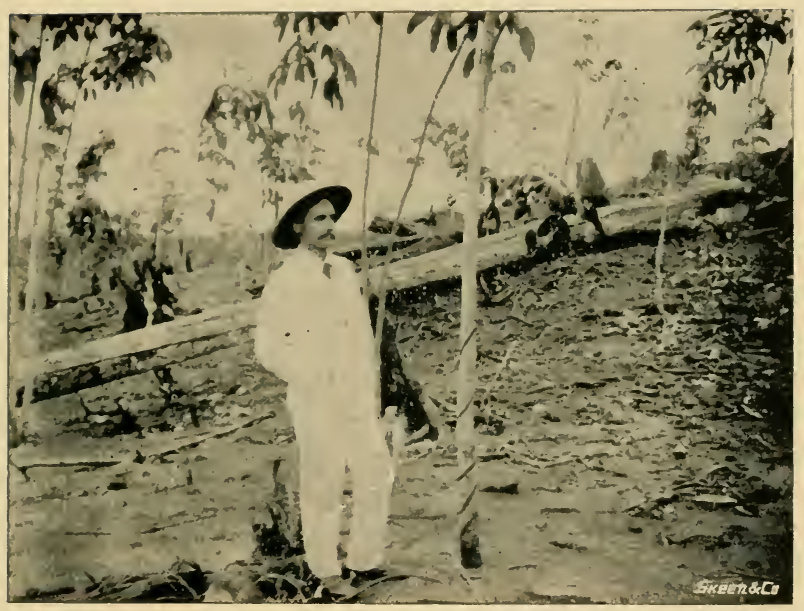

Photo by M. Kelway Bamber.

PARA RUBBER IN CEYLON.

A.MBALANGODA DISTRICT.

Two-Year-Old Para RubBer Trees. 
the composition of only one series of samples, and should not be taken as showing the constant composition of rubber from trees of the ages quoted. The rubber from two-year-old trees was sticky, and snapped when slightly stretched; it was obviously unfit for sale. The illustration on Plate 7 , Series $\mathrm{D}$, shows the tree from which the rubber was obtained, and it is perfectly clear that the available tapping area on such trees is very small.

Parkin proved that the preparation of good rubber from young stems and leaves of Hevea brasiliensis was an impossibility, and other observers have shown that rubber from young trees is adhesive and lacks the required elasticity and strength ; nevertheless, it is still the subject of much discussion as to whether age is the only criterion for cultivators of Para rubber in the East.

Stanley Arden has shown that in parts of the Straits the rubber from trees 31 to 4 years old is decidedly inferior. His results have been quoted in the section dealing with "Yields of Rubber," and it is only necessary to point out that the yield from trees up to four years old was exceedingly small, and that rubber in paying quantities was only obtained when the trees were about or over seven years old. He calculated that by the time the trees in the Straits are six years old, 75 per cent. should give an average yield of 12 ounces.

On certain Malacca rubber properties the Para rubber trees, even though catch crops have been taken off the ground during the first few years, attain in four years a circumference of 18 inches, and in seven years 35 to 40 inches. These trees are planted 15 feet apart and can be tapped after the fourth year.

Samples of Para rubber from four-year-old trees have, however, been depreciated in certain quarters, and in one case they were classed as being similar to common African* sorts for hardness, but superior in cleanliness. They were described as being soft, and would not stand much working on the machine, and the value put upon them was only equal to that for "Congo ball or a similar quality of African."

\section{Ace and Size.}

With regard to our experience in Ceylon it should be pointed out that under favourable circumstances the Para rubber tree will show an increase in circumference of about 4 to 5 inches per year up to the first six or eight years, and that though the rubber from two to six-year-old trees is adhesive, and may have a high percentage of resinous compounds, it is by no means always the case. The analyses of Para rubber from 2, 4, and 6-year-old trees have been previously given, and though the results cannot be accepted as conclusive, it was pointed out by Mr. Kelway Bambert that the rubber did not possess a very high percentage of resin, and in this respect was certainly quite contrary to what Weber and others have observed in the rubber from young Castilloa trees. But when one considers

* India Rubber Journal.

$\dagger$ Committee of Agrieultural Experinents, Peradentya. M. Kelway Bamber. 
that the rate of growth of the Para rubber tree in Ceylon is such that a circumference of 20 inches cannot be attained much before the fourth, fifth, or sixth year, it is obvious that, under ordinary methods of cultivation, all ideas of extracting rubber from trees under these ages should not be encouraged.

One manufacturer is reported* as saying that the rubber does not attain its full strength until the tree is at least 8 or 9 years old, and material from younger trees "has not the the strength of hard cure Madeira fine Para, and is uneven in strength." It is also asserted that there is no difference noticeable in the rubber from 8-year-old trees from different plantations, but it is not yet safe to use it for the finest work, such as thread and the best bladders.

\section{Minimum Size for Tapping.}

If the tree has a circumference of much less than 20 inches, tapping cannot be recommended, because the available tapping area is too small. The production of new tissue would be a strain on the young plant, and the thin bark tissues would probably be quickly cut away long before the desired quantity of rubber had been obtained.

The illustration on Plate 7, Series D, clearly indicates this. If the circumference is anything above 20 to 24 inches, a yard from the ground, and the tree is four to six or more years old, it can, in Ceylon, be lightly tapped. I have seen good rubber from such trees. A tree 24 inches in circumference cannot have more than two spiral curves for tapping.

On one estate in Ceylon $4 \mathrm{I}$ trees of considerable height, but having a circumference of from 18 to 25 inches a yard from the ground, gave with very light tapping during liarch and April $19 \frac{1}{2} \mathrm{lb}$. of dry rubber, which was favourably reported upon in Europe.

From the foregoing remarks it is clear that the question of the available tapping area at a given age must be considered; it is as important as the age of the trees. A ninimum circumference of 20 inches, a yard from the ground, and a minimum age of 4 to 6 years can be accepted for most rubber properties, the better developed trees being tapped first.

\section{How to increase the Tapping Area.}

The foregoing statements refer to trees of known ages that have attained the minimum circumference when allowed to develop very long and slender stems. But it has been previously remarked that by pruning the trees at a certain stage the plant may be made to increase in girth at the expense of the longitudinal growth, and a very striking illustration is to be seen in the first clump of old Para rubber trees in the Henaratgoda Garden. The dimensions of forked and straight-stemmed trees on various estates in Ceylon have been previously given.

\footnotetext{
* India Rubber Worid, December, 1905.
} 



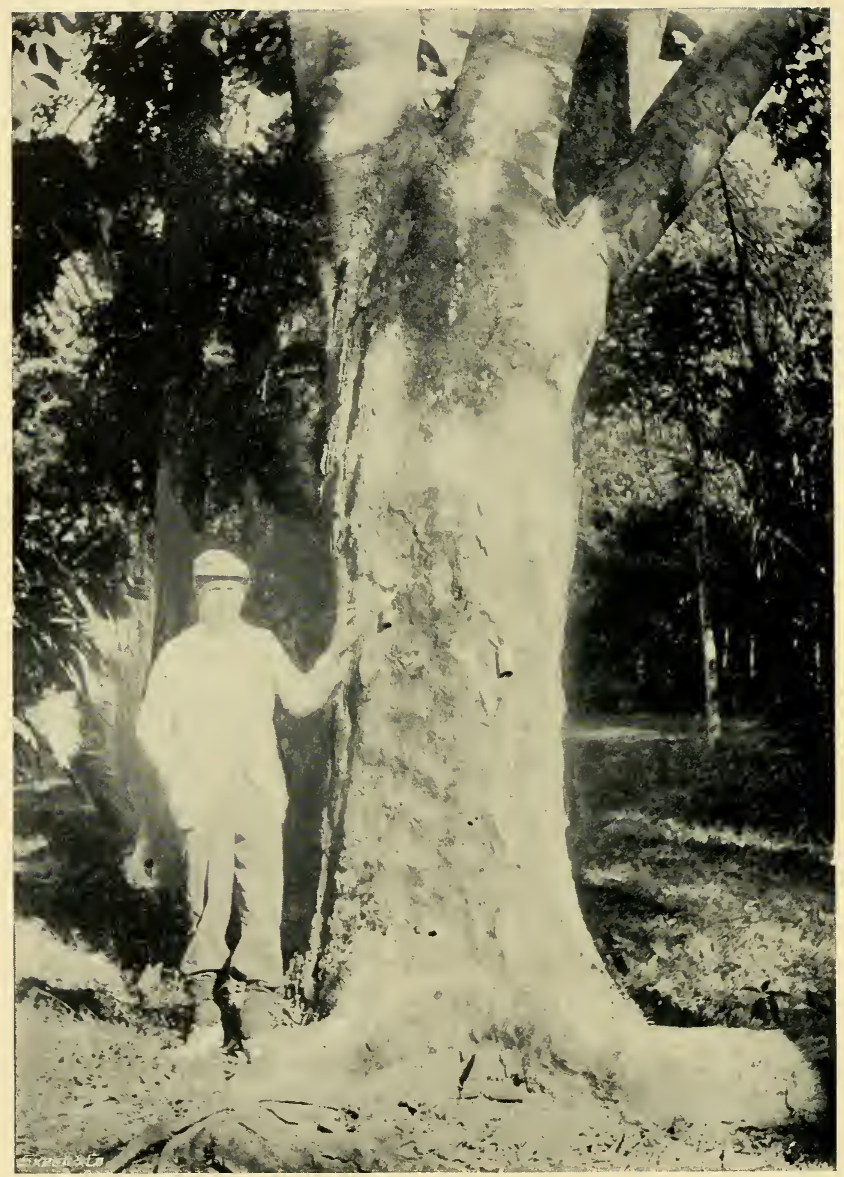

Photo by luor Etherington.

A FORKED TREE AT HENARATGODA. 
In the particular group referred to the majority of the trees have long straight stems, unbranched to a height of 30 to 60 feet. But in addition to these there are a few which, from some cause or other, have forked at from 7 to 11 feet from the ground, and in al these cases the trunks are conspicuously larger in circumference and therefore present an increased tapping area. The following are the dimensions of some of the low-branched and straight. stemmed trees -

\section{Henaratgoda Trees.}

Circumference of trunk, in inches, a yard from the ground.

\begin{tabular}{|c|c|c|c|}
\hline $\begin{array}{l}\text { Trees with } \\
\text { long straight } \\
\text { Stems. } \\
\text { Inches. } \\
1,65,83,85,76\end{array}$ & $\begin{array}{l}\text { Tree forked at } \\
11 \text { feet from } \\
\text { Base. } \\
\text { Inches. } \\
109\end{array}$ & $\begin{array}{l}\text { Tree forked at } \\
7 \text { feet from } \\
\text { Base. } \\
\text { Inches. } \\
104\end{array}$ & $\begin{array}{l}\text { Tree forked at } \\
9 \text { feet from } \\
\text { Base. } \\
\text { Inches. } \\
109\end{array}$ \\
\hline
\end{tabular}

In all instances those trees which have forked near the ground have a much larger hasal circumference, and an illustration of one. which has forked at about 11 feet from the ground, is shown on Plate 17 , Series A. This tree has a girth of nearly 110 inches, a yard from the ground; the surrounding trees, though of the same age, have an average circumference of about 75 inches.

It does not need any argument to prove that an increase in circumference of over 30 inches is an advantage, and the fact that such an increase has occurred in the tapping areas of trees about 30 years old is sufficiently encouraging to tempt the planter to carry out a few bud-pruning experiments, once his trees have attained a height of about ten to twenty feet. The buds which appear in undesirable p?aces can be removed by "thumb-nail" pruning. Experiments have been made with young trees in their first and second years, and in each case the increased rate of circumference has been obtained in trees within the second year. In dealing with young plants it is an easy matter to nip off the terminal bud of the main stem, when the desired height has been obtained; this is usually followed by the development of lateral shoots, the growth of which should be encouraged according to circumstances. An increase in the number of lateral shoots means an ultimate increase in the foliage, and it is on this point that the success of the work depends. The pruning should be carried out in such a manner that the resultant plant has an increased quantity of foliage, whereby a larger food supply can be built up for the benefit of all parts of the plant. If the work is done in such a manner as to deprive the plant of its leaves for a long periorl of time, the growth of the stem will be temporarily checked, and the immediate increased rate of growth of the stem tissues cannot be expected.

\section{The best Shason to Tap.}

The Para rubber trees in Ceylon drop their leaves in February or March, produce new leaves and flowers after a leafless phase of a few days or a couple of weeks, and yield ripe fruit in August and 
September. 'There is an active vegetative period from September to February, a short resting period in February, and a floral and foliar condition from February to September. The climate during these months has been dealt with in Chapter II.

Several writers have associated the yield of latex with atmospheric conditions, the general contention being that a low temperature in the Tropics and plenty of moisture were conducive to a copious and more or less continuous exudation of latex. During hot dry weather the amount of water lost by transpiration from the leaves is very great, and it has been argued that this loss reduces the tension in the cortex and therefore in the latex tubes; hence the poor flow obtained during such times.

Dr. Haas, as a result of his experiments in Java, concludes that if the humidity of the soil is great, and if the rains are equally distributed, the difference in yield during the year is not great, and he further states that though the best times for tapping, in Java, are at the beginning and the end of the wet season, in wet years it does not matter when the trees are tapped.

In parts of the F. M. S., where the climatic periodicity is not so strongly marked as in Ceylon and South India, there is said to be but little variation in the yield of rubber during different months.

"Mr. I.arkin, whose estate at Castlewood* I have recently visited, tells me that during the late dry month of March all his trees in one part of the estate shed their leaves simultaneously, and remained bare for a time. He continued to tap during this period, and found no diminution in the amount of latex produced."

According to the above theory, the yield of latex should be most abundant when the trees are leafless, as they cannot then lose much water by transpiration, and it is of interest to note that the experiments made by Arden in 1902 seem to give support to this view. Arden states that the yield from trees tapped when they were leafless was much greater than that from trees tapped when the leaves were beginning to appear or when in full foliage. In Nicaragua the latex from other rubber trees contains the highest percentage of caoutchouc during the dry season. The possession of abundance of latex during the dry season lends support to the theory of its function as a water store during drought.

In many parts of the Tropics, however, the leafless period occurs when the dryness and temperature of the air are at the maximum, and the collecting of latex would, during such a time, be limited to the very early part of the day and the evening. The results quoted elsewhere tend to show that the best flow of latex is obtained in Ceylon, when the air and soil are abundantly supplied with moisture and when the temperature is comparatively low. A period of drought lasting only seven or twelve days appreciably affects the flow of latex, but though, under such conditions, the quantity is reduced, the quality is usually improved.

* H. N. Ridley, Agri. Bull, Straits and F. M. S., May, 1904. 
The latex rapidly dries on the tree in hot dry weather; this can, however, be overcome by the use of ammonia, formalin, \&c., placed in the drip-tins at the top of each incision. In the Amazon valley the native collectors never tap the trees when in flower, as they believe the amount of rubber then obtainable is much less than at other times-an idea supported by Ridley's experiments at the Botanic Gardens, Singapore.

It is very unlikely that the collection of latex will be limited to the dry period, when the trees pass through their foliar phase, and in practice tapping almost every month is much more likely to be adopted.

\section{Results at Henaratgoda.}

Regarding this question the results given below may be of value. The trees marked " $\mathrm{H}$ " were first tapped when the leaffall commenced, and the operations were continued through the period of leaffall and renewal. The trees marked "I" were tapped from the first of October right through the rainy and dry seasons; on a few days tapping was not carried out owing to inclement weather. The experiment was made at Henaratgoda.

\section{Number of Times tapped.}

Trees tapped every day from

October 1, 1905, (I)

Trees tapped every day: first

tapped on February 1, $1906(\mathrm{H})$. .
Yield of Dry

Rubber per 5 trees.

lb. oz.

$38 \quad 12 \frac{5}{5}$

$\begin{array}{rrrrr}157 & \ldots & 38 & 12 \frac{5}{5} \\ 68 & \ldots & 13 & 14 \frac{5}{8}\end{array}$

The tapping operations (I) were continued at Henaratgoda right through the dry months of January to April ; towards the end of the latter month the flow of latex was proportionally less, and in some cases the coagulation, instead of being complete in 24 hours, required a period of nearly two days.

On estates possessing rubber only it is difficult to see how the labour can be kept employed if tapping is suspended during the dry months, and the point to determine is the maximum frequency that the trees can be tapped with the minimum damage to the tree during these months. The above phenomena were observed in trees (I) which had been regularly tapped twice or three times per week from September, 1905, to April, 1906, during which period the trees shed all their leaves and produced new foliage and flowers.

\section{What PaRT OF the Day to TAP.}

The best flow of latex with the minimum quantity of scrap rubber is obtained in the early morning or evening on sunny days, but tapping may be done further on into the day, when the temperature is low and clouds and moisture are abundant. In a district like Peradeniya the tapping may be continued up to 8 or 9 A.M., 
and re-commenced at 3 to 4 P.M. All-night tapping is of course only possible when the artificial lighting of estates is more perfect than at present.

In the early and late parts of the day the temperature is lower, the air usually more moist, and there is less transpiration of water from the leaves; the combined effect of these factors is a better flow of latex during such times. According to Ridley* the girth of the tree decreases during the day and increases towards evening, an observation which may throw some light on the theories regarding tension of the laticiferous tissue and transpiration.

Ridley also states (Annual Report on the Botanic Gardens, Singapore and Penang, for 1904) that the most favourable times for tapping are morning and evening, and from the same number of trees which produced a total amount of $578 \mathrm{lb}$., the morning trees realized 314 lb., while the evening trees gave only $263 \mathrm{lb}$., showing a difference in favour of the morning tapping of $51 \mathrm{lb}$. Ridley and Derry concluded that evening tappings to be successful should be deferred to as late an hour as possible.

\section{COMPASS TAPPING.}

Several experiments have been carried on with the object of proving which is the best part of the tree to tap during morning and evening. It would appear that the tapping areas of the trees can be conveniently divided into four parts : one side to face north, the next south, and the other two east and west respectively. Each side can be tapped on a definite system, say once per day, twice per week, and so on, but when the east side has to be tapped it is best to perform the operation in the afternoon or evening, and to tap the west side during the early part of the day. Such a method, applicable to the east and west sides of the tree, prevents direct exposure of the tapping area to the sun's rays during working operations, and allows the flow of latex to continue for a slightly longer period of time.

\section{Frequency of Tapping.}

The frequency of tapping varies considerably, but it is by no means clearly proved that the tree will not stand tapping every alternate day throughout the greater part of the year. The fact that an interval of one day is sufficient for the wound response to become obvious is of interest and importance.

It is perhaps not advisable to judge the effect of very frequent tapping from the results obtained in the Amazon Districts, as there the trees are usually very old and in many cases have never been tapped before. Nevetherless, it is of interest to learn that in those districts the Para rubber tree is often tapped for 180 days continually without apparently doing very serious damage to the trees.

* Annual Report of the Director, Botanic Gardens, Singapore. 
In Ceylon tapping every day throughout alternate months, or every day when moisture is abundant, or on alternate days throughout the year, has given good yields.

The following results of experiments at Henaratgoda are of value as they show what yields have been obtained by tapping trees of similar age at varying intervals. The tapping operations were commenced in September, 1905, and ended in February, 1906, the full spiral system being adopted in all the cases quoted below, from the base to a height of five to six feet.

These results suggest that the average amount of rubber, obtainable per tapping operation, is likely to increase when an interval of one or more days is allowed between successive tappings. They also indicate that the average yield, per tapping, is better when the trees are tapped every alternate day than when tapped once per day or once per week. From a practical standpoint, however, the total quantity of rubber obtainable when the trees are judiciously tapped at regular intervals is of more importance than the deductions just made; the latter must not be construed as contradicting the accepted theory of wound response previously discussed.

Frequency of Yield of Dry Yield of RubNumber of Number of Rubber per ber per tap
Tapping. Times tapped. Trees. five trees. ping, per five trees.

\begin{tabular}{|c|c|c|c|c|c|c|c|}
\hline & & & & lb. & & & \\
\hline Every day (D) & 168 & . & . & 42 & $7 \frac{1}{8}$ & - & $4 \cdot 0$ \\
\hline Every alternate day(E) & 83 & $\ldots$ & . & 49 & $7 \frac{7}{5}$ & . & $9 \cdot 5$ \\
\hline Twice per week (A) & 57 & .. 25 & $\ldots$ & 14 & 0 & . & $4 \cdot 0$ \\
\hline nce per week (F) & 28 & .. 5 & . . & 12 & $9 \frac{1}{8}$ & . & $7 \cdot 7$ \\
\hline nce per month (G) & 7 & .. & .. & 0 & 155 & & $2 \cdot 1$ \\
\hline
\end{tabular}


CHAPTER IX.

\section{YIELDS OF PARA RUBBER.}

Natural variations-Yields in Ceylon and Brazil-Henaratgoda trees and Amazon yields-Yields on estates in Ceylon : Matale, Uva, Kalutara, and Ambalangoda Districts-Illustration showing the rubber trees on Passara Group Estate- $\frac{3}{4}$ to $5 \frac{1}{2} \mathrm{lb}$. averages over large acreages-Yields obtained in the Kalutar.. District for 1905 by the Kalutara Rubber Co., Rayigam Tea Co., Neboda Tea Co., Vogan Tea Co., Southern Ceylon Tea and Rubber Co., Putupaula Tea Estate Co., Yatiyantota Ceylon Tea Co., Eastern Produce and Estates Co., Sunnygama Ceylon Estates Co., Yataderiya Tea Co., Kepitigalla and Passara Group Estates, Ceylon Tea and Cocoanut Estate Co., and Gikiyanakanda for 1905-Yields on Imboolpittiya estate, Nawalapitiya-Illustration showing rubber trees at Peradeniya tapped on the full spiral system-Exceptional yields at Culloden, Elpitiya, and Peradeniya-Comparison of yields at Peradeniya and Henaratgoda_Experiments at Henaratgoda-Comparative yields from different systems of tapping-Spiral and herring-bone tapping compared-Results of high tapping at Henaratgoda from base to 50 feet-16 tappings yield $3 \frac{1}{6} \mathrm{lb}$. rubber-Average yielding capacity per square foot of the bark tissues-Comparison of yields obtained at Henaratgoda-Illustration showing the Elpitiya tree after $14 \mathrm{lb}$. rubber extracted-Yields at Peradeniya by the $\mathrm{V}$ and spiral methods - Rubber from shavings-Rubber yields in the Straits-Yield from the Sandycroft Rubber Co., 1905-Variation in yields in JavaYields in South India at high elevations-Hawthorn Estate and Mergui Rubber Plantations-Para yields in the Gold Coast-Yields of Para and African rubber compared-Difficulty in forming average estimates-IEffect of repetitional bark stripping-Illustration showing the tapping of renewed bark-Excision and incision-Bark peeling.

\section{Natural Variations.}

$\mathrm{W}$ HEN dealing with the question of yields of dry rubber for a known acreage or number of trees, it is necessary to indicate the method of tapping adopted, the age of the trees, and the quality of the resultant rubber. The age and size of trees greatly influence the quantity and quality of the rubber, and it is to be regretted that the yields over large acreages for several years in succession are not at hand. Nevertheless, we do possess information of the yield of particular trees during certain years and of large acreages of known age for a limited period, and from these a fairly reliable statement of probable yields can be arrived at. It should be clearly under- 
stood that the yield from trees of the same age may be doubled, trebled, or quadrupled within a year by a change in the method of tapping, and that those methods usually give the largest yields which tap the latex tubes over the largest area.

It should also be remembered that individual trees, either from internal or external causes, show considerable variation in the quantity and quality of latex they give, though of the same age and tapped in a similar manner. At Henaratgoda, where the trees range in age from 15 to 30 years, and where tapping has been done on various sections of the trees from the base to $6,16,20,30$, and 50 feet, the opportunities to observe the variation in yield of latex and rubber have been numerous. The first six feet from the base, though tapped over the same area, in the same manner, and with the same implements, have given a yield varying from six twenty-fifths of an ounce to nearly two ounces of rubber per tapping per tree : other parts of the stems of individual trees have varied in their daily yield of rubber from three-fifths of an ounce to five and one-fifth ounces, one-quarter to one and one-twentieth ounces, nine-fortieths to thirty-three fortieths of an ounce, \&c., and in one case, where the tree has been regularly tapped from the base to a height of 50 feet, the yield of dry rubber has sometimes been as high as eight and three-quarter ounces per tree per tapping, and on other occasions as low as a quarter of an ounce. Such variations can, in most cases, be mainly attributed to internal conditions rather than external climatic forces. Results of tapping operations are available from different countries, and it will be best to commence with those obtained in Ceylon.

\section{Rubber Yields in Ceylon.}

The yield of rubber varies from $7 \mathrm{lb}$. per 400 trees in one tapping to a maximum of $25 \mathrm{lb}$. per tree in twelve months' tapping

The first series of reliable yields* are those obtained at Henaratgoda from 1888 to 1896 . One tree at Henaratgoda was lightly tapped every second year, and gave for nine years an average annual yield of $1 \frac{1}{2} \mathrm{lb}$. of dry rubber :-

$$
\begin{array}{r}
273 \mathrm{oz} \text {. in } 1888 \\
42 \mathrm{oz} \text {. in } 1890 \\
5 \mathrm{oz} \text {. in } 1892
\end{array}
$$

51 oz. in 1894 $48 \frac{1}{4} \mathrm{oz}$. in 1896

This tree was twelve years old when first tapped, and the annual yield of $1 \frac{1}{2} \mathrm{lb}$. was from the 12 th to the 20 th year of the tree's life. The method of tapping consisted of scraping off the rough outer bark and making numerous $V$-shaped incisions to a height of about five feet. The tree had a circumference of $50 \frac{1}{2}$ inches and was growing with other trees of nearly equal size, distanced 30 feet apart.

Other experiments have been made at Henaratgoda which indicated similar results by consecutive weekly tappings of the trees.

* Dr. Trimen, Notes on Rubber Experiments. 


\section{YieLDS IN BRAZIL.}

In Brazil, from a group of 120 to 180 trees, each man is expected to collect about 8 to 10 litres of latex, and though this is regarded as a fair average, as much as 40 litres (10 gallons) have been collected from such a group in one day. Bonnechaux* states that the average yield of rubber per tree, per day, is from 26 to 33 grammes, and that a group of 150 trees will yield during the tapping season in each year 400 to 500 kilos of caoutchouc.

Seeligmann $\dagger$ states that in the Amazon valley as much as 30 c.c. of milk are obtainable from single oblique incisions, the latex flowing from one to three hours. Parkin was of the opinion that the Amazon yields were far in excess of those obtainable in Ceylon, and gave a modest average of 2 to 3 c.c., which might be worked up to 10 to 12 c.c. of latex as a yield to be expected from single oblique cuts in Ceylon.

\section{Yields on Estates in Ceylon.}

'To form an estimate of the yield to be obtained from large acreages of Para rubber trees of known age is no easy task, and the best way to deal with this part of the subject is to give only the results which have been obtained on rubber estates in this island.

\section{Matale District.}

In the Matale District there are estates where an average yield of $\frac{3}{4} \mathrm{lb}$. of dry rubber per tree from 5,000 trees has been obtained in one month's tapping. The average circumference of these trees was 35 inches a yard from the ground.

On another property a yield of $3 \frac{1}{1} \mathrm{lb}$. of rubber per tree has been obtained from 499 trees in seven months' tapping. Another estate, in the same district, has obtained an average yield of $3 \frac{1}{2} \mathrm{lb}$. of dry rubber per tree from 311 trees in one year. The age of these trees varied from 10 to 15 years, and the trees varied in circumference from 30 to 70 inches at a yard from the ground. These trees were tapped on the full herring-bone system; the tapping area covered half the tree and extended from the base to a height of seven feet. The tapping was done very carefully, the distance of seven feet being worked through in 240 days of continuous tapping. The yield from these particular trees will probably be increased by a change in the method of tapping and tapping instruments during the current year.

On a third Matale estate the Para rubber is interplanted among cacao; the cacao is planted 12 by 12 feet and the rubber through alternate lines of cacao 24 by 12 feet. By the $V$ method of tapping a yield of $3 \mathrm{lb}$. of dry rubber from each of 10,000 trees is expected during the present year, the trees being 8 to 15 years old. On this

* See Jumelle l.c.

† Seeligmann, Caoutchouc et lu Gutta Percha, p 48. 


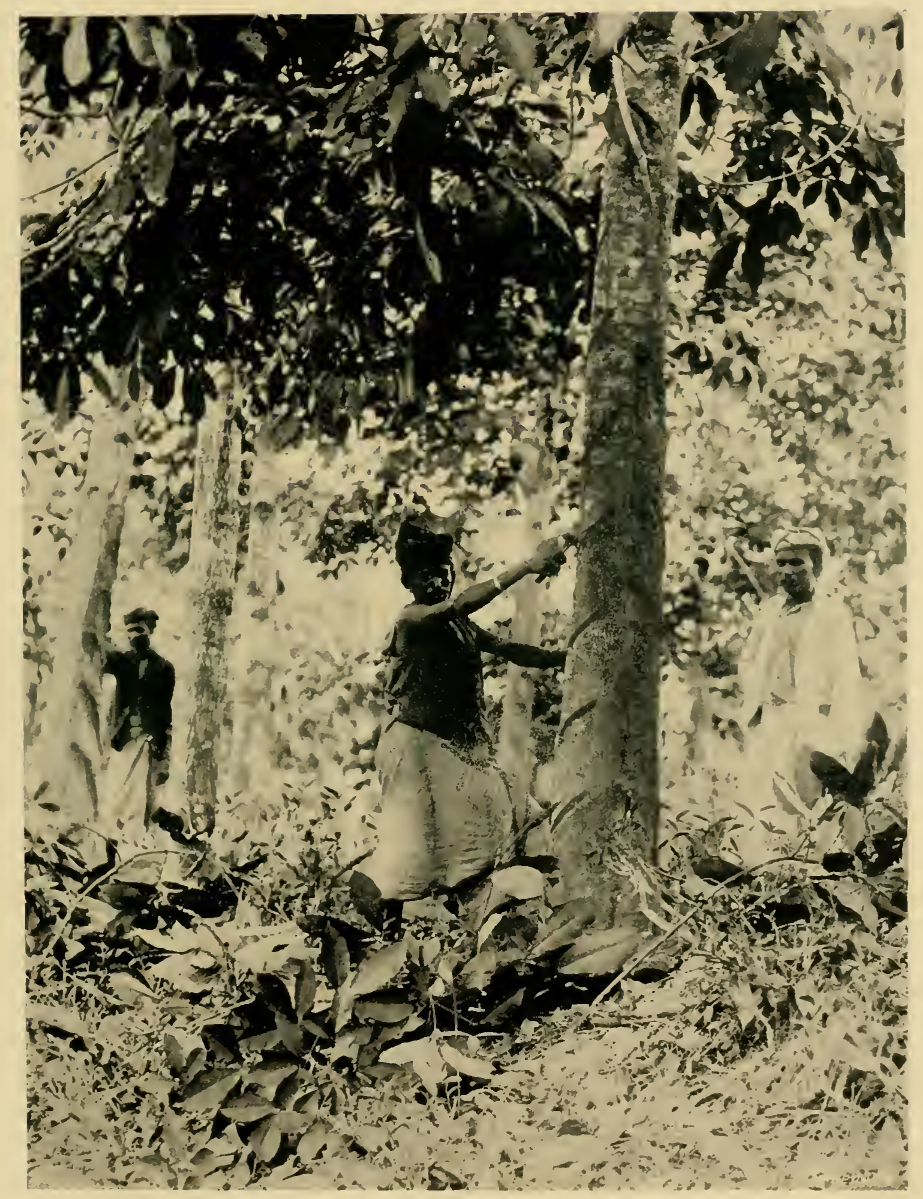



estate several encouraging experiments in tapping from 6 feet upwards to a height of 15 feet have been made, light ladders being used for the purpose.

\section{The Province of Uva.}

The most successful results at high elevations in Ceylon have probably been obtained in the Province of Uva. On Passara Group estate, Passara, Para rubber is being cultivated up to and over 3,000 feet above sea-level. The trees are of various ages, and one specimen 13 years old measures 54 inches in circumference a yard from the ground, and 60 to 70 feet in height, though growing at an elevation of about 2,600 feet. Tapping is being carried on with promising results up to 2,800 feet, and from the trees at an elevation of 2,600 feet, varying in age from 7 to 13 years, an average yield of $2 \mathrm{lb}$. of dry rubber per tree was obtained during 1905 . These results are of considerable interest and importance, and I have to thank Mr. W. Stewart Taylor for the information he has given me. The illustration on Plate 12. Series D, shows the rubber growing at 2,600 feet above sea-level.

A considerable amount of Para rubber is likely to be planted in the Badulla, Passara, Monaragala, and Bibile Districts, and in many cases the altitude is considerably over 2,000 feet.

South Ceylon: Kalutara, Ambalangoda, Rayigam, \&c.

In the South of Ceylon equally good and often better results have been obtained. On one estate 8,731 trees, having a minimum circumference of twenty inches, gave in one year an average of 1.72 lb. of dry rubber per tree. On the same property an average of $2 \mathrm{lb}$. per tree from each of about 10,000 trees is expected during the current year. There are on this estate four old trees which have given 10 to $25 \mathrm{lb}$. of dry rubber per tree in twelve months; the trees are perfectly healthy, and gave a good crop of sound seed during 1905. Further tapping has been done on these trees during 1905 and 1906 with excellent results.

A section of another rubber property in the South of Ceylon has given, from 11 -year-old trees, the average circumference of which is 30 inches only, no less than $5 \frac{1}{2} \mathrm{lb}$. of dry rubber from each of 255 trees. The eight largest trees on this property have vielded no less than $16 \mathrm{lb}$. of dry rubber each in twelve months, and though the original tapping has only just been completed the newly-formed cortex has been tapped again, and gives a promise of a good flow of latex in the future. These results have been obtained by the half or full spiral system of tapping.

The quantity of rubber harvested during 1905 in the Kalutara District was $101,978 \mathrm{lb}$. from 88,667 trees, which shows an average of about $1 \cdot 15 \mathrm{lb}$. per tree. A large number of these trees, about 43 per cent., were tapped for the first time, but as nearly all the older trees in the district are planted in selected spots and at great distances, the Kalutara Association do not expect to see any increase in the vield per tree for a considerable number of years. 
As yet there are insufficient trees in bearing in rubber alone to enable the Kalutara planters to estimate with any degree of certainty what the yield per acre is likely to be.

During the year 1905 the Kalutara Rubber Company, Limited, tapped 1,135 trees, and obtained a yield of $1 \frac{1}{4} \mathrm{lb}$. of rubber per tree. The Ceylon Tea \& Cocoanut Estates Co., Ltd., tapped in 1905, 1,751 trees, and obtained $958 \mathrm{lb}$. of rubber.

The rubber trees on the property of the Rayigam Tea Co., Ltd., were tapped in $1905,2,220 \mathrm{lb}$. of rubber being obtained from about 1,800 trees.

The Neboda Tea Co. of Ceylon, Ltd, in their annual report for 1905 , state that 370 trees reached the tapping stage during the year, and gave $820 \mathrm{lb}$. of dry rubber or an average yield of $2 \frac{\mathrm{I}}{\mathrm{lb}}$. per tree per annum.

The Vogan Tea Co. of Ceylon obtained in 1905 a crop of 3,056 lb. of rubber from 2,800 trees, the cost of harvesting, including all expenditure on tapping knives, cups, \&c., being Re. 1.05 per lb. of rubber.

The Yataderiya Tea Co. obtained, in 1905, 2,855 lb. of rubber from 5,324 trees, the greater number of the trees being only lightly tapped towards the close of the season.

The Southern Ceylon Tea \& Rubber Co., in their report for 1905, state that in about 8 months' tapping, from 577 trees, $614 \mathrm{lb}$. of rubber have been obtained, most of the trees being in their seventh year.

The Putupaula Tea Estate Co., Ltd., in their annual report for 1905 , state that $4,982 \mathrm{lb}$. of rubber were harvested, the crop being equal to $1 \frac{2}{3} \mathrm{lb}$. of rubber per tree.

The Yatiyantota Ceylon Tea Co., Ltd., report that during 1905 the crop of rubber amounted to $8,212 \mathrm{lb}$. from about 4,636 trees, or an average of $1 \frac{7}{10}, \mathrm{lb}$. per tree.

The Eastern Produce \& Estates Co., Ltd., report for 1905 that $12,515 \mathrm{lb}$. of rubber were obtained, and that 12,000 trees will be available for tapping in 1906 ; it is, therefore, probable that a little over $1 \mathrm{lb}$. per tree was obtained during last year.

During 1905 one hundred Para rubber trees on the property of the Sunnygama Ceylon Estates Co., Ltd., gave $3 \frac{1}{4} \mathrm{lb}$. of dry rubber each.

\section{YieldS ON GIKIYANAKANDA FOR 1905.}

The results obtained on the above estate for 1905 are of importance as showing reliable details of yield and dimensions of trees. During the year, 5,598 trees were tapped; of these, 2,207 had been previously tapped. Between January and March 1,346 new trees were operated on for the first time, and again between July and October other 2,045 trees were tapped for the first time. The minimum girth of the trees, which were tapped for the first time, was 20 inches at a yard from the ground, and the census at the end of the year showed that 3,811 out of the 5,598 had a circumference of 24 


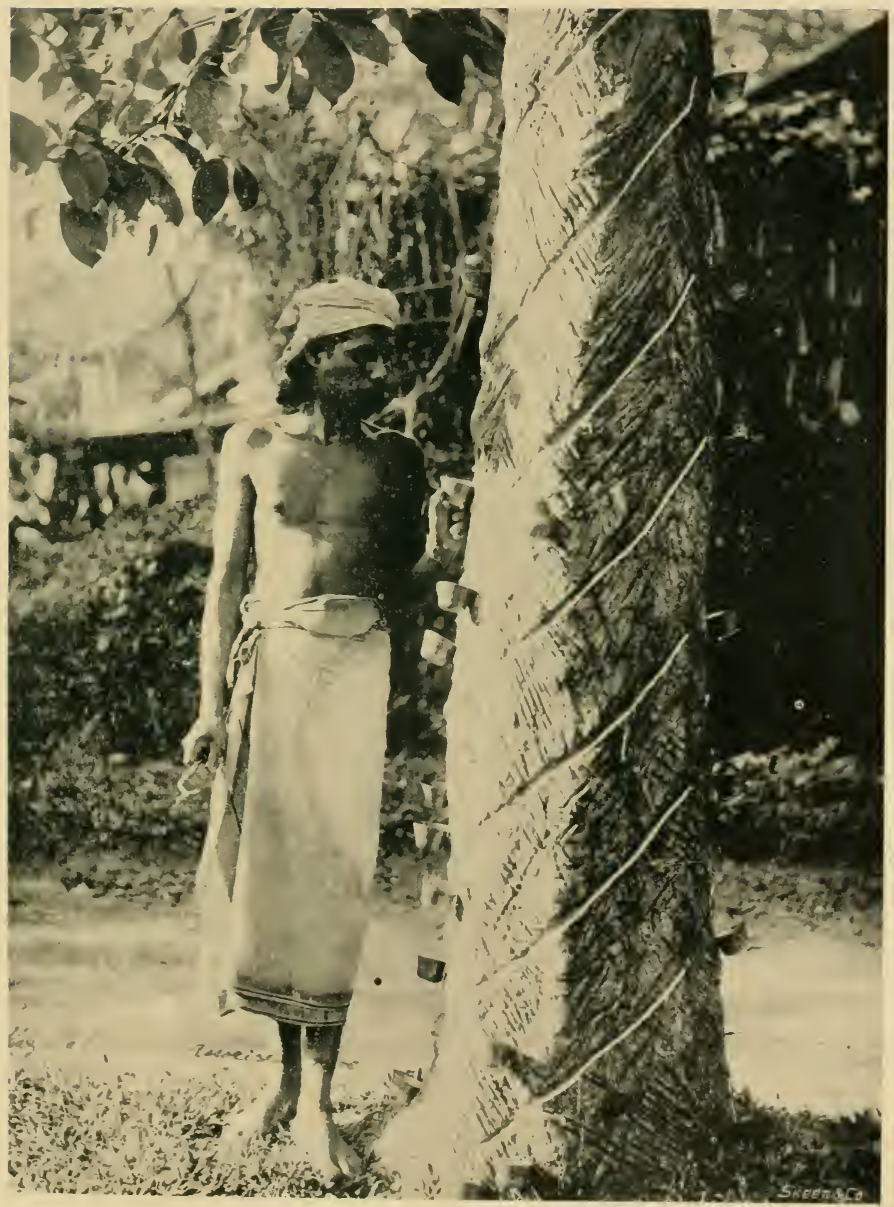

Photo lent by the Kegalle Planters' Association. 

inches or over. The trees were tapped on the full herring-bone system, each tree being tapped every alternate day. The paring operations were done carefully, the width of excised bark being slightly less than one inch per month. The total quantity of rubber from the 5,598 trees, some of which were tapped from January onwards, others only from October, was $7,592 \mathrm{lb}$. or $\mathbf{1} \cdot 34 \mathrm{lb}$. per tree. It is interesting to know that the total cost per lb. for collecting, including knives, tins, \&c., was $53 \cdot 46$ cents and for curing $6 \cdot 25$ cents per pound of rubber. I have to thank Mr. G. H. Golledge for his kindness in favouring me with the results of his work during 1905.

Yields on Imboolpitiya Estate, Nawalapitiya, C'eylon.

An interesting series of yields, for which I am indebted to Mr. Albert Rosling, have been obtained on the above estate, situated in the Ambagamuwa District, at an elevation of 2,000 feet, where the rainfall average for 20 years is $144 \frac{1}{2}$ inches per year.

The tapping operations were commenced on 18th December, 1905, and terminated on 18th March, 1906, so that the collection of the latex was carried out during three very dry months and through the period when the trees changed their foliage. The following are the yields obtained, inclusive of scrap :-

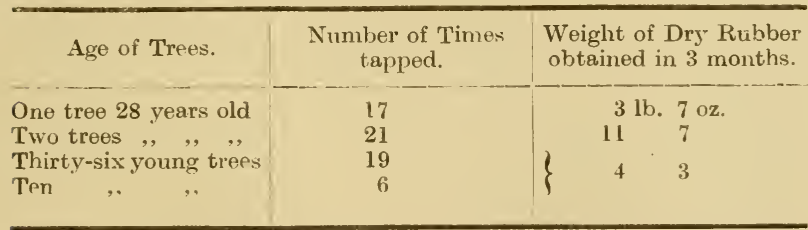

The two trees, 28 years old, gave during September and October, $1905,12,000$ seeds ; the other tree of the same age seldom yields more than 400 to 500 seeds anmually.

Comparison of Yields from Ceylon Properties.

Having indicated the yields obtained in various parts of the world and those from estates and exceptional trees in Ceylon, the following synopsis is given to assist those who desire to form in estimate of probable future vields:-

\begin{tabular}{c|c|c|c|c}
\hline $\begin{array}{c}\text { Name of Rubber } \\
\text { Property. }\end{array}$ & $\begin{array}{c}\text { Yield of } \\
\text { Rubber ob- } \\
\text { tained in } \\
1905 .\end{array}$ & $\begin{array}{c}\text { Number } \\
\text { of Trees }\end{array}$ & $\begin{array}{c}\text { Yverage } \\
\text { tapped. } \\
\text { tree per } \\
\text { year. }\end{array}$ & $\begin{array}{c}\text { Particulars } \\
\text { of Trees } \\
\text { tapped. }\end{array}$ \\
\hline $\begin{array}{c}\text { Neboda Tea Co. of } \\
\text { Ceylon.Ltd.. Ceylon. }\end{array}$ & $\begin{array}{c}1 \mathrm{~b} . \\
820\end{array}$ & 370 & $2 \frac{1}{5}$ & $\begin{array}{c}\text { Young, and } \\
\text { attained tap- } \\
\text { ping stage in } \\
1905 .\end{array}$ \\
\hline
\end{tabular}

¡Continued over.? 


\begin{tabular}{|c|c|c|c|c|}
\hline $\begin{array}{l}\text { Name of Rubber } \\
\text { Property. }\end{array}$ & $\begin{array}{c}\text { Yield of } \\
\text { Rubber ob- } \\
\text { tained in } \\
1905 .\end{array}$ & $\begin{array}{c}\text { Number } \\
\text { of Trees } \\
\text { tapped. }\end{array}$ & $\begin{array}{c}\text { Average } \\
\text { Yield per } \\
\text { tree per } \\
\text { year. }\end{array}$ & $\begin{array}{l}\text { Particulars } \\
\text { of trees } \\
\text { tapped. }\end{array}$ \\
\hline $\begin{array}{l}\text { Passara Group estate } \\
\text { in Uva, Ceylon : ele- } \\
\text { vation } 2,600 \mathrm{ft} \text {. }\end{array}$ & 740 & 370 & 2 & $\begin{array}{l}\text { Trees } 6 \text { to } 13 \\
\text { years old. }\end{array}$ \\
\hline $\begin{array}{l}\text { Kalutara Estate, Cey- } \\
\text { lon. }\end{array}$ & 15,017 & 8,731 & $1 \cdot 72$ & $\begin{array}{l}\text { Minimum cir- } \\
\text { cumference } \\
\text { of trees was } \\
20 \text { inches. }\end{array}$ \\
\hline $\begin{array}{l}\text { Kalutara Rubber Co., } \\
\text { Ltd., Ceylon. }\end{array}$ & 1,419 & 1,135 & $1 \frac{1}{4}$ & \\
\hline $\begin{array}{l}\text { Kalutara District in } \\
\text { Ceylon. }\end{array}$ & 101,978 & 88,667 & $1 \cdot 15$ & $\begin{array}{l}43 \text { per cent. } \\
\text { were tapped } \\
\text { for the first } \\
\text { time. }\end{array}$ \\
\hline $\begin{array}{l}\text { Vogan Tea Co. of Cey- } \\
\text { lon. }\end{array}$ & 3,056 & 2,800 & $1 \cdot 09$ & \\
\hline $\begin{array}{l}\text { Rayigama Tea Co. of } \\
\text { Ceylon. }\end{array}$ & 2,220 & 1,800 & $1 \cdot 2$ & \\
\hline $\begin{array}{l}\text { Putupaula Tea Estate } \\
\text { Co. }\end{array}$ & 4,982 & - & $1 \frac{2}{3}$ & \\
\hline $\begin{array}{l}\text { Yatiyantota Ceylon } \\
\text { Tea Co. } \\
\text { Sunnygama Ceylon Es- }\end{array}$ & 8,212 & 4,636 & $1 \cdot 7$ & \\
\hline tates Co. & 325 & 100 & $3 \frac{1}{4}$ & \\
\hline $\begin{array}{l}\text { Yataderiya Tea Co.. } \\
\text { Ceylon. }\end{array}$ & 2,855 & 5,324 & 0.5 & $\begin{array}{l}\text { Varied in cir- } \\
\text { cumference } \\
\text { from } 18 \text { to } \\
61 \text { inches. }\end{array}$ \\
\hline $\begin{array}{l}\text { Kepitigalla, Matale, } \\
\text { Ceylon. }\end{array}$ & 30,000 & 10,000 & 3 & $\begin{array}{l}\text { Trees from } 8 \\
\text { to } 15 \text { years } \\
\text { old. }\end{array}$ \\
\hline $\begin{array}{l}\text { Henaratgoda Gardens, } \\
\text { Ceylon. }\end{array}$ & $\begin{array}{c}132 \frac{5}{16} \\
\text { in } 4 \frac{1}{2} \\
\text { months }\end{array}$ & 75 & $\begin{array}{c}1 \cdot 7 \\
\text { in } 4 \frac{1}{2} \\
\text { months }\end{array}$ & $\begin{array}{l}\text { The circum- } \\
\text { ference of } \\
\text { the tapped } \\
\text { trees ranges } \\
\text { from } 33 \text { to } \\
69 \mathrm{in} .\end{array}$ \\
\hline $\begin{array}{l}\text { Gikiyanakanda, } \\
\text { boda, Ceylon. }\end{array}$ & 7,529 & 5,598 & $1 \cdot 34$ & $\begin{array}{l}\text { Some tapped } \\
\text { for first time; } \\
\text { others pre- } \\
\text { viously tap- } \\
\text { ped. }\end{array}$ \\
\hline
\end{tabular}




\begin{tabular}{|c|c|c|c|c|}
\hline $\begin{array}{l}\text { Name of Rubber } \\
\text { Property. }\end{array}$ & $\begin{array}{l}\text { Yield of } \\
\text { Rubber ob- } \\
\text { tained in } \\
1905 .\end{array}$ & $\begin{array}{l}\text { Number } \\
\text { of Tries } \\
\text { tapped. }\end{array}$ & $\begin{array}{l}\text { Average } \\
\text { Yield per } \\
\text { tree per } \\
\text { year. }\end{array}$ & $\begin{array}{c}\text { Particulars } \\
\text { of Trees } \\
\text { tapped. }\end{array}$ \\
\hline $\begin{array}{l}\text { The Ceylon Tea and } \\
\text { Cocoanut Estates } \\
\text { Co., Ltd. }\end{array}$ & $95 x$ & 1,751 & $0 \cdot 5$ & $\begin{array}{l}\text { Mainly young } \\
\text { trees. }\end{array}$ \\
\hline $\begin{array}{l}\text { Rubber Estate, Matale, } \\
\text { Ceylon. }\end{array}$ & $1,08 \mathrm{~s}$ & 311 & $3 \frac{1}{2}$ & $\begin{array}{l}\text { Girth of trees } \\
\text { varies from } \\
30 \text { to } 70 \text { in. }\end{array}$ \\
\hline $\begin{array}{l}\text { Rubber Estate, Matale, } \\
\text { Ceylon. }\end{array}$ & 1,596 & 499 & $3 \frac{1}{3}$ & $\begin{array}{l}11-y \text { ' a r-old } \\
\text { trees in seven } \\
\text { months' tap- } \\
\text { pings }\end{array}$ \\
\hline $\begin{array}{l}\text { Rubber estate, Matale. } \\
\text { Ceylon. }\end{array}$ & 3,750 & 5,000 & $\frac{3}{4}$ & $\begin{array}{l}\text { Average girth } \\
\text { of trees is } 35 \\
\text { inches. }\end{array}$ \\
\hline $\begin{array}{l}\text { Rubber estate. Amba- } \\
\text { langoda, Ceylon. }\end{array}$ & 1,400 & 255 & 5 & $\begin{array}{l}\text { Average girth } \\
\text { is } 30 \text { inches. }\end{array}$ \\
\hline $\begin{array}{l}\text { Rubber estate, Amba- } \\
\text { langoda, Ceylon, } 1904\end{array}$ & $20 s$ & 501 & 0.41 & $\begin{array}{l}\text { Tapped on V } \\
\text { system. }\end{array}$ \\
\hline 1905 & 908 & 617 & $1 \cdot 47$ & $\begin{array}{l}\text { Some trees } \\
\text { tapped spi- } \\
\text { rally. }\end{array}$ \\
\hline
\end{tabular}

The trees on the various rubber properties enumerated above differ widely in age, size, \&c., and are growing in dissimilar climates. The results are, however, of value in so far that they show the yields obtained in an early stage of the industry, when our knowledge is necessarily meagre and our methods open to considerable improvement.

\section{Exceptional Yielns.}

These results have, however, been completely surpassed by those obtained on exceptional trees during the last few years. Trees of unknown age in Ceylon (probably 20 to 25 years) have given 10 , 18,23 , and $25 \mathrm{lb}$. of rubber in twelve months' time; other trees, only eleven years old, have in eight months' tapping given $14 \mathrm{lb}$. of dry rubber each, and others from 2 to $4 \mathrm{lb}$. in two to three months. Light tapping of young trees has given $1.72 \mathrm{lb}$. of rubber per tree on a well-known Kalutara property. These results are so significant 
that space for tabulating them is here given, although it must be clearly understood that they are exceptional:-

Age of Trees.

District.

Culloden

. 20 to 25 years

Elpitiya

. 11

,

12 ,

Tapping

period.

12 months

Peradeniya .. 29 ,"

Kepitigalla .. 8 to 15 ,,

12 months
12 weeks

8 months

12 ,
Tapping

Yield. method.

(a) 10 lb.)

(b) 18,

(c) $23,$,$\} Various.$

(d) 25,

16, Spiral curves

with knives

1 and 2

about $3,, \quad \mathrm{~V}$ cuts

$6 \frac{3}{4}$, Spiral curves with knives 1 and 2

$2,, \quad \mathrm{~V}$ cuts

$3, \quad V$ cuts

The ten old trees on Culloden were again tapped on the herringbone system from 1st November to the 8th December, 1905, and gave an average of over $12 \mathrm{lb}$. of dry rubber per tree. A photograph is, by permission of the Agents and Messrs. Capper \& Sons, Colombo, given elsewhere showing the trees from which these large yields have been obtained. (See Plate 4, Series D.)

The Elpitiya tree had a circumference of 46 inches; the tapping was commenced in October, 1904 ; the tree was rested in November, tapped again in December, rested in January, 1905, and continuously tapped from February to June, 1905. Tapping was re-commenced in September, 1905. Plates 18 and 19, Series A, show two of the trees in June, 1905, after they had given 14 and $16 \mathrm{lb}$. of rubber respectively.

\section{Yield from Peradentya Trees.}

The following are the details of the trees at Peradeniya, which were tapped either on the spiral or $\mathrm{V}$ system. The letter $\mathrm{P}$ indicates the days on which the spur knife was used.

It will be noticed that the quantity of latex obtained by the use of Bowman's and Northway's spur knife was usually much greater than that obtained by the paring knife ; this was to some extent due to the fact that the innermost laticiferous tubes near the cambium were penetrated by the points of the spur.

It is, however, an open question whether the total yield from a series of pricking and paring operations is in excess of that obtained by the same number of parings, if a long enough interval of time is allowed to elapse. The large yield resulting from the use of the spur knife was followed by a poor flow after paring. 


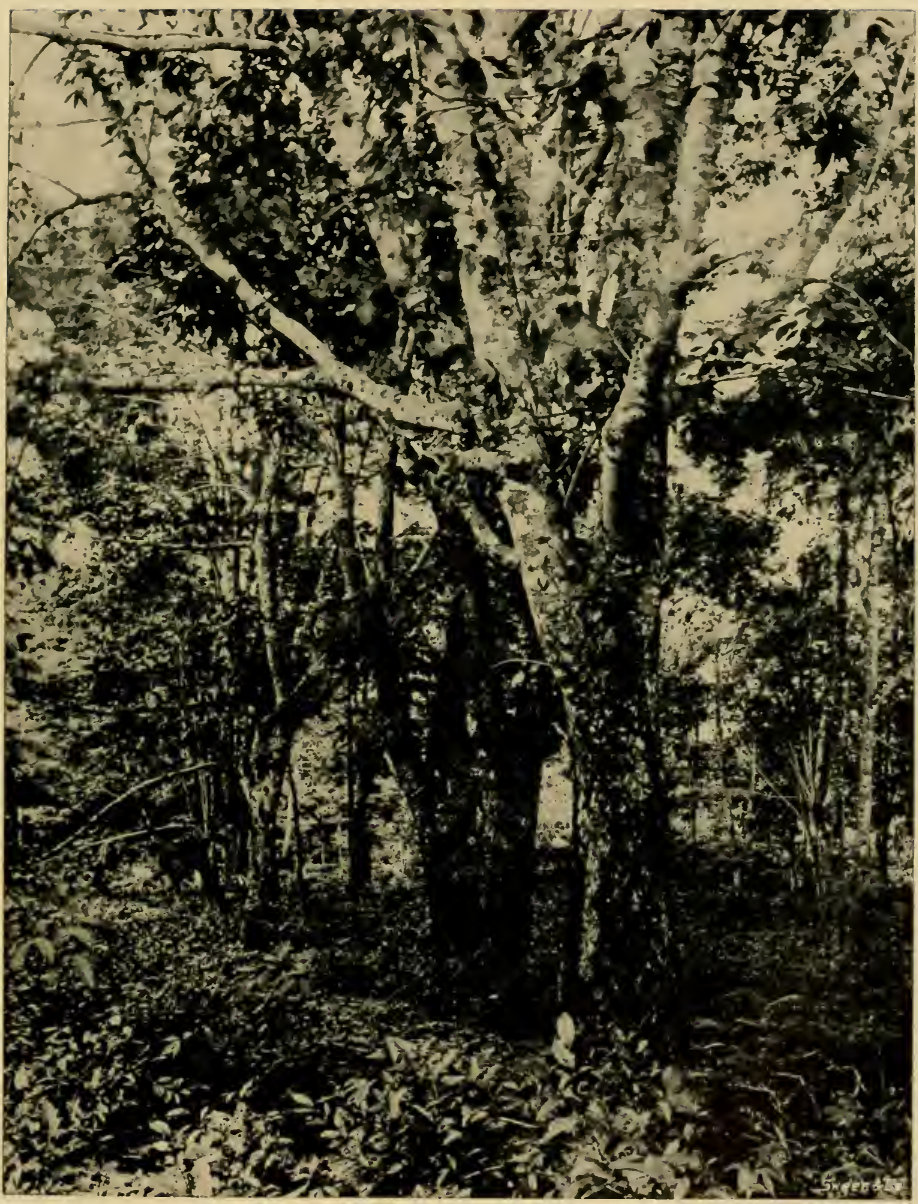

PARA KUBBER IN CEYLON.

Photo by C. H. Kerr.

Kalutara District.

The Fayous Trees, some of which have given 25 lb. Rubber in one Year.

Culloden Estate, Kalutara, Ceylox. 

The illustrations on Plates 11 and 13, Series A, show the Pera deniya trees referred to in the following records of yields :-

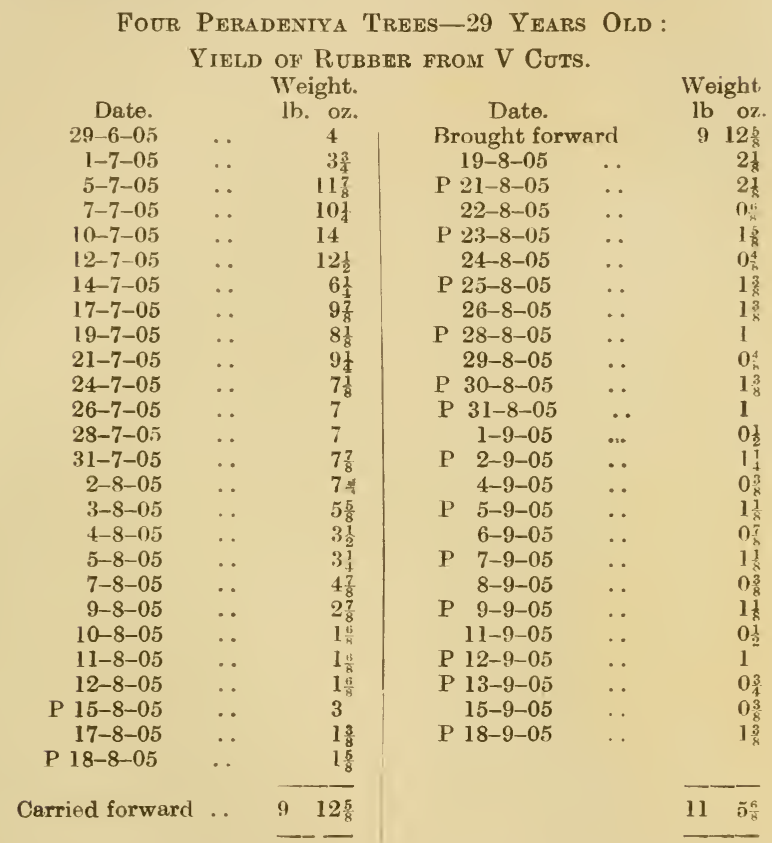

The figure on Plate 11, Series A, shows the condition of one of the trees at the end of the tapping operations; the lines of adjacent $V$ 's were beginning to interfere with one another, and the trees were therefore being rested. The average vield in the first five weeks was two pounds of rubber per tree, but subsequently the yield fell off ronsiderably.

Rubber Yield from LoNg Spiral Lines.

Four Peradentya Trees-29 Years Oud.

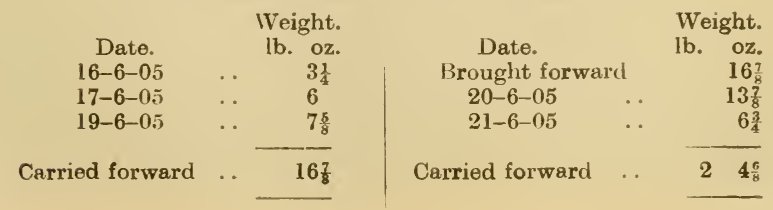




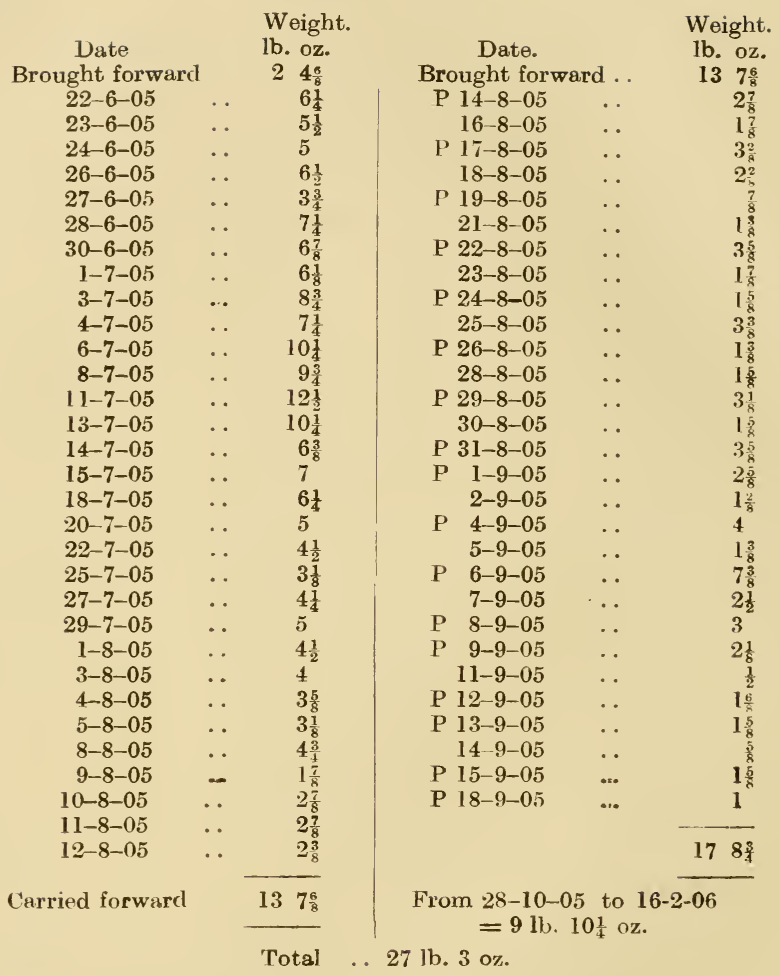

\section{('omparison of Yields at Peradeniya and Henaratgoda.}

The results which have been obtained from the full spiral system at Peradeniya are not as satisfactory as those at Henaratgoda, and are only briefly indicated here. At Peradeniya four trees, now nearly 30 years old, have been tapped from June, 1905, to February, 1906, at irregular intervals. About three-quarters of the bark tissues have been removed from the base to a height of five to six feet by alternately pricking and paring the lower surface. Altogether each tree has been tapped on 150 occasions during the time specified, and the yield obtained is approximately $6 \frac{3}{4} \mathrm{lb}$. of dry rubber per tree.

At Henaratgoda 25 trees, from 15 to 20 years old, have been tapped approximately twice per week from September 25, 1905, to Fehruary, 1906. The pricker has been used alternately with the paring 


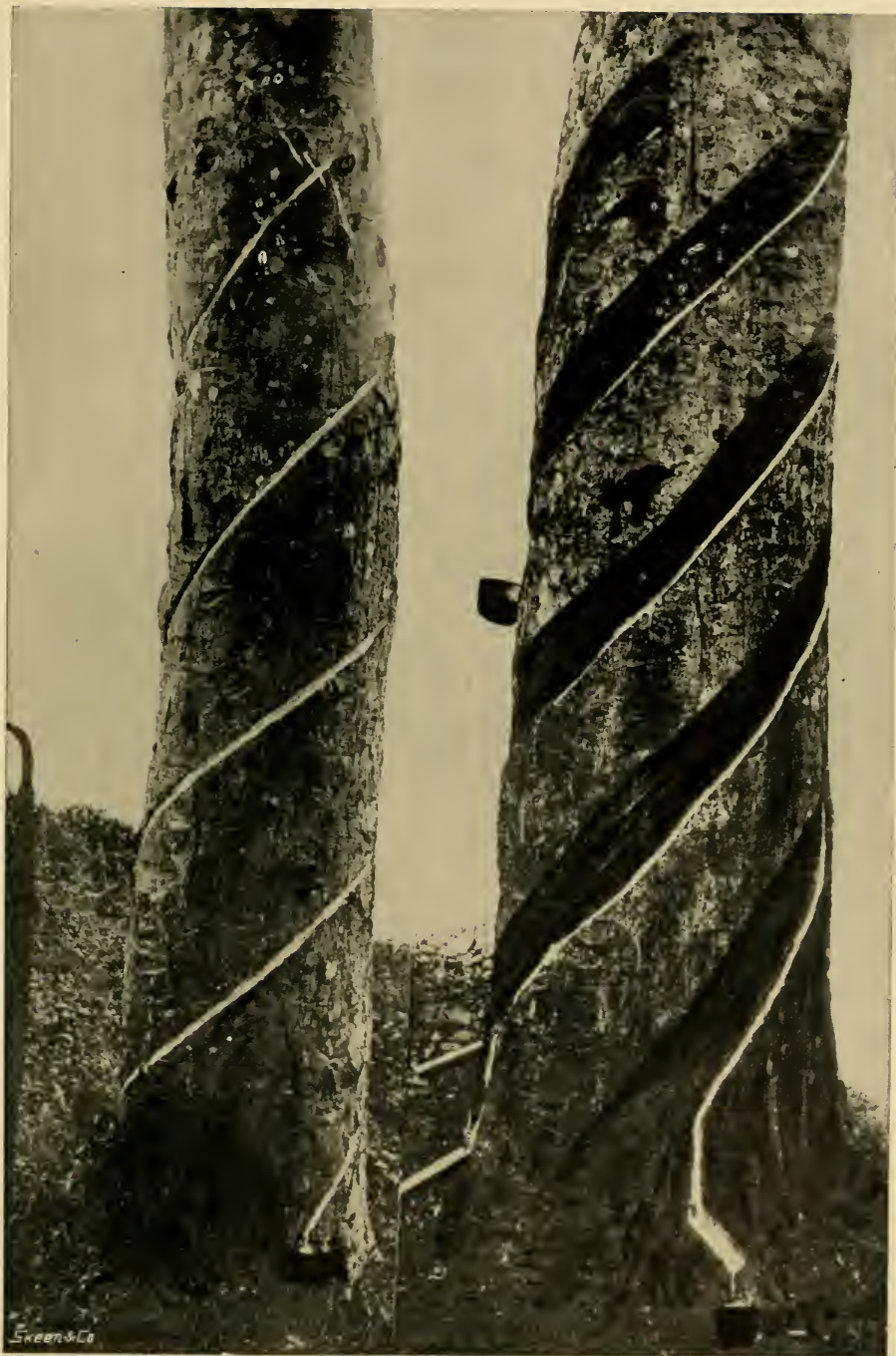

A

B

THE FULL SPIRAL SYSTEM.

Photo oy H. F. Macmillan.

A.-THE FIRST INCISION. $\quad$ B.-AFTER THE TREE HAS GIVEN 2 LB, DRY RUBBER, 

knife, and in an interval of $4 \frac{1}{2}$ months the width of bark tissues removed along each line is only $1 \frac{1}{2}$ to 2 inches. The results show that by tapping on 37 occasions a total of $50 \frac{7}{x} \mathrm{lb}$. of dry rubber can be obtained from 25 such trees.

The following shows some of the yields obtained by tapping on the long spiral system at Henaratgoda; each tree was tapped from the base to a height of 5 or 6 feet during a period of about $4 \frac{1}{2}$ months :-

Long Sptral Tapping Explerments.

\begin{tabular}{|c|c|c|c|c|}
\hline $\begin{array}{l}\text { Number of } \\
\text { times tapped. }\end{array}$ & & $\begin{array}{l}\text { Number of } \\
\text { Trees. }\end{array}$ & & $\begin{array}{c}\text { Yield of } \\
\text { Rubber. } \\
\text { lb. }\end{array}$ \\
\hline 37 & $\ldots$ & 25 & . & $50 \frac{7}{8}$ \\
\hline 112 & . & 5 & . & $30 \frac{1}{6}$ \\
\hline 56 & .. & 5 & . & $26 \frac{1}{16}$ \\
\hline 18 & . & 5 & . & 89 \\
\hline 100 & .. & 5 & . & $27 \frac{s}{1}$ \\
\hline
\end{tabular}

Experiments at Henaratgoda.

The objects of the experiments at Henaratgoda are numerous and have been made public on several occasions. One of them is concerned with the yield of dry rubber obtainable by different systems of tapping, and is of particular interest to those persons having rubber trees in bearing. A plantation of 75 rubber trees, 15 to 20 years old, was selected (see Plate 1, Series A) and 25 trees in each of three groups were marked out and tapped on the $(a)$ full spiral, (b) half-spiral, and (c) the full herring-bone systems. Tapping was commenced on the 26th September, 1905, and continued until the 13th of February, 1906, the latter being the period when most of the trees were undergoing their change of leaf.

It was impossible to obtain exact equality in all the physical conditions, and it is beyond the power of any one to calculate the individual potentialities of the selected trees; nevertheless, the following details will serve to indicate the results which may be obtained from such trees under conditions similar to those prevailing at the time of the experiments.

Comparison of Yields by different Systems of Tappinc.

Base to 5 and 6 feet; 25 Trees in each Group.

Systeras.

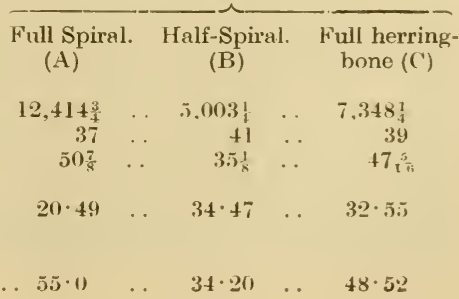

Area excised, in square inches

Number of times tapped

Yield of dry rubber in $1 \mathrm{~b}$.

Yield of dry rubber per 5,000 square inches in $1 b$.

Yield of dry rubber per 40 tappings from 25 trees in lb. . . 


\section{Spiral and Herring-bone Tapping compared.}

It is probably unwise to draw final conclusions from the above experiments, as the period occupied for the whole of the work lasted only about five months and the trees were 15 to 20 years old at the time of the experiment. But care was exercised to equalize, as far as possible, the physical conditions in the three sections and to avoid erroneous deductions being made. A synoptical statement of the significance of the above table is here given.

In the first case it is obvious that the full spiral system necessitates the stripping of the cortex or bark at the quickest rate, and the halfspiral at the minimum rate.

The largest yield per group of 25 trees has been obtained from the full spiral system, the next best from the full herring-bone, and the poorest yield from the half-spiral system of tapping. This is only what may be expected when one realises that the bark removed in the full spiral, full herring-bone, and half-spiral systems was in the ratio of $12: 7: 5$, respectively. It seems reasonable to conclude that since the above results show that the maximum quantity of rubber per tree has been obtained from the full spiral system, such a system is to be recommended where it is expedient that the rubber should be placed on the market as quickly as possible irrespective of the effect on the trees. The adoption of this system removes the maximum quantity of bark, in a given time, and it is, therefore, the best one to adopt in thinning-out estates which are too thickly planted.

On the other hand, it appears that the maximum quantity of rubber for equal areas of bark has been obtained from the halfspiral system, and, therefore, that this system is not only the least harmful, but is the most economical, and is one which, on a permanent estate, will give the best vield from the available tap. ping area.

It should, however, be pointed out that in these experiments the different systems have been carried out in such a manner that the paring operations have only removed from $1 \frac{1}{2}$ to $2 \frac{1}{4}$ inches of cortex, along each incision, in five months. The tapping lines were originally 12 inches apart, so that the whole of the area prepared for tapping will only be worked through once in about two to three years. If the Para rubber tree is not too seriously injured by complete cortical stripping once every three years, it seems likely that the full spiral system of tapping, though the least economical, is one which will be largely adopted in the future on account of the large yields obtainable thereby.

\section{Results of High Tapping at Henaratgoda.}

The foregoing results were obtained by tapping selected sides of trees from the base to five or six feet from the ground. In addition 


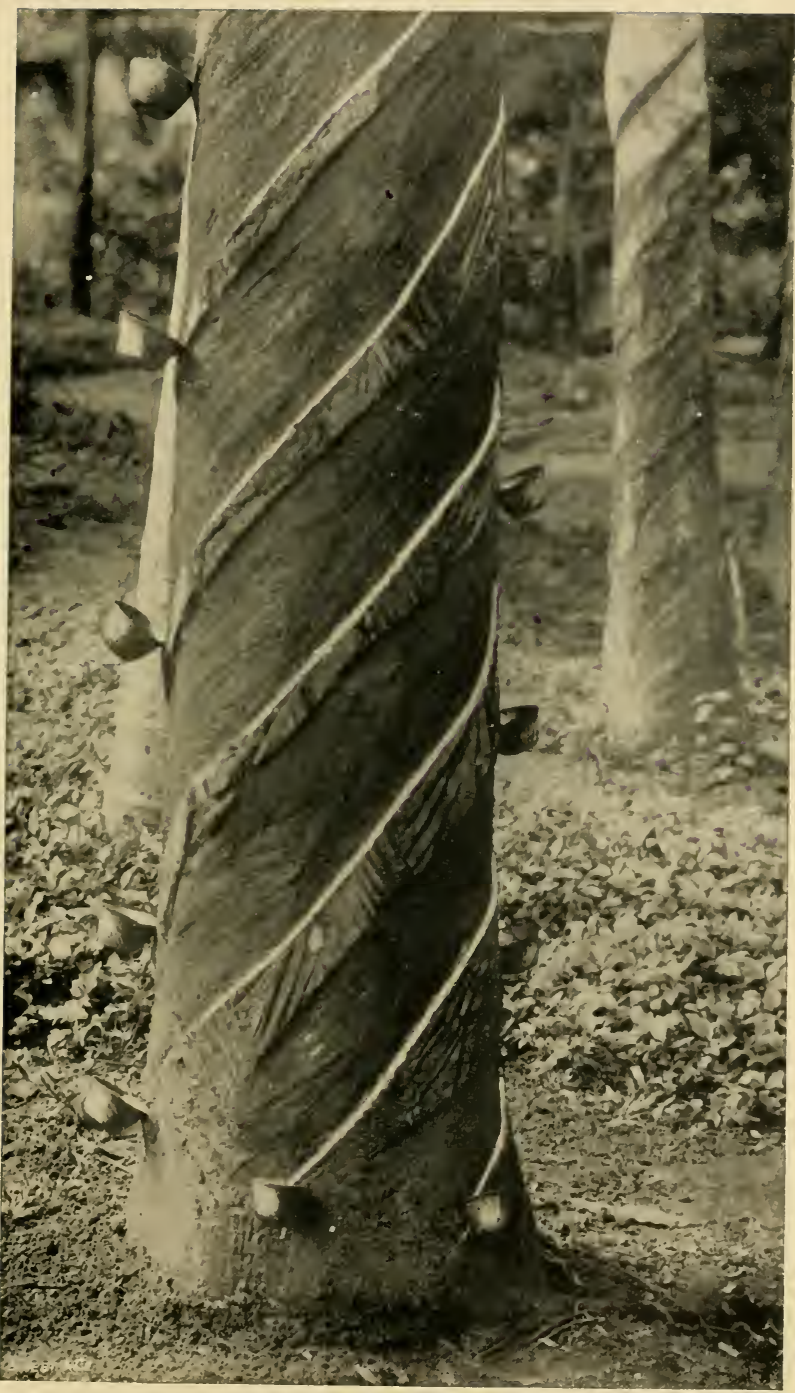

HALF SPIRAL SYSTEM. 

to these, other experiments were conmenced in order to dete mine the yield of dry rubber obtainable from different sections of the tree above the area usually tapped on estates.

\section{Rubber-yielding Capacity of Different Areas. Base to 50 jeet.}

Yield of dry rubBase to 6 to 1610 to 2020 to 30 Base to Base to
5 \& 6 ft. feet. ber per 5,000
lb.
lb.
lb.
lb.
lb.
lb. square inches

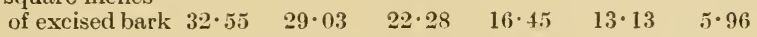

The above results were obtained at Henaratgodla between September, 1905, and February, 1906, the system of tapping adopted being the full herring-bone. In most eases the quality of the rubber was good; the quantities are as given in the above synopsis.

These experiments prove most definitely that the first six feet of bark produce larger proportions of rubber, per unit of excised bark, than any other, and that there is a general deerease in the rubber-yielding capacity of the bark the higher one goes up the stem. In the above results one ean diseern a fairly regular agreement, and as the figures for parts of the stem as ligh as fifty feet from the base have not been given before, the conclusions to be drawn are all the more interesting. Other results over larger surfaces agree, more or less, with the above, except that the average yield of rubber per square foot is often higher than that here given for the stem between 6 to 16 feet.

\section{Tappings give $3 \frac{1}{6} \mathrm{lb}$. Rubber.}

It is of considerable interest to note that though the rubberyielding capacity of the eortex of the stem gradually decreases from below upwards, the yield of rubber obtainable from the higher parts of single trees, similar to those at Henaratgoda, is often surprisingly large. The following results show that as much as $3 \frac{1}{6} \mathrm{lb}$. of rubber may be obtained from one tree in 16 tapping operations.

Where tapped.

6 to 16 feet

10 to 20 feet

20 to 30 feet

Base to 30 feet

Base to 50 feet
Number of times tapped.

16

16

16

23

8
Yield of Rubber. per tree. 2 lb. $5{ }_{10}^{5} \mathrm{oz}$. 3 lb. 3 oz. $2 \mathrm{lb} .6 \mathrm{oz}$. $4 \mathrm{lb} .6 \mathrm{oz}$. $1 \mathrm{lb} .10 \mathrm{oz}$. 
Other trees, tapped at similar levels, show very large but variable yields.

\section{Average Yielding Capacity of the Cortical Tissues.}

The yielding capacity of the Para rubber tree is influenced by its constitution and environmental conditions, and it may, at first, seem impossible to arrive at any reliable conclusions as to the rubber capacity per square foot or yard of cortical tissue. Dr. Haas has determined the rubber-yielding value, under known conditions, per square metre of cortex for certain Para rubber trees in Java. A large number of results will be required before anything deflnite can be asserted, and the following figures should be useful for comparison with those of other observers. The experiments were carried out at Henaratgoda between September 26, 1905, and February 13, 1906 , on trees 15 to 20 years old. The original groove, about onequarter of an inch wide, was made without obtaining rubber in quantity ; in subsequent operations the bark was removed by paring only when the yield of latex obtained by pricking the tubes was considered too small. The rubber was therefore obtained more by incising rather than excising the latex tubes.

\begin{tabular}{|c|c|c|c|}
\hline Tapping Section. & $\begin{array}{l}\text { Area excised, in } \\
\text { square inches. }\end{array}$ & $\begin{array}{l}\text { Yield of } \\
\text { Rubber. }\end{array}$ & $\begin{array}{l}\text { Yield of Rubber. } \\
\text { in ounces, per } \\
\text { square foot o } \\
\text { cortex removed. }\end{array}$ \\
\hline Base to 5 and $6 \mathrm{ft}$. & . $7,348 \frac{1}{4}$ & $471 \frac{5}{6}$ & $14 \cdot 8$ \\
\hline 6 to 16 feet & $796 \frac{1}{2}$ & $4 \frac{5}{8}$ & $13 \cdot 37$ \\
\hline 10 to 20 feet & $\ldots \quad 1,472 \frac{1}{2}$ & $6_{16}^{9}$ & $10 \cdot 26$ \\
\hline 20 to 30 feet & . $1,424^{3}$ & $=\frac{11}{16}$ & $7 \cdot 58$ \\
\hline Base to 30 feet & . 1,666 & $4 \frac{3}{8}$ & $6 \cdot 05$ \\
\hline Base to 50 feet & . $\quad 2,726$ & $3 \frac{1}{4}$ & $2 \cdot 74$ \\
\hline
\end{tabular}

The above results show what may, on an average, be expected by different systems of tapping-spiral and herring-bone-from parts of the tree from the base to a height of fifty feet. The trees, on account of their age, had moderately thick bark tissues, and the average yields per square foot are higher than those obtainable from younger trees. It is important to note that an average yield of over 13 ounces of rubber may be obtained per square foot of excised cortical tissue from the base up to 5 or 6 feet and from 6 to 16 feet from the base. It remains to be seen what proportion of rubber the remaining and renewed bark will give. In a fairly general way it may be stated that an increase in circumference of five inches gives an increase in the basal tapping area of 360 square inches, and from such an area an average of about $\frac{1}{2}$ lb. of dry rubber may be extracted from the bark of trees younger than those just dealt with. 


\section{Comparison of Yields obtaned at Henaratgoda.}

The following synopsis is given to bring the results at Henaratgoda up to date; the yields from all the systems employed are included:-

\begin{tabular}{|c|c|c|c|c|c|c|c|c|c|}
\hline \multicolumn{2}{|c|}{$\begin{array}{l}\text { Method of } \\
\text { tapping. }\end{array}$} & $\begin{array}{l}\text { Number } \\
\text { of Trees }\end{array}$ & $\begin{array}{l}\text { Are: } \\
\text { tapp }\end{array}$ & ed. & $\begin{array}{l}\text { Nun } \\
\text { imes }\end{array}$ & $\begin{array}{l}\text { nber of } \\
\text { s tapped }\end{array}$ & & $\begin{array}{c}\text { Total } \\
\text { of Ru }\end{array}$ & ield \\
\hline 'ull Spiral & (A & $\begin{array}{l}\text { tapped. } \\
. \quad 25\end{array}$ & Base & to $66^{\prime \prime}$ & & 57 & & 71 & 1. \\
\hline , , & , (I) & .. 5. & Base & to $60^{\prime \prime}$ & . & 168 & & 42 & $7 \frac{2}{8}$ \\
\hline ., &,$\quad(\mathrm{E}$ & . & Base & to $60^{\prime \prime}$ & . & 83 & & 49 & $\frac{8}{8}$ \\
\hline , &,$\quad(\mathrm{F}$ & 5. & ," & , & .. & 28 & & 12 & 9 \\
\hline ", & $\Rightarrow \quad(\mathrm{G}$ & .5. & ," & ", & .. & 7 & & 0 & $15_{8}^{\circ}$ \\
\hline &,$\quad(H$ & 5. & ", & & .. & is & & 13 & \\
\hline ," & (I) & . & ," &, $6 z^{\prime \prime}$ & . . & 157 & & 38 & \\
\hline & (I) & .. & ., & .. $30^{\prime \prime}$ & . . & ; & & 7 & 13 \\
\hline Half-Spira & al (B & . . 25 &, &, $666^{\prime \prime}$ & ... & 6 & & 46 & \\
\hline \multicolumn{10}{|c|}{ ull herring- } \\
\hline bone & (C) & .. 2.5. & & , $66^{\prime \prime}$ & . & .57 & & 72 & \\
\hline &, & .. & 6 to 1 & & $\ldots$ & 4.5 & & 10 & \\
\hline 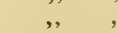 & ," & .. & 10 to & 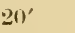 & .. & 4 & & 4 & \\
\hline & ic & 2. & 20 to & & .. & . 44 & & 0 & \\
\hline &,$\quad$ (I & . . & Bas & to $30^{\prime}$ & & 47 & & 9 & \\
\hline ," & , (V) & .. & Base & to $50^{\prime}$ & & 37 & & 13 & \\
\hline
\end{tabular}

The above results have been obtained from the 26th September, 1905, to April, 1906, from trees at Henaratgoda ranging in age from 15 to 20 years. In all cases but little of the available bark lias been excised, the excised area measuring from $\frac{1}{2}$ to $2 \frac{1}{2}$ inches only in width, the original cuts being 12 inches apart.

\section{RUBBER FroM SHAVINGS.}

According to MIr. G. H. Golledge it is estimated, in the Straits, that the shavings from 100 coolies' work will give about $25 \mathrm{lb}$. of dry rubber, but he is inclined to think that the parings to produce this must be rather thicker than those produced on carefully worked estates in Ceylon. Mr. Golledge's figures are not final, but experience shows that he can obtain from $100 \mathrm{lb}$. of shavings some 7 to $8 \mathrm{lb}$. of dry rubber by the use of a rubber washing machine, consisting essentially of two rollers driven at different speeds under a stream of water.

\section{Rubber Yield in The Stratts.}

The results obtained by Ridley, Stanley Arden, Derry, and others have been published from time to time, and from them the following synopsis is made. The range in yield varies from 10 ounces per tree for 6-year-old trees to $9 \mathrm{lb}$. per tree for older specimens; in one ease as much as $3 \mathrm{lb}$. of rubber has been reported from a well-grown three-year-old tree. Some trees, having a circumference of 36 inches have given $3 \mathrm{lb}$. of dry rubber per tree; other trees, 24 inches or more in circumference, have been known to give only $21.0 z$. of dry rubber each, probably on account of their being too young. 
The following results" are of considerable interest, as they show the yield obtained by tapping trees of different ages on 12 alternate days by the herring-bone system :-

\begin{tabular}{|c|c|c|c|c|c|c|}
\hline No. & & $\begin{array}{l}\text { ference } \\
\text { ground }\end{array}$ & & $\begin{array}{l}\text { Age. } \\
\text { Years. }\end{array}$ & & $\begin{array}{l}\text { Yield. } \\
\text { Ounces. }\end{array}$ \\
\hline 1 & . & $17 \frac{1}{2} \mathrm{in}$. & .. & $3 \frac{1}{2}$ & $\ldots$ & $1 \cdot 5$ \\
\hline 2 & .. & $26 \frac{1}{2}$, & .. & 4 & .. & $2 \cdot 2$ \\
\hline 3 & .. & $26 \frac{1}{3}$, & .. & 7 & $\therefore$ & $14 \cdot 27$ \\
\hline 4 & .. & $393 \%$ & . & 8 to 9 & .. & 16.7 \\
\hline 5 & .. & - & $\because$ & 10 & $\because$ & 28.2 \\
\hline
\end{tabular}

From these and other results Arden concluded that trees under four years were too young to be tapped, and that an average annual yield of 12 ounces per tree should be obtained from trees 6 years old. Other results have shown that an average of $3 \mathrm{lb}$. of rubber per tree per year, from trees in their 11 th to 15 th year, may be reasonably expected.

Two very old trees at Perak, $\nmid$ having a circumference of 56 to 89 inches respectively, and reported to be $\mathbf{2 5}$ years old, have given in two months' tapping no less than 12 and $18 \mathrm{lb}$. of dry rubber, including scrap.

Other trees at Peral:, 14 years old, have given an average yield of over $4 \mathrm{lb}$. each, and others of the same age quoted by Johnson show a yicld of $3 \mathrm{lb} .1 \mathrm{oz}$. per tree in Malacca, and 6-year-old trees in Selangor $1 \mathrm{lb} .2 \mathrm{oz}$. per tree. The figure on Plate 1 , series $\mathrm{B}$, shows a tree being tapped on the herring-bone system in Malacca.

The Sandyeroft Rubber Co., in their annual report for $\mathbf{1 9 0 5 ,}$ state that 4,050 Para rubber trees were tapped during the first portion of the year, and these 4,050 trees were re-tapped 6 months later together with 5,238 other trees : the dry rubber from these tappings totalled $6,979 \mathrm{lb}$. sheet and $1,823 \mathrm{lb}$. scrap, or a total of $8,802 \mathrm{lb}$. of rubber from 9,288 trees.

In Java, according to Dr. Haas, there is a large variation in the yield of trees of the same age or between equal areas of bark on the same tree.

\section{RUBber Yielde IN INdA DURTig 1906.}

There are very few records of the yield of rubber in South India, but in a recent issue of the Madras Mail information was given regarding the growth and yield obtained on Hawthorne Estate, Shevaroy Hills. On this property the Para rubber is growing among coffee, at an elevation of 3,000 to 3,500 feet, and in a climate having only about 50 inches of rain annually. The photographs of the rubber on this estate show fairly good growth, most of the trees having been allowed to produce tall and slender stems. Early in 1906, 91 Para rubber trees, twelve of which were seven years old and

* Report upon Hevea brasiliensis in the Malay Peninsula, Stanley Arden

$\dagger$ India Rubber Journal, Nebruary, 1903. 
the rest five and six years, were tapped, and an average yield of $1 \mathrm{ll}$.) of dry clean rubber per tree for one month was obtained. An estimate of 1 to $1 \frac{1}{2} \mathrm{lb}$. of rubber per tree, per year, was given as the probable yield in the future, hased upon the above results. In conjunction with this it must be remembered that at an elevation of 2,600 feet in Ceylon, in a relatively dry climate, a yield of $2 \mathrm{lb}$. of rubber per tree has been obtained during 1905.

On the Mergui Rubber Plantation, South India, tapping by the $V$ method was recently carried out, and it was found that morning tapping gave much better results than evening tapping. The figures for the whole season show the average quantity of latex per incision, each 6 inches in length, obtained in the morning to be 3.54 c.c. compared with 1.89 c.c. in the evening. Tapping in the rains was found to give almost double the amount of latex per incision, namely, $6 \cdot 62$ e.e., but the yield of dry rubber per 1,000 c.e. of latex was much less, being $1: 2 \cdot 8 \mathrm{oz}$. as eompared with $16 \cdot 4 \mathrm{oz}$. from morning tapping and $15 \cdot 1 \mathrm{oz}$. from evening tapping before the rains. The best season for tapping was found to be from October to February.

\section{Yields in The Gold Coast.}

Four trees, 10 years old, were tapped for the first time in 1903, and yielded $4 \mathrm{lb} .3 \mathrm{oz}$. of dry rubber, or an average of $1 \mathrm{lb}$. $3 \mathrm{oz}$. per tree. Notwithstanding the quantity of rubber extracted, Johnson states that the trees show no signs of having suffered in the slightest degree.

The amount of rubber yielded by the Para and African trees* may be compared by consulting the tables given below :-

Number of. Agre of Trees, Date of Average yield of Trees tapped. in years. Tapping. Rubber per tree.

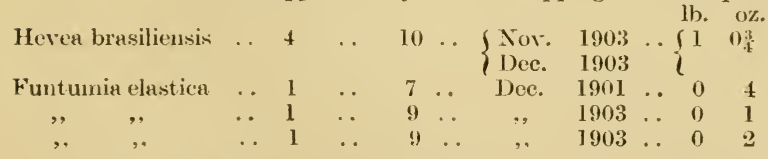

Regarding the yield from Hevea brasiliensis, Johnson remarks that it must not be taken as a criterion of the anticipated yield for trees of this age cultirated in West Africa, and points out that the trees referred to are growing in poor, gravelly soil on the top of a hill under unfavourable conditions.

\section{Estimate of YieL1).}

From these and other considerations it is obvious that to offer an estimate of the yield from trees of known age, one must be conversant with the climate and soil conditions, the available tapping area, the trees, and the method and care adopted in tapping operations. The results warrant the conclusion that trees from four

* Jolmson's Report on Rubber in the Gold Coast, 1905. 
to six years onwards, having a minimum circumference of 20 inches, may be expected to yield an average of one to three lb. of dry rubber per tree each year up to their 10th year, and a higher yield in subsequent years. The adoption of better systems of tapping, which obviate the necessity of paring away the tissues wherein the milk accumulates, and drawing supplies of latex by merely cutting and not excising the laticiferous tissues, is bound to result in an increased yield, since the life of the tapping area is so much prolonged. The fact that a few well-developed trees have been made to give as much as 12 to $25 \mathrm{lb}$. of rubber per year, and promise abundant yields in the very near future, shows? what a tremendous amount of material there is to draw upon, providing the environs of the plant and tapping operations are fully understood. The heavy yields reported in one part of this chapter are, however, from exceptional trees, and when forming an estimate of the average yield over a large acreage may be neglected.

The reader is referred to the details given in the present chapter, showing the yields obtained from Ceylon properties during 1905 , and those giving the yield of rubber per square foot of cortical tissues removed, if he is anxious to form an estimate of the rubber obtainable on an estate where the available tapping area and bark thicknesses are known.

\section{The Effect of Repetitional, Bark Stripping.}

It is common knowledge that many of the excessive yields have been obtained by completely excising the whole of the bark tissues from the base up to a height of six to fifteen feet, and it is natural that some questions should be put forward as to the probable effect of such treatment on the plants.

At the outset it must be recognized that the great function of the cortical or bark tissues is to conduct the elaborated food materials produced in the leaves, from above downwards, to various sections of the growing plant and also to store up, in certain of its cells, a quantity of food as reserve material. As a store house and conducting channel it is of vital importance to the plant, and if it is removed too quickly the life of the tree may be endangered. The internal wood, though of great importance to the plant in conducting, from below upwards, the water and mineral food absorbed by the roots, is less vital than the cortex, and the internal portion may, to a certain extent, be dispensed with without very seriously injuring the tree. The cortical tissues are dependent for their renewal on the activity of the cambium-a delicate tissue separating the inner cortex from the wood-and in the natural course of events gradually dry up near the surface and peel off in the form of dead bark. The inner cortex, originally containing the latex tubes, is therefore ultimately cast off as dead bark, so that it may be said that cortical stripping, in tapping operations, is one way of expediting the removal of the bark tissues and may be effected without seriously disturbing the execution of the normal functions of the plants. 


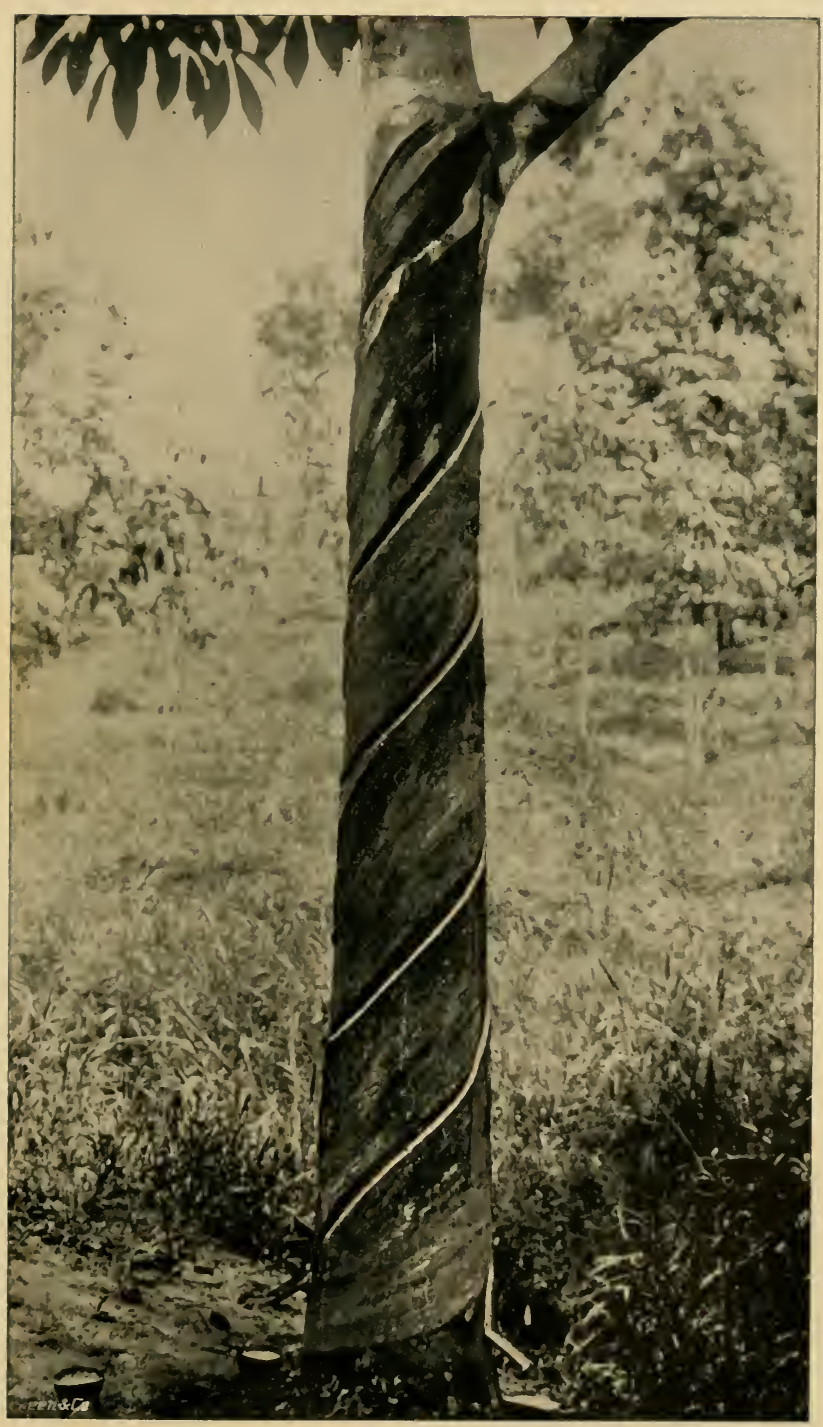

Photo by D. L. innuardane.

TAPPING THE RENEWED BARK AT ELPITIYA

THE FIRST CORTICAL STRIPPING GAVE 16 LB. OF RLBBER IN 1 YFAR, 

It must be obvious to every one that the stripping of the bark, as executed in tapping, is an unnatural process and not exactly comparable with the same phenomenon in nature. It differs from the natural process in so far that the cortical cells are excised while they are in a living condition, and are entirely removed at a time when they contain reserve food intended for the use of the plant; it also differs from the natural process in so far that the average operator exposes the inner and more delicate and vital tissues of the cortex and cambium to atmospheric influences. Such treatment does affect the vigour of the trees, and if carried out too frequently may hasten the death of the plants. Under these circumstances it may be suggested that the complete stripping of the bark, every year, is a forward but dangerous plan on which to work. The writer has seen many trees which are not thriving under such a treatment, and is inclined to recommend it only in cases where thinning-out of the trees is desired. (On many estates where the parallel tapping lines or areas are originally planned out twelve inches apart, the bark can be excised at the rate of one inch per month, which means complete stripping in a year, or an inch may be made to last from two to four months.

\section{Excision and Incision.}

If the area is excised at such a rate that the whole of the bark is removed in three years, the oldest renewed tissue, by the time it can again be tapped, may be considered near maturity, and can be operated on with comparative safety. Three to four years is near the minimum time required for the young plants to produce what is considered mature bark, i.e., fit for tapping. The suggestion for less rapid excising is made from a study of the observed effect on Para rubber trees in Ceylon, and it is a question whether it would not be better to only excise the bark tissues when fresh areas are required for the use of the pricking instrument. It is very doubtful whether the paring of the bark should be looked upon as the one and only operation required to obtain a flow of latex; it might, perhaps, be better regarded as a means of facilitating the collection of the latex obtainable by incising and not excising the milk tubes.

The effect of paring away the outer bark and exposing the internal and more delicatestructures to atmospheric intiuences has in some cases been detrimental. In a particular case in mind the inner tissues dried up and peeled off in flakes, exposing the whole of the wood. This effect is more noticeable on Ceara rubber trees, but is also known to occur on trees of Para rubber. It has been suggested that a covering of some waterproof material or of any substance which, while affording protection from rain or sun, will not harbour insects, might be used to cover the tapping area or renewed bark when collecting operations have been completed. The covering might be arranged loosely in the form of a mantle or be wound round the oblique excised areas like an ordinary " puttie" for one's legs. 


\section{CHAPTER $\mathrm{X}$.}

\section{PHYSICAL AND CHEMICAL PROPERTIES OF LATEX.}

Colour-Consistency-Alkalinity-Sap exudations and acidityCaoutchoue globules-Object of producer-Mechanical impuritiesAnalyses of the latex of Para rubber by Seeligmann, Feraday, Scott, and Bamber-Variation in composition-Properties of caoutchoue -Occurrences of resins and oily substances-Sugars-Proteids or Albuminoids-Removal of proteids with formaldehyde and centrifugal separators-Mineral matter-Effect of temperature, ammonia, formalin and acids on coagulation.

\section{The Physical Properties of Latex.}

$7 \mathrm{TE}$ latex of Hevea brasiliensis, as it flows from a freshly made 1 incision, is white or pale yellow in colour, and varies in consistency mainly according to whether drought or rainy weather prevails. It is slightly alkaline when fresh, and, as it flows from the tree, consists of minute globules of caoutchouc and other bodies suspended in a liquid containing various materials in solution and a varying proportion of mechanical impurities.

The latex obtained from the first incisions usually contains a large proportion of sap exudations, which cannot be excluded as they How from the freshly-cut cortical cells; they can be reduced by incising instead of excising the laticiferous tubes. In several instances the latex, by mixing with such exudations, becomes neutral, and may rapidly develop acid properties. The conversion to an acid state is followed by coagulation, and hence the first tappings are frequently but unavoidably accompanied by a large proportion of scrap.

The object of the producer in the Tropics is to separate the globules of caoutchouc from the mechanical impurities and some of the materials in solution, and it is necessary to explain clearly what these substances are and their general characteristics.

The planter, who aims at producing the highest quality of rubber or perfecting the chemical and mechanical processes involved in its manufacture from latex, must thoroughly grasp the nature of the substances he has to deal with, and it is, therefore, necessary to enter into a little detail.

The mechanical impurities present in most samples of latex in the field consist of pieces of bark, fibre, sand, \&c., and they may be easily separated by filtering the diluted solution through butter cloth or fine gauze. 
The filtrate from such material is composed of water, caoutchouc, resins, proteids, sugars, gums, insoluble substances, and mineral matter. The amount of water in pure latex varies considerably, but it is usually estimated at 50 to 56 per cent. The latex from trees which have been frequently or heavily tapped usually contains a much higher proportion of water ; in some instances even as much as 90 per cent. of water is present. The latex collected during the dry months of February and March at Henaratgoda contains much less water than that obtained from the same trees in the rainy season. The following table will serve to indicate the general range in composition according to the analyses of Seeligmann,* Lascelles Scott, and Bamber :- +

\section{Analsses of the Latex of Hevea Brasilievsis}

\begin{tabular}{|c|c|c|c|c|c|c|c|}
\hline & & & eeligmann. & & $\begin{array}{l}\text { Scott. } \\
\text { per cent. }\end{array}$ & & $\begin{array}{l}\text { Bamber. } \\
\text { per cent. }\end{array}$ \\
\hline Water & & .to & 55 to 56 & . & $52-32$ & .. & $55 \cdot 15$ \\
\hline Caoutc & or & . & 32 & $\ldots$ & $37-13$ & . & $41 \cdot 29$ \\
\hline I'roteic & bui & $\therefore$ & $2-3$ & . & $2-71$ & .. & $2 \cdot 18$ \\
\hline Resin & .. & .. & Traces & . & $3-44$ & & \\
\hline Ash & .. & .. & & . & $0-23$ & .. & 0.41 \\
\hline Sugar & .. & .. & & .. & $4-17$ & $\cdots$ & $0 \cdot 3$ \\
\hline Salts & .. & .. & & .. & & $\cdots$ & \\
\hline Essent & & $\cdots$ & $9-7$ & $\ldots$ & Traces & 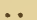 & \\
\hline
\end{tabular}

The above analyses show the general composition of the latex of Hevea brasiliensis and the different classifications adopted by chemists. The analyses by Lascelles Scott is one of a latex of unnamed origin, but Weber accepts it as being not far from the truth for our species. There is an indefiniteness about several of the constituents, which are grouped under such general heads as proteids, resins.

It will be noticed that the caoutchouc varies from 32 to over 41 per cent., and the other constituents such as resin, sugar, insoluble substances and the ash show considerable variation. This is not surprising, as the latex examined in each case was obtained from a different country and the ages of the trees were probably quite different. Furthermore, the methods of extraction of the latex involve the cutting of bark tissues to different depths, and the inevitable mixing of liquids would account for much variation in the soluble impurities.

\section{Caoutchouc Globules.}

The caoutchouc exists as globules in suspension. When pure it is practically colourless, and is much lighter than water. It consists essentially of carbon and hydrogen, and belongs to a class of bodies known as terpenes. It is insoluble in water, but according to Weber

*India Rubber and Gutta Percha, by Falconet, Seeligmann, and Torrillom, 1903, p. 84 .

† Bamber, Circular R. B. G., June, 1899. 
may be obtained fairly pure by making a benzene solution, allowing the insoluble matter to settle out, and subsequently precipitating the rubber from the clear solution by the addition of alcohol.

\section{Resinous and Sugary Substances.}

The resins, gums, and oily substances are present in varying quan. tities. Generally the latex from young trees, branches, and twigs contains a large proportion of these substances ; they may occur as globules suspended in the latex or in solution. In the ordinary processes of coagulation the greater part of the resin becomes part and parcel of the rubber, and the extraction from the latter by the manufacturers in Europe is a difficult and tedious task.

The sugars are rarely present in large proportions, and a maximum of 0.5 per cent. may be taken as correct. The yare known as inosite, ${ }^{*}$ bornesite, matezite, and dambinite, and are dissolved in the liquid in which the globules of caoutchouc and resins are suspended, and in the washing of the freshly-coagulated rubber are generally removed.

\section{The Proteins.}

The proteid or albuminous matter, about which more will be said, varies from $1 \cdot 9$ to $2 \cdot 7$ per cent. of the fresh latex, or approxinately 3 to 4 per cent. of the dried coagulated product. This is a very high proportion, but from the analyses quoted above no other conclusion can he drawn. It is believed that this proteid matter is of a con:plex nature, and, alone or with the gums and sugars, is responsible for the development of bacteria nn the finished product, which lead to putrefaction or "tackiness." The use of formaldehyde in connection with the elimination of the proteid matter has been corsidered when dealing with coagulation.

When the rubber is prepared by simple roagulation the insolubie proteids become a part of the rubber, but if a centrifugal method is adopted, and the freshly-coagulated material frequently and well washed, pressed and dried quickly, a considerable amount may be removed or rendered less harmful. In the purification of rubber this subject will be dealt with. It is believed that the removal of the proteids from the commercial rubber, though so much desired, is almost impossible, and in the perfecting of mechanical processes and the use of antiseptic reagents for dealing with the proteids in the latex as it comes from the tree lies a considerable amount of important profitable work for the planters in the Tropics.

The mineral matter occurring in suspension and solution in the latex and the various insoluble compounds indicated in the analyses previously quoted, may be regarded as impurities of minor importance, and can be better dealt with in the sections concerned with the components of commercial rubber and the purification processes. 


\section{Geveral. Characters.}

The behaviour of the latex, when subjected to physical and chem. ical agencies, may here be touched upon. It readily mixes with water without creaming. Parkin kept some latex diluted four times in an ice chamber for days without showing any signs of creaming. It is very difficult to separate the caoutchouc by centrifugal force, and on several occasions a speed of over 10,000 revolutions per minute did not effect a separation of the caoutchouc of normal latex. The effect of freezing was tried by Parkin, a mixture of ice and common salt being used to give the low temperature; after thawing, the latex appeared to be the same as before, and creaming was not hastened by the changes of temperature. Addition of ammonia or formalin prevents or delays coagulation, the former by neutralizing the acids as soon as they are formed, and the latter by acting as an antiseptic and preventing the decomposition of the proteid matter. Acids bring about coagulation in the cold, but the action is much quicker when warmed. The latex may, however, if diluted, be boiled and yet coagulation is not brought about.

These points should be borne in mind by the planter who is inclined to experiment mechanically and chemically with the object of extracting the undesirable substances usually present in latex.

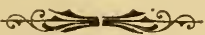




\section{CHAPTER XI.}

\section{THE PRODUCTION OF RUBBER FROM LATEX.}

Production of rubber by natural coagulation-Production on a small scale illustrated - Suggestions for curing rooms - Effect of heat and chemicals on coagulation-Smoking and coagulation-The eleemistry of the Amazon method-Coagulation by chemical reagentsAcetic acid-Formic acid-Hydrofluoric acid-Tannic acid-Corrosive sublimate-Amount of acid to be used-Determination of completeness of coagulation-A method of determining the amount of acetic acid required-Advantages and disadvantages of adding chemicals to the latex-Value of acids and preservatives discussed-Components of coagulated rubber-Amount of proteid in mother liquor and rubber -Putrefaction of rubber-Analyses of sound and tacky rubberKeeping the proteid inactive-Antisepties, drying, dilution, and washing-The removal of the proteid from the latex-Formalin and sodium sulphate-Rapid coagulation and removal of proteids by mechanical means-Biffen's centrifugal machinc-Experiments in Ceylon with the Aktiebolaget Separator-Principles of mechanical separation-Rapid coagulation by mechanical and other meansThe Michie-Golledge machine: construction, action, and illustration -Mathieu's apparatus.

$\mathrm{H}$

AVING briefly described the physical and chemical properties of the latex as it is obtained in the field, it now remains for us to consider the operations upon which the production of good rubber from latex depends. If the pure latex is allowed to stand in a receptacle, it finally coagulates and the caoutchouc globules with other substances float to the top, leaving a more or less clear liquid behind.

By the addition of chemical reagents or by subjecting the latex to different temperatures coagulation may be hastened or retarded. The coagulated substance after washing, pressing, and drying is ultimately known as the rubber of commerce.

In the production of rubber from latex the planter may either take advantage of the presence of coagulable constituents in the latex or adopt chemical and mechanical means for the separation of the caoutchouc globules from the rest of the latex.

\section{Production of Rubber by Natural Coagulation.}

This change is due to the presence, in solution, of albuminous o.I proteid matter, which quickly coagulates or becomes insoluble. The coagulated proteid carries with it the suspended globules of caoutchouc and other bodies, so that the whole process is more or less one 



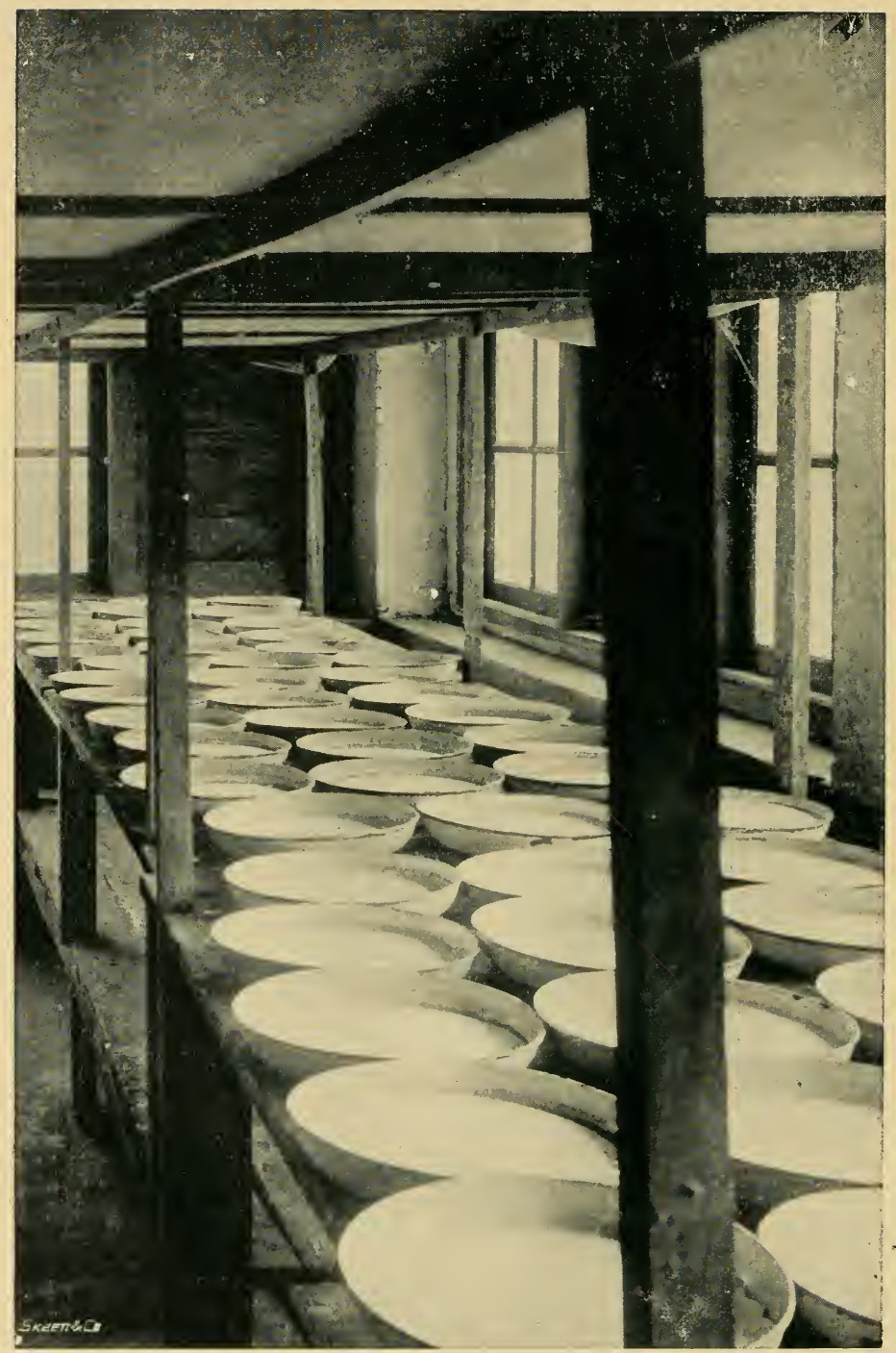


of clarification, the liquid left behind usually containing only those ingredients of the latex which have remained in solution. The coagulation of the proteid material occurs as soon as the latex becomes neutral or faintly acid, no matter what proportion of suspended globules of caoutchouc or other constituents may be present in the latex.

Burgess states that the natural method of coagulation is only possible where a washing machine is used, and suggests that where the latter is in use the latex might be allowed to stand for 24 or 36 hours, and the natural fermentation allowed to take place and produce coagulation. It is difficult to understand this contention, if by a washing machine is meant one similar to that recommended by the same authority for the manufacture of crêpe rubber in the Straitsindeed, if it were so it would constitute a serious disadvantage to the method of coagulation by natural means. As a matter of fact, biscuit and sheet rubber can be prepared by the natural and artificial methods with equal ease, without the use of any machinery beyond an ordinary mangle and a blocking apparatus.

On estates where the daily quantity of latex is small, the use of chemicals and machinery for rapidly coagulating it is not always necessary; the latex is put in shallow pans (see Plate 20 , Series A), and allowed to set. The biscuits, when ready, are rolled to squeeze the water out and then placed on wire gauze, wooden, or coir shelves to dry. A strong current of dry air might be obtained by drawing the air by means of a fan through a chamber containing chemicals such as freshly-burnt lime or calcium chloride, which would absorb the water. It should not be difficult to arrange a building on a plan somewhat similar to the tea-drying and cacao-curing rooms in common use all over Ceylon.

\section{Effect of Heat and Chemicals on Coagulation.}

Some kinds of latex can be heated for a long time-almost indefinitely-without coagulation being effected, whereas other kinds coagulate rapidly on the application of heat.

According to Parkin the diluted latex of Para rubber is unaffected by boiling. If the undiluted latex is boiled, water is driven off, and the thickened milk may then become charred.

The addition of certain chemical reagents to the heated latex brings about coagulation; dilute mineral acids, acetic acid, and tannic acid are particularly active.

\section{Sioring and Coagulation.}

The coagulation of the latex may be hastened by exposing it to heat and the products of combustion of a fire. The latex can be coagulated fractionally by such a process, and the finished product, when properly manufactured, is less liable to putrefaction than the rubber prepared by many other methods. The smoke from burning palm nuts used in the Amazon district contains, among other substances, 
small quantities of acetic acid, acetone, and creosote. The acetic acid is probably the agent responsible for effecting the coagulation ; the other substances, particularly the creosote, are absorbed, the latter acting as an antiseptic in preventing the rapid decomposition of the albuminoids present. In Brazil the latex is poured into a shallow basin $60 \mathrm{~cm}$. to 1 metre in diameter and 20 to $30 \mathrm{~cm}$. deep, and pieces of bark, dirt, \&c., removed. A fire is then made of wood and resinous substances, and is kept going either with green branches of Mimusops elata, All., or with palm nuts from Attalea excelsa, Mart., and Maximiliana regia, Mart; these palms are usually grown in the Botanic Gardens of in various parts of the Tropics, the latter species being more commonly known as the "Cocurito" pa $\mathrm{m}$. A chatty, open at both ends, is placed on the fire and the smoke allowed to issue from the upper aperture.

A paddle-like implement is then dipped into or covered with the latex, and held over the smoke until the latter is coagulated. It is stated by Bonnechaux* that 8 litres of latex are completely coagulated in about $1 \frac{1}{2}$ hour by these means. The decomposition of the albuminous substances in the rubber may be prevented by the addition of suitable antiseptic reagents to the latex, when the rubber is prepared in other ways, though quickness in drying or complete extraction of the moisture from coagulated rubber is often sufficient to bring about the same result. Dickson's apparatus is devised to meet many of these requirements.

\section{Coagulation by Chemical Reagents.}

In coagulation by such means the object is to use reagents which, while effectively and rapidly precipitating the albuminous material, will not have a detrimental effect on the rubber produced.

Many compounds, such as picric acid, would rapidly coagulate the proteids, but the effect on the resulting rubber would be bad. Weber and Parkin have shown that many acids may be used in the coagulating process, but it is unnecessary to do more than mention those which have, from practical experience, been proved more or less acceptable to producers in the Tropics and manufacturers in Europe.

Acetic acid.-This is cheap, always procurable, is not dangerous to handle, and is as effective as formic acid. It is not as powerful as tannic acid, though it is effective in bringing about the coagulation of the latex while cold. The commercial article varies in strength, and the quality should be noted by the purchaser.

Formic acid.-This, though similar to acetic acid in its effect, is more expensive, weight for weight. The advantages of using this reagent are (1) that less is required than acetic acid, and (2) it has antiseptic properties. Whether acetic or formic acid is used, it should be applied in definite proportions, and no more need be used than is required to just precipitate the albumen in the latex. The same may be said of hydrofluoric acid. 
Tannic acid.-This is, according to Weber, the most powerful of the acids which ean be used for this process, and he asserts that on a laboratory scale it is excellent for use with the latex of Para rubber. If rubber coagulated by tannic acid, while still wet, be placed in an incubator at temperatures from $100^{\circ} \mathrm{F}$. upwards, it rapidly passes into a state of putrescid fermentation, but such a change does not occur if the rubber is thoroughly dry.

Mercuric choloridc.-Corrosive sublimate effectively coagulates the proteid while the latex is cold, and also acts as an antiseptic. It is very poisonous, and if used a small quantity of mercury is unavoidably left in the rubber.

AMount of ACID to Be USED.

The quantity of acetic or formic acid required depends upon the proportion and condition of the albumen in the latex. According to Weber the latex of Para rubber in its native habitat contains only about 1.5 per cent. of albumen, and one-third of an ounce of anhydrous formic or half an ounce of glacial acetic acid per gallon of the latex is quite sufficient to produce a rapid and complete coagulation. The behaviour of the latex from Para rubber trees with acids is due to the fact that the milk is, when fresh, usually slightly alkaline or neutral, and the proteid substances are insoluble in a feebly acid solution but soluble in alkaline or strongly acid solutions. It has been asserted that the proteid matter is insoluble in a neutral solution, but on several occasions the fresh latex from the Henaratgoda trees remained liquid, though the reaction with litmus paper did not indicate acidity or alkalinity. Only a small quantity of acid is required to neutralize or acidify the latex, and therefore lead to the precipitation of the proteids. It is a mistake to add excess of acetic acid, as the proteids would be partly re-dissolved and, therefore, still remain in solution.

The amount of pure acetic acid necessary for complete coagulation depends upon the quantity of proteids to be preeipitated, and the latex in Ceylon, aceording to the analyses already quoted, contains from $2 \cdot 3$ to 2.8 per cent. of these substances. If ordinary latex is allowed to stand for some time, the proteid matter decomposes and acidity sufficient to lead to coagulation is developed. Diluting the latex will not reduce the total quantity of acid required. Every 100 volumes of pure C'eylon latex require approximately one volume of pure acetic acid. MIany planters add one or two drops of acetic acid to about half a gallon of the cliluted latex. If the acetic acid is added until the mixture beeomes neutral after stirring-i.e., will neither turn litmus paper red nor blue, or until it is feebly acid-very little harm will be done. The addition of excess of acid may bring about a re-solution of the proteids and eoagulation be thereby delayed. It is very rare that the latex on a large seale is heated before treatment with acetic acid.

The completeness of the precipitation is judged by the elearness or turbidity of the liquid in which the rubber floats. When the separation of caoutchouc is complete, the mother liquor is quite clear. 
Method of Determining the Amount of Acetic Acid Required.

It has been contended that many inventions which have recently been brought forward necessitate dilution, to varying degrees, with water, ammonia, and formalin, and that such dilution prevents the planter from knowing how much latex the coolies collect, and how much acetic acid will be required in the process of coagulation. It is quite true that the latex so treated will contain varying quantities of rubber, but when one considers the variation in composition of ordinary samples of undiluted latex from different trees, or when obtained at different times of the year from the same trees, it is obvious that the same difficulty lias ordinarily to be overcome; the objection is, therefore, not a very serious one so long as latex is not sold by volume.

The application of the same quantity of acetic acid to the same volume of latex cannot be recom mended except for expediency. The acid should be added in order to neutralize or faintly acidify the latex, and it is better to determine the exact quantity required rather than add too much.

The amount of acid required can be determined with ease. Let the coolies pour the diluted latex from the different trees into a settling tank or ordinary receptacle and fill up to a known level, so that the exact volume will be known. After thoroughly stirring the mixture take a small sample of known volume and add dilute acetic acid of constant strength, drop by drop, from a burrette or graduated glass tube, until the whole mixture after stirring is neutral or faintly acicl. On measuring the volume of acetic acid used, the amount required for complete coagulation of the latex in the settling tank can be easily calculated and added. Litmus paper can be used to determine when sufficient acetic acid has been used; the resultant solution should be only faintly acid or neutral, blue litmus paper becoming faintly red and red litmus paper remaining unchanged respectively in such solutions.

Such a method involves the accumulation of the latex in receptacles of known capacity and provided with mechanical neans for keeping the latex in a liquid state. Some such apparatus may or may not be required as the trees on the various rubber estates are more frequently tapped.

Advantages and Disadvantages of adding Chemicals to the LATEx.

It has been frequently contended that the home manufacturers object to the use of chemicals in the coagulation of the latex, particularly mineral and vegetable acids, on account of the fact that even after thorough washing and pressing some of the acid may still remain in the rubber and subsequently prove harmful in the manufacturing processes. The retention of a large proportion of foreign chemical ingredients is said to lead to the production of bubbles and blow holcs and to be oceasionally accompanied by early deterioration of the prepared rubber. 
On the other hand, it can be shown that the addition of reagents such as formalin, corrosive sublimate, creosote, or acids such as formic or even hydrofluoric, have a preservative effect on the rubber when used in infinitely small quantities. When one considers the chemicals which are incorporated in rubber of good repute prepared by the natives in the Amazon district and the inert characteristic of rubber itself, the objection to the use of minimum quantities of reagents such as acetic acid and creosote seems to be less tenable. But apart from the preservative action of some of the chemicals used, there is a much more serious advantage, to the producer, accompanying the use of the required quantity of acetic acid, viz., the rapidity and completeness of the coagulation effected.

In one experiment about $1 \frac{1}{2}$ gallon of ordinary latex was poured into a large glass beaker and allowed to coagulate naturally. At the end of two days a large cake of rubber had formed at the top of the liquid, but the mother liquor was still quite milky ; the cake of rubber was removed, and subsequently thinner cakes appeared at the surface and were removed; after six days the mother liquor still remained turbid, and a further quantity of rubber was prepared from it by treatment with a small quantity of acetic acid and heating. The completeness of coagulation, when the latex is allowed to set untreated with acids, does not always take such a long time, but it is probable that the same phenomenon may repeat itself, and thus necessitate considerable delay and perhaps waste ; certainly it would involve considerable irregularity to the producer. The use of acetic acid, on the other hand, effects coagulation in a few hours, and the mother liquor becomes perfectly clear in less than a day; the precipitation is complete, and there is therefore no waste of rubber.

If the producer is compelled to cease using acetic acid for assisting coagulation, and has to produce his rubber by simply allowing the latex to slowly ferment, there are other difficulties in the way. It is obviously to the advantage of the producer to reduce the proportion of scrap in his rubber and to keep the latex flowing as long as possible, and the use of ammonia and formalin to accomplish this is being adopted on many estates during tapping operations; the presence of these reagents in the latex tends to prevent coagulation, and they would, therefore, further aggravate the question of delay necessary if the natural process of coagulation were compulsory ; a longer period of time would be required for the necessary acidity to develop in presence of either of these reagents.

In the absence of definite information from home manufacturers, the use of minimum quantities of acetic acid, determined by the simple method previously described, is likely to be continued by the producer in the Tropics, and is an essential point in the preparation of fine Para rubber in Brazil ; it will be necessary to prove that the effect of the use of acetic acid is really bad before the producer will risk the possible loss in yield suggested by the frequent turbidity of the mother liquor, and the uncertainty or delay incurred in the production of rubber from latex by the natural process. 
For the present, therefore, the application of the correct quantity of acetic acid followed by thorough washing and rolling may be adopted, but care must be exercised not to add excess, and every effort be made to subsequently expel the reagent by suitable mechanical processes.

\section{Components of Coagulated Rubber.}

Whenever the rubber is prepared by the coagulation of the proteid, either by the smoking method or the use of familiar chemical reagents, hot or cold, it is obvious that the rubber must contain the precipitated proteids together with the suspended globules of caoutchouc, resin, \&c. Analyses of well-dried Para rubber show only a small percentage of substances other than caoutchouc-practically from 4 to 5 per cent.- and it may at first sight appear unnecessary to draw attention to the desirability of extracting them. If one compares the analyses of latex and rubber from Hevea brasiliensis, it is surprising to find that when chemical reagents have been used the percentage of proteid matter in the rubber shows that the whole of that in the latex was not precipitated, and Bamber and Parkin proved that the clear liquid remaining after coagulation with acetic acid often gave re-actions with the tests for proteids. The amount of proteid in the clear liquor may, according to Bamber, be as much as 50 per cent. of the original. It may be asserted that a great part of the proteids generally occurs in the prepared rubber, and their presence along with other substances leads in many cases to putrefaction.

\section{Putrefaction and Tacky or Heated Rubeer.}

The proteid matter is responsible for much of the "tackiness" or the "lheating," which is seen in many rubber samples. The rubber first becomes sticky, and sooner or later appears to melt as if due to excessive heat. It often emits a strong odour when in this stage. This is due to the inclusion of the proteids and perhaps the sugary and gummy constituents in the rubber and the subsequent development of micro-organisms on these substances. If the rubber is free from these materials it will not undergo such a change, and the removal of the latter from rubber takes us into several important methods of purification. The chemical change which takes place in tacky rubber is indicated in the analyses, made by Mr. M. Kelway Bamber, of sound rubber and material in various degrees of tackiness. They are here quoted in full :-

Analyses of Sound and Tacky Para Rubber.*

\begin{tabular}{|c|c|c|c|c|c|c|c|}
\hline & Sound Rul & ser. & Tacky No & 1. & Tac & 2. & Very $\mathrm{Ta}$ \\
\hline Moisture & . $\quad 0.30 \%$ & . & $0.36 \%$ & . & $0.06 \%$ & . & $0.44 \%$ \\
\hline Ash & $0 \cdot 38$ & . & $0 \cdot 28$ & . . & 0.54 & . & $0 \cdot 72$ \\
\hline Resin & . $2 \cdot 36$ & . & $2 \cdot 32$ & . & $2 \cdot 66$ & $\cdots$ & $3 \cdot 70$ \\
\hline Proteids & .. $3 \cdot 50$ & . & $3 \cdot 85$ & . & $3 \cdot 50$ & .. & $4 \cdot 90$ \\
\hline Rubber & . $93 \cdot 46$ & . & $93 \cdot 19$ & 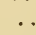 & $93 \cdot 24$ & . & $90 \cdot 24$ \\
\hline & $100 \cdot 00$ & & $100 \cdot 00$ & & $100 \cdot 00$ & & $100 \cdot 00$ \\
\hline
\end{tabular}

* Committee of Agricultural Experiments, Peradeniya, Sept., 1905. 
These analyses show a relationship between the degree of tackiness and the percentage of proteids and resins; the latter miy be due to oxidation. Too rapid drying is said to induce softening and tackiness in raw rubber.

\section{Keeping the Proteid Inactive.}

If the local conditions are such that the rubber cannot be prepared by any method other than coagulation, and the proteid and other materials must be included, it will be necessary to take steps to keep the obnoxious ingredients in a quiescent state. This can be done by treating the latex with some reagent which has antiseptie properties, such as creosote or corrosive sublimate, and quickly drying the rubber after effectively washing and pressing the freshly-coagulated material.

In some cases it is doubtful whether it is even necessary to add antiseptic reagents if the rubber is thoroughly dried, as the lecomposition of the proteids is dependent upon a supply of water being present. A communication from Messrs. Lewis and Peat on this subject is given in the chapter dealing with plantation and fine l'ara rubber.

No matter whether the latex has been treated with antiseptics or not, the coagulated substance should be very well washed; too much water cannot be used. In the washing processes the water may carry away a considerable portion of the soluble proteid or that precipitated on the surface, and thus minimise the danger.

The use of washing machinery or antisepties or both is almost certa:n to become a necessity in the near future, judging by the reports of European firms on the condition of various packages of plantation rubber which they have received. Dilution of the latex before coagulation might also reduce the proportion of proteid in the prepared rubber. The quicker and more effectively the rubber is dried, the less likelihood there is of putrefaction or tackiness setting in.

\section{The Removal of the Proteid from the Latex.}

But it is not beyond the ingenuity of the chemist or planter to treat the latex with some reagent which will keep the proteicls in solution while the caoutchoue globules are segregating, and ensure their expulsion by subsequent pressing and washing.

Weber, as the result of experiments mainly with Castilloa latex, suggested that the treatment of dilute hot solutions of latex with formaldehyde (Formalin), or the use of the latter with sodium sulphate, may be effective in reducing the amount of proteid matter in prepared rubber:-

"To every gallon of the rubber latex, from $\frac{1}{2} \mathrm{oz}$. to $1 \mathrm{oz}$. of formaldehyde (formalin 40 per cent. solution) is added, the latex well stirred and allowed to stand for one hour. Then to each gallon of latex a solution of $1 \mathrm{lb}$. of sodium sulphate (eommercial) in one pint of boiling water is added while still hot, and the mixture stirred for some 
time. Coagulation may take place immediately or after several hours' standing, according to the condition of the latex. Great care must be taken to use a sodium sulphate of entirely neutral reaction.

"What actually happens is this: The diluted rubber milk, freed from all its mechanical impurities by straining, is, to begin with, rendered non-coagulable by the addition of the formaldehyde. On adding to the rubber milk the solution of sodium sulphate the rubber substance rapidly rises to the top, where at first it forms a very thick, creamy mass, the individual globules of which rapidly coalesce. The coalesced (and as a matter of fact, not coagulated) mass, on being worked upon the washing rollers, undergoes a very curious polymerisation process, and thereby rapidly acquires the great strength and toughness so characteristic of high-class indiarubber.

"On cutting the cake open it will be found to be rather spongy, being full of little holes which are still filled with some of the albuminous, though very dilute, mother liquor. If, therefore, the rubber were dried in this state, it is obvious that it would still contain a small quantity of the objectionable albuminous matter. For this reason the rubber so obtained should at once be taken, cut into strips, and subjected to a thorough washing upon an ordinary rubber washing machine." The formalin acts more as an antiseptic to prevent the decomposition of the proteid than anything else, and does not affect the specific gravity of the mother liquor.

Johnson made several attempts, when in the Gold Coast last year, to separate rubber from Para latex in the manner above suggested, but failed in each instance, although the latex stood, in one or two instances, for nearly three weeks without the rubber separating out.

This method has been tried by many persons, and evidently requires further experiments before it can be pronounced as perfect. It should be remembered that certain reagents e.g. ammonia, serenguiana, \&c., will keep the latex in a liquid state for a very long time, and might be used with advantage in such experiments.

\section{Rapid Coagulation and Removal of Proteids by Mechanical Means.}

It has been stated that mechanical appliances have been invented which can effectively eliminate the proteid while forming part of the latex

\section{Biffen's Centrifugal Machine.}

Biffen* recognized that in latex the indiarubber existed as suspended globules, lighter than water, and employed for separating the caoutchouc, a centrifugal machine similar to that used in separating butter from milk. The machine is a modified form of the ordinary centrifugal milk tester, capable of being rotated 6,000 times per minute. The caoutchouc of Para latex is said to be effectively separated in a few minutes and to consist of the pure

*Biffen; Annals of Botany, June, 1898. Journal of the Society of Arts, 1898. 
SERIES A. Pl. 21.

Fig. 1.

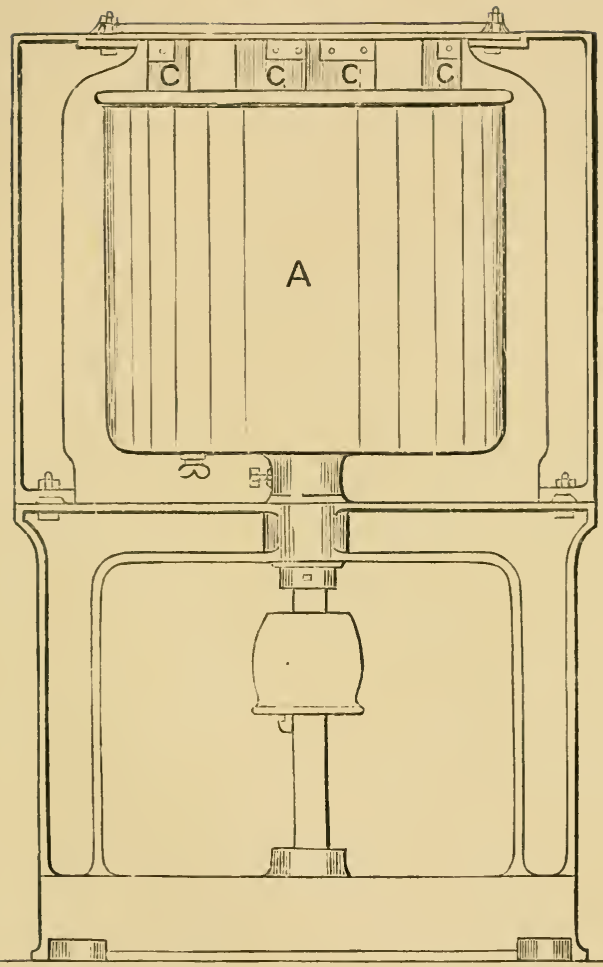

fig. 2.

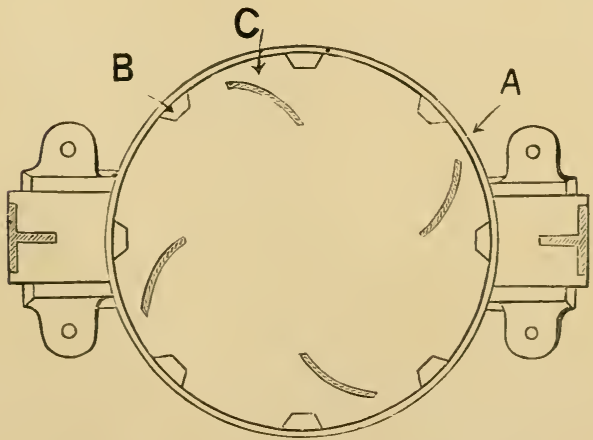

THE MICHIE-GOLLEDGE COAGULATOR. 


SERIES A, PL. 22.

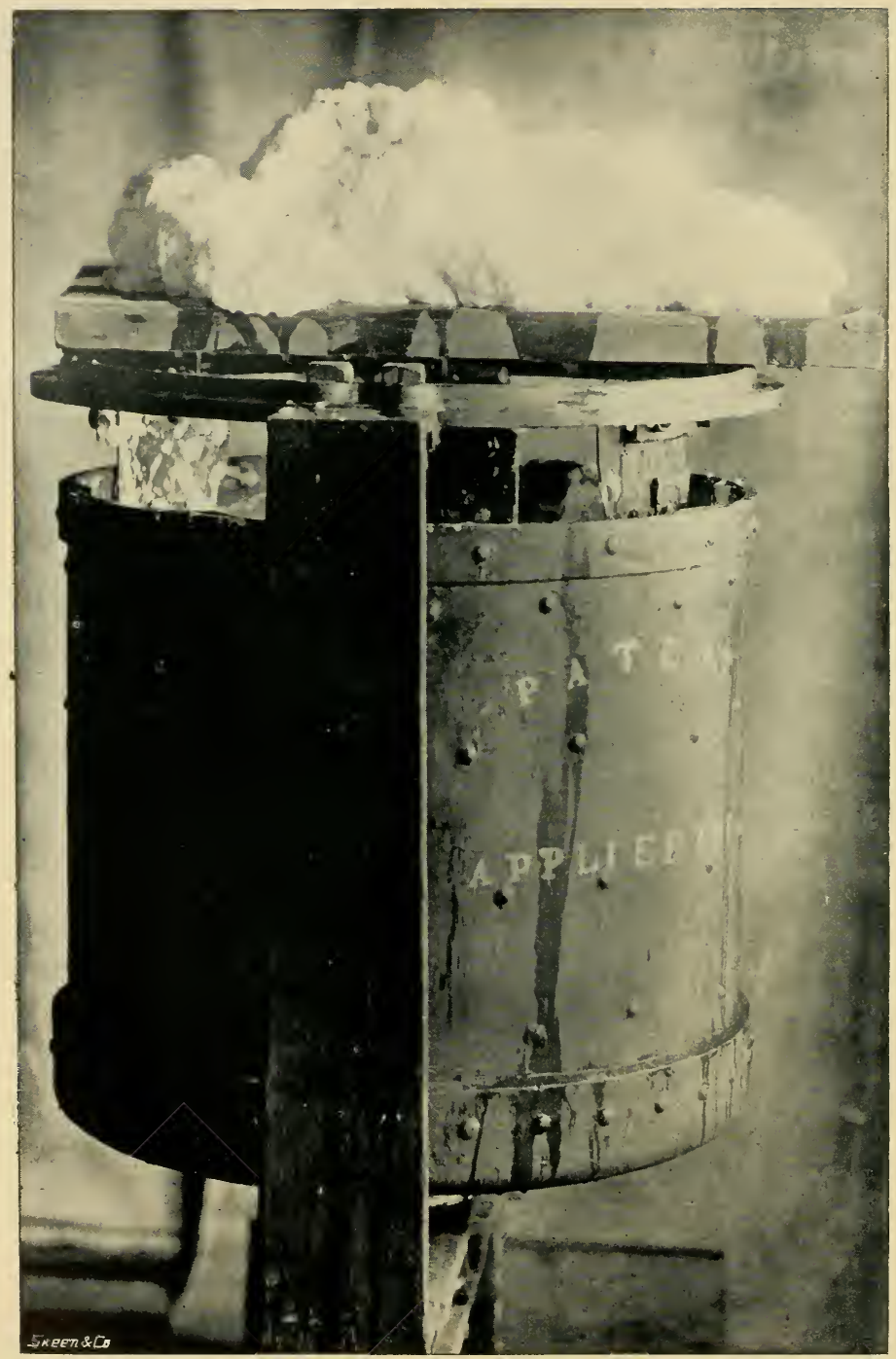

THE MICHIE.GOLLEDGE COAGULATOR.

Photo by C. H. Kerr.

THE SPONGY MASS OF FRESHLY COAGULATED RUBBER IS SHOWN AT THE TOP. 
article, free from mixtures of proteids, resins, \&c. Weber strongly recommended such a process of treating the latex for eliminating proteid constituents.

Biffen claims that the rubber may thus be prepared by purely physical means; the light rubber globules are thrown out of the bowl in an almost dry state, and the rubber is free from any obnoxious smell and danger of decomposition. It is, however, questionablo whether pure caoutchouc free from resinous and other impurities is desired by the manufacturers.

\section{Experiments in Ceylon.}

Furthermore, several small experiments carried out in Ceylon have proved that the caoutchouc in ordinary Para latex is not rapidly separated by the centrifugal machine, even when the speed is as high as 11,000 revolutions per minute. In these experiments various heavy chemicals have been added to the latex after the formalin; the chemicals used do not show an acid reaction, and considerably increase the density of the alkaline mother liquor. The whole of this mixture has been placed in the "Aktiebolaget Separator," and then been subjected to centrifugal force for over an hour, and yet the caoutchouc globules have not been effectively separated from the other constituents.

Though these experiments cannot at present be considered a success, the principle of increasing the density of the mother liquor by addition of readily soluble and heavy substances, and then causing a separation of the caoutchouc globules by mechanical means, is one which cannot be too strongly impressed on the experimentalist.

\section{Rapid Coagulation by Mechanical and other Means.} The Michie-Golledge Mackine.

Construction.-On Plate 21, Series A, a sketch of parts of this machine is shown. The Michie-Golledge Rubber Coagulating Machine consists of a revolving cylinder $\mathrm{A}$, with angular ribs $\mathrm{B}$ on its inside, and curved blades $\mathrm{C}$ which are fixtures, as shown in the accompanying sketch. The latex is poured into the cylinder $A$, which is then set in motion, the machine revolving in the direction indicated by the arrow. The revolving cylinder and its ribs $B$ force the latex forward on to the blades $\mathrm{C}$, which carry it into the centre of the cylinder, creating a kind of vortex or whirlpool, and depositing the rubber in the central space in the form of a sponge-like mass shown on Plate 22, Series A. When the mass of rubber reaches the right consistency, it is removed by hand, separated into lumps of the required size, and rolled out while it is still soft into sheets in a small rolling machine.

Method of Using.-The latex is diluted, often as much as 400 per cent., and after being strained to remove the mechanical impurities and treated with acetic acid in the proportion of 1 dram of acetic to 1 gallon of the diluted latex, is placed in the churn-like cylinder. 
The cylinder is then rotated horizontally at the rate of about 180 revolutions per minute for about $1 \frac{1}{2}$ minute, after which the speed is reduced to about 100 revolutions per minute for the next $3 \frac{1}{2}$ minutes. The coagulated latex accumulates in the centre, and the watery portion remains in the outer part between the vertical plates and the wall of the cylinder. When the watery portion is clear the separation of the rubber is considered to be complete, and the coagulated latex is removed. The freshly-coagulated mass is, as shown on Plate 22 , in the fresh state very spongy and is torn into irregular pieces, which are pressed between the rollers of a mangle. A figure of the mangle used and the cakes obtained is shown on Plate 23, Series A ; the irregular cakes, obtained by passing the spongy mass through the rollers, are then cut into worm-like threads by means of shears worked by hand; the "worms" are next placed on wooden shelves to dry. The rubber so prepared may at first contain most of the ingredients present in the latex, the soluble portion of which may be partially removed by repeatedly washing the rubber during the rolling process. Two analyses of this rubber are given elsewhere.

\section{Mathiou's Apparatus.*}

An apparatus for coagulating rubber in large quantities by means of heat alone has been considered by Mathieu, which follows in principle the manipulation of the latex as practised by the Brazilian seringuero. As far as I can understand it, the apparatus is devised to subject thin films of the latex to the action of a surface heated to a constant degree, and can be worked in situ or be put on wheels and transported to any part of the estate where collecting operations are being carried out. Dickson's drying and coagulating machine is described in Chapter XI. of this book.

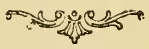





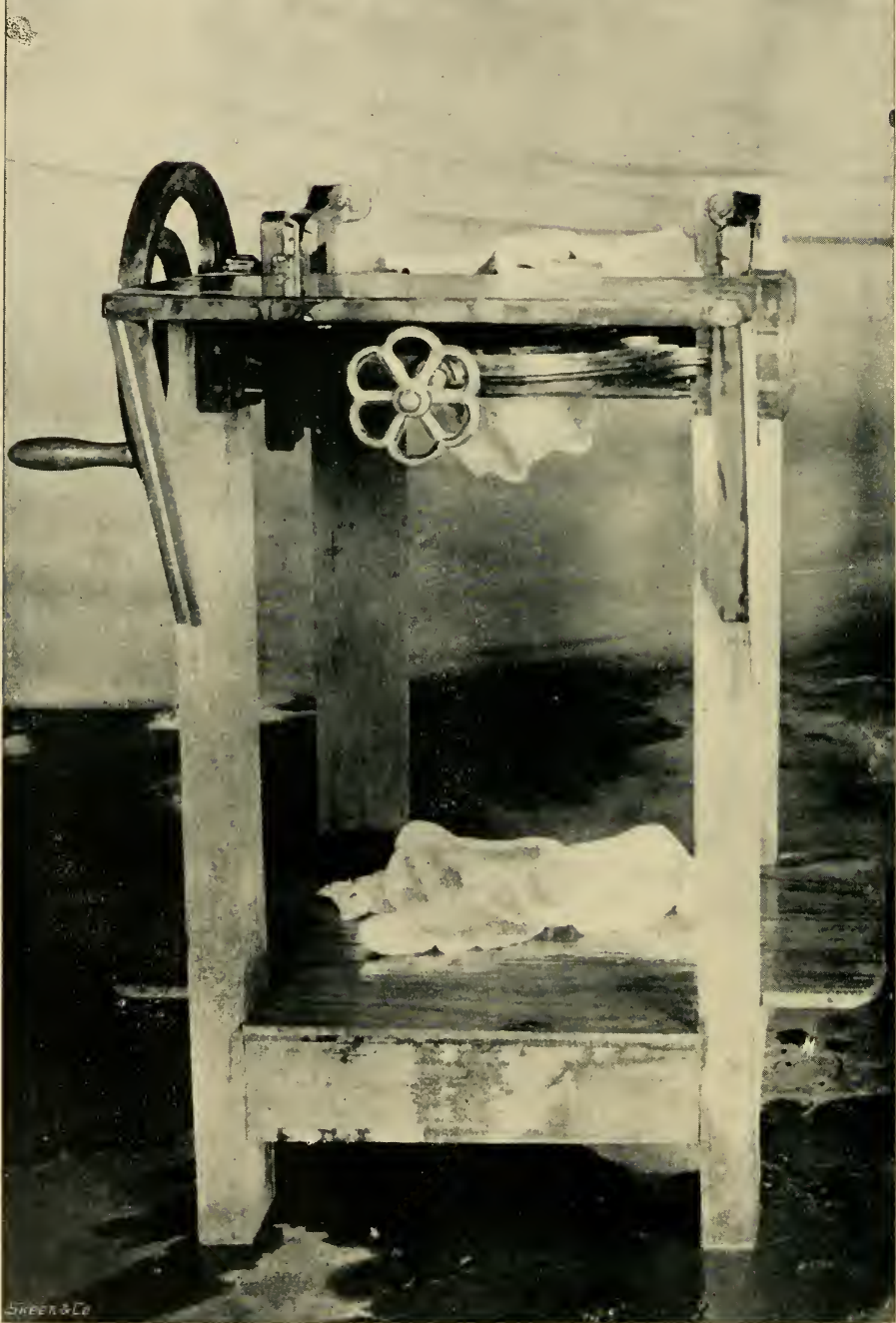

MACHINERY FOR EXPELLING WATER.

Photo by C. H Kerr.

SPONGY RUBBER PREPARED BY THE MICHIE-GOLLEDGE PROCESS. 


\section{CHAPTER XII.}

\section{DRYING OF RUBBER.}

General methods-Illustration showing a method of drying biscuit rubber-Presence of water, putrefaction, and surface depositsChemicals and artificial heat for drying-Suggestions by Parkin, Burgess, and Weber-Drying in vacuum chambers-Construction of vacuum chambers-High temperatures undesirable-Dickson's drying and coagulating machines-Use of calcium chloride-Advantages-Simple rubber-drying sheds for use with calcium chlorideDisadvantages-Experiments in Ceylon, and softening of rubber.

$\mathrm{N}$ most estates the freshly-coagulated rubber is rolled to drive out as much water as possible, and then either hung up on cords or placed on shelves made of coarse wire netting,coir matting, or wood, and allowed to dry. The rubber cannot be dried in the sun, though a current of warm dry air may be used without any bad effect. The ordinary cacao and tea-drying factories might easily be used for this purpose. The preparation of the rubber in sheets as thin as possible is desirable in order to obtain a dry rubber in the shortest time, though a minimum thickness of one-eighth of an inch is preferred by buyers in Europe. Though the drying process may be hastened by various methods, it is well-known that rubber of good quality can be produced without resorting to any devices for hastening the drying or curing of the product. The illustration on Plate 24, Series A, shows a simple method of drying biscuit rubber as adopted on many rubber estates. Crêpe, flake, and lace rubber are capable of being dried more rapidly than thick biscuits or sheets.

The presence of water in the rubber is often a serious drawback, and the fact that the rubber, if dry, will not undergo putrefactive changes is of sufficient importance to warrant attention to this part of the subject. It should be remembered that when the biscuits or sheets are hung up to dry the evaporation of the water is followed by a deposition of the suspended or dissolved impurities on the surface of the rubber, which should be removed. Rapid drying is essential in order to prevent deterioration consequent on oxidation, but too rapid drying is said to induce a softening of the rubber.

Chemical and Artificlal Heat for Drying.

Parkin* pointed out that to dry rubber by heat did not seem advisable, and suggested that perhaps quicklime or calcium chloride might be used in the drying chamber. 
Burgess* states that the raw rubber, before it is vulcanized, is very sensitive to heat, and a temperature of $150^{\circ} \mathrm{F}$. may render Para rubber sticky on the surface, and a higher temperature utterly destroy the "nerve" of it; he declares that it is, therefore, injudicious to use artificial heat in hastening the drying of rubber. $\mathrm{He}$ also states that if artificial heat were absolutely necessary a very carefully regulated temperature, never exceeding $120^{\circ} \mathrm{F}$., would probably not cause any great damage.

Weber $\dagger$ asserted that certain brands of indiarubber cannot be hung up to dry in the form of sheets after the washing process, as they become so soft as to fall to pieces. The temperature at which indiarubber begins to soften varies according to the percentage of the resinous and oily substances present, and many samples of good Para rubber pass into a more or less fluid state at about 170 to $180^{\circ} \mathrm{F}$.

It is, therefore, obvious that the question of drying rubber is apt to be a delicate one where high temperatures are concerned. In the "India Rubber World" (November 1, 1905) a suggestion is made that the principle of drying rubber in vacuo might be tried. It is maintained that the drying in vacuo is accomplished rapidly, only low temperatures are necessary, and a great saving in fuel, space, and labour is effected. The vacuum drying chambers may be obtained in rectangular and in cylindrical styles and fitted with plate shelves or shelf coils inside. According to Burgess, a vacuum chamber consists of a large iron box, of from 100 to 200 cubic feet capacity, fitted inside with shallow trays with perforated bottoms, and heated with steam pipes, the interior being connected by an iron pipe with an exhaust pump. The temperature of the chamber is raised to 120 to $130^{\circ} \mathrm{F}$., and after the air has been drawn through the chamber for a few hours the rubber is usually sufficiently dry for most purposes. Most manufacturers, however, have not adopted drying in vacuo, as they believe the rubber is softened by the heating and the nerve and quality of the rubber injured, but prefer to dry the rubber gradually in dark warm rooms,

Dickson's Machine for Coagulating and Drying Rubber.

Mr. Dickson has kindly supplied me with the following description of his machine :-

"This machine consists of a small furnace, on the top of which is a smoke box containing a revolving drum. Between the furnace and the smoke box is a series of baffle plates to divert the fumes and ensure that no flames and sparks pass into the smoke box. At one side is a shallow pan for receiving the latex. In this pan is a small roller partly immersed in the latex, with its surface in contact with the surface of the large drum. A fire is placed in the furnace, and the fumes are allowed to pass between the baffle plates and round the large drum to the chimney. When the

* Burgess, Lecture at the Agri-Horticultural Show, Kuala Lumpur, 1904.

+ Chemistry of India Rubber, p. 21 

- iuñfer cagulating \& Drying Machlie-

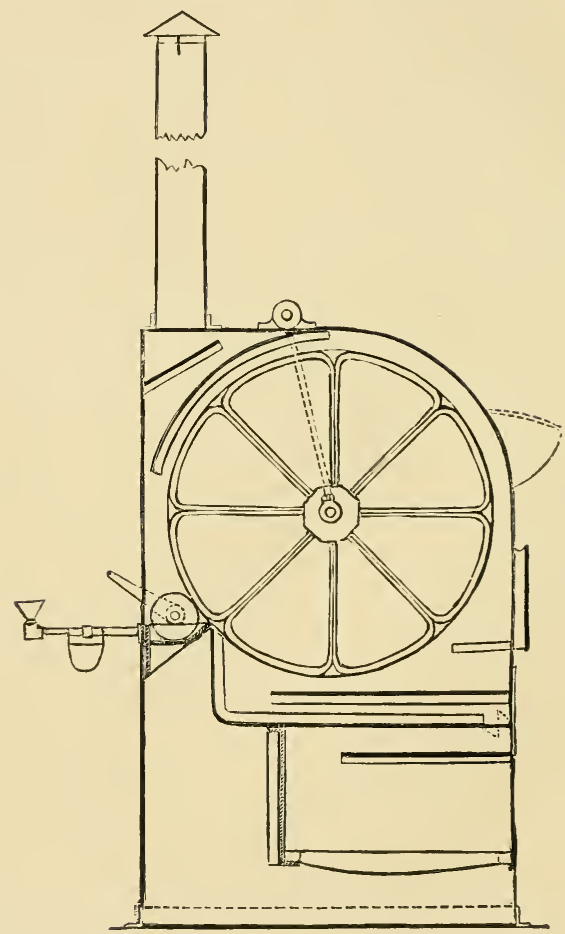

DICKSON'S COAGULATING AND DRYING MACHINE. 
desired temperature has been reaehed the pan is filled with latex from the feeder, and the small roller is turned by hand or power.

"The surface of the small roller being in contact with the sur. face of the large drum turns it, and at the same time spreads a thin film of latex on its surface. The action of the heat and fumes on the thin film of latex coagulates and dries it. Continuing the process the latex is spread film by film, coagulated, and dried until a thick deposit of rubber surrounds the large drum. The damper on the centre baftle plate is then shut and the door in the smoke box opened. The rubber on the drum is slit across with a knife and unrolled in a large sheet, which can be eut to any size for packing.

"The antiseptic qualities of the fumes tend to preserve the rubber, and the sheets are treated through and through."

In communication with Mr. Dickson I learned that in his machine there are several doors, which can be opened to let cool air in or regulate the temperature-a most important and essential feature when drying rubber with hot air or fumes. The illustration on Plate 25, Series A, shows the general plan of the apparatus.

Another apparatus has been devised in Ceylon to dry the rubber quickly and to coat the freshly coagulated and rolled product with creosote, but has not yet been made public.

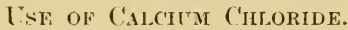

Mr. Burgess, in his lecture already referred to, stated that it is possible to dry mbber quite well and satisfactorily without any artificial heat, by the use of some agent that will dry the air. For this purpose he recommended calcium chloride. This substance is made enmmercially on a large scale; it is comparatively cheap and very effective as a drying agent. The material as bought is in white granular lumps which, when placed in the open air, absorb moisture from it, and the calcium chloride becomes moist and eventually absorbs so much water that a syrupy liquid results. The great merit of this substance lies in the fact that it can be recovered from the wet state by simply heating and thereby driving off the moisture. A simple form of rubber-drying shed adopted for use with calcium ehloride could easily be made with shelves to hold iron pans, in which the calcium chloride could be placed and freely exposed to the air in the chamber. As the ealcium chloride absorbs the moisture and becomes sloppy, the pans should be removed and the water driven off over a brisk fire, stirring the mass meanwhile. Whien quite dry and porous again the pans should be returned to the rubber-drying chamber to do their work again. In this way there would he little or no loss of substance, and the air inside the chamber being constantly dry, mould would be absolutely prevented, and the rubber would diy in half the time. The pans, if used inside the rubber shed, should be placed above the rubber.

"A still more efficient system would be to devise a circulation of dry air in the chamber, and if this system were adopted it would be best to dry the air before blowing it with fans into the chamber. 
This could be easily done by causing it to pass over a series of iron pans of calcium chloride contained in a drying box outside."

A writer in the "India Rubber Journal" objected to the use of calcium chloride on the ground of expense and the danger of accidental contamination with the rubber, and expressed his opinion that the circulation of dry air was preferable to the use of this ehemical. Mr. Ridley, in reply to these objections in the "Straits Bulletin," stated that in a manufactory on a large scale the calcium chloride would be in pans, well away and above the rubber, and that there would, therefore, be no risk. If calcium chloride is allowed to remain in contact with the rubber it destroys it, but if cleared off immediately it does no harm.

At Peradeniya a series of experiments has been made. A current of dry hot air is made to pass rapidly through a specially constructed chamber in which the rubber is arranged on a number of wooden trays. The air is first dried by passing it through a series of crates or cells containing hygroscopic chemicals. The crates can be easily removed, dried, and replaced. The dry air is then drawn over a fire by means of a fan, the latter being turned by hand or power. By this means the rubber is dried fairly rapidly ; if the temperature is maintained at about $90^{\circ} \mathrm{F}$, the rubber is thoroughly dried in a few days if the sheets are not too thick, and softening does not occur if the rubber is not dried too quickly. It is as well to mention that the softening of rubber alone, when due to too rapid drying, is not objected to by manufacturers, as the masticating process, through which the dry rubber passes, converts the material into a substance void of all toughness and elasticity; but any softening of the rubber before it leaves the factory of the producer might prove very serions as the sheets or biscuits would be bound to adhere to one another, and probably become tacky before their arrival in Europe.

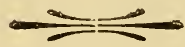




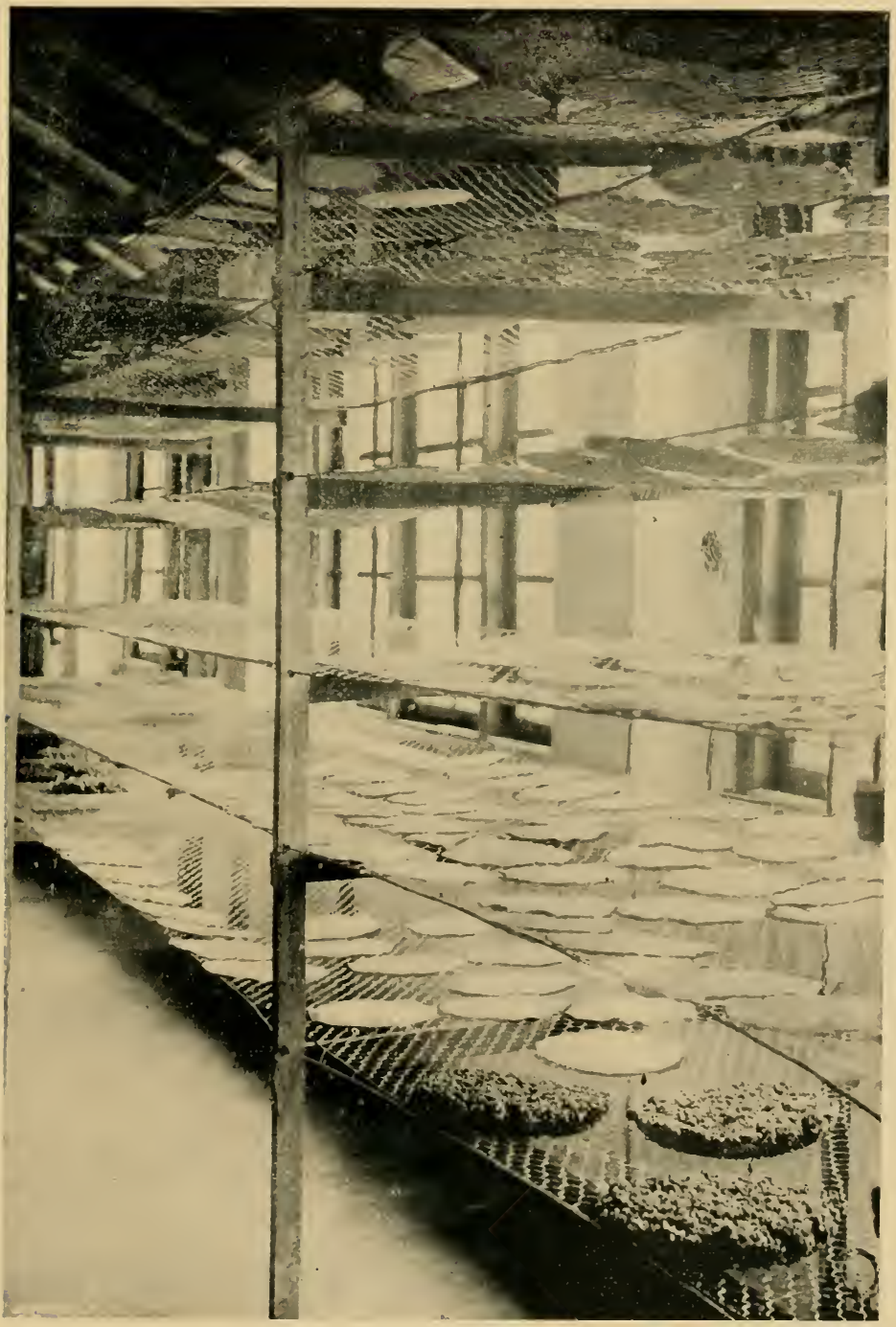





\section{CHAPTER XIII.}

\section{PHYSICAL AND CHEMICAL PROPERTIES OF RUBBER.}

Analyses of Para rubber from Ceylon, Bukit Rajah Co., F.M.S., Penang, Straits, and Fold Coast-Market value of the samplesPara and African rubber analyses compared-Resins in Para and Castilloa rubber-Resins in rubber from parts of the same treeResins in rubber from Para trees of different ages-Para compared with other rubbers-Chemical composition and value of Ceara. Castilloa. Ficus, Landolphia. Ureeola, and Rhynocodia rubber-Extraction of resins from rubber by mamufacturers and growers-Albuminoids and cause of putrefaction-Removal by mechanicial and chemical processes-Ash impmities and ingredients present in Para. Ceara, and African rubbers-The insoluble constituent in rubber-Properties of indiarubber, reaction with alkalies, halogens, and acids-Absorption of water-Sulphur reaction-Action of heat on incliarubber.

TI AYING briefly indicated the composition and characters of the H. latex as it appears in the factory of the cultivator, the same features in the finished product can now be considered with a view of gaining an insight into the changes which have taken place, and the processes that have been adopted in Europe to free the rubber of the impurities originally present in the latex. The prepared article may be expected to contain all the insoluble components of the latex, except those removed by mechanical operations. The following analyses of plantation rubber, prepared from Hevea brasiliensis in various parts of the world, may be taken as good examples :-

Para Rubber

Gold Coast

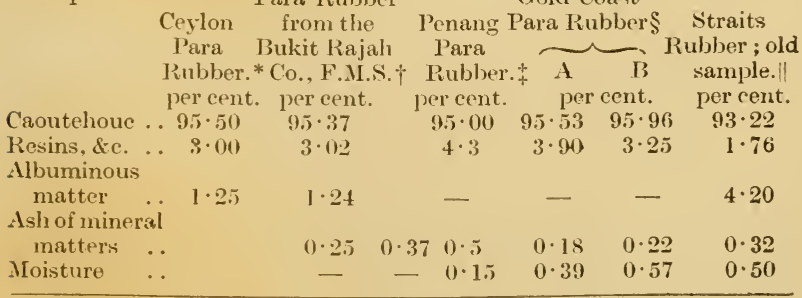

* Tropical Agriculturist, Vol. XXIV. No. 5, November, 1904.

† Journal d'Agriculture Tropicale, April, 1905.

†. Agr. Bull. of Straits and F.M.S.. April. 1904.

$\$$ Johnson. "Report on Rubber in the Gold Coast, 1905.

By M. Kelway Bamber. 
The sample from Ceylon was valued at 5s. $7 \frac{1}{4} d$. per lb., and the report stated that the rubber was free from moisture, very strong, and vulcanized well. The sample from the Bukit Rajah Co. was considered to be very suitable for vulcanization, and sold at a little over 7 francs per pound. The Penang sample was prepared in rectangular cakes, was dark brown in colour, transparent, and contained no mechanical impurities; one piece was sticky. The value was considered to be equal to the current market rate of good Para.

The samples from the Gold Coast were considered to be of excellent quality, free from mechanical impurities, and in February, 1904, were valued at $4 s .6 d$. to $4 s .7 d$. per $\mathrm{lb}$. The old sample of Straits rubber had been kept in Ceylon for a considerable length of time.

The high percentage of caoutchouc in Para rubber, grown in different countries, is so far very satisfactory. Johnson has shown that whereas the cultivated Para may contain over 95 per cent. of caoutchouc and less than 4 per cent. of resinous matter, the native African rubber (Funtumia elastica) contains less than 90 per cent. of caoutchouc and over 8 per cent. of resinous compounds. From the foregoing analyses and valuations it may safely be asserted that Hevea brasiliensis bids fair to beat many rubber trees indigenous to tropical areas. Resins in large quantities, albuminoids, and ash constitutents are not required, and in many articles of commerce are injurious.

Resins.-In Para rubber the amount of resinous and oily substances varies from 1 to 4 per cent., when obtained from mature trees. Many analyses have been made of rubber from trees of various ages and of different species. In the case of Castilloa elastica, Weber* proved that not only does the percentage of resin decrease with the age, but that it increases as one passes to younger parts of the same tree. His figures were as follows :-

\section{Resins in Rubber of Castilloa Trees.}

From

$\begin{array}{lll}\text { Trunk } & . . & \\ \text { Largest branches } & \ldots \\ \text { Medium } & \ldots & \ldots \\ \text { Young } & \ldots & \ldots \\ \text { Leaves } & \ldots & \ldots\end{array}$

\section{Per cent.}

$$
\begin{array}{cr}
\ldots & 2 \cdot 61 \\
\ldots & 3 \cdot 77 \\
\ldots & 4 \cdot 88 \\
\ldots & 5 \cdot 86 \\
\ldots & 7 \cdot 50
\end{array}
$$

A similar increase in resin in the rubber from young Castilloa trees of different ages was also described, the variation being from $7 \cdot 21$ per cent. from eight-year-old trees to 35.02 in rubber from trees three years old.

Weber concluded that it could scarcely be doubted that rubber rom other kinds of rubber trees would exhibit similar relationships; 1902.

* Weber, India Rubber and Gutta Percha Trades Journal, Sept. 29, 
subsequent research has not confirmed this contention as far as Para rubber is concerned.

Mr. M. Kelway Bamber has made a series of analyses of Para rubber from trees of different ages, and the proportion of resin is here shown :-

\section{Para Rubber from Trees of Different Ages.}

\begin{tabular}{|c|c|}
\hline ars. & Four years. \\
\hline B. & B. \\
\hline
\end{tabular}

Resin .. $3 \cdot 25 \% \quad 3 \cdot 60 \% \ldots 3 \cdot 28 \% \quad 2 \cdot 72 \% \ldots 2 \cdot 75 \% \ldots 2 \cdot 10 \%$

Eight years. Ten-Twelve years. Thirty years.

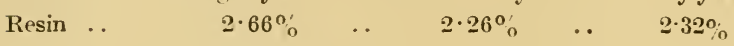

\section{Para and Other Rubbers.}

It has been suggested that the addition of analyses of other rubber might be of value, and acordingly the following tables have been draw up :-

Ceylon-groun Para, Ceara, and Castilloa Rubber.

\begin{tabular}{|c|c|c|c|c|c|c|}
\hline & & $\begin{array}{c}\text { Para } \\
\text { Rubber. } \\
\text { per cent. }\end{array}$ & & $\begin{array}{l}\text { Cearn } \\
\text { Rubber. } \\
\text { per cent. }\end{array}$ & & $\begin{array}{l}\text { Castillon } \\
\text { Rubber. } \\
\text { per cent. }\end{array}$ \\
\hline Caoutehoue & .. & $94 \cdot 60$ & $\cdots$ & $76 \cdot 25$ & $\cdots$ & $86 \cdot 19$ \\
\hline Resin & .. & $2 \cdot 66$ & .. & $10 \cdot 04$ & . & $12 \cdot 42$ \\
\hline Proteids & . & $1 \cdot 75$ & . & $8 \cdot 05$ & .. & $0 \cdot 87$ \\
\hline Ash & .. & $0 \cdot 14$ & . & $2 \cdot 46$ & .. & $0 \cdot 20$ \\
\hline Moisture & $\ldots$ & 0.85 & .. & $3 \cdot 20$ & .. & $0 \cdot 32$ \\
\hline
\end{tabular}

Para compared with Rubber from Landolphia.

(2)

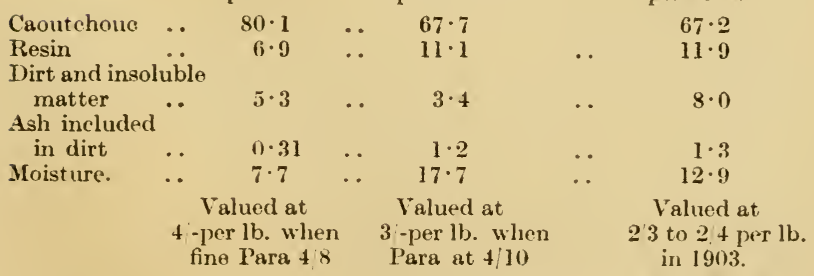

Landolphia Landolphia Watsonians Kirkii. Petersiana. (East African rubber). per cent. per cent.

(1) M. Kelway Bamber, Committee of Agrieultural Experiments, November, 1905 .

(2) Bulletin of the Imperial Institute, June, 1904.

(3) Do. do. do. June, 1904 (rubber from Natal)

(4) Do. do, do, Jan, 1905 (rubber from East Africa). 
Para compared with Ficus, Urcela, and Rliynocodia Rubber.

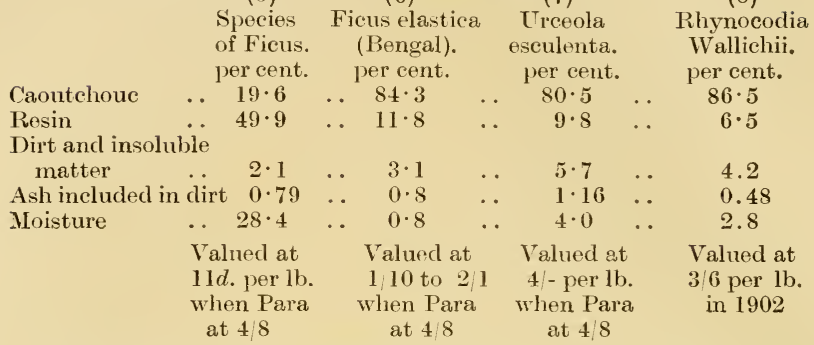

Though the various "Plantation" and "Wild" rubbers which arrive in Europe contain resin in quantities varying from 1 to about 40 per cent., they appear to be all subjected to the same process in the attempt to extract this ingredient. According to Weber, ${ }^{*}$ the resins can be removed by extracting with acetone in a Soxhlet extractor, the highly porous waslied slieets of rubber lending themselves best to this purification process. The complete extraction of these resins from rubber requires many days. The presence of the resinous impurities influences the behaviour of the rubber in practical working and also the stability of the finished article. Owing to the supposed detrimental effect of the resins after vulcanization, no efforts are spared to reduce them to the desired quantity in the inferior brands of rubber. The extraction of some of the resinous bodies from the latex of certain plants is a subject which, though crowded with difficulties, might profitably engage the time of the producer in the Tropics.

Albuminoids.-The albuminoids, which either alone or with other substances lead to putrefaction, exist almost entirely in solution in the fresh latex. Their removal from commercial rubber on a large scale is considered by many to be almost impossible, and Weber suggested that an expeditious method would be to centrifugalize the solutions, a method which has been dealt with when describing the machines used in prenaring and purifying rubber.

The addition of formaldehyde to some latices is supposed(1) to prevent the coagulation of the albumen and (2) to cause the indiarubber to collect on the top of the mixture. The proper application of this reagent to (astilloa latex is said to free the rubber from every trace of albuminous matter. It has, however, been questioned whether the caoutchouc would coagulate or even coalesce, if all albuminoids were removed from the latex.

(5-6) Bulletin of Imperial Institute, Sept. 1904 (Rubber from Burma).

(7) Technical Reports and Scientific Papers, Imperial Institute, 1903.

(8) Bulletin of Imperial Institute, Vol. 1, p. 69, 1903.

* Weber, l.c., p. 3. 
There is a slightly higher pereentage of proteids and resins in Para rubber from young trees, and the poor physical properties of young plantation rubber may be ultimately associated with the proportion of these constituents present in the samples.

Ash.-This impurity is present in almost negligible quantities0.18 to 0.5 per cent. (ienerally, Para rubher contains 0.3 per cent. of ash, as against $(0 \cdot 2$ jer cent. in other rubbers. Weber is responsible for the statement " that it may yet he possible to chemically identify the brand of indiarubler from ash analyses." Lime is said to predominate in J'ara rubber, magnesia in C'eara. and ferrous iron in African rubbers. The presence of the ash impurities is undesirable on account of their tendency to interfuse with the indiarubber and the resinous constituents during the jrocesses of manufacture.

The insoluble constituent present in rubber is a substanee which is free from stickiness, is remarkably tough, and has moderate distensibility. Its nature and importance is imperfectly understood.

There is a quantity of oxygen present in indiarubber, but the proportion of this is according to Weber, reduced practically to vanishing point in successive purifying processes.

\section{Gener.l Jropelities of Indiarubber.}

Alkalies have not a pronouneed aetion upon indiarubber at low temperatures. Heinzerling states that on prolonged digestion with ammonia the indiarubber passes into the state of an emulsion, in appearance elosely resembling indiarubber milk.

The effect of chlorine, bromine, and iodine on indiarubher is very complicated, and for a full knowledge of the various ehanges which are indueed by their action reference must be made to Weher (pp. 31-37). Acids excert a strong action on indiarubber articles commonly used. Strong sulphuric acid oxidises rubber : strong nitric acid attacks rubber vigorously, forming at first a yellow compound which is subsequently decomposed. The effect of oxygen on crude and vuleanized rubber is to cause deterioration, a compound known as Spiller's resin being formed. ('rude indiarubber, particularly just after it leaves the washing machine for the drving room, is apt tosuffer considerably from oxidation during the drying process, and it seems possible that similar ehanges may occur after coagulation and pressing in the tropics.

Though indiarubber is insoluble in water, it rapidly swells when inmersed in it and absorbs a considerable amount of the liquid, the actual amount capable of being absorbed inceasing witl a decrease in the resin and oily substances. (On this account the rubber from young trees may perhaps be roughly detected by the water capacity of the sample of rubber, allowing for normal variations. When vulcanized the water absorption power of indiarubber is small. Though indiarubber does not readily react with many common reagents, it does react in a surprising degree with sulphur in its various forms, the process of combination being commonly spoken 
of as vulcanization. Pure sulphur does not combine with indiarubber at temperatures below $270^{\circ} \mathrm{F}$., but sulphur mono-chloride readily reacts with it at ordinary temperatures.

The elasticity, resiliency, colour, and odour of rubber vary considerably, according to the age of the trees, and the methods of collecting, coagulating, and curing the product. Rubber from mature trees, if well prepared, is of a pale amber colour, has a slight odour, and is very tough; badly-prepared rubber or that from young trees is frequently speckled, emits a foul odour, and may on keeping become sticky, plastic, or brittle.

\section{Action of Heat on Indiarubber.}

Indiarubber becomes sticky if subjected to high temperatures. It passes into quite a liquid state at ordinary temperatures under certain conditions; if sound rubber is subjected to 170 to $180^{\circ} \mathrm{C}$., it becomes more or less fluid. The melting point, if rubber can be said to have one, is much higher than this if the resin has been extracted. It is important that all drying and coagulating processes should be so devised as to ensure the temperature being regulated, and a maximum temperature considerably below that just quoted should be guaranteed.

Indiarubber articles, if exposed to ligh temperatures, are apt to lose their strength, and to develop either sticky or brittle properties.

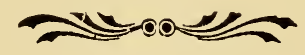


CHAPTER IIV.

PURIFICATION OF RUBBER.

Analysis of washed and dried Para-Purification by the manufacturers - Loss in brands of Para rubber-Plantation versus WVild ParaLawrence's apparatus-Loss on washing rubber-Oily and resinous substances and ash in various rubbers-Determination of loss on washing-High loss undesirable-Purification by the growersRubber wasling machines-Burgess's account of a washing machine: construction and action - Illustration of a washing machineAdrantages of washing rubber Scrap and dirty rubber.

I AVING dealt with the properties of the latex and the various 1 methorls of preparing rubber therefrom, it is now necessary to consider the important question of the condition of the rubber when it enters the market, and the processes through which it passes in purification. It is possible that much time and trouble may be saved, and at the same time a rubber of higher quality be produced, by carrying out certain purification processes in the initial stages. The condition of the rubber when it arrives in Europe is well-known to most cultivators, as it undergoes no changes during transit if it has been properly prepared. An ordinary sample of washed and dried fine Para rubber may contain the following:-

$\begin{array}{llll}\text { Rubber } & \ldots & 94.0 & \text { per cent. } \\ \text { Resinous matter } & \ldots & 2 \cdot 5 & , \\ \text { Albumious matter } & \ldots & 3 \cdot 0 & , \\ \text { Mineral matter } & \ldots & 0 \cdot 5 & ,\end{array}$

Very often grades of washed rubber, prepared carelessly, contain nearly 20 per cent. of impurities, and in the case of "scrap" rubber the question of purification may become a serious one.

\section{Purification BY the Manufacturers.}

The scraps of fibre, particles of sand, abundance of resins, albuminoids, and mineral matter are not required in the finished product, and the mechanical and soluble impurities are, as far as possible, removed by the manufacturer. In Europe the rubber is first cut into small pieces and placed in tanks containing hot or boiling water. It is then put throngh the washing machines, the rollers of which tear, cut, and expose all parts of it to a current of clean water. 'The success of this method depends upon the rubber being cut into sufficiently small pieces and soaked for the proper length of time in water maintained at the desired temperature. The washing process removes every kind of meclianical impurity, the fragments of fibre, sand, \&c., flying out of the softened rubber when it is stretched and 
torn between the rollers. These impurities are loosely embedded in the rubber, but if the temperature is raised too high the resins may be converted into sticky substances, which will cement the rubber and mechanical impurities and thus render it impossible to remove the latter by this process.

The fragments rejoin and finally form a porous sheet which, when dry, is known as washed rubber to the manufacturer. The rubber may then undergo various masticating, mixing, and vulcanizing processes.

Lawrence has, according to the "India Rubber Journal," November 20,1905 , brought out a patent method for cleaning crude rubber, which is to some extent applicable to ordinary scrap rubber on estates. The process consists of first grinding or macerating the rubber, and then subjecting it to liquids or solutions having different specific gravities. It is specially devised to deal with the extraction of the fibrous and woody matter in crude or scrap rubber.

\section{Loss in Manufacturing.}

The actual loss in these purification processes is often surprising. The loss on washing some of the Para rubber collected by the natives in the Amazon District varies from 10 to 40 per cent., and Biffen states that the loss in the factories is as follows for different grades of Para rubber :-(1) fine Para, $10-15$ per cent. ; ( 2 ) extra fine, the carelessly smoked pieces, $15-20$ per cent.; Sernamby, rubber pulled from the cuts on the tree and cups, 20-40 per cent. Many lots of fine wild Para have, during recent times,* shown a loss on washing of from 15-16 per cent. in samples containing $2 \cdot 2$ to $2 \cdot 9$ pei cent. of resin and 0.27 to 0.29 per cent of ash. According to Johnson, the loss from fine Para is from 10-15 per cent., whereas that from the plantation biscuit, sheet, crêpe, \&c., rubber is only about 1 per cent. Weber $\dagger$ states that the fine Para rubber from the Amazon District shows a loss on washing of 12 to 18 per cent., and contains 1.3 per cent. of resin and 0.3 per cent. of ash in the dry washed material.

Different brands show a variation in the amount of the loss on washing as indicated below, and the composition of the impurities are clearly put forward by Weber:--

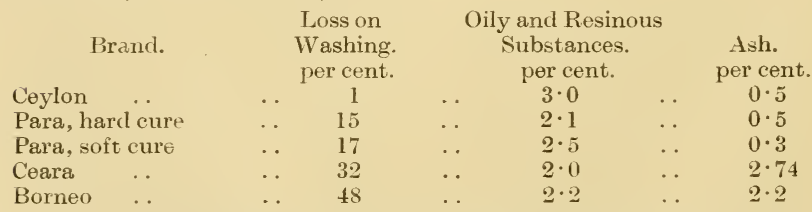

The loss on washing is estimated by determining the yield of dry washed rubber obtainable from a known bulk of crude rubber. This

* India Rubber Trades Journal, April 28, 1902.

$\dagger$ Weber, l.c., p. 122. 
loss consists mainly of water, salts, wood fibres, and mineral impurities. The oily substances form a very small part only of the total extract. Weber states that the resinous matter is generally semi-transparent. yellowish-brown, or brown; in some cases it is semi-resilient and slightly sticky, sometimes hard and brittle, and in a few cases is white and powdery in appearance. The estimation of these oily and resinous constituents is best carried out by extracting 5 to 10 grammes of the perfectly dry washed rubber in a Soxhlet extracter by means of acetone. Many persons assume that the percentage of resinous matter in indiarubber is an indication of the care bestowed upon it by the producer. This is not correct, as the resinous maiters exist in the latex as the latter flows from the trees. The variation in the resin of the same brand of rubber is probably due to the condition or age of the tree from which the latex is obtained, or to the mixing of milks of different qualities.

\section{High Loss undesirable.}

If the loss on washing is beyond a certain amount the rubber will be naturally classed as inferior, and in a paper* read before the International Congress of Ipplied Chemistry the following interesting passage oceurs:- - While fifteen yearsago, fine Para rarely showed a loss in washing exceeding from 10 to 12 per cent., this rose within the last ten years from 12 to 16 per cent., and in the last five years had rearhed from 15 to 20 per cent. During the same time Colombia Virgin, at one time one of the finest brands of ruhher, has practically entirely disappeared from the market. What little still occurs under the name is an altogether inferior product."

\section{Purificaton by the Growers.}

The use of machinery is bound to become more general when more rubber is collected, and the means adopted for straining, purifying, and coagulating the latex will minimise the loss, which normally occurs in the manufacturing process. Already a machine for washing the rubber by the grower has been strongly recommended hy Mr. Burgess and others.

\section{Rubber Washing Machine.}

In rubber districts a modified wringing machine is frequently used, which, though it is light and cheap, cannot usually be recommended as efficient. If a sufficiently powerful and well-equipped rubber washing machine is used, the effect is not only to free the rubber from a large proportion of the soluble impurities, but to produce a dried product possessing good physical properties.

\section{A Rubber Washivg Machine.}

The following is Mr. P. J. Burgess's account of the new rubber washing machine :-

"This machine consists essentially of two steel rollers, which revolve on horizontal axes parallel to one another; the distance

* India Rubber Journal, July 20. 
hetween the surfaces of the two rollers can be adjusted, and varies from ${ }_{4}^{3}$ inch to practical contact.

"The rollers revolve at different speeds and are driven by power transmitted from belt and pulley through gear wheels to the rollers themselves.

"The axes of the two rollers may be on the same horizontal plane, more usually one is slightly above the other; a stream of water flows over the surface of the rollers all the time they are in use.

\section{The Machine at Work.}

"When the machine is used, freshly-coagulated lumps of rubber are put between the rollers, which are separated about $\frac{1}{4}$ inch. The rubber is passed through several times, the rollers being gradually approximated to each other, and the rubber becomes compacted and to some degree hardened. At the same time the effect of the differential rate of movement of the two roller surfaces is to subject the rubber to a shearing stress, which stretches and tears it to pieces, and it is here that the peculiar property of rubber is clearly seen. The elastic stretching and rebound kick out any gross mechanical impurity that may be present, and when the machine is used on scrap rubber there is a perfect shower of dirt, pieces of bark and wood being thrown out from the front of the machine. Freshly-cut or torn surfaces of rubber reunite on contact and pressure; for this reason the fragments, into which the rubber is torn by the machine, reunite and emerge as a continuous sheet. At the same time the stream of water thoroughly washes out any impurity soluble in water that may be left in the rubber. The final product is a coherent but granular sheet of rubber, the thickness of which can be regulated by the distance left between the rollers. The function of the machine is thus three-fold. :-

"1.-It ejects mechanically any solid impurity.

" 2 .-It breaks up the rubber, and subjects all portions of it to the washing effect of flowing water.

"3.-It produces a granular thin sheet of uniform thickness, which is clean and which can be easily and rapidly dried.

"The interests at stake are so great that I may be permitted perhaps to put in condensed form the advantages of the use of a washing machine in preparing rubber.-

"1.-The rubber produced will be as pure as it possibly can be without costly chemical treatment.

" 2.-The rubber, being pure, will be of uniform quality.

"3.-The rubber, being washed, will be ready for immediate use by the manufacturer.

"4.-It will effect a saving of labour to the planter by eliminating the petty hand labour involved in preparing rubber in small plates, rolling the sheets by hand, and manipulation of the small biscuits. 


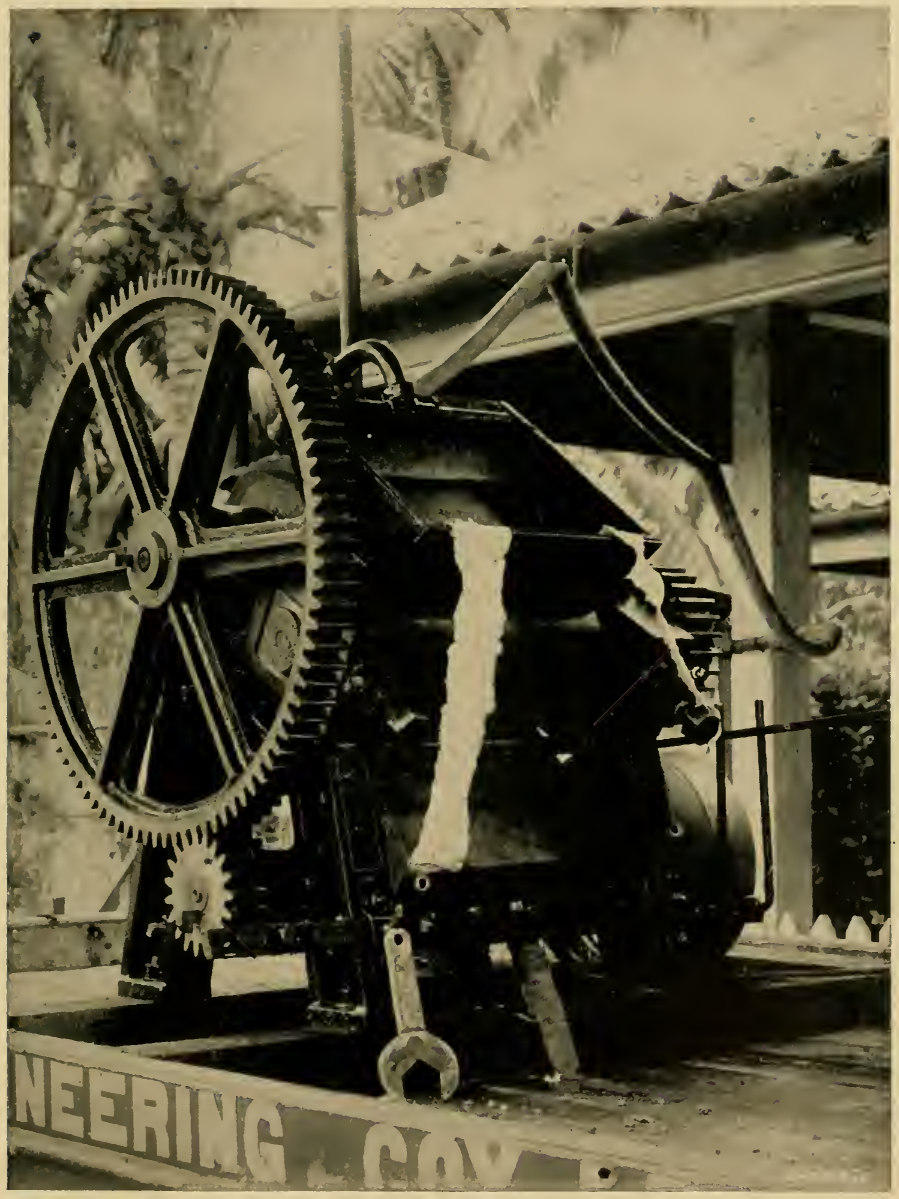

A RUBBER WASHING MACHINE.

Federated Engineering Co. SHOWING WATER PIPES AND CRÊPE RUBBER. Sec Page xiii among Adits. for Illustration of Rolling Machine. 

"5.-There will be an enormous saving of time in drying the rubber; this will involve a saving of storage room and labour in looking after the rubber when drying.

"6.-There will be no possibility of putrefaction of rubber in drying, or discolouration by the growth of mould, the substances which putrefy or which feed mould being to some extent eliminated.

" 7.-The machines will clean and deal efficiently and economically with scrap.

" 8.-The washed rubber can be turned out of any length or thickness required, and will be easier to handle and pack. It keeps better than the best of the biscuits prepared in the old way.'

\section{Washing Scrap and Dirty Rubber.}

"But the use of a washing machine driven by an engine is not by any means confined to freshly-coagulated latex. In dealing with scrap and dirty rubber its efficiency is very marked. The scrap is cleaned, mechanical impurities are ejected, dirt and mud are washed away, and the scrap is finally turned out in a form precisely similar to that taken by the first-class rubber, and in a state of purity which is only a trifle inferior to it. With rubber from Ficus elastica or Rambong the machine deals in a similar manner, and an easy and simple method of treatment of this hitherto intractable latex is made possible. Great difficulty has been found in dealing with Rambong up to the present, because it cannot be coagulated in sheets in the same way as can Para rubber. If, however, the thick latex be churned, beaten, or violently shaken it coagulates in a great lump, and to treat this lump in the old way, to dry and render it fit for export, has been a matter of great difficulty and of many months. The lumps may he treated at once with the washing machine and thin sheets produced, which are clean and which rapidly dry without difficulty."

The question of rapid washing and drying is one of the most serious with which large rubber growers have to contend. The preparation of small quantities of rubber by the "setting pan" method, and drying in spacious chambers, is not applicable to large estates: it would appea advisable to collest the latex in large tanks until a sufficiently large quantity has been ohtained, coagulation being prevented by the addition of reagents; the large quantity of latex ran then be rapidly coagulated, and the fresh rubber put through a washing machine, which will turn the rubber out in such a condition that it can be properly cured in two or three days. I am indebted to Mr. Burgess and the Federated Engineering Co., Ltd., F. MI. S., for the illustration on Plate 26, Series $A$, showing the nature of the washing machinery used in the Straits: in addition to this, rolling machinery is supplied by the same firm, the two machines to be worked in conjunction with one another in the manufacture of crèpe rubber. 
CHAPTER XV.

PULCANIZATION AND USES OF RUBBER.

Vulcanization of rubber-Heat, sulphur, and indiarubber-The heat cure and cold cure-Quantity of indiarubber in common articles - Rubber in roller coverings, steam packing, tyres. tobaceo pouch, and garden hose-High proportion of mixtures-Automobiles. inetruments, clothing, and cables-Disuse of rubber and use of substitutes.

1 FTEEAT part of the rubber industry is dependent upon the 1 material being in a vulcanized condition, the change being effected by mixing sulphur in one of its many forms with the mastirated rubber and then heating the mixture. Usually only from 4 to 5 per cent. of sulphur is used in ordinary vulcanization, but in the production of ebonite or vulcanite as much as 20 to 40 per cent. of sulphur may be used. A more complete distribution of sulphur through the indiarubber may be possible if a solution containing sulphur be added to the latex before coagulation. Prismatic sulphur is readily soluble in carbon bisulphide, benzene, ether, \&c., and solutions may be made with any of these and other reagents to contain varying amounts of sulphur.

The main factor upon which the action between sulphur and indiarubber depends is beat; there is no action between the two constiinents until the temperature is equal to or above that of boiling water, and in Europe a temperature varying from $125^{\circ}$ to over $300^{\circ} \mathrm{C}$, is commonly used in the process of rulcanization. If alkaline polysulphides are used, vulcanization can be effectert at temperatures little above $100^{\circ} \mathrm{C}$.

In this process a great part of the sulphur becomes fixed by the indiarubber, but not the whole of it ; there is always a certain quantity of the sulphur in a free state in vulcanized articles of commerce. Ordinary sulphur, or various compounds of sulphur, may be used in this process, and the articles manufactured from such material are usually considered to be tougher, more resistent, and less easily melted.

\section{The Hent and Cold Cures.}

Rubber may be vulcanized either by what is known as the heat curc or the cold cure. [n the heat cure the rubber and sulphur are mixed together by machinery and the temperature raised to $300^{\circ} \mathrm{F}$. 
when chemical union takes place between the components, and vulcanized rubber is formed. The whole of the sulphur does not combine with the indiarubber, but if the high temperature is maintained for a long period, more and more of the free sulphur enters into eombination and produces a darker and tougher vulcanized product. Thongh most of the rubber is vulcanized by the above process, the cold cure, dependent upon the action of sulphur components in the cold, is often adopted. In the cold cure, diluted sulphur monochloride is mixed with the rubber, with which it readily combines at ordinary temperatures, and produces a vulcanized product suitable for the manufacture of goods which would be damaged by high temperatures. Sulphur monochloride is a liquid at ordinary temperatures, and on aceount of its violent action with indiarubber is diluted by dissolving in carbon bisulphide before being used for vuleanizing.

\section{Quantity of Indiaubber in Common Articlas.}

The important part which indiarubber and sulphur, together with other substances, play in the manufacture of articles in commun use, is little less than remarkable.

The following analyses are given by Weber :-

$$
\begin{aligned}
& \begin{array}{ccccc}
1 & 2 & 3 & 4 & 5 \\
\text { Roller } & \text { siteam } & \text { Outer Cover Tobuter } & \text { Garden }
\end{array} \\
& \text { (uveriug. l'acking. of a tyre. Pouch. Hose. } \\
& \text { percent, percent, percent. percent. percent }
\end{aligned}
$$

\begin{tabular}{|c|c|c|c|c|c|}
\hline Ludiarubleer & . $24 \cdot 44$ & $12 \cdot 73$ & $54 \cdot 70$ & $50 \cdot 2 \cdot 2$ & $31 \cdots 4$ \\
\hline Free sulphur & $1 \cdot 23$ & $2 \cdot 10$ & $11 \cdot 58$ & $0 . .27$ & $1 \cdot 83$ \\
\hline Sulphur of vulerni- & (1). $5 t$ & - & 1.04 & 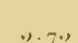 & ). \\
\hline Mineral watter & $72 \cdot 33$ & $62 \cdot 81$ & $41 \cdot u s$ & $2 \cdot 1 !$ & $26 \cdot 28$ \\
\hline Organic extract & $1 \cdot 10$ & $2 \cdot 8 \cdot 2$ & $1 \cdot 34$ & $4 \cdot 88$ & $7 \cdot 34$ \\
\hline Carbonaceous matte & - & $1 !) \cdot 53$ & - & - & - \\
\hline fatty substitute & - & 一 & 一 & $37 \cdot 21$ & $\cdot 90$ \\
\hline Chlorine in rubber. & - & - & _- & .50 & $2 \cdot 20$ \\
\hline
\end{tabular}

The presence of as much as 50 to 54 per cent. of indiarubber in an ordinary tyre and tobacco pouch, the use of nearly 30 per rent. of fatty substitutes in garden hoses, and over 70 per cent. of mineral matter in roller eovering made from fine Para, should be noted.

The uses of Para rubber have been greatly augmented in recent years by the increased production of automobiles and accessories, and it is difficult to accurately forecast what the demand for rubber will be when it is adopted for wheeled traffic and public passenger vehicles generally in many parts of the world. It has also been largely used in recent times in the making of parements. balls, boots, articles of clothing, instruments, belting. \&c., and "solution." Plantation rubber is preferred by many munacturers for "solutions," on account of their being able to use it direct with the solvents without purification. 
The use of eheap substitutes, and of rubber mixed with various materials for cables, is now becoming a serious matter. The cable maker cannot easily afford to pay $8 s .6 d$. per $\mathrm{lb}$. for the pure material.

In Ceylon the Telephone and Telegraph sections of the Post Office Department have, according to Mr. Cook, been contemplating the use of the paper and dry air insulation afforded by the so-called Dry Core cables for underground and sub-aqueous extensions, but the local conditions are so peculiar in regard to the soil and the atmosphere, that the engineers have not made up their minds as to the desirability of the change from vulcanized rubber insulation. Nevertheless, cheap substitutes are being used in cable work in many parts of the world.

Burgess, as a result of inquiries made during 1905 in Europe, was able to state that land cable carrying telephone wires, and which at one time were insulated with rubber, are now largely insulated with dry paper, and that heavy cables for electric light supply are demanding for use in their manufacture less and less rubber every year, its place being taken by papier-maché and cellulose pulp. He attributes this to the high price of raw rubber, and is of the opinion that there will be a great extension of the electrical application of rubber when the price of raw rubber is reduced.

Guttapercha has been tried both in Ceylon and India, but the concensus of opinion is that for tropical installations it is far inferior to indiarubber. 


\section{CHAPTER XVI.}

\section{KINDS OF PARA RUBBER.}

Plantation and fine hard Para-Uses of Plantation and cultivated rubber-Burgess on Plantation rubber and its inferiority-The effect of moisture and smoking on Plantation rubber-Chemical and physical tests-Commercial reports on Plantation rubber from Ceylon and the Straits-Biscuit and sheet rubber-Crêpe rubber, characters, preparation, and value - Worm rubber, characters, preparation, and value-Illustration showing forms of Plantation rubber-Lace rubber, preparation by mechanical means-Illustration of machinery used in the manufacture of lace rubber-Flake rubber-Scrap rubber - Chemical analyses of biscuit, erêpe, lace, and worm rubber.

\section{The Difference between Puantation and Wild Rubber.}

THE comparison of the kinds of Para rubber may appropriately 1 be prefaced by a few remarks regarding the differences between Plantation and Wild or fine hard Para rubber, the former being obtained from the newly-planted trees in the Tropics and the latter from the wild trees in the Amazon District.

The methods of preparation in the East are such that Plantation rubber is made much purer than the fine hard Para ; it contains very little, if any, moisture, and is obtained with or without the use of chemical reagents. It is, of course, usually obtained from younger trees than the fine hard Para. The Plantation rubber, when placed on the same market as the "wild," obtains a higher price, weight for weight, because of the small quantity of water and other impurities present, the loss on washing being only ahout 1 per cent. as against 10 to 20 per cent. for some grades of fine hard Para rubber. The extraction of the impurities from the latter rubber is not always very troublesome, and if allowance is made for the large quantity of water it contains the price realised is really much better than that for Plantation rubber free from moisture.

The preference of the manufacturers for purified fine hard Para rubber is said to be due not so much to its being obtainable in large quantities, as to the fact that its properties are much more constant and lasting.

The "India Rubber World" of December 1st, states that several manufacturers in Great Britain are unable to give their opinion as to the value of Plantation Para rubber, but they all seem agreed that there is a wide variation in the quality as received in England. 
Examples are known of specimens of pure Para Plantation rubber which in two years have resolved themselves into a gummy substance void of all the desirable properties of indiarubber, whereas samples of purified fine hard Para rubber have been perfectly sound after seventy years. The Plantation rubber is usually regarded as wanting in resiliency and recuperative power, but when put on the market as clean biscuit, crêpe, or worm rubber, is eagerly bought on account of its purity and, therefore, adaptability for "solution" purposes

The opinion in many quarters is that the use of chemicals such as acetic acid, formalin, \&c., should not be continued if the Plantation rubber can be effectively prepared and purified by mechanical means.

Burgess, in his report upon a visit to Great Britain to investigate the indiarubber industry and its relation to the growth and preparation of raw indiarubber in the Malay Peninsula, states that the manufacturers who had tried Plantation rubber from Ceylon and the Straits were agreed that the " rubber was good and very serviceable, but that it was by no means as good as South American fine Para, either hard or soft cure. The Plantation rubber is lacking in "nerve," it works soft between the masticating rollers, and its keeping qualities are inferior to South American Para. After vulcanization the tensile strength is less, and the elastic recovery of shape after deformation by stretching or compression is less perfect than South American Para under precisely similar conditions." He further points out that the Plantation rubber shows an inferiority from 8 to 15 per cent. compared with wild Para, and that this inferiority is not only in the physical properties which are capable of immediate measurement, but also in the keeping qualities of the rubber, the plantation samples often tending to become soft and gummy whilst wild Para remains tough and elastic after inany years' keeping. Burgess suggests that the superiority of the wild Para may be due to the fact that the rubber trees of South America, which are tapped, areselected both by natural and artificial selection, and therefore only the best and oldest trees are used as sources of rubber. This idea is original, but does not appear to be supported by the results obtained from the old trees at Henaratgoda and Peradeniya, where only the first tappings gave tacky or soft rubber, or by the observations quoted by Jumelle.

\section{The Smoking Method and Plantation Rubber.}

In a recent communication to the Press dated March 22, 1906. Messrs. Lewis \& Peat point out that consignments of biscuits have arrived in London in a heated and sticky condition, and raise the query as to whether the present mode of preparing biscuits is the best. It is pointed out that Amazon-grown smoke-cured rubber is still the standard, and has for a record of 50 years maintained its reputation for elasticity, strength, and durability. One of their advisers is inclined to believe that "Ceylon and Straits biscuits and sheets are 
at present made too pure-too much moisture being taken out of the rubber-with the result that the elasticity and strength are reduced; such rubber, it is stated, will not keep, but inevitably becomes soft and treacly if stored for any time or subjected to pressure and a raised temperature." It is finally suggested that the Plantation rubber should be smoked and made up into large balls, bottles, or cakes, as in Para. The same firm in their circular dated December, 1905, state that " the very greatest care should be taken that all rubber is absolutely dry before being packed." Obviously, in the opinion of Messrs. Lewis \& Peat, the question of how to prepare the rubber for the market is a vexed one and deserving of much experiment.

It has been pointed out, elsewhere, how Para rubber is smoked in Brazil, and in addition to the nuts of specified palms ccrtain antiseptic reagents such as creosote, dilute hydrofluoric acid, and corrosive sublimate have been mentioned as being of use in the preparation of rubber. It has also been shown that rubber prepared from trees 30 years old may, if not properly dried, become quite as heated or tacky as that from young trees. If a larger proportion of moisture is left in Plantation rubber, putrefactive changes will be more apt to occur, and the use of antiseptics either by direct application to the latex or by smoking or coating the rubber will be imperative. In any case, the coating of the rubber particles or smoking the freshly-prepared rubber biscuits or sheets with any antiseptic is always an advantage as far as the keeping properties of the rubber are concerned; most of the heating or tackiness in Plantation rubber is due to bacteria, which can be prevented from spreading by the use of antiseptics; if not destroved they will lead to putrefactive changes in rubber with whish they are brought into contact. It is really a disease which in unsmoked rubber can certainly be spread by contact; but whether it is more likely to develop on rubber from young or old trees, is still a point to be determined. If the consumers will accept the Plantation rubber, prepared by the use of antiseptics as described, the producers will find no difficulty in meeting their requirements; in fact, several Ceylon estates have, for some time past, sent their rubber to Europe in the sinoked condition, but whether better average prices for large quantities have been obtained is not known to the public.

The subject of Plantation versus wild fine Para has been discussed in a recent issue of the "German Rubber Trade Journal," by Gustave van der Kerckhove, and, as in other communications, the writer points out that fine Para has not been deposed by the plantation product, and that the former probably owes its better physical properties of elasticity, durability, \&c., to the creosote emitted during the smoking process.

\section{Chemical and Physical Tests.}

'The inferiority of Plantation rubber is commonly attributed to the trees being immature as compared with those in the Imazon District. 
But it has been previously shown that in the Amazon District trees are tapped when they are 15 years old, and when forest Para rubber trees are 25 years old they are described as having reached maturity. In view of these facts it is interesting to reflect on the chemical analyses of rubber from trees $4,6,8,10-12$, and 30 years old, given elsewhere. These analyses have been made from rubber obtained from Ceylon-grown trees, and it is fortunate that the age can be guaranteed. They show very clearly that the variation in chemical composition between the rubber from young and 30-year-old trees is insignificant, and that the reputed defects of rubber from young trees cannot be explained from the differences in the chemical analyses given. There is as much variation between the chemical composition of samples of rubber from trees of the same age as between those given for the material obtained from trees 4 to 30 years old, and the ordinary analytical methods do not appear to give indications of the great differences in physical properties. From these and other considerations one feels compelled to seek for some other tests, of a physical nature, whereby the rubber may be scientifically classified, and which will allow of the value being calculated on a sound basis. Colour cannot be accepted as a guide, though preference seems to be given to the pale amber colour by many manufacturers; only in the case of really bad samples can odour be taken as indicating quality, as the best biscuits have often a cheesy putreseid smell which is more or less transient. In this chapter it will be seen that certain physical tests have been devised, and the results obtained with samples of Plantation rubber from the East are given. It is not impossible that the physical properties of rubber will ultimately be associated with the quantity and nature of the ingredients indicated in the numerous chemical analyses which have been quoted. At the present time the valuation of different kinds of Plantation rubber is not usually based on chemical analysis, except by a few firms on the continent of Europe, but mainly on appearance and physical characters.

The "India Rubber Journal" of August 28 published a series of reports regarding various samples of Plantation rubber from the East. Opinions as to the strength and general value of cultivated rubber have shown considerable variation, and though the conclusions embodied in the previous paragraph may be taken as representing the opinions of a large number of manufacturers, it has frequently been stated on good authority that cultivated Para rubber was equal in tensile strength to native-cured Para, and after vulcanization gave very good results. The differences in strength noticeable in Plantation rubber are usually ascribed to the tapping of young trees and irregularity in mixing the latex from trees of different ages; the latter cannot help but occur on small estates, where only a small proportion of the trees are even ten years old.

Regarding certain samples of Plantation rubber it has been stated that when worked on the mill the light coloured samples gave the odour peculiar to fine Para when prepared without the use of smoke. 



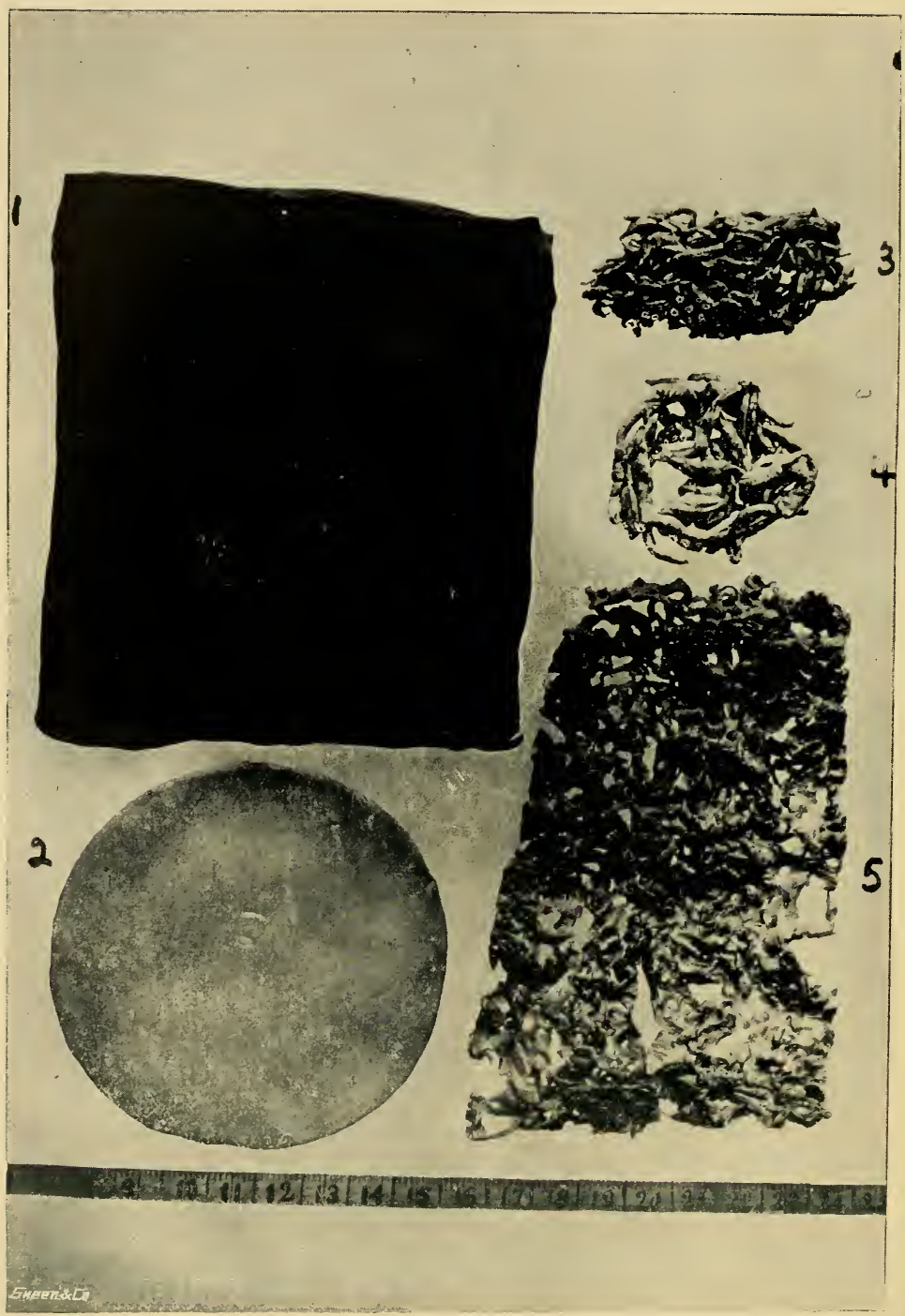


On the mill they prove to be much softer than dry sheet Brazilian Para. They also take the "compound" much more rapidly than the Amazonian variety. To assist in comparing the tensiles obtained from the several brands of Plantation rubber the data are presented in tabular form. The term "Tensile" means the pounds required to break $\frac{1}{4}$ in. by $\frac{1}{4}$ in. in section of the compounded rubber.

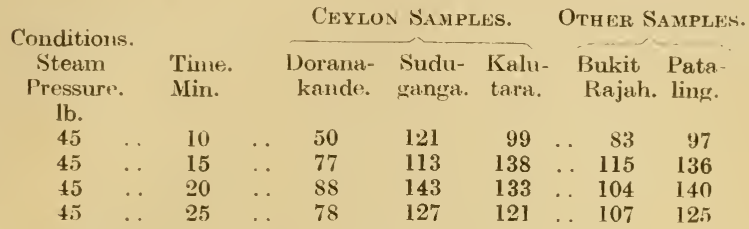

From the above analyses the same journal proceeds to state : (1) "That Ceylon Para when used to denote the Oriental source of fine Para means a grade lacking in uniformity, when the tensile strength is considered ; (2) the curing qualities of Ceylon fine indicate that it has a decidedly slower action than the South American product; (3) all the Oriental samples are much softer and are less nervous th an the Occidental types."

\section{Forms of Plantation Rubber.}

Having compared the differences of Plantation and Brazilian rub. ber, it now remains to deal with the various forms of the cultivated rubber which are briefly (1) sheet, (2) biscuit, (3) crêpe, (4) worm, (5) lace, (6) flake, and (7) serap rubber. The illustrations on Plate 27 , Series A, will show their general appearances.

In packing Plantation rubber the packages should not exceed one to two cwt. in weight; a little Fuller's earth can. according to some authorities, be used. It is not adrisable to pack the rubber between paper.

\section{Biscuit and Sheet Rubber.}

The biscuit and sheet rubber are most commonly met with, and are prepared by allowing the latex to set in shallow receptacles, with or without acetic acid, and washing and rolling the cake of rubber which appears at the top. The biscuits are more or less circular and the sheets rectangular in outline. They are sometimes pressed together to form blocks, and the sheets, on account of their shape, lend themselves to more economic packing than most other forms.

According to Nlessrs. Lewis and Peat, there is a tendency for shipments of sheets of rubber to be taken in preference to biscuits, those having a clear amber colour and measuring about 2 feet by 1 foot having obtained high prices. Biscuits which were clear and pale amber-coloured also obtained high prices in 1905.

An adviser to Messrs. Lewis \& Peat is of the opinion that biscuits and sheets will have to be abandoned in favour of balls or other forms like those in which fine Para arrives in Europe, as the former 
are very liable to become heated or tacky. He argues that "the very form of thin biscuits lends itseif to heating when under pressure, whereas the ball shape and thick biscuits are far less liable to this "hange, and he prophesies that when the rubber is arriving in tons the defects will be very evident by the state the material arrives in and that even if the rubber does not get heated on the voyage it will inevitably do so if stored for any length of time in the warehouse. He gives as proof of his theory that the same thing occurred to certain other rubbers, and the remedy in their case was making it into large balls."

Sheets measuring $24 \times 12$ inches and $\frac{1}{8}$ to $\frac{1}{4}$ inch in thickuess are received with favour in Europc.

\section{Stze AND Shape, \&C., of Biscuits.}

In many instances the biscuits, on drying, curl up at the edges and present an objectionable appearance. This can to some extent be overcome by pressing them in a vessel of definite outline hefore subjecting them to the rolling process; after rolling, the eakes partake of the shape of the vessel in which they were pressed, and if the margins of the latter are correctly made the tendency to curl and become wavy in outline is not as noticeable.

The biscuits and sheets are usually very pure, and can without washing be used for "solution" work by the manufacturers; the material is practically ready for the naptha bath on its arrival in Europe. It has been stated that the material from Ceylon shrinks about 1.4 per cent., and that it is not liked for cements. In past times it has been very irregular in quality, sometimes being little better than elastic gum, sometimes sticky and only equal to recovered rubber in elasticity. The rubber biscuits from old Para trees are tough and elastic, and much of the irregularity referred to might to some extent be obviated by not mixing the tappings from trees of different ages. If the irregularity in quality is allowed to continue, it may spoil all prospects for use of our rubber in fine work, such as thread, bladders, \&c., and if the "solution" market should become overstocked the position might under such circumstances be embarrassing to rubber planters in Ceylon and the Straits.

Biscuits should be made from $\frac{1}{8}$ to $\frac{1}{4}$ inch in thickness and 12 to 14 inches in diameter.

\section{Crêpe Rubber.}

Crêpe rubber differs from the foregoing on account of the stretching and tearing it has undergone between the rollers of the washing machine and the low quantity of soluble and mechanical impurities it contains. It is, of course, only washed rubber, but it may have been obtained from purified scrap as well as the other class. It has an irregular surface, is very uneven in thickness, and like lace and flake rubber dries very rapidly. On account of its purity it has been well reported upon in Europe, and owing to the efforts of Burgess is likely to come to the front in the Straits. Crêpe rubber has been described in Europe as "fine pale, strong, quite clean, and in good 
condition." The material has been sold at a good price, but on account of the washing and re-washing which certain manufacturers subject all rubber to, it has been questioned as to whether the extra labour involved in its preparation will be paid for by the higher price. According to the "India Rubber World" of December 1, 1905, very few consumers have looked upon this form of rubber with favour, and most of them prefer to do the washing themselves.

Lewis and Peat stated in 1905 that " manufacturers are still prejudiced against any rubber that has been washed or otherwise treated. as a certain amount of the natural fibre and elasticity is lost in the process, and the true quality of the rubber is much more difficult to tell in this form; but the prejudice seems to be wearing off." In any case it will always rank as a relatively pure rubber, and will allow of the conversion of scraps and other kinds to one class of uniform standard.

\section{WORM RUBBER.}

Worm rubber is essentially the produet obtained by cutting irregular sheets of freshly-coagulated rubber into thin worm-like rods of unequal length. The Michie-Golledge machine is used to coagulate the latex; the fresh rubber is rolled to express the water. and the irregular cakes are cut up by means of large shears. The fresh rubber being cut into such fine parts dries quickly ; the "worms" "au be economically packed in ordinary tea boxes.

Lewis and Peat, in their report on Plantation Rubber for 1905, state that worm rubber is not so attractive as biscuits or sheets, and buyers are rather apt to treat it as a form of very fine scrap, although the quality is every bit as good as sheet or biscuits.

Samples of worm rubber have, up to the present, received good reports, the concensus of opinion being that the rubber so prepared was very clean and contained very little moisture : onee it has established a name it might command a price equal to, or higher than. biscuits on account of its purity and dryness. Plate 22. Series A, shows the freshly-coagulated spongy mass, which after passing through the rolling machine shown on Plate 23, Series $\mathrm{A}$, is ready for entting into "worms."

\section{Lace Rubber.}

Lace rubber has been prepared by Mr. Francis Holloway, Matale. It consists of very thin perforated sheets of considerable length. In the preparation of lace rubber the latex is coagulated without the use of mineral acids or application of heat, and after heing converted into "lace" is dried in air kept at about $95^{\circ} \mathrm{F}$. The porous sheet is very thin, of a pale amber colour, and can be easily pressed into biscuits or sheets of any rlesired thickness. The "lace" comes out of the machine in a continuons strip ; it is cut into pieces 6 feet long as it runs on to wire trays. The rubber is very thin and dries rapidly; it is maintained that it ean be turned out ready for drying within seven minutes of the latex arriving at the factory The time taken for coagulating the latex, conversion into lace 
rubber, and drying ready for despatch is 48 hours. Mr. Holloway assures ?me that only mechanical methods are adopted, a point of considerable importance. The illustration on Plate 28, Series A, shows the machinery used by Mr. Holloway.

\section{Flake RUBber.}

Flake rubber is quite a recent introduction, and I have to thank Mr. C. O. Macadam, Culloden, Neboda, for the information on this form of rubber. Flake rubber is made by Mr. Macadam by placing small pieces of freshly-coagulated rubber in a small rolling machine or washer, the corrugations of which run horizontally; the rollers are close together and the cut rubber issues as thin strips. The strips or flakes are very thin, and can be easily smoked and packed in any form. The sample I have seen was pale amber in colour, free from mechanical impurities, and possessed good physical properties. It is apparent that the very thin flakes can be rapidly dried, and in this respect compares very favourably with crêpe or lace rubber

\section{Scrap Rubber.}

Scrap rubber is mainly the coagulated rubber obtained from the incised areas, rolled into balls or made up into cakes. It may be sent to Europe in the crude state, with all its mechanical impurities, or washed, purified, and converted into crêpe rubber before being despatched. Scrap rubber, if free from bark, dirt, and other impurities, obtains a high price.

\section{Analyses of Plantation Rubber.}

The following analyses of the different forms of rubber are tabulated for reference, though a wide variation must be allowed in each case. A general average composition cannot be given until more analyses have been made :-

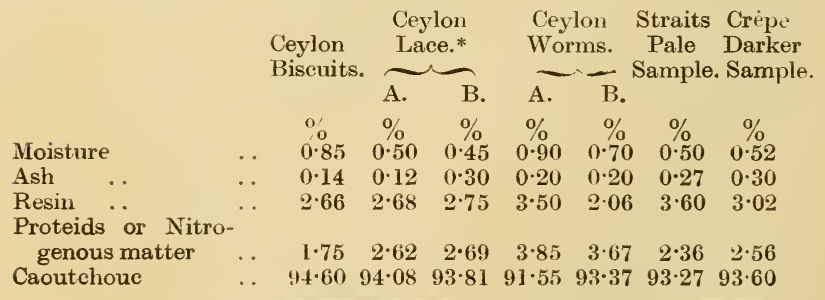

$100.00100 \cdot 00100 \cdot 00100 \cdot 00100.00100 .00100 \cdot 00$

I am indebted to Mr. M. Kelway Bamber for the analyses of biscuit, lace (A), and worm rubber, and to Mr. P. J. Burgess, for the privilege of using the analyses of crêpe rubber from the Straits by Herbert Ballantyne, F.I.C., F.C.S.

* By Ballantyne, in India Rubber Journal. 


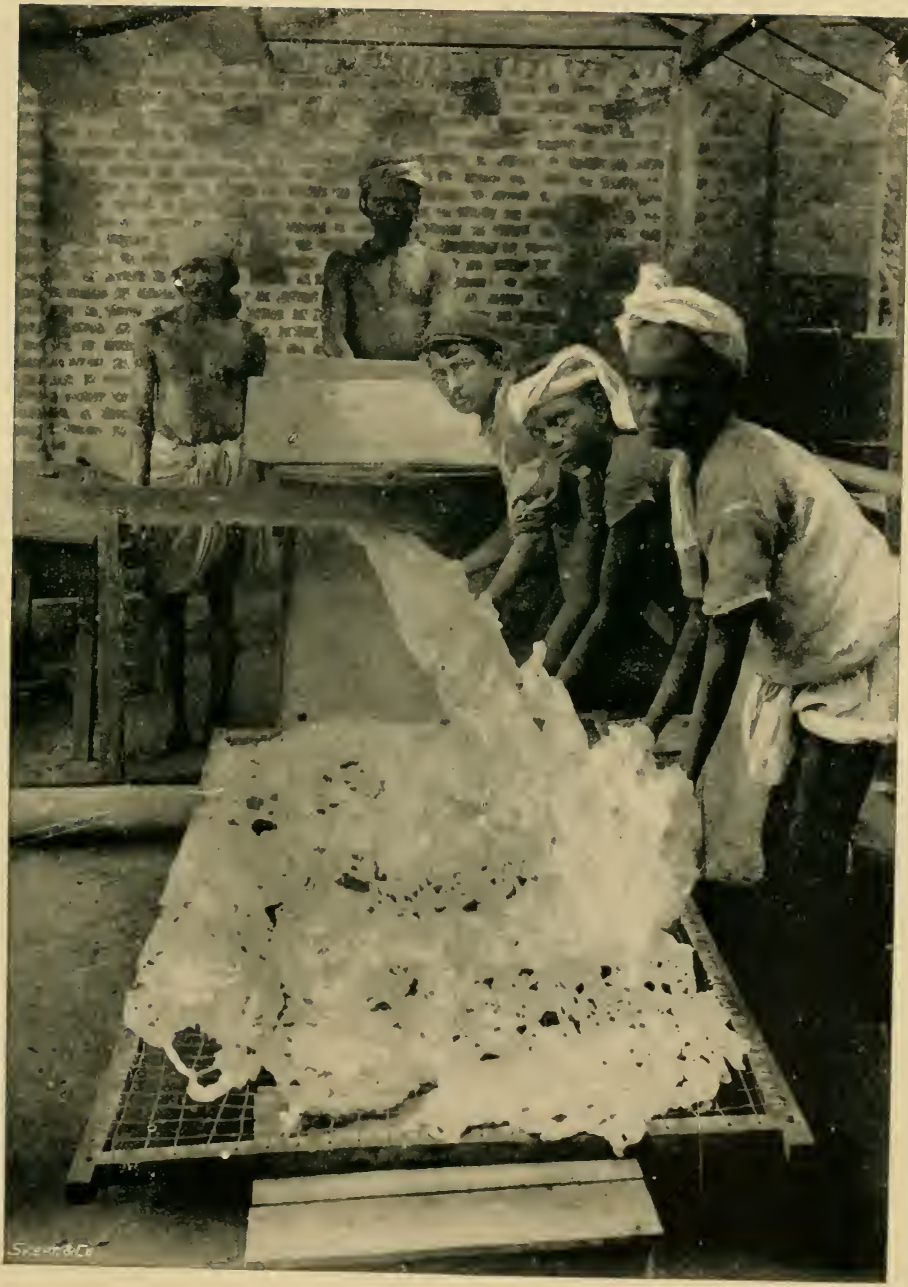



CHAPTER XVII.

\section{DISEASES OF PARA RUBBER TREES.}

Diseases of plants grown on small areas-Epiclemics over large acreages -Checking disease by tree belts-Illustration showing hardy. characteristies of Herea brasiliensis-Para rubber pests in Brazil and Java-Leaf diseases of Para rubber-Fungi, Helminthosporium, Periconia, Cladosporium, Macrosporium, Pestalozzia, CercosporaPreventive measures-Insects, plant-sucking bugs, weevils, and mites-Preventive measures-Fruit cliseases of Para rubber-Fungi. Nectria and Phytophthora-Preventive measures-Stem diseases of Para rubber-Fungi on old stems and green twigs-Preventive meastures-A bark fungus in the Straits-Insects, wood-borers, ants, and slugs-Preventive measures - Ront diseases of Para rubberFungi in Straits and Ceylon-Fomes in the Straits-Polyporus Helicobasidium and Hymenochrete-Insects, termites, cockchafers, grubs-Preventive measures-A disease on prepared rubberProbablo eauses and preventive measures-Analyses of black and yellow tacky rubber-Chemical analyses of tacky and sound rubber.

T $\mathrm{T}$ is often relatively easy to successfully grow a small number of plants in any particular district without their suffering from the ravages of innumerable insects and fungi. But if the same crop is grown on a large scale matters often take a different turn. It has frequently been my experience when dealing with minor products on a small scale to find that the diseases to which they were subject never developed to a serious extent, but when onee the product was greatly extended the insignificant diseases became a serious menace to the plants and often rendered further eultivation impossible.

It would appear on first considerations that any pest, which found a desirable means of sustenance on the tissues of a partieular plant, would increase to such an extent that the few host plants in the neighbourhood would be exterminated. But, for some reasor. or other, many pests do not appear to behave in this manner, and it is only when the host plant occurs in large numbers and over extensive areas that anything like an epidemic is noticeable.

Perhaps the occurrence in large numbers of the host plants in widely' separated distriets ensures that the pests will find the requisite means of sustenance, no matter where they occur, and their pro- 
pagation be thereby ensured. The larger their food supply, the quicker they will increase in number and ultimately prove more serious to the crop on which they are living. On these grounds the contention of Colombo friends "that the cultivation of Para rubber to the exclusion of other kinds of rubber is a dangerous system," has probably much to recommend it. On some large estates the Para trees are being grouped, and each group is separated from its neighbour by a belt of forest or of Castilloa elastica trees. Such a belt would prevent, to a certain extent, the spread of disease, and would allow one to more easily combat insect or fungus pests, as soon as they made their appearance on the enclosed Para rubber trees.

In any case it is well to realize that trees of Para rubber, whether growing under unhealthy or perfect conditions, are not immune from the attacks of parasitic fungi and insects, even at a time when the number and age of the host plants may seem to be almost negligible. The best advice which can be given is to attack all diseases in their earliest stages before the parasites have increased beyond easy control. It is fortunate that among the thirty odd diseases or pests mentioned below none are of a very serious nature, but they are nevertheless worthy of full consideration.

\section{Para Rubber Pests in Brazil and Java.}

Hennings* has described and figured five leaf fungi, viz., Phyllachora Huberi, Dothidella Ulei, Aposphaeria Ulei, Ophiobolos Heveæ, and Parodiella Melioloides. These have been found in Brazil, but dn not seem to be very serious, though the Ophiobolos is said to destroy the leaf and is perhaps the most dangerous of them.

On sick and rotten trees of various species of Hevea, Allescheriella uredinoides was found.

In Java, Zimmermann in the Bull. Inst., Buitenzorg, has recorded several fungi on Para rubber. Phyllosticta Heveæ, Zimm., is a fungus causing brown spots especially at the tips of the leaves; Glœosporium elasticæ, Cooke and Mass., is another leaf fungus which produces light greenish spots and masses of reddish spores

\section{Leaf Diseases.}

There are already several insects and fungi which live on the leaves of the Para rubber trees, but none of them are very harmful. To a very limited extent the annual fall of leaf that takes place on all Para rubber trees after they have passed their second or third year is an advantage when dealing with leaf pests, as the foliage can be easily and regularly collected and burnt. Again, the leaves may happen to fall prior to the formation of the spore-producing bodies, and in this way assist, to some extent, in checking the spread of disease. But it should be remembered that the Para rubber trees are in pos-

* Notizblatt des Konigl. Botanische Gartens und Museums zu Berlin (Vol. 4, No. 34, p. 133). 

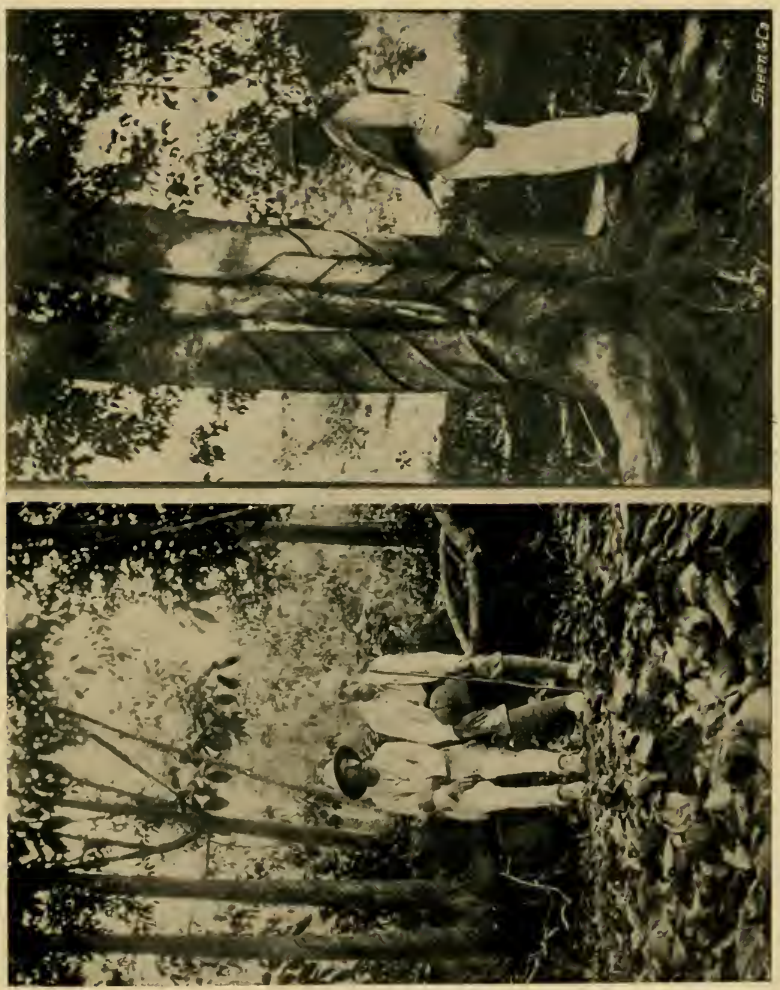

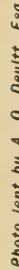

\section{3.}



session of their foliage for about 50 out of every 52 weeks each year, and to assume that the leaves, owing to their deciduous character, are not likely to contract a permanent disease is by no means sound.

Fungi.-Leaves of Para rubber seedlings and of older plants have been attacked by a species of Helminthosporium ;* the leaves were "studded with circular, semi-transparent spots, each surrounded by a brown cushion from which arose the threads of the fungus." It was suggested that the spots were due to punctures by insects and the fungus grew on the dead tissue. Damaged parts of the leaves of Para seedlings are also subject to the attacks of Periconia pycnospora, $\dagger$ and species of Cladosporium and Macrosporium.

A species of Pestalozzia-identical with that which is associated with the "grey Blight" on tea leaves - has also been found by Petch on leaves of nursery seedings of Hevea, and according to that mycologist were probably infected by wind-blown spores from the adjacent tea. The fungus produces white irregular areas spreading generally from the tip of the leaf. In the Straitsi the leaves of the Para rubber seedlings have been attacked by a fungus, regarding which Mr. Nassee reported: "The pale blotches on the leares are caused by some species of Cercospora, but the absence of fruit prerents specific identification." Ridley states that this leaf fungus is common all over the Nalay Peninsula, but that except in the case of seedlings does not do much harm.

Petch has recently found a species of Glœosporium on the leaves of seedlings; the fungus forms light brown spots on the upper surface of the leaves, and finally the latter turn yellow and fall.

It is satisfactory to know that, up to the present time, the leaves of mature Para rubber trees are practically free from parasitic fungi, but the disease on the leaves of seedlings is one which leads to partial defoliation and checks the growth of the young plants. In all such cases the diseased leaves should be pulled off and burnt and the rest of the plants sprayed with Bordeaux mixture; this consists of $6 \mathrm{lb}$. of copper sulphate and $4 \mathrm{lb}$. of freshly.slaked burnt lime in 45 to 50 gallons of water.

Insects.-According to Green $\%$ the leaves of Hevea are reported to have been punctured by certain plant-sucking bugs, the most likely species being Leptocorisa acuta and Riptortus linearis ; the former is known as the "Rice-sapper." It appears that these pests puncture the leaves and stems. "The injured leaves show numerous small spots, each bordered by an irregular dark rim, within which the tissues have dried and turned white." It is believed that the injury to the leaves is due more to a fungus than to an insect.

A scale bug-Lecanium nigrum, Nietn.- - has also been observed by Green on the leaves of young Para trees, but this can be easily destroyed by means of Macdougal's mixture. The tips of seedlings

* T. Petch, Mycological Notes, Tropical Agriculturist, June, 1905.

$\uparrow$ Agriculturist Bul. of the Straits and F.M.S., July. 1905.

E. E. Green, Entomological Notes, Tropical Agriculturist, April and May, 1905. 
occasionally turn hlack and dry up, and it has been suggested that this may be due to some plant-sucking hug. A species of weevil, allied to if not identical with Astycus lateralis, has been known to ea.t the leaves of Para rubber in the Straits, ${ }^{*}$ and the only remedy is to collect and destroy the weevils.

Green has also recorded in the T. A. and Mag. C. A. S., Decemher, 1905, a new species of scale bug (Coccid) upon the leaves, belonging to the geuus Mytilaspis, but he considers that it is unlikely to cause any serious trouble.

"Mites" in rubber nurseries have also been reported from the Straits. $\uparrow$ Arden states that in some cases the young leaves fall from the plant before they are fully developed, and in other cases the mature leaves present a crinkled appearance, are yellowish-green in colour, and appear to be dotted with numerous punctures. He compares it to "Red Spider," and believes that the disease is mainly limited to plants growing under unfavourable conditions.

Spotted locusts have also been reported to do considerable damage to the young rubber plants in Ceylon and the Straits.

Locusts have been reported from various districts in Ceylon, and are said to destroy the seedlings and also the leaves of mature plants. According to Green (Tropical Agriculturist. November. 1905 ) poisoned baits have been found effective in such cases, one of the best being "Arsenic salt horsedung" mixture, made by compounding one part of Paris green or white arsenic with two parts salt and forty parts fresh horsedung. It is recommended that this should be broadcasted among the affected plants or wherever the locusts may be noticed.

\section{Fruit Disease.}

Para rubber planters in many parts of Ceylon have occasionally been alarmed at the curious behaviour of certain fruits; some dry up and remain attached to the twigs, and others of all ages fall to the ground without expelling the seeds. The fall of the unexploded fruits is often due to wind, and there is no parasitic fungus to be found in the tissues. It has been stated that the fruits are subject to the attack of a parasitic fungus belonging to the genus Nectria, and Carrutherst reports having successfully inoculated Para rubber fruits with this fungus, but was not certain as to whether it attacked the fruits when on the tree or only when they fell to the ground. Petch subsequently stated that the disease on Para rubber fruits is due to a parasitic fungus similar to, if not identical with, that which causes the decay of cacao pods. All the Hevea fruits examined were attacked by a species of Phytoph thora, which permeates the soft outer tissues of the fruits; the seeds dry up later when the supply of food and water is cut off. In addition to the ordinary spores which infect

* Wray, Perak Museum Notes, 1897.

$\uparrow$ Stanley Arden. Agr. Bull. of the Straits and F.M.S., June, 1905.

* T. B. Carruthers, Circular of the R.B.G.. Peradeniya. January, 1905.

$\S \mathrm{T}$. Petch, Mycological Notes, Tropical Agriculturist, 1905. 
other fruit while the original fungus is flourishing, resting spores are formed in the dead fruit. These are liberated when the fruit decays, and thus serve as a source of infection to the following crop. In this way the fungus bridges the gap between the crop.

The most effective way of fighting the fruit discasc is to collect all dried fruits which are on the trees and those which have fallen to the ground and hurn the lot on the spot. On the average rubber estate there can be no real objection to burning such small quantities of fruits as this treatment involves.

\section{Stey Diseases.}

Fungi.-In his account of canker (Nectria) of Para rubber Carmithers points out that a parasitic fungus occurs on the stems and hranches, which may prove fatal to the trees. The area attacked hy the fungus can be detecterl often by the change of eolour of the bark or by the exudation of the latex. When, however, the fungus has got a firm hold of any local patch of tissue, the latex tubes become quite empty and dry up, so that it not only threatens the life of the tree, but also robs the planter of the latex or rubher for which the tree is being cultivated. It is necessary that all cankiered areas should be excised and the tissue burnt on the spot. All the disroloured areas should be removed, even if the woody tissues below the cambium are permanently clamaged in the operation. In some cases it is true that the cankered area is, by means of a layer of cork. prevented from extending to other parts of the stem, but it is unwise to leave the matter to chance.

The disease mentioned above has heen found by ('arruthers on " almost all parts of the tree except the young branches and the roots," but even these parts have now been shown to be attacked by other fungi.

Petch* has observed a blackening of green stems of Para ruhber trees to be due to a fungus which produces a network of clarkcoloured threads on the exterior.

A bark fungus has been described in the Straits Agricultural Bulletin, $\dagger$ November, 1995:- " This fungus takes the form of a pinkish-white mass, coating the bark irregularly so as to have an appearance often of hieroglyphics. Attacking usually the upper branches or occasionally the stem, it quite destroys the bark and causes the death of the wood beneath. Fortunately it is easy to see from its conspicuous whitish colour, and easily dealt with by destroying infected branches, and in the case of the trunk being affected by scraping it off and treating with copper sulphate and lime."

Grey blight on the stems of seedlings has also been observed by Petch. The fungus forms a white zone about an inch long just above the surface of the ground. The stems lose their pith. become hollow, aud the plants die.

* T. Petch, Mycological Notes, Tropical Agriculturist, August, 1905.

† Straits Agricultural Bulletin, November, 1905. 
The curious knobs and irregular surfaces on the trunks of Para rubber trees are not due to parasitic fungi; they are wounds which have been made either by falling branches or by carelessness in tapping operations. Of course, they may serve as lodging areas for the spores of fungi or undesirable insects.

Insect pests.-Pidley has reported the existence of a borer which may attack the wood of Para trees, and identified it as belonging to the genus Platypus.

Ants* attack the incised areas six eet from the ground, and in some cases construct earthworks up to a height of 30 to 40 feet and enter the tree at some weak point or wound area. The white antTermes gestroi-is reported to be one of the most troublesome pests in the Federated Malay States. Arden, when dealing with the loss of Para rubber trees in the Straits, points out that there may be some association between the ravages of the white ants and the fungus of the roots of Para rubber. Similar relationships have been suspected in Ceylon, $\uparrow$ where the taproot had probably been eaten by white ants and the dead roots were covered with a network of white fungus hyphr. "The fungus attacked the sound wood and bark, and that the injury was due to this was supported by the receipt from another locality of a young plant which had been killed hy apparently the same fungus. In this ease there were no side roots ; the plant therefore died after the taproot had been permeated by the fungus, and as this was indicated by the withering

$f$ its leaves. it was uprooted hefore the white ants discovered it."

Green states that he has repeatedly received specimens of dead branches and stems of Herea brasiliensis, perforated by a Bostrichid beetle (Xylopertha mutilata. Wek.), but he believes that in every case the beetle has effected its entrance after the death of the parts.

Slugs (Limax sps.) have also been reported as attacking the stem and eating the remains of the latex left in the wounds after tapping. "Living specimens of the slugs received at Peradeniya wer fed with fresh latex. Its presence was almost immediately scented out by them. One of them drank for about ten minutes." Hand-picking or the use of quick-l me should be effective.

Mr E. E. Green has the following notes regarding pests which are associated with the stems, in the Tropical Agriculturist, February, 1906 :-

"The cut ends of young Hevea stumps are frequently tunnelled by various small species of bees and wasps. But these insects are not responsible for the dying back. The pith of any dead stem would be utilized in a similar manner.

"When a Hevea plant is stumped it usually dies back to the node, and it is in such dried ends that the tiny wasps construct their nests. They cannot be regarded as pests, but more properly as friends,

* Stanley Arden, Annual Report, 1902.

$\uparrow$ T. Petch, Mycological Notes, Tropical Agriculturist, October, 1905.

+ E. E. Green, Entomological Notes, Tropical Agriculturist, September, 1905. 
for most of them provision their nests with Aphides taken from some other plant. Specimens of a small Longicorn beetle, said to be responsible for the death of young Hevea trees, have been received from Southern India. The insect proves to be Pterolophia annu'ata, Chevr., a species that occurs in Ceylon also. I have no records of injury done by this insect to Para rubber in this country, but I have bred out a specimen from the diseased bark of a Ceara rubber tree. My correspondent from India reports that the beetles girdle the stems ; the upper parts of the trees dying back down to the injured area. This girdling habit is common to many species of Longicorn beetles. The object of the mancuvre is believed to be to check the sap and induce the degree of decay best suited to the nourishment of the grubs of the beetle ; the eggs having first been inserted in the back above the point of injury. If this pest should become eommon, it might cause serious damage on rubber plant. ations. In case of any occurrence of the pest the stems of all the trees should be carefully searched. The adult beetles will probably be found clinging to the bark of the trees, when they can be easily captured and destroyed."

\section{Root Diseases.}

Fungi.-A root disease due to a fungus has already been mentioned as occurring in the Straits and Ceylon in association with white ants, but probably preceding them. Petch has shown that the Ceylon fungus can spread underground on roots of grasses, \&c.. and that it is a species of Polyporus (Fomes semitostus). The hyphæ are described as occurring on the first six inches of the trunks as well as the roots. Any trees so affected should be isolated by digging a deep trench round them about a foot wide, as in the case of the root disease in tea, and, if possible, the diseased specimens should be uprooted and burnt.

The Fomes fungus, affecting the roots of rubber plants in the Straits, is described as follows in the Agricultural Bulletin of the Straits and F. M. S. for May, 1904 :-

" The fruiting part of Fomes semitostus is a broad, flat, rounded plate often very irregular in form, usually reniform 4 to 6 inches across, and of an orange-red colour beneath, paler above, where it is marked with rings and fine striae; beneath can be seen with a lens the honeycomb-like structure of the hymeneal surface. The texture of the fungus is tough, and it possesses a strong mushroom-like scent.

"This fungus is very common on decaying stumps of all kinds of trees and is, properly speaking, a dead wood feeder, but like a number of allied species attacks also living trees.

"As a disease fungus I would class this as contagious, as opposed to an infectious fungus, as it appears to spread from root to root in the ground without being dangerously dispersed through its spores. 
A dead stump may be attacked above or just below the ground, and the mycelium spreading along the decaying roots may come into contact with those of a living tree, and so the attack is spread. These contagious fungi are more easy to deal with than the infectious ones of which the spores are blown from tree to tree and attack the plant where they alight (as in the fungus previously described). The infected trees should be destroyed and the roots dug out, every bit of dead root or decayed timber being removed and the ground well saturated with copper sulphate and lime.

"Tubeuf, in writing of a similar parasite in Europe (Fomes annosus) whose habits are very similar to those of F. semitostus, states that the best way of combating the ravages of the parasite is isolation of infected areas. These should be isolated with ditches with vertical sides deep enough to cut through all roots, care being taken to leave no diseased stems or roots outside the circle. After remaining open for a time the diteh must be filled again with soil to prevent the formation of sporophores on the exposed roots. All diseased stems should be felled and burnt, or deeply covered with soil to prevent the formation of sporophores; in fact, isolation of these contagious parasites should be done by ditches in the same way as the infectious parasites are isolated by screens of trees of another species." In the opinion of Mr. H. N. Ridley, Director, Botanic Gardens, Singapore, this is one of the most important diseases in the Straits on Para rubber, and deserves prompt attention.

As Messrs. Ridley and Derry have pointed out, this fungus, the mycelium of which is underground, is the worst feature against close planting, as under such conditions it might spread very rapidly. The uprooting of all dead stumps of trees would appear to be necessary if this disease is to be kept in check.

A fungus (Helicobasidium sps.) has been found attacking the roots of Para rubber in the Straits.* This fungus usually spreads rapidly from tree to tree by means of strands of mycelium, and trenching and liming are generally recommended as preventive measures.

Another root disease has been found in Ceylon by Petch. $\dagger$ This one has also been found on cacao, tea, and Caravonica cotton in Ceylon, but is not very dangerous. "The roots are covered with a thick yellowish-brown felt which sometimes develops a black crust exteriorly. Stone, sand, \&c., are firmly attached to this covering, and give the appearance of pudding-stone." It is believed to be a species of Hymenochæte.

Insect Pests.- "Specimens of Termites: (T. redemanni) have been sent with the report that they were eating off the tap roots of young rubber plants. A mixture of lime and sulphur, forked into the soil immediately round the plants, has been found effective in preventing the attacks of white ants. The proportions are one part powdered

* Johnson, 1. e. p. 29.

† T. Petch, Mycological Notes, Tropical Agriculturist, Oetober, 1905.

$\ddagger$ E.E. Green, Entomological Notes, Tropical Agriculturist, April, 1905 . 
sulphur to four parts of lime. In replanting, the holes shouid be filled with earth mixed with lime and sulphur in the proportion of one basket of sulphur, four of lime, and seven of soil. 'This should protect the new plants from any underground attacks.

Grubs of a large cockchafer (Lepidiota pinquis, Burm.) have been received by Green from Yatiyantota, Ceylon, with the report that they are found about two inclies below ground-level. "It is stated that the pest bites through a live stump (of Para rubber) of any size. The only way one can tell that it is working is by seeing the green shoot on the stump die back. On touching the stump it breaks off. Specimens of injured stumps (of about the thickness of a lead pencil) were sent in with the grubs. The taproot has been severed an inch or two below the collar, and every vestige of a side root has disappeared. Alkaline manures, such as kainit and nitrate of soda, have been found useful in driving away cockchafer grubs. The manure should be forked in round the plants in clearings affected by the pest. The same species was recorded in 1902 from the Negombo District, where it attacked the roots of cinnamon bushes. The adult beetle is of considerable size, being fully an inch long and proportionately stout. The larva is a white fleshy grub, two inches in length, the body curved round into the form of a horse shoe. It has very powerful jaws, with which it works great havoe on the roots upon which it feeds."

"A formidable looking grub of some large beetle (Buprestid or Longicorn?) has been sent by a correspondent from Ruanwella. It is said to have been found in the taproot of a rubber tree that had died and broken off. The pest in its larval stage, working-as it does-below ground-level, will be difficult to attack."

\section{A Disease on Rubber.}

It seems as though enough has been said regarding the troubles of all parts of the plants with fungi and insects, but this note deals with a disease on the prepared rubher and cannot be omitted. The signs of the disease are that the rubber becomes at first sticky or tacky, and rapidly softens until it is almost liquid. It can be spread from one biscuit to another by contact. It is supposed to be due to bacteria, which first commence to grow on the sugary and gummy substances in imperfectly washed rubber and ultimately on the decomposing proteid or albuminous material previously referred to. It can to a great extent be kept in check by well washing and squeezing the freshly-coagulated rubber, rapid drying without exposure to high temperatures, and the use of formalin in the latex and on the prepared rubber. Mr. Kelway Bamber recommended that the biscuits be wiped with a solution of formalin, diluted to make a 2 per cent. solution, and not be allowed to touch one another earlier than necessary. 1905.

$\S$ E. E. Green, Entomological Notes, Tropical Agriculturist, October, 
The following are analyses of two samples of tacky rubber by Mr. M. Kelway Bamber :-

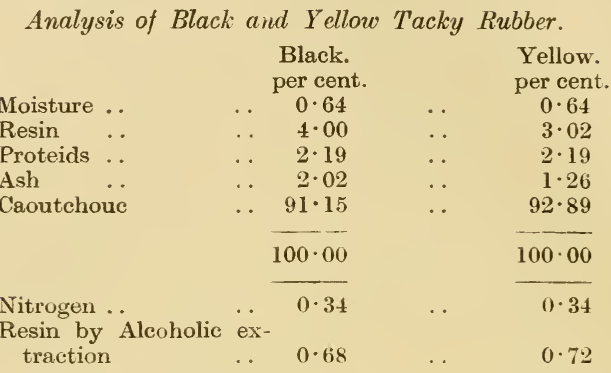

The first rubber obtained from old trees or that from young trees seems very liable to undergo putrefactive changes. It has been suggested that these decomposition processes may be due to molecuar changes of one or more of the constituents of prepared rubber, in lwhich case it would be very difficult to adopt measures to prevent the undesirable result. It has also been pointed out that the presence of large quantities of oily and resinous substances having a low melting point may be the cause of much liquefaction and subsequent decomposition. The chemical analyses of rubber showing varying degrees of tackiness have already been given. They appear to indicate some relationship between the high percentage of resins and proteids and the degree of stickiness and hiquefaction. For the sake of comparison the analyses of sound and very tacky rubber are here reproduced :-

\begin{tabular}{|c|c|c|c|}
\hline & & $\begin{array}{l}\text { Sound Rubber. } \\
\text { per cent. }\end{array}$ & $\begin{array}{l}\text { Very tacky Rubber. } \\
\text { per cent. }\end{array}$ \\
\hline Moisture & . . & $0 \cdot 30$ & 0.44 \\
\hline Ash $\mathrm{H}$ : & . . & $0 \cdot 38$ & 0.72 \\
\hline Resin & . & $2 \cdot 36$ & $3 \cdot 70$ \\
\hline Proteids & . & $3 \cdot 50$ & $4 \cdot 90$ \\
\hline \multirow[t]{2}{*}{ Rubber } & . & $93 \cdot 46$ & $90 \cdot 24$ \\
\hline & & $100 \cdot 00$ & $100 \cdot 00$ \\
\hline
\end{tabular}

The development of bacteria, which has been shown to be associated with putrefactive changes of rubber, can. however, be overcome either by inoculation, effective drying, or the use if antisentics. 


\section{CHAPTER XVIII}

WHAT TO DO WITH THE SEEDS.

Number of seeds per tree-Seed characteristics-Value-Seed oil and fat-Meal and cake-Analysis of meal-Cake of Para rubber seed compared with linseed and cotton cake-Packing Para seeds for transport-Experiments at Trinidad and Singapore-Charcoal, sawdust, and Wardian esses.

T $\mathrm{T}$ is well-known that trees of Hevea brasiliensis flower and fruit after their fifth year in Ceylon. In other countries plants raised from cuttings have been known to produce fruits within three years. Each fruit usually contains three seeds, and the number of seeds anuually produced per tree is about five hundred when the trees are mature.

The following interesting information was published in the "Times of Ceylon" regarding the number of seeds produced from a five-year-old tree and its offspring, assuming that each tree after attaining its fifth year produces 500 seeds annually :-

\begin{tabular}{lrr|rrr}
\multicolumn{1}{r}{ Year. } & & $\begin{array}{r}\text { Total Seeds at end } \\
\text { of each year. }\end{array}$ & Year. & \multicolumn{2}{r}{$\begin{array}{r}\text { Total Seeds at end } \\
\text { of each year. }\end{array}$} \\
1st & $\ldots$ & 501 & 11 th & $\ldots$ & $130,255,501$ \\
2nd & $\ldots$ & 1,001 & 13 th & $\ldots$ & $1,259,006,501$ \\
3rd & $\ldots$ & 1,501 & 15 th & $\ldots$ & $14,388,757,501$ \\
4th & $\ldots$ & 2,001 & 17 th & $\ldots$ & $323,019,508,501$ \\
6 th & $\ldots$ & 253,001 & 18 th & $\ldots$ & $952,522,759,001$ \\
Sth & $\ldots$ & $1,504,001$ & 19 th & $\ldots 2,208,151,259,501$ \\
10th &. & $3,755,001$ & 20 th & $\ldots 4,402,530,010,001$
\end{tabular}

The 500 old trees at Henaratgoda and Peradeniya produce annually about 200,000 seeds, equal to approximately one ton by weight. At the present time there are about 60,000 acres of Para rubber trees in Ceylon, probably more in the Straits, and very large areas in other parts of the world. It is, therefore, necessary to study the properties of the seeds in the event of more being produced than are required for planting purposes. It is obvious from a glance at the above table that, hefore long, very large quantities of seeds will be available.

The seeds of Para rubber contain an oil which has been ralued at $£ 20$ per ton, and also yield a cake which may be valued at $£ 5$ to 
$£ 6$ per ton. The decorticated seeds have been valued at $£ 10$ to $£ 12$ per ton, and brokers in Europe consider that it would be more profitable to ship the seeds from the Tropics to Europe.*

\section{Para Rubber Seed Oil and Fat.}

"The kernels constitute-about 50 per cent. by weight of the whole seeds, and yield $42 \cdot 3$ per cent. of oil. The husk and kernel together yield 20 per cent. of oil. The oil is clear, light yellow in colour, and on saponification with caustic soda furnishes a soft soap of yellowish colour. If the seed has been ground to a meal the oil extracted is solid owing to decomposition; but that expressed from the freshly-ground seed is liquid. The husks contain a solid fat in small quantities."*

\section{Para Rubber Seed Meal and Cake.}

Old ground seed so finely divided as to form a meal was reported upon by the Imperial Institute as follows:-

\section{Chemical Analysis.}

\begin{tabular}{|c|c|c|c|c|}
\hline Moisture & $\ldots$ & $\begin{array}{c}\text { per cent. } \\
\quad 9 \cdot 1\end{array}$ & Oil & $\begin{array}{c}\text { per cent. } \\
\ldots \quad 36 \cdot 1\end{array}$ \\
\hline Ash & .. & . $3 \cdot 53$ & Proteids .. & .. $18 \cdot 2$ \\
\hline Fibre & .. & $3 \cdot 4$ & Carbohydrates & $29 \cdot 67$ \\
\hline
\end{tabular}

The ash was found to contain $30 \cdot 3$ per cent. of phosphoric acid present in the form of phosphates, which is equivalent to 1.07 per cent. of phosphroric acid in the meal.

The meal thus prepared is unsuited for cattle food on account of the large quantities of free fatty acids and cannot be used for oil extraction. "It is probable, however, that if the oil were expressed from the decorticated seeds, the residual cake could be utilised as a feeding material, as is shown by the following comparison hetween the calculated composition of such a cake and the $\mathrm{com}$ positions of some commerical feeding cakes."

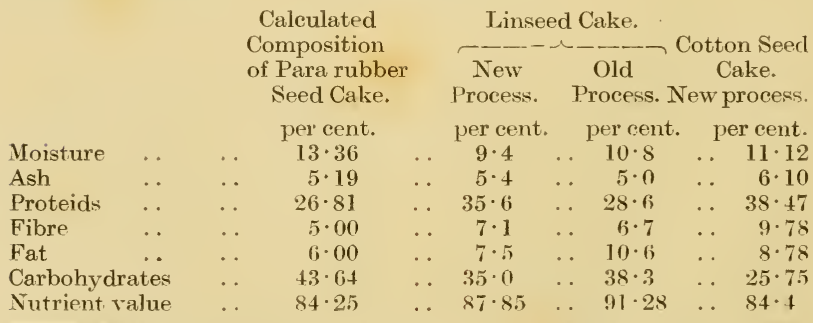

* I Report of the Director, Imperial Institute, London. 
"These figures show that a cake prepared from Para rubber seed meal may form a good cattle food, and that it contains very little indigestible matter."

There is, therefore, in Para rubber seeds an economic product which may soon become important commercially, and, providing the oil is expressed from the kernels before the meal or cake is made, the residue may be used in the Tropics either as cattle food or manure.

\section{Packing Seeds for Transport.}

The difficulty of transmitting seeds of Hevea brasiliensis to distant countries is well-known; the seeds do not retain their germinating capacity for a very long time except great care is taken in collecting and packing operations.

Twenty seeds were sent from Singapore on Feburary l2 to Mexico, where they arrived on May 2 in the same year: from these fourteen plants were raised.

Seeds of Para rubber, after being dried in the sun for a short time, packed in dry earth, and sent from Penang and Ceylon to India, have arrived in the latter place with only 17 and 31 per cent. of loss due to the seeds going bad. They have also been successfully sent in powdered charcoal in liermetically sealed boxes or tins over very long distances. From 30,000 seeds packed with charcoal and sawdust in ordinary cases, sent from Ceylon to the Gold Coast, 3,650 plants have been raised.

Wardian cases have also been used with conspicuous success. Each ease is nade to hold from 1,500 to 3,000 seeds, the earth and packing material forming alternate layers with the seeds. From 201000 seeds packed with moist soil in Wardian cases. sent from Cerlon to the Gold Coast. some 3.400 plants were raised.

\section{EXPERMENTS AT TRINIDAJ AND SINGAPORE.}

Mr. Hart, Superintendent, Botanic ( me that he always keeps Para rubber seeds damp and never dries them, and objects to the use of charcoal in packing, as he helieves the latter abstracts the moisture from the seeds. Mr. Hart informs me that coconut dust is best when "tobacco damp," and seeds packed with this material, in small tins of $?_{2}^{\mathrm{lb}} \mathrm{lb}$. or so, keep sound. germinate freely, and do well when disentangled.

The Director, Botanic Gardens, Singapore, has recently sent quantities of Para seed to Jamaica, Kew, Mexico, \&c., with satisfactory results. The seeds were sent to Jamaica in biscuit tins. packed in slightly damped incinerator earth, with the upper part filled with sawdust to reduce the weight; the other seeds were sent in biseuit tins filled with danu finely-jowdered charcoal.

"In packing, a certain amount of care is required in damping the charcoal so as to get it equally moistenerl all through and not either over wet or over dry. This is best done by damping the charcoal 
thoroughly and then drying it in the sun, consistently stirring and turning it over till it is uniformly slightly damped. The incinerator earth, which had been exposed to the elements, was damp when received, and only wanted partial drying to fit it for packing. Its weight is against its use, but both it and the powdered charcoal have the great advantage of preventing any attacks of mould or bacteria likely to cause decomposition. Other experiments with powdered coir fibre and coirdust, sawdust, and variously prepared soils have been tried, but the results do not seem to have ever been as successful."*

I am obliged to Mr. H. F. Macmillan, Curator of the Royal Botanic Gardens, Peradeniya, for the following notes on the methods of drying and packing seeds of Para rubber :-

"Unless the seeds are sown or despatched almost as soon as collected they should be spread on a dry cool floor, and turned over frequently to prevent heating. It is often unavoidably necessary to keep the seeds on hand for several days, and an important question is the condition under which they may be stored to preserve their vitality best. When a large amount has to be dealt with a quantity of broken-up charcoal should be in readiness for mixing with these, or, if this be not available, dry sand may with advantage be used instead. On no account should the seeds be covered or surrounded with any damp material; nor should they, on the other hand, be unduly exposed to sun heat. Small quantities of Hevea seeds may he packed with coconut dust in biscuit or tobacco tins and sent long journeys by post. On short journeys not exceeding six or seven days they may be sent by post, without any packing, in small gunny bags holding 500 and weighing about 6 pounds. Obviously, however, this would not be practicable for a large quantity, even if the postage were not prohibitive. For journeys of abont a fortnight to three weeks ordinary strong cases, about $30^{\prime \prime} \times 16^{\prime \prime} \times 12^{\prime \prime}$, and holding when packed 6,000 to 7,000 seeds may be used. A thin layer of dry charcoal mixture is placed in the bottom of the case, then a covering of paper (to prevent the compost filtering to one side in transit), next a layer of seed followed by mixture, and so on. One part charcoal to two of coconut dust or sawdust is very satisfactory. This has also the merit of being light in weight, which is a consideration in transport charges. It must be remembered, however, that the success of this method depends upon the freshness of the seed as well as on the length of journey. The method of packing the seed in sealed kerosine oil tins has been tried, but with indifferent results. Treating the seed with a 4 per cent. solution of copper sulphate or formalin may have the effect of preventing the growth of mould on the seeds and thus prolonging their ritality, but its application is unnecessary, except perhaps in extreme cases. $B_{y}$ far the most satisfactory means of transporting Hevea seeds is by way of Wardian cases."

* Straits Agrieuitural Bulletin. 1906. 


\section{Warniay Cases.}

The principle of the foregoing methods, it will be seen, is to retard the effort of the seed to germinate and remove conditions which induce germination; that of the Wardian case is to encourage germination; for the seeds being sown, not "packed," are at once encouraged to germinate and grow into plants. The initial cost in this instance is greater, but the saving in the long run is evident. If good seeds are sown they will germinate in about ten or twelve days, and the pereentage of failures would be nil; the secdlings may then be tended in the cases as if they were in a nursery bed, and an opportunity of shipping may be awaited without risk or anxiety. Thus on arrival at destination instead of receiving seed with a doubtful percentage of germinating power you should have good-sized plants or "stumps." The principle of the Wardian case consists of filling the body of the latter to a depth of five inches with a light porous compost (say two parts leaf-mould to one of decayed coconut dust, with a sprinkling of charcoal); upon this is placed a layer of about 1,500 seeds (or if necessary two layers of 1,000 each with compost between), finishing with a covering of about an inch of compost. The whole is then thoroughly watered. after which small bamboo twigs are placed thinly and longitudinally on top; across these are placed narrow battens three inches apart, these being kept in plare by a longitudinal strip nailed along both insides of the case. The latter is then raised on four bricks to allow the escape of water as well as to prevent attack by white ants. The eontents must be kept moist by watering them each day if the weather be dry. It is best to allow the seeds to germinate before despatching. 'The two glazed top sides are left off to the last. These when screwed on admit the necessary light, whilst fresh air is provided by a ventilator in each end covered with fine gauze with a box nailed on to the inside for preventing sea spray reaching the plants. The advantage of thus having plants instead of szeds at destination, which may mean a year gained in planting, only costs about Rs. 5 per thousand more than the price actually paid for seeds that have been packed and despatched in the dry mothod-that is allowing 'for 50 per cent. of these to germinate and the cost of the Wardian case to be Rs. 15. 


\section{CHAPTER XIX.}

\section{ESTIMATES OF RUBBER PLANTERS IN CEYLON : COSTS OF PLANTING RUBBER.}

Estimate I. by E. Gordon Reeves,Rs. $322 \cdot 40$ per acre at end of 5 th year for Matale-Estimate II. by F. J. Holloway, Rs. 283.50 per acre at end of 6th year-Estimate III., Peradeniya District for first two years-Estimate IV., Kalutara District for first six yearsEstimate V., Ambalangoda District for first two years-Estimate VI., Ambalangoda Distriet for first two vears in swampy land -Estimate VII., Ambalangoda District for first two years.

1

$\checkmark \mathrm{HE}$ cost of clearing, draining, and planting up large acreages of Para rubber necessarily varies according to the condition of the forests to be cleared, the nature of the land, and the rates of wages paid, \&c. The following estimates have been kindly supplied to me by friends in Ceylon (Rupee $=1 s$. 4t.) :-

\section{ESTIMATE J.}

Estimate of Cost of Purchasing 100 acres of Land and Planting with Para Rubber.

Cost of 100 acres of Land-

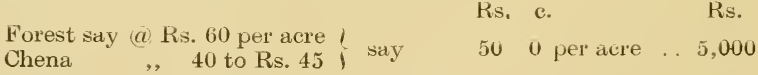

Clearing- -

100 acres Forest $(a)$ Rs. 20 per acre
100 acres Chena $@$ Rs 15 to Rs.17

1750 per acre .. 1,750

Nurseries AND Seeds-40,000 seeds at

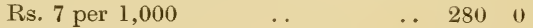

30,000 Baskets, Rs. 4 per $1,000 \quad$.. $120 \quad 0$

Making nurseries, including sheds for basket plants, sowing seed $\quad$. $\quad 600$

Upkeep, watering for 3 months regularly $30 \quad 0$

Further occasional attendance for six months

$$
\text { . } 20 \quad 0
$$

Roads AND Drains-at Rs. 6 per acre

LINING-say $15^{\prime}$ by $15^{\prime}$-about 200 trees per acre, including cost of pegs, @ 75 cents per acre

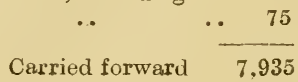


Brought forward . .

Holixg-Holes $18^{\prime \prime}$ by $12^{\prime \prime}$ : task 40 per man, say Rs. $1 \cdot 80$

Planting-20,000 Basket plants including transport from nurseries: dipping in liquid manure, \&c., 80 cents per acre

$$
\text { .. }
$$

$$
\text { -. }
$$$$
\text { .. }
$$

SupPlying-Putting out 6,000 basket plants @ 50 cents per 100

SHADING-30,000 cadjans (a) Rs. 10 per 1,000 Rs. 300

Making up : fixing and general attendance, say Re. 1.50 per acro $\quad$. $\quad \ldots \quad$, 150

Lines-1 set of temporary lines, 20 rooms: jungle $\overrightarrow{\text { post }}$ thatched roof; mud and wattle walls; @ Rs. 20 per room

$$
\text { … }
$$

.. $\quad$. .

WEEDING--Forest land : first 3 monthis say 10 mont lis' weeding at Re.1.25; thereafter (a) 80$\}$ of lst year at Re. $1 \cdot 50$ cents

Chena Land:

First 3 months

Second 3 montlis

Thereafter

Thereafter
Fexcixg.-Cost of wire and staples? about Rs. 150 per mile, 3 wires at 1 foot apart Posts: cutting holes, \&c., and fixing, Rs. 30 per mile

Rs. 187 per mile allowedper 3 miles

561

Carpenters at Rs. 7 per mile;

Toous, say Rs. 100 ,

Contingencies, Rs. 100$\}$

Superintexdexce at Rs. 100 per month

Coast Advances ; 80 coolies say Rs. 30

Brought forward, first year's expenditure

Add interest at $7 \%$ say

.

2nd Year .. Superintendence say

$\cdots$

Rs.

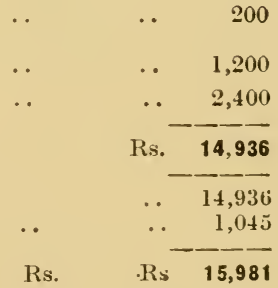

Weeding 100 acres at Re. 1 . 1,200

Nurseries, supplying cadjans, \&c., $\quad . .30$

Roads and drains upkeep $\quad$. $\quad 50$

Thatching liues Re. 1.50 per room

Cpkeep of fence

Contingencies

$$
\text { . } 50
$$$$
\text { .. }+30
$$$$
\text { . } 50
$$$$
\text { .. } 100
$$

Add interest on Rs. 18,511 at $7 \%$ 


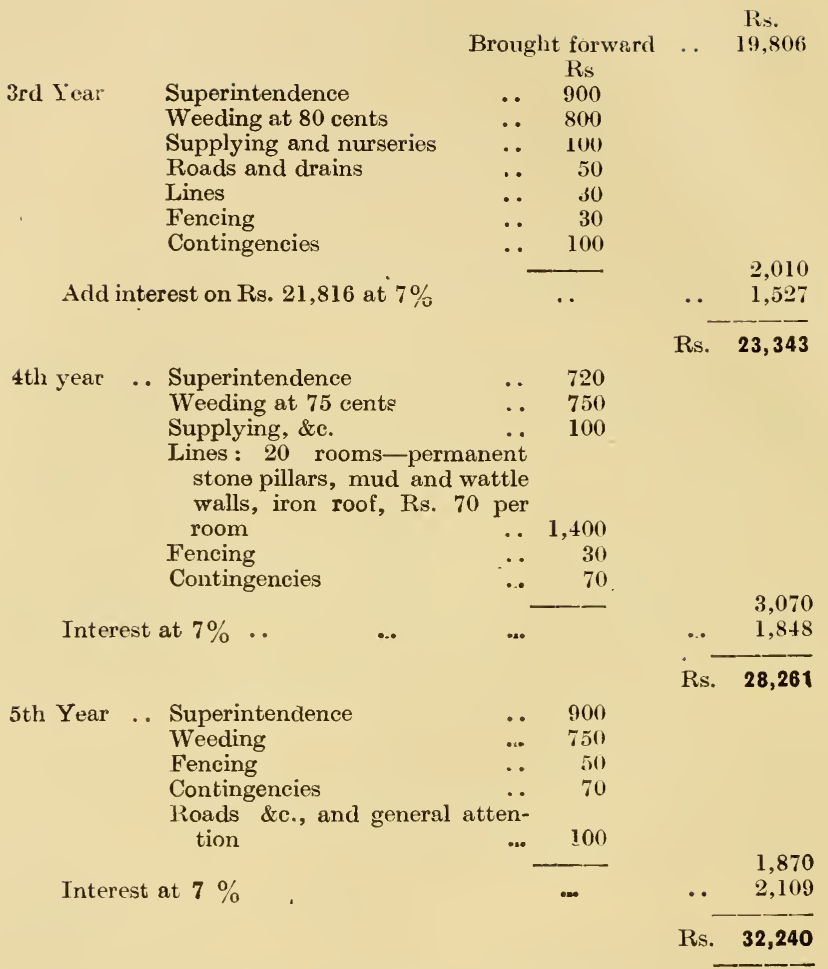

Rs. $322 \cdot 40$ per acre at end of fifth year.

Mexos.-I close the estimate at termination of the fifth year as it is now generally admitted that tapping may commence according to growth between the end of fourth and sixth years.

The estimate is framed on the lines of Rubber planting as ordinarily carried on in the district of Matale, and might serve as a guide to the planting of Rubber in such districts as Badulla Valley, Kurunegala, Dumbara, \&c., districts usually not heavily influenced by the rains of the south-west monsoon.

Felling.- The cost of felling and clearing both of forest and chena land is so very variable, that it is impossible to give an estimate which would apply to the Rubber districts generally.

Clearivg.-In some districts I have had chena lands cleared for Rs. 9 per acre; and, again, the felling of forest will not be taken up by contractors in some localities for less than Rs. 25 per acre. 
RoAds AnD DRaiss. - The eost would be from Rs $j$ to Rs. $S$ per acre according to lay of land, soil, \&e

Fencing. - Feneing ean only be estimated for by the mile. Many estates or clearings, eovering perhaps only 100 to 150 acres, would require 3 to 4 miles of feneing owing to established rights of way. My estimate is for a treble wire fence.

It is not at all certain that it would not pay in eases where clearings have a jungle frontage to put up 2 wires only say at 1 foot 6 inches and 3 feet, backed by galvanized wire 3 feet by 3 inches mesh.

The eost of the barbed wire fence would be reduced to Rs. 50 per mile. The galvanized wire would eost about Rs. 285 per mile. The total cost of sueh feneing would therefore work out at about Rs. 422 per inile.

It would effectually put a stop to the depredations of muntjak deer, mouse deer, poreupines, and hares, and those who have clearings along a jungle edge know what damage such animals ean do.

Plantixg.-The use of basket plants and sliading with cadjans adds about Rs. 5 to Rs. 6 per acre to the cost of planting ; but results prove that this extra expense is well repaid

WEEDING. - This is an item which may very easily exceed the estimate I have given as regards chena lands. The first year's weeding should not, however, in any case eost over Rs. 3 per acre per month-say Rs. 36 per acre for the year for the weediest chena lands. It may cost this unless labour is very plentiful. From fourth year the weeding should be redueed in either forest or chena land clearings to an average of 75 cents per acre.

SUPERINTENDENCE.- - Has been estimated for on the supposition that the clearing is being looked after by the manager of an adjoining property. In the case of an estate of considerable acreage being concerned this item would be chargeable at Rs. 10 per acre per annum althrough.

Buildivas.-I make no estimate for Factory, Superintendent's Bungalow, \&c., though both would be required. Superintendent's bungalow could be built for about Rs. 2,000 .

It is useless at the present stage of the industry to make an estimate for a Factory, as the invention of suitable machinery, which is suro to follow during the next year or two, will revolutionise the curing of Rubber. It would probably be safe, however, to allow at the rate of Rs. 50 per acre as the cost of the building only.

Cosst Advances. - I have charged as an ordinary item of expenditure. It is only fair to do so, as it is an item which, though slightly varying in amount, is never absent, and is just as really a charge on the estate as superintendenee or any other item and should be recognised as such. The amount Rs. 2,400 would probably be exceeded from and after the sixth year on tapping operations commencing.

\section{E. GORDON REEVES.}

Wiltshire,

Matale, October 10, 1905. 


\section{ESTIMATE II. \\ Para Rubber in Central Province. \\ Estimate for Opening Land and Notes on Same.}

In making an estimate for opening land there are many things to be taken into consideration, such as (1) the nature of the jungle to be felled-whether high or low; (2) nature of soil-whether good soil with rocks or hard grav lly soil ; (3) lay of land-if the land is fairly flat with few rocks or stones the work will be much cheaper than on a rocky and hilly estate ; (4) local conditions of labour-in some districts the cooly is paid 33 cents per day, in others 50 cents.

Therefore, I should not think of framing an estimate until I saw and examined the land. The whole work with the exception of felling and

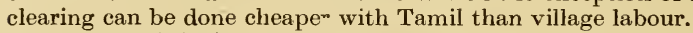

The cost of felling and clearing varies from Rs. 12.50 to Rs. 20 ; roads and drains according to lay of land Rs. $7 \cdot 50$ to Rs. 12, and even Rs. 20 per acre in rocky and hilly land, as blasting and building is an expensive item.

Barbed wire and fencing is an important item, and I have added this to the estimate.

I have slightly revised my estimate as published in the India Rubber Journal of May and June, 1904, and have now brought it up-to-date, having benefited by the experience in opening 869 acres during the past twelve montlis.

The following estimate is made for an estate in the Central Province worked entirely by village labour. Lay of land, mostly on hillsides, with a fair number of rocks - average cost of labour a bout 40 cents per day. I strongly advocate seed at stake in all new clearings.

Estimate of PURChasing Avd OPENing 300 aCRes of LAND.

1.-Purchase of land, say 300 acres, at Rs. 50 per acre ..Rs.15,000

2.-Felling, burning, clearing, rooting 300 acres, at Rs. 15 $\begin{array}{llllll}\text { per acre } & \ldots & \ldots & \ldots & \ldots & 4,500\end{array}$

3.- Roads and drains, blasting and building, at Rs 12 per acre $\quad 3,600$

4.-Lining and pegs, 15 by 15 , at Re. $1 \cdot 50$ per acre .. 450

5 .- Holing $2 \mathrm{ft}$. by $15 \mathrm{in}$. and filling, at Rs. 6.50 per acre $\quad \ldots \quad 1,950$

6.-Cost of seed at Rs. 6 per 1,000, 3 in a hole, at 5 cents per acre, and planting .. . .

7.-Nursery basket plants for supplies, 6,000 and upkeep .

8.-Planting, 1.50 per acre $\ldots$..

9-Weeding, April to December. at Rs. 20 per acre $\cdots \quad 6,000$

10.-Bungalow Rs. 2,500, lines (20 rooms) Rs. $600 \quad$.. $\quad 3,100$

11.- Superintendent Rs. 3,000, Conductor Rs. $600 \quad \ldots \quad 3,600$

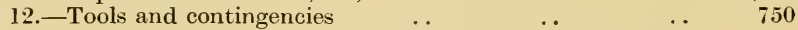

13.-Barbed wire fence, 4 strands put $8 \mathrm{ft}$. apart, and erection of same, at 15 cents per yard, or, in round figures, say at Rs. 5 per acre .. .. .. .

([f 2 -in. wire netting buried and put in ground-and 3 strands of barbed wire and erection, at Rs. 9 per acre.)

2 , to 6 th year supervision, Rs. 3,600

Weeding second year st Rs. 20 per year, Rs. 6,000

,, third year at Rs. 15 per year, Rs. 4,500

,, fourth to sixth year at Ris. 10 per year, Rs. 9,000

$\mathrm{U}^{\dagger}$ pleep of roads and drains at Ric. 1 per acre, 5 years at 1 is. 5 .. 
Brouglit forwerd .. 81,551

Upkeep of lines and bungalow, \&e., 5 years $\ldots \quad \ldots \quad 1,250$

Supplying and attending young plants, 5 years at Rs. $200 \quad \ldots \quad 1,000$

Sundries and contingencies, 5 years at Rs. $250 \quad \ldots \quad \ldots \quad \ldots \quad 1,250$

Total cost of 300 aeres, at $1 s .4 d .=£ 5,670$ or $£ 1818 s$. per acre. Rs. 85,050

October 14, 1905 .

FRANCIS J. HOLLOWAY.

\section{ESTIMATE III.}

First and Secoxd Years-Peradeniya District.

First Year. Sccond Year.

\begin{tabular}{|c|c|c|}
\hline Superinten & denee & . \\
\hline Felling & & \\
\hline lining, 18 & feet by 18 & cet \\
\hline Pegging & & . \\
\hline Roads and & drains & \\
\hline Fencing w & th barbed & ire \\
\hline Holing & & . \\
\hline Filling and & planting & . \\
\hline Plants & .. & • \\
\hline Weeding & . & . \\
\hline Buildings & $\ldots$ & • \\
\hline Tools & & \\
\hline Contingenc & ies & \\
\hline Supplying & and fene & \\
\hline
\end{tabular}

Ris. 10 o Rs. 100

.. 12 12 0 . $\quad$ -

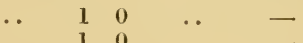

$\begin{array}{lrrrr}\cdots & 1 & 0 & \ldots & -\end{array}$

$\begin{array}{llllll}\ldots & 15 & 0 & \ldots & 150 \\ \ldots & 14 & 0 & \ldots & -\end{array}$

$\begin{array}{rrrrr}\ldots & 14 & 0 & \ldots & - \\ \ldots & 6 & 0 & \ldots & -\end{array}$

$\begin{array}{lllll} & 3 & 0 & \ldots & -\end{array}$

. $\quad 150 \quad \ldots \quad 050$

$\begin{array}{lllllll}\ldots & 10 & 0 & \ldots & 9 & 0\end{array}$

$\begin{array}{llllll}\cdots & 8 & 0 & \ldots & 0 & 25\end{array}$

$\cdots \quad 050$

…2 20

.

20

$$
840 \quad \overline{2325}
$$

ESTIMATE IV.

First to Sixth Year-Kalutara District.

The following estimate of the cost of opening up Para rubber land is about the average for light low-country jungle land in the Kalutara District. On many estates the eost for the first six years works out at from Rs. 180 to Rs. 200 per acre.

1st year, 2nd year, 3 rd year, 4 th year, 5 th year, 6 th year.

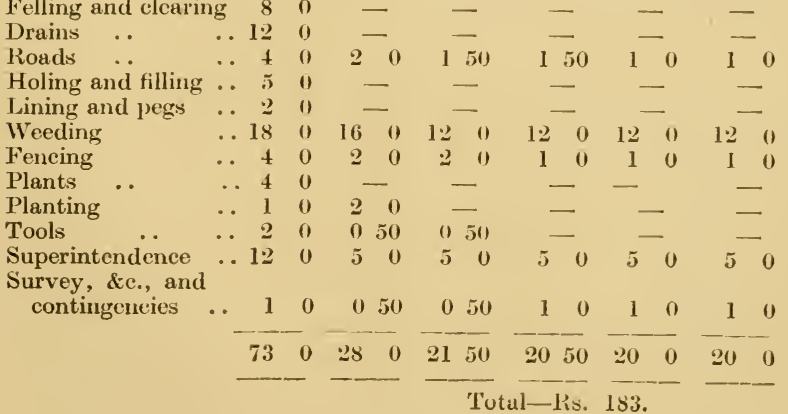


First and Slecond Years-Ambalangoda District.-Cost per Acre. First Year. Second Year.

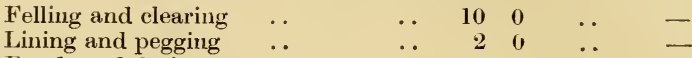

$\begin{array}{lllllllll}\text { Roads and drains } & \ldots & & \ldots & 15 & 0 & \ldots & 1 & 50\end{array}$

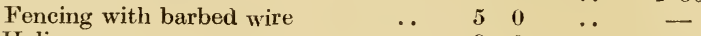

Holing

Filling and planting :..

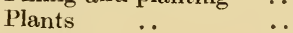

Weeding..$\quad$..

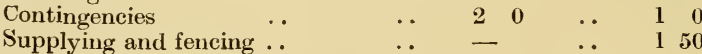

ESTIMATE VI.

First and Second Year-Ambalangoda District.

Principal Items in opening Swampy Land.

First Year. Second Year. Rs. c. Rs. c.

\begin{tabular}{|c|c|c|c|c|c|c|}
\hline ing and clearing & $\cdots$ & .. & 4 & 0 & .. & - \\
\hline Lining and pegging & . & . & 2 & 0 & .. & \\
\hline Roads and drains & .. & .. & 30 & 0 & .. & \\
\hline Heaping soil & .. & . & 8 & 50 & .. & - \\
\hline Fencing with wire & .. & .. & 5 & 0 & .. & \\
\hline Filling and planting & $\ldots$ & .. & 7 & 0 & .. & - \\
\hline Needing & .. & .. & 24 & 0 & .. & \\
\hline ncies & .. & .. & 2 & 0 & .. & 10 \\
\hline upplying, \&c. & .. & .. & & & .. & 150 \\
\hline
\end{tabular}

ESTIMATE VI1.

Estinate of Opening One Acre under Rubber in Low-country, Ambalangoda.

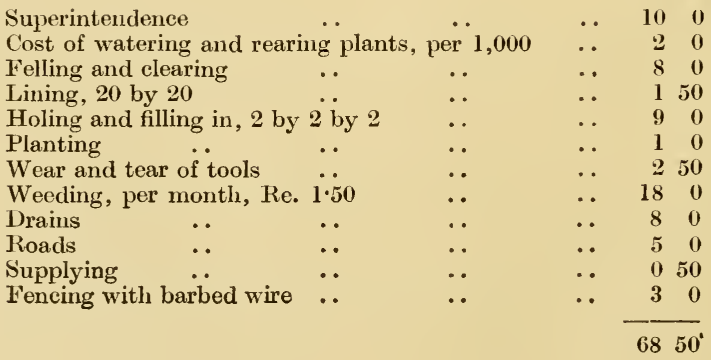


No bungalow or lines estimated for in either first or second year. Cost of plants or watchman not taken into consideration, the cost of former being too fluctuating.

\begin{tabular}{|c|c|c|c|c|}
\hline SECOND Yé.h. & & & & s. \\
\hline Superintendence & . & $\cdots$ & 5 & 0 \\
\hline Weeding, per acre per month, Re. 1 & . & .. & 12 & 0 \\
\hline Supplying $\quad \ldots \quad$.. & .. & .. & 1 & 0 \\
\hline General upkeep-drains, roads, and & ontingencies & .. & 5 & 0 \\
\hline & & & 23 & 0 \\
\hline
\end{tabular}

In the foregoing estimates I have given the figures as presented to me by my friends. Items such as superintendence and Interest are not always shown, and the variation in cost of folling, clearing, and weeding is very great.

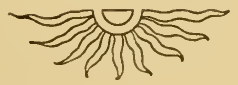





\section{NDEX}

\begin{tabular}{|c|c|c|c|}
\hline \multirow[b]{2}{*}{ 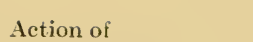 } & & PAGE \\
\hline & $\cdots$ & . & 100,110 \\
\hline - - Idvantages of & . & . & 110 \\
\hline ___ Amount required & . & ... & 111 \\
\hline ___ Method of determinin & ge amount & required & 112 \\
\hline ___ _ Disadvantages of & . & .. & $112-11$ \\
\hline - Excess of $\ldots$ & .. & . & 11 \\
\hline Acids, Action on rubber of & $\cdots$ & $\cdots$ & 12 \\
\hline - Advantages and disadvantage & ges of & $\cdots$ & $112-11$ \\
\hline - Effect on coagulation of & $\cdots$ & ... & $109-11$ \\
\hline Acreage in rubber ... & $\cdots$ & . & $3,4,5,1$ \\
\hline Age of trees, Effect on rubber of & $\cdots$ & $\cdots$ & $75-78,12$ \\
\hline _- Impo & ariation of & $\cdots$ & $\cdot 75,7$ \\
\hline __ of trees ar & . & $\cdots$ & 76 \\
\hline Albizzia moluccana & . & $\because$ & $24,28,48$ \\
\hline _- Composition & of & $\cdots$ & \\
\hline - Lopping of & -. & $\cdots$ & \\
\hline noids (see Proteids) & .. & -. & \\
\hline Alkalies, Effect on rubber of & .. & . & 12 \\
\hline Ammonia, & . & $\ldots$ & \\
\hline Use of & .. & ... & $65,66,107$ \\
\hline Antisepties, Use of.. & .. & ж. & $109-111$ \\
\hline __ Disadvantages of & . & . & $112-11$ \\
\hline - and smokir & . & - & $109-11$ \\
\hline Arachis hypogeae & .. & ... & $30,31,46$ \\
\hline - Chemical com & osition of & $\cdots$ & \\
\hline sh in latex & fron & $\cdots$ & \\
\hline sh in latex & .. & . & 105,106 \\
\hline - in rubber $\ldots$ & . & $\cdots$ & 127,131 \\
\hline - Constituents of & $\cdots$ & $\cdots$ & 127 \\
\hline abber & -. & . & 153,154 \\
\hline Bark, Incision of .. & . & . & $52,10: 3$ \\
\hline - Excision of $\ldots$ & . & $\cdots$ & $49,52,69,103$ \\
\hline - re & .. & . & $69,102,10$ : \\
\hline - thickness $\ldots$ & . & . & \\
\hline ugal m & $\cdots$ & . & 116,11 \\
\hline uover, A & . & $\ldots$ & 123,14 \\
\hline $\begin{array}{l}\text { Prepa } \\
\text { ffect on } r\end{array}$ & $\ddot{*}$ & $\begin{array}{l}\cdots \\
\cdots\end{array}$ & 109,14 \\
\hline & & & \\
\hline
\end{tabular}


Cables, Rubber in .

Calcium chloride, Use and action of

Caoutchouc, Coalescence of ..

C- Separation of $\quad-.$.

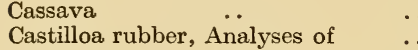

Castilloa rubber, Analyses of Resins in

Catch crops, Distance apart for ..

Ceara rubber, Chemistry of $\quad$ -

Centrifugal machines

Chemical analyses, Value of $\quad$..

Chemicals, Advantages and disadvantages of

Chemistry of rubber

seeds

Chlorine, Effect on rubber of

..

..

..

.

Circumference, Pollarding and effect on

__ Rate of increase of tapping area ..

Climate in Africa . .

— in Ceylon ..

— in India $\quad$.

—_ in Java

_ in Para ...

- in Penang ...

— in Perak ..

in Selangor ...

in Seremban ...

in Singapore ..

in Straits

Coagulating machinery

Coagulation and acids

Centrifugal force for

Chemicals for

Denisty of mother liquor in

Effect of heat on

in Amazon

Mechanical means for

Removal of impurities in

Simple

Smoking for ..

Coalescence of caoutchouc

Cacao, Intercrop of

Coffee, Intercrop of

Cold cure in vulcanization

Collecting tins ..

Colour of rubber ..

Corrosive sublimate

Cortical stripping, Effect of

Creosote, Action of
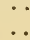

.

.

.

.

.

..

.

.

.

.

.

.

..

$\cdots$

.

.

.

..

.

..

.

.

..

..

..

..
121, 122

105,107

105,107

30,31

76,125

76,124

$30,31,32$

$30,31,32$

125,130

116-118

$105,139,140$

112,114

$76,123-127,129,144,154$

156,157

114,154

44

127

. $28,29,30,78,79$

$28,29,30$

28,29

.

10,11

14,15

13,14

13

13,14

13

12

12

12

13

11

116-118

109-113

116,117

110-112

115-118

109

109,110

116-118

115,116

108

$109,110,138,139$

$105,106,116$

$30,31,32$

1 б, $30,31,32$

135

68

123

111

$69,102,108$

110 
Crêpe rubber, dualysis of

PAGE

129,144

Preparation of $\quad$..

Value of

.. 131-133, 142, 143

.. 143

Crotalaria, Chemical composition of

- Equivalent of . . ..

Kinds of ..

- Organic matter from $\quad \ldots$

.

Cultivation in Africa ..

Cultivation acreage in Ceylon $\quad \ldots$

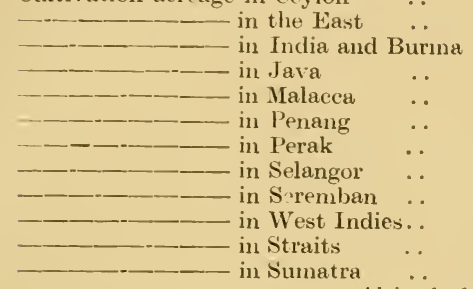

in swampy land

Altitude for

..

46

.

.

.

.

3,4

$\cdots$

..

.

.

.

.

Cuttings, Propagation by

.

5,36

1,2

Dadaps (see Erythrina).

J)ickson's drying and coagulating machine

Diseases of Para rubber

- and large acreages

.

- and defoliation and inoculation

— Number of ..

..

$\cdots$

$\cdots$

and preventive measures

$\because$

- on fruits ..

- on leaves ..

on roots ..

- on seedlings ..

- on stems

.

- - and forest belts

Distance for planting

Draining

Drip-tins

.

Drying of rubber . .

—— Apparatus fö

Oxidation during

sheds for

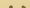

and vacuum chamber:

$\because$

$\therefore$

..

.

..

.

..

$\because$

.

$\because$.

..

..

120,121

145-154

145,146

146

148

146

147-153

148,149

$146-148$

151-153

147,148

149-151

146

$25,26,27$

2.5

65,66

119-1222

119-122

119

121

120

Erythrina lithosperma

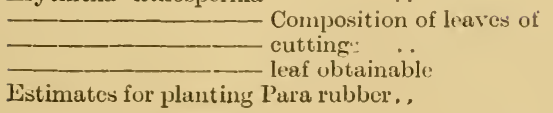

. . $27,28,32,47$

.. 
Fatty substitutes in rubber articles.. Federated Engineering Co., Washing machinery of .. Ficus elastica rubber, Chemistry of $\cdots$ Flake rubber

\section{.} Flowers of Hevea brasiliensis Flowering of Para rubber in Amazon

\begin{tabular}{|c|c|}
\hline _- Ceylon & $\ddot{x}$ \\
\hline Forest, Effect on soil of & .. \\
\hline Formalin, Use of . . & .. \\
\hline Formic acid, Action of & $\ldots$ \\
\hline Fruit diseases, Nature of & . \\
\hline $\begin{array}{l}\text { Garden hose, Composition of } \\
\text { Green manuring }\end{array}$ & . \\
\hline \multicolumn{2}{|c|}{ _______ method of sowing ... } \\
\hline - - , using & . \\
\hline - - Nitrogen in & . \\
\hline __ _ plants to use & . \\
\hline Groind nuts & $\therefore$ \\
\hline Growth in circumference & . \\
\hline - in height $\ldots$ & . \\
\hline \multicolumn{2}{|l|}{ - interplanted with tea and cacao } \\
\hline - in Federsted Malay Strtes & . \\
\hline - in Gold Coast & . \\
\hline — in India & .. \\
\hline — in Straits & . \\
\hline — of roots . . & . \\
\hline - Rate of, in Ceylon & . \\
\hline
\end{tabular}

Heat cure in vulcanization

Henaratgoda, Soil of - Experiments at Hydrofluoric acid ..

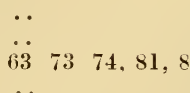

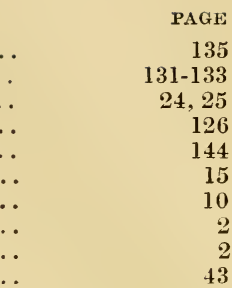

.. $65,66,107,126$

110

148,149

135

43-48

$\cdots$

.

.

..

.

..

.

$\because$

$\because$

$\because$

$\because$

.

.

.

.. $17,18,19,26$

.. $\quad 126$

134,135

$33,34,43$
$2.83,90,94-99,105$

110

Impurities in rubber

- Removal of ..

Insoluble constituent in rubber

Intererops .

- Distance fcr ..

Introduction of Para rubber to Australia

..
$\ldots$
$\ldots$
$\cdots$
$\cdots$
ustralia
0,

Coast
..
ca

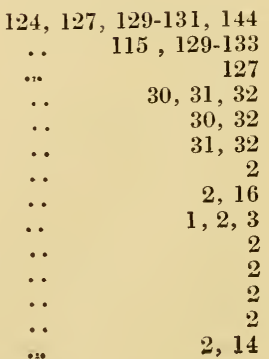


Introduction of Para rubber to Queensland

PACE
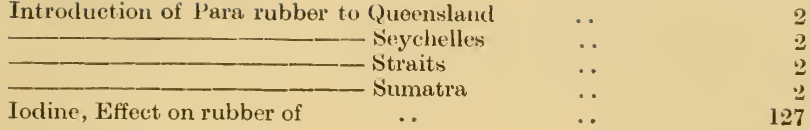

Jace rubber, Analysis of Preparation of

Landolphia rubber, Chemistry of Latex, Alkalinity of Analyses of .. Ash of .. Caoutchoue in Centralization of Collection of .. Composition of Consistency of Effect of light on

.

.

$\because$ - manures on

Function of ..

$\cdots$ 69, $104-107$ Liquefaction of

.

.

Physical properties of

.

Proteids in . .

Resins in ..

Salts in ..

.

$\cdots$

Sap constituents in

Storing of ...

. Sugar in .. variation in, Reason of

Water in .

- water store, Function of

.

.

..

$\cdots$

$\cdots$

$\because$

Laticiferous tubes, Contents of . .

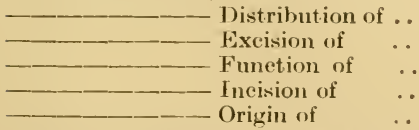

Laticiferous system, Oecurrence of . .

Leaf diseases-Fungi

— insects $\quad .$.

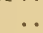

Leaf fall, Time of . .

Leaves, Chemical composition of . .

- of Para rubber

Lemon grass

\section{..}

Loss on washing rubber

.

.

69, 104-107

..

$8,105,106$

$8,72,76,105,106$

$\begin{array}{rr}\ldots & 105,106 \\ \cdots & 8,104\end{array}$

.

64,66

.

8,105

.

8,105

.

$6,7,105$

$\cdots$ 6,7

.

.

$\cdots$ 8

..

$\cdots$

.

.

..

$5,6 \quad 69$

49, 52

$\cdots$

$5,6,4 !$

146,147

147,148

..

$2 \cdot 2,23,43$

. $43,45,46,47,48$

.. $5,43,44$

. 30,31

.. 129-131

Manures, Artificial

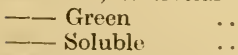

. 
Marking trees for tapping

Mathieu's coagulator

Mercuric ehloride, Action of

Michie-Golledge machine

Moisture in rubber. .

$\begin{array}{ll} & \\ \cdots & \\ \cdots & \\ \cdots & \\ \cdots & \\ \ldots & \end{array}$

PAGE

Nitric acid, Effect on rubber of

Odour of rubber

Oxygen in rubber ..

Para, Climate of ..

$$
\text { Forests of }
$$

..

Pests of the rubber plant

Physical properties of rubber tests for rubber

Picric acid. Action of

$\cdots$

9,10

9,10

.

45-154

.

141

.

139-141

.

110

Plantation rubber, Analyses of

$\cdots$

C__ Chemical tests for Deterioration of Inferiority of .. Kinds of Liquefaction of .. Loss in washing of Moisture in Packing of . Physical tests for Preparation of .. Properties of .. Smoking of ... Source of $\quad$.

Planting operations Tensiles of ...

—— Effect of $\quad$... $\quad$.

Propagation by euttings $\quad$.

- by seeds .. ..

Protector ..

Proteids in latex ..

-_ in mother liquor

-

.

.

.

.

.

.

- Separation of

Proteids, tackiness

Purification of Rubber by munufacturers in the tropics Loss in

Putrefaction, Prevention of

$\cdots$
$\cdots$
$\cdots$

$123-126,144,154$

139,140

. . $128,153,154$

. $137-140$

.. 123-126, 141-144

.. $114,153,154$

.. 130,131

. $123-126$

.. 141

. 139,140

.. 108-118, 141-144

. $123-128$

. 109, 110, 138, 139

.. 123-126, 138-144

.. 141

. $\quad 24,25$

.. 28, 29, 30, 78, 79

.. $\quad 29,30,78,79$

. 2,23

$2,23,24$

.. $\quad 64$

.. $\quad 8,105,106$

.. 105

$105,106,123-126,144$

.. 106,107

.. $106,114,115$

.. $129-130$

.. 131-133

.. 130,131

.. 153

$\ldots 106,114,115,154$

and albuminoids

$\cdots$

153

Resins and vulcanization Castilloa rubber Extraction of..

$\begin{array}{lll}\ldots & \ldots & 126 \\ \cdots & \ldots & 124 \\ & & 126\end{array}$ 
PAGE

Resins, in Para rubber

- in plantation rubb)

-_ in tacky rubber

- in wild rubber Spiller's

Rhynocodia rubber

Roller covering, Composition of

Rolling rubber

Root diseases, Nature of

- Preventive measures for

Root system Nature of

- Rate of increase of

Rubber, Colour of. .

- Composition of

Disease on ..

from 6 to 50 feet

- from 2 to 30 -year-old trees

- from different levels

- heat, Effect of, on

- Impurities of . .

Insoluble constituent of

Odour of

Oxygen in

..

Physical properties of

- Purification by cultivators of

- Manufacturers of

Quality of ..

and age

.

$\begin{array}{ll}\text { Softening of } & \text {. } \\ \text { Tacky } & \text {.. }\end{array}$

Unes of

$\cdots$

Value of

Washing of ...

Washing machinery for

.

...

8, $76,105,106,130$

. $72,76,77,105,106,123-126,130$

. $\quad \therefore \quad 106$

.. $\quad \ldots \quad 125,126,130$

$\begin{array}{lll}\ldots & \ldots & 127\end{array}$

.

126

$\cdots$

135

.

..

.

$118,129-132$

151-153

152,153

$\cdots$

$23,30,43$

..

.

.

$\cdots$

.

.

.

$\cdots$

.

.

.

.

.

..

$\because$

$\because$

$\cdots$

$\cdots$

$\cdots$

.

$\cdots$

..

Scrap rubber, Cliaracter of Washing of ..

Seeds of Para rubber, Cake of

- Characters of

Chemistry of

Oil of

Number of ..

Packing of ..

Settling tanks

Shade trees

Sheet rubber, Analysis of
Preparation of Preparation of
Properties of

Size of trees .. Sodium sulphate ...

Soils in Ceylon ...

..

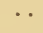

.

128

$76,123-126,129,144$

. $\quad 139,153,154$

.. $73,74,96-99$

. $\quad 76,125$

.. $\quad 69-74,96-99$

. $109,128,134$

$76,123-127,129-131$

.. 127

.. 128

.. 127

.. $77,123-128 ; 141$

.. 131-133

. $129,130,137-140$

. $\quad 72,137-144$

. $\quad 75-78,96-99$

$114,115,120,153,154$

.. $114,138-142$

. 135,142

. 124-126, 141-144

. 129-133

.. 129,131

.. 133,144

$\begin{array}{lr}\ldots & 133\end{array}$

$\begin{array}{lll}\cdots & \ldots & 156,157\end{array}$

$\begin{array}{lll}\cdots & \ldots & 5,156,157\end{array}$

$\begin{array}{lll}\ldots & \ldots & 156\end{array}$

$\begin{array}{lll}\text {. } & \ldots & 156\end{array}$

$\begin{array}{lll}\ldots & \ldots & 23,155\end{array}$

$\begin{array}{lll}\text {. } & \ldots & 157-159\end{array}$

. 606

$\begin{array}{lll}\cdots & \cdots & 23,24,47,48\end{array}$

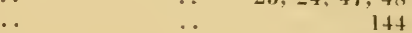

$\begin{array}{lll}\cdots & \ldots & 1+2\end{array}$

$\begin{array}{lll}\ldots & \ldots & 142\end{array}$

$\begin{array}{lll}. . & \ldots & 18,19,20\end{array}$

$\begin{array}{lll}\cdots & \ldots & 75,77-79\end{array}$

$\begin{array}{lll}. & \ldots & 115\end{array}$

$\begin{array}{lll}\text {. } & \ldots & 33-42\end{array}$

$\begin{array}{lll}\text {.. } & \ldots & 35,36\end{array}$ 
\begin{tabular}{lcc} 
Soils Cabooky & $\ldots$ & \\
in Federated & Malay States & $\ldots$ \\
\hline - Galle & $\ldots$ & $\ldots$ \\
\hline Kalutara & $\ldots$ & $\ldots$ \\
\hline Kegalla & $\ldots$ & $\ldots$ \\
\hline Kelani & $\ldots$ & $\ldots$ \\
Kurunegala & $\ldots$ & $\ldots$ \\
\hline Matale & $\ldots$ & $\ldots$ \\
- Passara & $\ldots$ & $\ldots$ \\
- Russellawa & $\ldots$ & $\ldots$ \\
Solution, Rubura & $\ldots$ & $\ldots$ \\
Spiller's resin & $\ldots$ \\
Spiral Tapping and herring-bone compared
\end{tabular}

Leonomy of ...

When to do
Steam packing, Composition of
Stem diseases, Fungi
- Insect
Sulphur reaction with rubber
__ and heat..
__ fixed in rubber
_- in articles of commerce
_- Quantity of, in rubber articles
- ebonite and vulcanite

Sulphuric acid, Effect on rubber of ..

Tackiness, Chemical changes in

- Conditions for

- Moisture and. .

- Production of

_- Proteids and resins

Tacky rubber, Characters of

Tannic acid, action of

Tapping age of trees

-- Areas for ..

- and flowering. .

and leaf fall ..

- and size of trees

- and wound response

- Effect of bad

- Best season for

$\cdots$

$\cdots$

.

..

.

-

.

$\cdots$

.

..

$\cdots$

$\cdots$

..

..

..

..

..

..

$\cdots$

$\cdots$

.

..

$\cdots$

$\cdots$

$\cdots$

$\cdots$

- Best time for ..

- Effect of repetitional tapping ..

- first in Amazon

- on Plantations

- Frequency of, in Amazon

in Ceylon
PAGE

\section{5}

35

39

39

38

37,38

39,40

41,42

.. $36,37,42,43,44$

.. 135,142

.. 127

.. 95,96

.. 96

$\ldots$
$\ldots$

.. 96

. $64,92-96$

.. 135

.. 149

$\begin{array}{ll}\ldots & 150\end{array}$

.. 44

.. $\quad 134,135$

.. 134,135

.. 134

$\begin{array}{ll}\cdots & 135\end{array}$

$\begin{array}{ll}\ldots & 135\end{array}$

.. $\quad 135$

.. 134

.. 127

.. 114,154

.. $114,115,154$

.. 119,139

.. $138,139,153$

.. $106,114,154$

$\ldots 106,114,153,154$

.. 111

$\begin{array}{ll}\text {.. } & 75-79\end{array}$

.. 69-74

$\begin{array}{ll}. . & 81\end{array}$

$\begin{array}{lr}. . & 80\end{array}$

$\begin{array}{ll}\cdots & 75-79\end{array}$

. $\quad 70,71$

.. $50,51,70,71$

.. $\quad 79,83$

.. $\quad 80,81$

.. 70,71

․ 75

$\begin{array}{ll}\cdots & 75-81\end{array}$

$\begin{array}{ll}\cdots & 75 \\ \cdots & 50,79-83\end{array}$

.. $50,79-83$ 
Tapping, Frequency of, in the dry season

PAGL:

- in the Amazon

- in the Gold Coast

in the Straits. .

..

$80-83$

- Herring-bone . .

Tapping knives …

.

js, 59

59

6.2

61,62

$51-57$

53

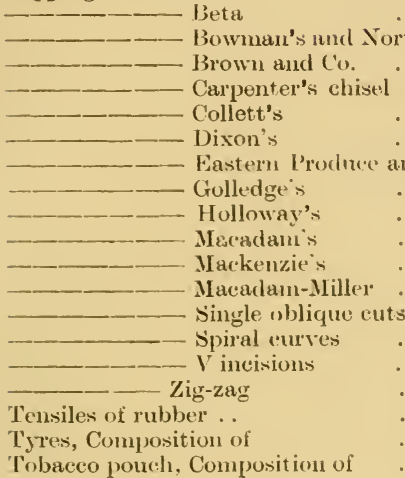

55,56

orthway's

..

..

..

Crecola rubleer, Chemistry of

Vacuum chambers. .

Value of rubber . .

V euts

.

..

$\cdots$ $3,124,125,126,141-144$

—_ Yields from ..

.

Vigna, Chemieal composition of

.

Vulcanization of rubber

..

_E Effect of ..

Vulcanized rubber

$\cdots$

Washed rubber, Aualyses of

\section{Loss on}

130,131

Washing of rubber. .

.

129-131

.

Wild rubber, Properties of

Windbelts Source of

Worm rubber

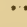

\section{Analysis of}

Worm Rubber l're'paration of

Wound response in Imazon
125,126

146 
Wound response Bursting of latex tubes due to . .

PAGE

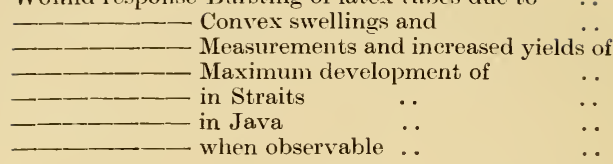

Yield and virgin areas

\section{- and high tapping}

_- at Baddegama

__ on Culloden . . on Eastern Produce and Estate

_ at Elpitiya .. . .

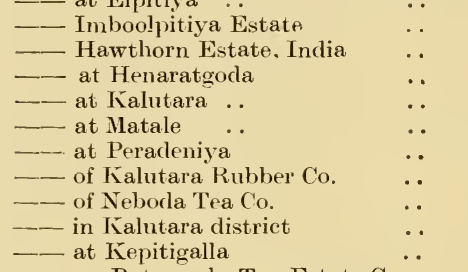

_ on Putupaula Tea Estate Co. .

- on Passara Group Estate . .

__ of Gikiyanakanda $\quad$ of Yataderiya Tea Co.

__ of Yataderiya Tea Co. $\quad \ldots$

-- on Southern Ceylon Tea and Rubber Co.

_- on Sunnygama Ceylon Estates Co.

— in South India
—- of Rayigam Tea Co.
— in Uva of Vogan Tea Co.

__ on Yatiyantota Ceylon Tea Co.

- - in Java .. ..

__ of Ceylon Tea and Coconut Estates Co.

_ best areas for, Experiments on

_ by herring-bone method

- by $V$ method ...

_- Cause of variation in

- Effect of pollarding on

__ Estimate of ..

—_ Exceptional ..

__ from basal portions

_- from upper portions.

_. in Amazon distriet

_- in Ambalangoda

—_ in Ceylon ..

—— in India

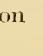

..

$\cdots$

.

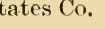

$\cdots$

...
70

$69,73,74,96-99$

. 91

91,92

88

92

89

100

$90,95-99$

$87,88,89,90$

$86,87,91$

$92-95$

88,90

98,89

$87,89,90$

86,90

88,90

87,90

$88,89,90$

88,90

100

88

88,90

100,101

88,90

87

88,90

98, 90

100

.. $69,70,72,73$

95,96

$64,92-97$

93

84,85

78,79

101,102

91,92

69. $96-99$

72-74. 96-99

$86 i$

90

$50,85-99$

101

100,101 
INDEX.

$\begin{array}{lccr}\text { Yield in Straits } & & \text { PAGE } \\ \text { - of Para and African rubber compared } & \ldots & 99,100 \\ \text { - Variation of . } & \ldots & 1,1 \\ \text { - Wound response and } & \ldots & \ldots & 84,85 \\ \text { - of different parts of the stem } & \ldots & \ldots & 70,71 \\ \text { - per square foot of bark } & \ldots & \ldots & .70,74 \\ \text { - from shavings } & \ldots & \ldots & 98\end{array}$

179 



\section{ADVERTISEMENTS.}





\section{RUBBER PLANTING.}

Estate Requisites of all kinds:

\section{Alavangoes}

(for holing rubber-specially large blades.)

Collecting Cups.

Setting Dishes.

Rubber Presses.

Latex Strainers.

Tapping Knives

of all descriptions

Barbed Wire

(for fencing young rubber.)

$\underline{\text { Rubber Machinery. }}$

Buildings.

The Eastern Produec \& Estates Co., Lidd. COLOMBO.

Head Office: Mincing Lane House, 59, Eastcheap. 


\section{The Eastern Produce \& Estates}

\section{Company, Limited,}

COLOMBO.

\section{ESTATE SUPPLIES AND REQUISITES OF ALL DESCRIPTIONS,}

Estate Engineering \& Building Works.

\section{RUBBER CULTIVATION:}

Planting and Curing Machinery and Requisites of all kinds: Collecting Cups. Tapping Knives, Latex Strainers, Barbed wire, Rubber Presses, \&c.

Monthly Price List on Application.

The Eastern Produce \& Estates Bo., Litd., COLOMBO.

HEAD OFFICE : MINCING LANE HOUSE, 59, EASTCHEAP. 


\section{Brown \& Davidson Ltd.,}

ENGINEERS.

TALAWAKELE, CEYLON.

Rubber Machinery \& Tools

RUBBER LATEX STORING AND COLLECTING

TANKS used for storing the latex in the field, while being collected from groups of trees, and for retarding coagulation for several days or longer if necessary.

(Patents applied for).

TREE BASE RECEPTACLE FOR LATEX. This is a Basal Coil or receptacle encircling the basc of the tree to receive the latex from the clrip spouts of the various cuts all round, and a conducting channel from tree to tree ; avoids the use of collecting cups at every cut.

(Patent applied for.)

RUBBER WASHING \& ROLLING MACHINES for small and large acreages, for producing pure and uniform rubber in sheets of any thickness and size.

( Patent applied for.)

LEMON GRASS OIL EXTRACTING APPARATUS specially designed for extracting oil from Lemon grass, now largely cultivated as a Rubber catcherop).

(Patent applied for.)

SPRAYERS for pests and blights in products of all kinds. (Brown \& Davidson's Patent.)

TOOLS for tapping, etc.

RUBBER CURING HOUSES built on the latest improved plan for quick drying by mechanical and chemical means.

All prices and particulars on application to

\section{Brown \& Davidson, Ltd.}

ENGINEERS.

Talawakelle, Ceylon. 


\section{The Latest in}

\section{RUBBER TAPPING}

COU MUST USE G. S. BROWN'S “DRIP TINS”
FOR ASSISTING THE FLOW OF LATEX and LEAVING A CLEAN TAPPING SURFACE fOr NEXT CUT.

These Tins are fixed to the Rubber tree by ordinary broad headed tacks, above the tapping area, on the original or healed bark, They are filled with pure witer or other solutions which percolate or drip slowly on to the tapping cut (Herring bone, Spiral, ete )

The liquid flows very slowly down the tapping ent, greatly aiding the flow of Latex, keeping the cut quite clean till the latex has ceaseil Howing, and thereby preventung the formation of scrap on the newly tapped areat.

The immense saving of Labour is at once quite obvious to any one arquanted with tapping. The following will be quite obvious to those acquainted with Rubber Tapping :-

( I) The immense saving in labour by having a clean surface to take the next cut on instead of having to clean or pick the scrap off by hand involving great loss of time.

(2) A much larger quantity of latex is obtained through the milk tubes being kept open until the last drop has exuded.

\section{ORDERS ARE NOW BEING BOOKED.}

APPLY,

\section{BROWN \& DAVIDSON, LTD.,}

ENGINEERS,

TALA WAKELE, GEYLON. 


\section{TFE \\ Ceylon Ilamure Works.}

THE LARREST MANURE WORKS IN THE ISLAXD.

White Castor Cake Rape Seed Cake Nitrate of Potash Bone Meal Sulphate ot Potash Superphospate
Ground Nut Cake Nitrate of Soda Sulphate of Ammonia Blood Meal Muriate of Potash Kainit

Steamed Bone Meal

Soncentrated Superphospate Precipitated Phosphate of Lıme Superior English Basic Slag Baur's Patent Fish Manure Burnt Coral Lime.

Any Mixtures Desired by Planters can be supplied.

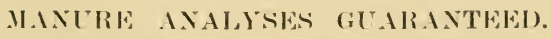

\section{Baur's Special Fertilizers}

for Tea, Cacao, Coconuts, Rubber, \&c.

\section{Chemical Laboratory.}

\section{SOIIS ANAIYSED.}

\section{A. BAUR,}

()ttice :- No. 5, Prince Street, Fort.

Works :-Kelaniya Station. 


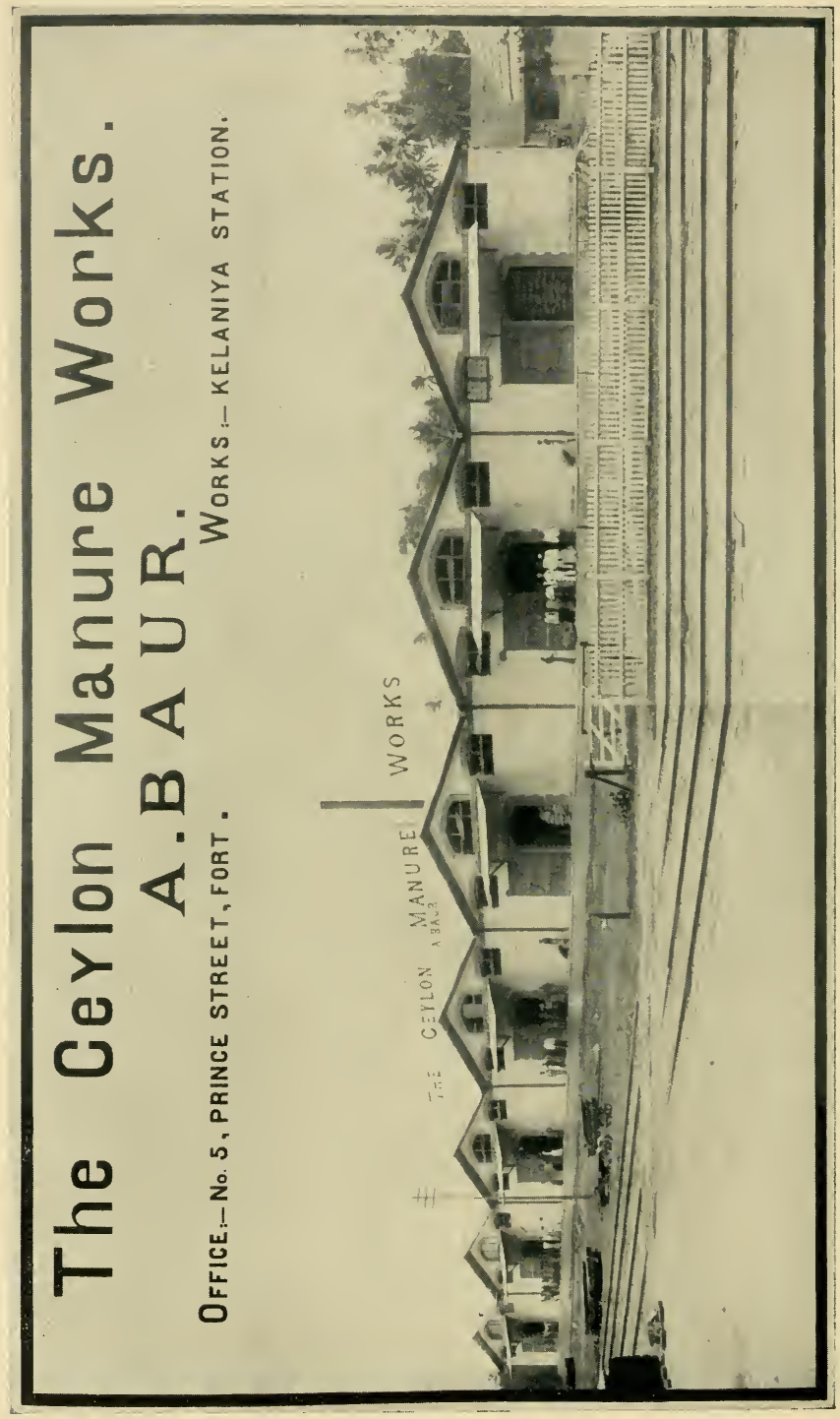




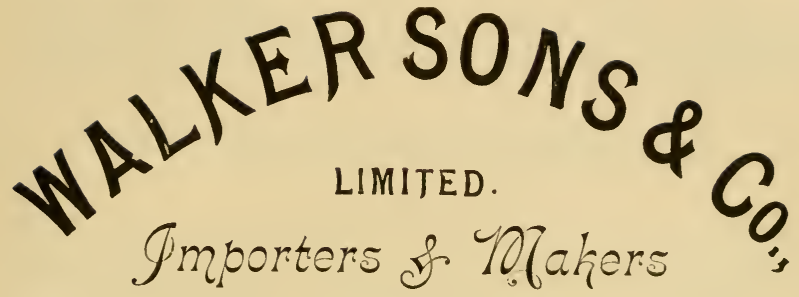

()1:

\section{Rubber Collecting \& Manufacturing Implements and Utensils.}

Biscuit and Sheet Rolling Mrachines with Lignum Vitce Rollers, and Steel Bow Springs.

"Michie-Gollege" Tapping Knives Latex Collecting Cups in

"Viper" Tapping Knife "Northways" Spout

"Northways" Drip Tin

"Holloways" Tapping Guide Latex Strainers, Etc., Etc, Etc.
Aluminium, also in Enamelled Stamped Steal, \& Tin Enamelled Transport Pails Enamelled Coagulating Pans

\section{Enquiries Invited. Estimates Free.}

Machines, Implements and Utensils of any special design can be made or imported to order.

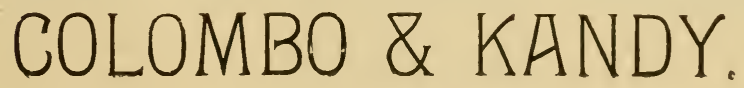




\section{Rubber' Coagulating Machine.} MICHIE-GOLLEDGE PATENT.

This is an inexpensive and simply designed Machine for Hand Power. By its use the Rubber is coagulated

\section{IN FIVE MINUTES}

from the time the Latex is poured in.

The coagulated Mass may be converted into "WORMS," "ROLLED STRIP," "LACE," "CRÊPE," Etc.

Price complete ex-Works, Colombo, R600 Nett.

This machine is capable of turning out from 200 to $240 \mathrm{lbs}$ wet Rubber per hour equal to 100 to 120 lbs dry Rubber.

For further particulars see text of the book.

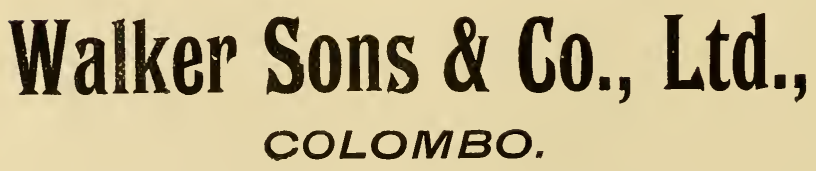




\section{FREUDENBERG \& Co.,}

Hold larie and varied stocks of the jollowing

\section{MANURES}

FOL SALE AT THE

\section{HULTSDORF MILLS MANURE WORKS.}

No, 1 \& Nc. 2 Castor Cake

Bone Meal

Crushed Bones

Ground Nut Cake

Rape Seed Cake

Nitrate of Potash

Sulphate of

Patent Steamed Bone Dust Peruvian Cuano

Nitrate of Soda

Superphosphate

Concentrated Superphos- Precipitated Phosphate

Good Ordinary Basic Slag Sulphate of Iron

Ammonia Extra Quality Basic Slag Cypsum

Best Indian Fish Manure Bone Phosphate

Flour Phosphate

\section{Sol" Agents of}

The German Potash Syndicate.

Kainit, Muriate and Sulphate of Potash, Sulphate of Potash Magnesia and all other Potash Salts.

\section{GUARANTEED ANALYSES.}

SOIIAS AN.AL\%EI).

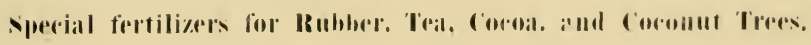

\section{AGRICULTURAL AND ANALYTICAL LABORATORY.}

\section{FREUDENBERG \& Co., Colombo.}

Worlis:...NEW BAZAAR, $1=8$ Mill Street, 28, 29, 3i Belmont Street, 47-49 Wilson Street, 37-39 Ferry Street,

32, Skinner's Road South.

Uffices:-29, 30, 31, 32 Chatham Street, Fort. 


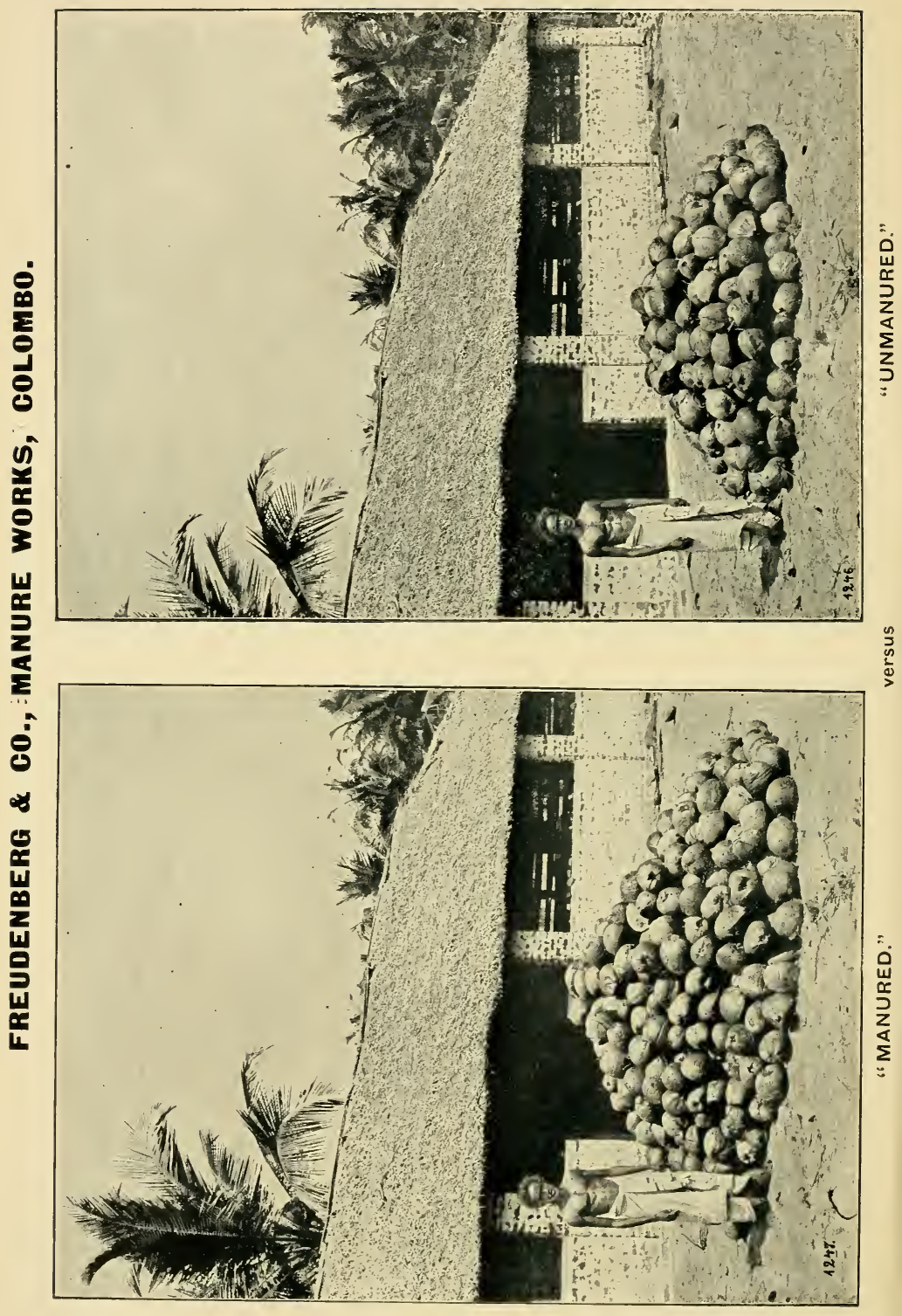




\section{Rubber Tapping}

THE VERY BEST

\section{TAPPING KNIVES}

IRE THE

\section{BOWMAN-NORTHWAY}

Undoubtedly superior to any other Tapping Knives. A copy of the Northway System of Tapping given away FREE to every buyer of these knives:

\section{RATES:}

No. 1 each Rs, 5-00 - per dozen Rs. 48.00 No. 2 (single or double) each Rs, 5-00 - per dozen Rs, 48-00 No. 3 each Rs. 2-50, - per dozen Rs. 24-00 Special Shields for No. 3. each Re. 1-00 SPECIAL TERUS FOR LARGE ORDERS.

FOR FURTHER PARTICULARS APPLY TO

Chas. P. Hayley \& Co., GALIE, CEYLON 


\section{Colombo Commercial Co.,}

Limited.

SLAVE ISLAND MILLS,

COLOMBO.

Rubber Planting Requisites of Every Kind.

\section{DIXON'S PATENT \\ Double Handed Tapping Knife Adaptable for all Methods of Tapping. ALSO}

Mamoties, Axes, Alavangoes, and other Estate Tools. Barbed Wire Fencing, Galvanized Netting, Collecting Cups, Settling Pans, Etc., Etc.

ALL AT LOWEST CURRENT PRICES.

Particulars on Application. 


\section{The FEDERATED ENGINEERING Co., Ltd.,}

KUALA LUMPUR.

Ceylon Agents : DODWELL \& Co., Ltd, Colombo.

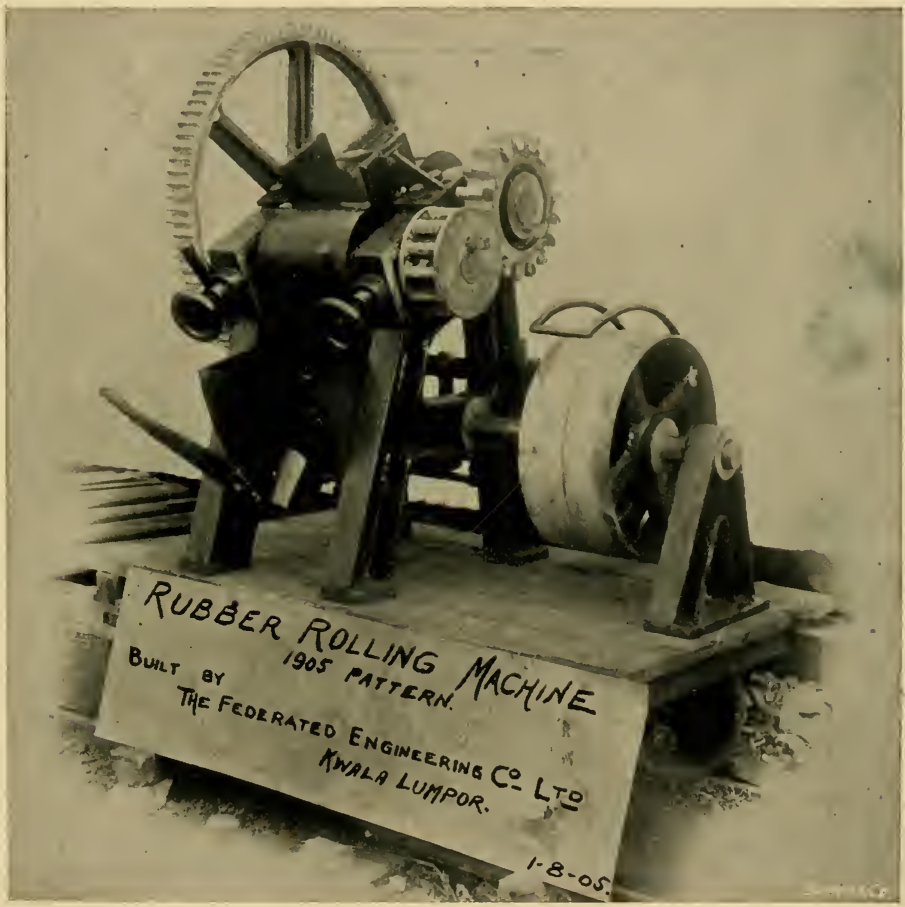

을

\section{Our WASHING \& ROLLING MACHINES}

(Nee Page 132 for Illustration of the Washing Machine)

have been specially designed for the purpose of treating freshly coagulazed latex and they produce the finest form of Crêpe Rubber, which can be dried, without the aid of a clrying house, in about three days.

The process of making the Crêpe may be entirely carried out on the Washing Machine, but a much finer sample can be obtained by passing the washed rubber through the Rolling Machine.

The Machines working together will treat at the very least One Hundred pounds of clried rubber per hour, or working singly, Fifty pounds per hour.

Ceylon Agents: DoDWELL \& Co., Ltd., Colombo.

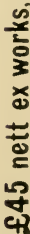

章

4

은 


\section{JOSEPH ROBINSON \& Co.,}

DESIGNERS AND MANUFACTURERS OF

MACHINERY FOR RUBBER AND GUTTA-PERCHA. SALFORD, MANCHESTER.

\section{RUBBER WASHING MILL FOR ESTATE USE.}

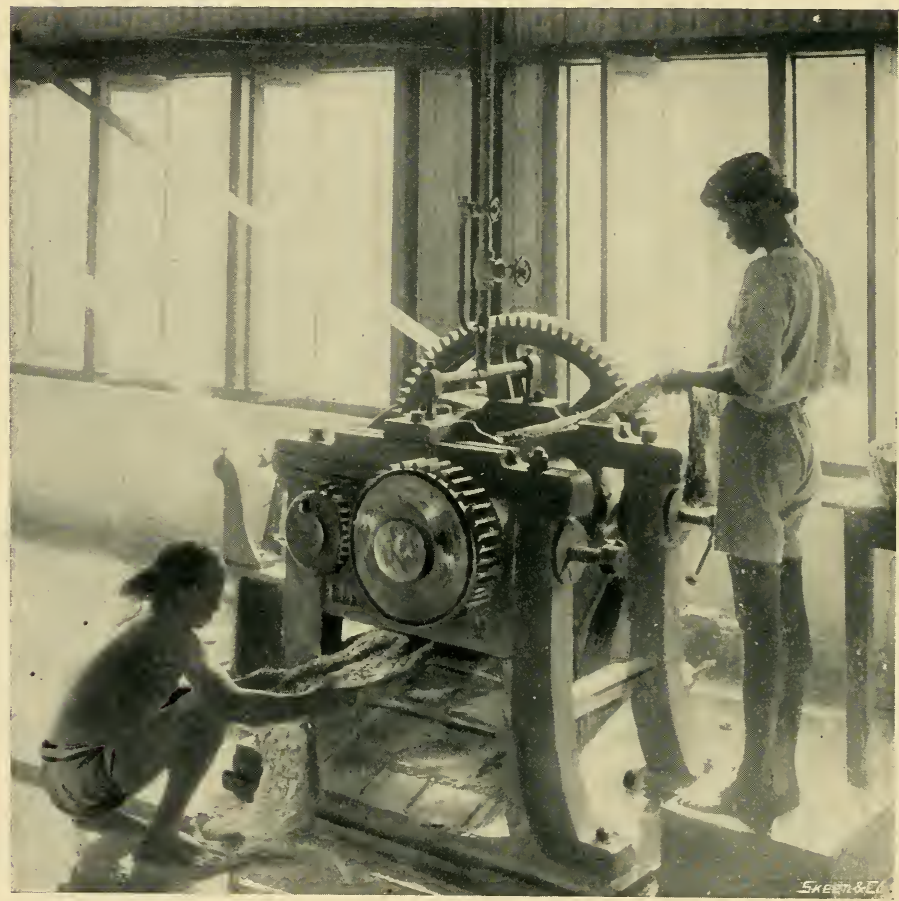

As supplied to:-W W Bailey, Esq., Lowlands Estate, Klang, Selangor. The Selangor Rubber Co,, Ltd., Selangor.

Culloden Estate, Kalutara, Ceylon

Machines supplied to remove all bark and dirt from Scrap and lower grades of rubber. To extract the small particles of rubber contained in the parings or shavings. To prepare Crêpe, Flake aud other forms of rubber. A special machine of suitable size and mamfacture for estate use to effectually carry ont the above processes is now in hand, and will shortly be on the market.

FOR FULL PARTICULARS API'LY TO

Sole Agents for C'eylon:-Messrs Nevett, Oswald \& Co., 81, Cracechurch Street, London. Local Representative:-C. 0. Macadam, Culloden Estate, Neboda, Ceylon.

Sole Agents for Struits Settlements, Federated Mirloy Strites, S'umatra :-Messrs. Barlow \& Co, Singapore 


\section{PARA RUBBER}

\section{SFED \& PLANST.}

\section{CULLODEN ESTATE,}

\section{KALUTARA DISTRICT, CEYLON.}

Culloden seed has been sold for the last 15 years to all parts of the world and most of the Estates now bearing in the Malay State, were originally supplied from this well., known Estate.

A Planter writes from India :-- "Trees 7 years old grown from your seed, at 3,500 elevation are giving latex just as freely as yours."

Seed carefully selected and specially packed for Export.

QUOTATIONS ON APPLICATION TO

MANAGER,

CULLODEN ESTATE.

NEBODA, CEYLON. 


\section{$-$ \\ "MACKENZIE'S" PATENT, \\ RUBBER TAPPING KNIFE.}

Rubber Planters are asked to note the chief features of this Invention.

(1) Two movable guide blades actuated by screws in such a manner that the depth of the cut can be regulated to an exceeding fineness.

(2) Independent movement of these guide blades so that they can be set to guide the knife when cutting on uneven surfaces.

(3) The guide blades are so arranged that either can be lowered at will and the knife is therefore changed from an incisor to shaving knife to cut either right or left hand as desired

Experience has taught us that the "Mackenzie" Knife $n$ ot only does better work than any other at present in use in Ceylon or the Straits. but that it enables the most Unskilled Coclies to do it in from 7-5th to 7-70th the time formerly required.

\section{Price Rs. 5.00 each.}

Special Quotations for large quantities.

Sole Agents for Ceylon.

\section{THE FAIRFIELD IRON WORKS.}




\section{LANGSLAND}

\section{Para Rubber}

\section{Seed}

FROM

10 to 14 years old Seed Bearers.

Owing to the large demand for this Season's expected Crop

No more orders for 1906 can be booked.

\section{R. J. BOOTH,}

GLENDON, NEBODA,

$$
\text { CEYLON, }
$$




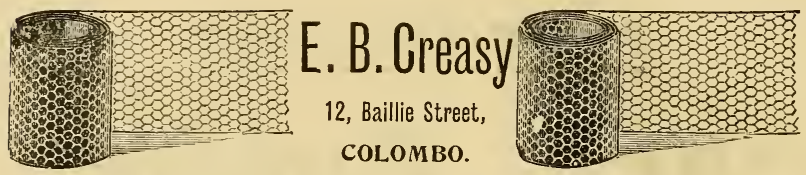

Estate Requisites of all descriptions - FOR -

\section{TEA or RUBBFR.}

Chests, Hoop-iron, Tea Lead, Wire Netting, Barbed Wire.

Write for Particulars and Quotations.

\section{CEMENT,}

\section{DRAIN PIPES, JEYES DISINFECTANTS.}

The London and Colombo Forwarding Agency. The ONE CHARGE System.

Payable at either end. Cost can be ascertained before despatch. SPECIAL RATES FOR

\section{TEA \& RUBBER in Quantity.}

Shipments to all parts of the World. Value Collected against delivery or goods delivered free to your friends:

\section{E. B. CREASY.}




\section{SPECIAL NOTICE}

TO THE

\section{Rubber Planting World.}

PARA, CASTILLOA, CEARA, \&c.

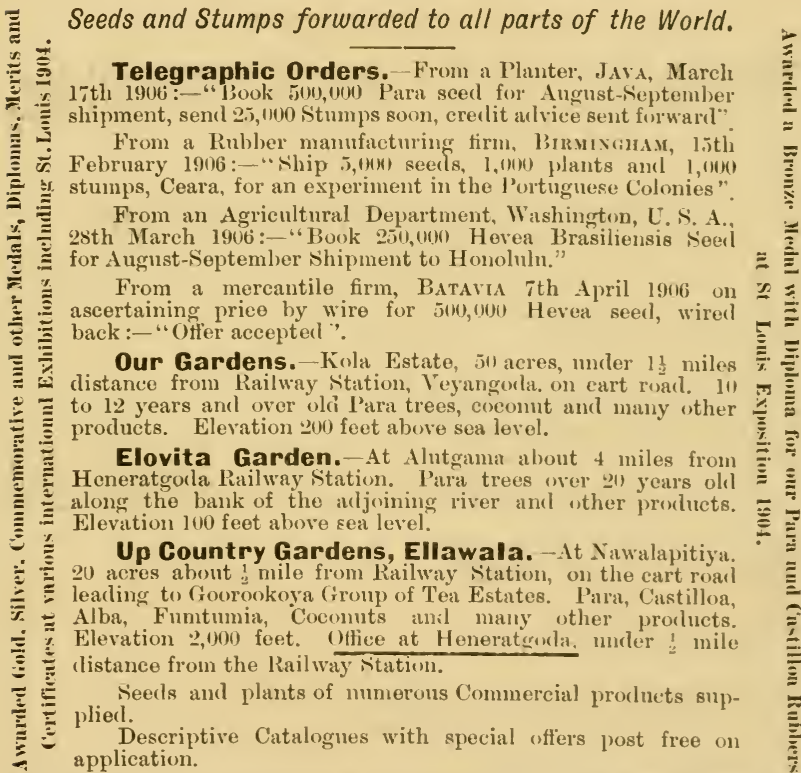

Agents in London:-Messrs P. W. Woolley \& Co, 90. Lower Thames St Ager:ts in Crylon:-F. B. Creasy Esq., Colombo.

\section{J. P. WILLIAM \& Bros,}

TROPICAL SEED MERCHANTS, HENAKATGODA, CEYMON.

Codes used

A. I., A. 13. C., Liber's. \&

Wait's Figure Code.
Telegraphir Address:

WILLIAMI,

Hexaratgoda, Ceylon. 


\section{THE \\ Colombo Apothecaries' Co.,}

LIMITED.

\section{Wholesale and Retail Chemists.}

LOWEST QUOTATIONS GIVEN

FOR :-

Acetic Acid

Slacial Acetic Acid

Formalin (Solution of Formic Aldehyde)

Orlercuric Chloride

Jannic Acid

Ammonia Liquid $\cdot 880$

Sodium Sulphate

Calcium Chloride

AND ANY OTHER

Chemical required in the process of Coagulation of Rubber. 


\section{GEYLON PLANTS.}

\section{Hevea Brasiliensis Seeds \& Plants.}

NURSERY GARDENS situated at MATI TACOOLY close by Messrs. Stevenson

$\&$ Soxs' Mills 15 minutes drive from Fort via

Victoria Bridge or through Nutwal road.

PASSENGERS CAN BE STPPLIEN WITH

Orchids, Bulbs, Palms, Ferns, Cycas, Bulbs, Anthuriums, Caladiums, Tree Ferns, Crotons, AND VARIOC'S KINDS' OF

Foliage \& Ornamental plants, Fruit 'Trees, TEA, COFFEE, COCOA, RUBBER, COCONUTS, PEPPER, NUTMEG, MANGO, DLRIAN, CLOVES,

and other Tropical Plants and Seeds \&c.,

\section{3
0
0
0}

\section{MANGOSTEEN,}

and other Tropical Plants and Seeds \&c.,

(1)

Plants delivered throughout the Globe, in Glass and close Gases.

Colombo Agent: E. B. CREASY, Esq, Fort.

\section{J. P. ABRAHAM,}

MUTWAL,

MATTACOOLY GARDENS, CEYLON. 


\section{FOR SALE. \\ Rubber Seeds, \\ Stumps \& Plants}

OF ALL THE PRINCIPAL VARIETIES, VIZ:--

Hevea Brasiliensis (Para Rubber) - 10 to 22 years old untapped seed bearers: some trees are 9 feet in girth at a yard from the ground Manihot Glaziovii (Ceara or Manicoba Rubber.) Castilloa Elastica (the most valuable Central American rubber tree )

Ficus Elastica (Assam and Java rubber) Landolphia Kirkii (West African rubber), \&c.

\section{Tropical Secds and Plants} of Commercial Products.

PACKED WELL TO STAND LONG VOVAGES.

Guarantee of Germination Given.

For further Particulars and Prices

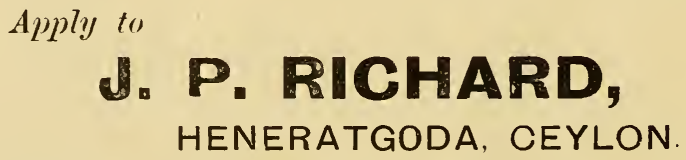

Telegraphic Addrcss:-RICH.ARD, Heneratgoda, Ceylon. 


\section{To Rubber Planters.}

\section{ESTATE REQUISITES}

OF EVELIT DESCRIJTION.

Barb Wire, Tapping Knives, Tin Collecting Cups. Enamelled Iron Settling Dishes.

Mamoties - _ Digging Forks

Alavangoes - Dynamite - -

Pickaxes - - Blasting

Felling axes - Powder -

Catties - -

Weighing

Machines \& \&c., \&c., \&c.

Rubber Seed and Plants.

Coagulation \& other Machinery.

W. H. Davies \& Co., 


\section{TEA SEED. \\ ROOKATENNE JÂT.}

This Seed is of the very best Indigenous Variety. Harsy and suitable for any Elevation.

Produces magnificent bushes of clean, straight wood.

Tea from this does not run to Seed and will last long from pruning.

Seed Bearers are selected and certified free from Disease or Blights.

Manger, Rookatenne Estate, Bandarawela, Ceylon.

\section{The Genitral Seed Stores \& Nurseries, NATURAL HISTORY, KANDYAN CURIOSITY, LIVE BIRD \& ANIMAL DEPARTMENTS.}

MOR SALE Ceylon Seeds and Plants, Bulbs, Roots, Ferns, Orchids, Fibre, dic., \& c., Natural History Specimens, Beetles, Butterflies Moths, Stick and Leaf Insects, Bird, Animal, Snake Skins \&c., Birds Eggs, \&c., Live Birds and Animals.

\section{Price Lists on Application.}

\section{E. SPEARMAN HUGHES, A.V.S.E., \&C.,}

Seedsman \& Taxidermist. 


\section{Passara Group Estate.}

\section{ALBIZZIA MOLUCANA SEED.}

The best shade tree and fertilizer for

TEA, RUBBER, COCOA, COFFEE \&c., Seed from the above Estate's well known trees, 15 years old, will be ready for delivery from

August onwards.

Price from Rs. 1'75 to $3 \cdot 00$ per Ib.

ACCORDING TO QUANTITY TAKEN

$\triangle P P L Y$

W. STEWART TAYLOR,

PASSALA GROUP, PASSARA.

\section{Gracelands, Pundaluoya,}

\section{Acres Young Tea}

INTERPLANTED WITH

PARA (1904 \& 1905).

AND

ADJUINING ABOUT 300 ACRES OF UNCULTIVATED CROWN TITLE LAND, 


\section{RUBBER TAPPING INSTRUMENTS.}

MACADAM'S

\section{Gomb Pricker, \\ SeE PAGe 56.}

MACADAM - MILLER'S

\section{$\frac{\text { Safety Paring Knife, }}{\text { SЕе }}$}

These instruments carry ont the complete process of tapping Kubber Trees.

\section{AGENTS, \\ Brown \& Co., Ltd. COLOMBO.}

\section{Castilloa Elastica Rubber Seed}

$$
\text { FOR SALE: }
$$

GROWN ON

Ambangfangia Estate, Matale. SHOWING FINE PERCENTAGE OF PLANTS.

Price Rs. 10 the 1,000 on the Estate.

CROPS : May-July and November-December.

W. E. GILDEA, 


\section{FOR SALE.}

\section{Para Rubber Seeds and Stumps.}

FOR 1906 DELIVERY.

SEEDS FROM OLD TREES-at $\mathrm{R}_{5}{ }^{\circ} \circ 0$ per $\mathrm{I}, 000$ delivery August onward.

STUMPS (from 1905 Seed) -at R20.00 per $\mathrm{I}, 000$ delivery May onward.

Special care given to packing.

$$
\text { APPLY }
$$

Yataderiya Tea Goy., Ltd., UNDUGODA, CEYLON.

\section{NEUCHÂTEL ESTATE.}

\section{Para Rubver Stumps and Seed}

FROM OLD TREES.

Now being Booked: 1906 Delivery.

For Prices,

APPLY TO

SUPERINTENDENT,

Neuchâtel, Neboda. 


\section{Manipur Tea Seed FROM}

\section{UNPLUCKED BUSHES.}

Orders are being booked for the well-known produce of the MANIPUR TEA SEED ESTATE.

\section{Apply to \\ Gillanders Arbuthnot \& Co.,}

\section{calcutta.}

\section{ESTATE SUPPLIES.}

IVE ARE PREPARED TO QUOTE

FOR

Teak Timber Sawn to Sizes.

BARBED Wire, Cement, Flooring Boards. Ceiling Boards, B Window Sashes, Door and Window Frames, Shingles, 0ver Door Ventilators, Window Glass, Plate and Sheet Glass, Muffled and Obseured Glass, Factory Lamps, Well's Industrial Lamps, Manglore Tiles, Ete.

The Famous "K" Brand Enamel Basins, Cups \& Dishes for Rubber.

SPECIAI TEER MS FOR QUANTITIES.

\section{H. Don Carolis \& Sons,}

Furniture Manufacturers, General Importers,

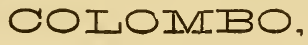




\section{PLÂTÉ \& Co.,}

ARTISTS \& PHOTOGRAPIERS.

STUDIOS in COLOMBO-Colpetty \& Galle Face Hotel

European Artists visit Estates at shortest notice.

Special Estimates for Photographic Work on application.

A comprehensive Stock of

\section{PHOTOGRAPHIC VIEWS}

of almost every interesting subject in Ceylon always kept.

IVe nave recently added a series of

\section{PHOTOGRAPHS OF RUBBER INDUSTRY.}

SPECIAL SUBJECTS TAKEN.

LANTERN SLIDES and ENLARGEMENTS made to order.

\section{Castilloa Rubber Seed,}

FROMI

\section{ALLIAWATTIE ESTATE,}

Has given satisfaction, as testimonals with repetition of orders, and the sales of seed in 1905 show. Castilloa has found favour where Para will not grow satisfactorily.

Price Rs, 10 per 1,000.

Packed well, I,Ooo seed weigh $3 \mathrm{lbs}$. Price is subject to alteration.

Apply, Superintendent,

ALLIAWATTIE ESTATE,

Moneragala, Ceylon. 


\section{BROWN \& Co., Ltd.,}

Colombo and Up-Country branches,

HOLD COMPLETE STOCKS OF

\section{Tools and Appliances}

\section{RUBBER PLANTERS,}

From the Opening of the Clearing TO THE

Harvesting of the Crop.

\section{TAPPING TOOLS}

OF THE MOST MODERN PATTERNS,

COLLECTING CUPS.

COAGULATING DISHES.

\&c. \&c. \&c.

Colombo Works : Lanka Works, Union Place.

Colombo Show Rooms: Chatham St., Fort. 


\section{The Tropical Agriculturist AND}

MAGAZINE OF THE CEYLON AGRICULTURAL SOCIETY.

An Illustrated Monthly Magazine dealing with all phases of Agriculture and planting in the Tropics.

RUBBER PLANTING INFORMATION.-in all its branches is a learling feature in the "T. A." The information each month is collected from all parts of the World. The latest about New Tapping systems, methorls of eoagulation and mannfactme, machinery for the planter; \&e.

SUBSCRIPTION \&I PER ANNUM

A. M. \& J. FERGUSOI, COLOMBO, CEYLON.

Planters in all parts of the World should Subscribe to the

"Weekly Ceylon Observer,"

WHICH gives the week's Ceylon news. Special attention is paid to matters of importance to Tropical Planters and the information regarding agrieulture in the Tropics is a special feature.

Extracts and Reviews from the World's Agricultnral Press make this paper one no practical Planter should be without.

Subscription Rs. 20 per annum.

\section{BOOKS for TROPICAL PLANTERS}

TO BE OBTAINED AT THE

\section{"CEYLON OBSERVER" BOOKSTORE, COIOMBO, CEYIOI.}

MANUALS on Tea, Rubber, Coffee, Cacao, Camphor, Cardamoms, Cinchona, Cinnamon, Coconuts, Cotton, Palmyra Palm, Pepper, Tobacco, Aloe, Agave and Rhea Fibres, Areca Palm, Wattles, Vanilla, etc.

Copy of Book Catalogue cun be had on application t)

THE MANAGER,

"C'ylon (1)server" Bookstore,

COLOMBO, CEYLON. 


\section{RUBBER PLANTING.}

\section{SEED}

a)

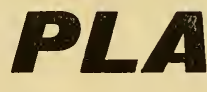

NTS

FROM

Arapolakande Estate,

KALUTARA, CEYLON.

Plants: Fine healthy rubber Stumps and Plants available for immediate delivery.

Seed : On delivery July--September from the Old Seed bearers.

Application may be made to

THE SUPERINTENDENT OF THE ESTATE

() $\mathrm{R}$

Eastern Produce \& Estates Co., Ltd.

COLOMBO.

Head Office :-

Mincing Lane House, 59, Eastcheap, London, E.C. 


